\title{
Where I was and how I will prove it
}

Citation for published version (APA):

Nieuwkamp, H. J. C. (2018). Where I was and how I will prove it: on the believability of alibis. [Doctoral Thesis, Maastricht University]. Maastricht University. https://doi.org/10.26481/dis.20180307rn

Document status and date:

Published: 01/01/2018

DOI:

10.26481/dis.20180307rn

Document Version:

Publisher's PDF, also known as Version of record

\section{Please check the document version of this publication:}

- A submitted manuscript is the version of the article upon submission and before peer-review. There can be important differences between the submitted version and the official published version of record.

People interested in the research are advised to contact the author for the final version of the publication, or visit the DOI to the publisher's website.

- The final author version and the galley proof are versions of the publication after peer review.

- The final published version features the final layout of the paper including the volume, issue and page numbers.

Link to publication

\footnotetext{
General rights rights.

- You may freely distribute the URL identifying the publication in the public portal. please follow below link for the End User Agreement:

www.umlib.nl/taverne-license

Take down policy

If you believe that this document breaches copyright please contact us at:

repository@maastrichtuniversity.nl

providing details and we will investigate your claim.
}

Copyright and moral rights for the publications made accessible in the public portal are retained by the authors and/or other copyright owners and it is a condition of accessing publications that users recognise and abide by the legal requirements associated with these

- Users may download and print one copy of any publication from the public portal for the purpose of private study or research.

- You may not further distribute the material or use it for any profit-making activity or commercial gain

If the publication is distributed under the terms of Article $25 \mathrm{fa}$ of the Dutch Copyright Act, indicated by the "Taverne" license above, 


\section{WHERE I WAS AND HOW I WILL PROVE IT}

ON THE BELIEVABILITY OF ALIBIS 
C H.J.C. (Ricardo) Nieuwkamp, Maastricht 2018

All rights reserved. No part of this book may be reproduced or transmitted in any form or by any means without prior permission in writing by the author.

Printing: Gildeprint - Enschede

ISBN: 978-94-6233-870-8 


\title{
WHERE I WAS AND HOW I WILL PROVE IT
}

\author{
ON THE BELIEVABILITY OF ALIBIS
}

\author{
PROEFSCHRIFT
}

Ter verkrijging van de graad van doctor aan de Universiteit Maastricht, op gezag van de Rector Magnificus, Prof. dr. Rianne M. Letschert, volgens het besluit van het College van Decanen, in het openbaar te verdedigen op woensdag 7 maart 2018 om 14.00 uur

door

Hendrikus Johannes Christoffel (Ricardo) Nieuwkamp

Geboren op 27 mei 1987 te Leuven 


\section{Promotor:}

Prof. dr. P.J. van Koppen

Copromotor:

Dr. R. Horselenberg

\section{Beoordelingscommissie:}

Prof. dr. M. Jelicic (voorzitter)

Dr. H. Fawcett (Manchester Metropolitan University, United Kingdom)

Prof. dr. H. Nelen

Prof. mr. dr. E. Rassin (Erasmus University Rotterdam)

Dr. M. Vanderhallen

Dit werk is gefinancierd, binnen de Vrije competitie, door de Nederlandse Organisatie voor Wetenschappelijk Onderzoek (NWO) en heeft projectnummer 404-10-349.

\footnotetext{
$\widehat{N W O} \mid \begin{aligned} & \text { Nederlandse Organisatie } \\ & \text { voor Wetenschappelijk Onderzoek }\end{aligned}$
} 


\section{CONTENTS}

\section{Chapter 1}

The Problem of Non-Believed True Alibis

\section{Chapter 2}

Our Whereabouts: a Review of the Literature on Alibis and Future Avenues

\section{Chapter 3}

The Illusion of the Perfect Alibi: Establishing the Base Rate of Non-offenders' Alibis

\section{Chapter 4}

You Don't Know: Knowledge as Supportive Alibi Evidence

\section{Chapter 5}

A Lie and a Mistress: on Increasing the Believability of Your Alibi

\section{Chapter 6}

Aligning Expectations With Reality: No Alibi Generation Effect Among Police Detectives

\section{Chapter 7}

True and False Alibis Among Prisoners and its Detection by Police Detectives

\section{Chapter 8}

The Bigger Picture and Building Bridges in Alibi Research

Chapter 9

The Mandatory Chapter: Why This Research is Important

SUMMARY

SAMENVATTING

DANKWOORD 

THE PROBLEM OF NON-BELIEVED TRUE ALIBIS

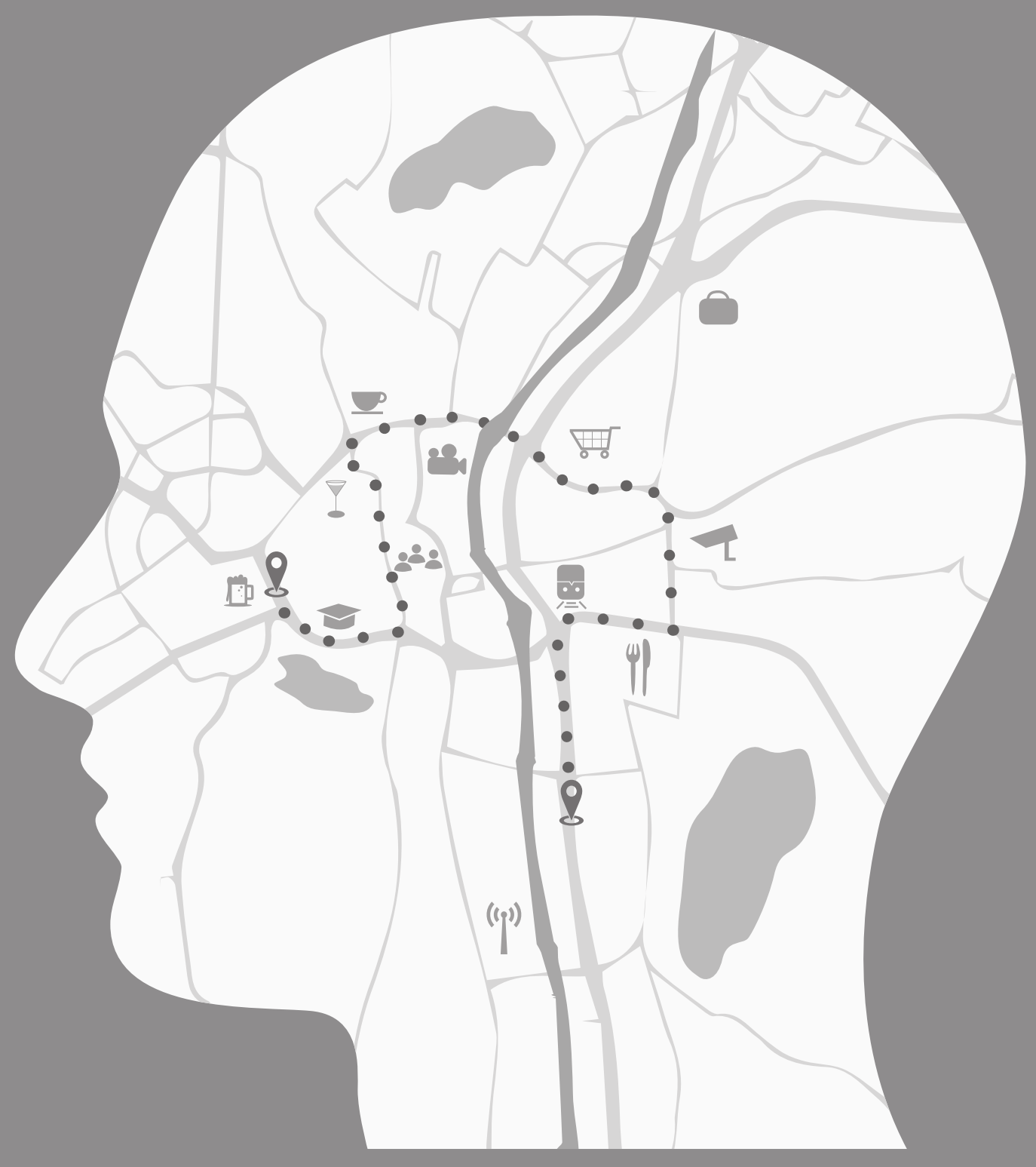





\subsection{NON-BELIEVED ALIBIS AND WRONGFUL CONVICTIONS}

Months later, when the case was judged by the appellate court, Aldo Tarziki remembered his alibi for the night of the murder. At first, he thought that he was in town and slept at his brother's residence. Later he remembered that he started dating his girlfriend that night and that they were together in town celebrating. This alibi also appeared to be in line with his girlfriend's diary (Havinga, et al., 2008).

An alibi consists of a suspect's claim that he cannot have committed the alleged crime because he was elsewhere. Therefore, an alibi can be considered as one of the strongest defences for an innocent suspect to prove his innocence. At best, that claim can be supported by evidence, either consisting of a witness testimony or physical evidence. Witness evidence refers to a supportive witness testimony in which it is stated that the suspect was elsewhere, together with the witness at the moment of the alleged crime. Physical evidence refers to various items of tangible evidence that support the suspect's claim that he was elsewhere (e.g., photographs, CCTV recordings). Having physical evidence has a greater impact on the alibi believability compared to witness evidence (Olson \& Wells, 2004) based on the assumption that witnesses can be mistaken or may have a motive to lie in the suspect's favour (Sullivan, 1971).

Over the past decades, non-believed true alibis, however, have been reported in various wrongful conviction cases all over the world (Burke \& Marion, 2012; Burke, Turtle, \& Olson, 2007; Wells et al., 1998). In fact, in 68\% of the first 250 DNA exoneration cases in the USA the defendant presented a true alibi that was not believed (Garrett, 2011). ${ }^{1}$ Most of the wrongful convicted people presented an alibi that was supported by no or weak evidence. Because evaluators (e.g., police detectives and jurors) tend to expect unrealistic strong evidence for all suspects' and defendants' alibis (Dysart \& Strange, 2012; Olson \& Wells, 2004), a true alibi is often not assessed properly on its veracity.

\footnotetext{
${ }^{1}$ Based on the first 250 DNA exoneration cases since the late 1980's. In 207 cases (83\%) a case transcript could be located and in 140 of the 207 cases (68\%) an alibi was presented. See also: https://www.innocenceproject.org/the-first-250-dna-exonerations-transforming-the-criminaljustice-system/.
} 


\subsection{THE COMPLEXITY OF DETERMINING ALIBI BELIEVABILITY}

In theory, an alibi can distinguish between innocent suspects and perpetrators. One can simply not be at two locations at the same time. However, people can lie about their whereabouts and supportive evidence could then be helpful to differentiate between the truth tellers and the liars. It could be assumed that an innocent person will be able to report supportive evidence to underpin the claim of innocence, whereas no evidence would be available to support a false alibi. However, one can also generate evidence for a false alibi (see below in this paragraph).

In reality, the determination of the alibi's believability is complex for a number of important reasons. First, as became clear when reviewing the wrongful conviction cases in which an alibi was presented, not every truthful alibi can be supported by evidence. A discrepancy thus exists between what evidence for alibis an innocent suspect can present and what evidence is expected by evaluators to find an alibi believable.

Second, to generate an alibi, memory for whereabouts must be available (i.e., where the suspect was and what he was doing on that moment). For innocent suspects that particular timeframe was probably not important to remember, while for the perpetrator it most probably was a memorable event (Simon, 2012). That makes it difficult to reconstruct their memory (Crozier, Strange, \& Loftus, 2017; Strange, Dysart, \& Loftus, 2014). As a result of the lack of motivation for the encoding of non-memorable events, innocent suspects are not inclined to reconstruct their whereabouts prior to police questioning. Prior to a police interview, innocent suspects are not aware that they will be asked to generate an alibi and to reconstruct their memory during the interview. In contrast, the perpetrator most likely has rehearsed his false alibi prior to the questioning.

Third, being questioned by the police can be a stressful event for innocent suspects (Guyll et al., 2013) and stress can impair the retrieval of information (Quaedflieg \& Schwabe, 2017), which makes it even more difficult to accurately reconstruct an alibi. When a suspect is only provided with a time cue in the interview (where were you on date $X$ at time $Y$ ?), such cue is the least effective in reconstructing our memory (Wagenaar, 1986). That may lead innocent suspects to rely on schemes (i.e., what they normally would be doing at that 
moment) to report their assumed whereabouts. The presentation of a location cue (e.g., were you at location $\mathrm{X}$ ?) results in the most accurate whereabouts. Remembering where one was, is easier for people who have a certain amount of routine in their lives compared to people who are self-employed, unemployed or homeless (Simon, 2012).

Fourth, it can be argued that innocent suspects are not aware of the impact of reporting an incorrect alibi (Thompson-Cannino, Cotton, \& Torneo, 2009). Their lack of awareness can be explained by the illusion of transparency - the believe that the officials can see that they are in fact innocent - and their believe in a just world, where innocent suspects are not convicted and people get what they deserve (Gilovich, Medvec, \& Savitsky, 1998; Kassin, 2005; Lerner, 1980). In addition, as time increases between the alleged crime and the suspect's interview, it becomes more likely that memory errors do occur (Olson \& Charman, 2012) and the risk increases that potential supportive evidence is no longer available (e.g., CCTV recordings that were erased).

Last, in practice the alibi evaluation can be difficult because suspects cannot only be mistaken about their alibi, they can also lie about them for various reasons. While an innocent suspect may lie about the alibi to conceal his involvement in shameful behaviour, a perpetrator may present a false alibi hoping that he will be released from police custody. In the latter case, the lying suspect will report fake evidence or even fabricated evidence to support the false claim of innocence. That, for instance, occurred in the case of the murder on Melanie Sijbers. In that case, the perpetrator Peter H. told his girlfriend and friends that he was not involved in the missing person case of Melanie. He told them he was making boxes in which marijuana would be grown and, given his prior conviction in a sexual assault case, he reasoned that his alibi could work against him during police questioning. His friends and girlfriend agreed to support his false alibi that he was fishing with friends in the afternoon and afterwards was at home with his girlfriend. The police verified his alibi, found support in the testimonies of his friends and girlfriend, and released him from custody. Afterwards, in his confessions, it became clear that he did rape, kill and bury Melanie (Besters, 2009).

Based on the aforementioned reflections, it can be concluded that a correct alibi evaluation is a difficult and complex task for the police, judicial authorities and potentially 
jurors. This is especially true considering the inevitable time pressure inherent to the police investigation, under which the assessment of a suspect's potential involvement in the alleged crime needs to occur. Taking these circumstances into account, decision-making has to occur based on limited information available at the earliest stages of proceedings.

\subsection{THE IMPORTANCE OF A VALID DETERMINATION OF ALIBI BELIEVABILITY}

As illustrated above, the stakes are high to correctly evaluate a suspect's alibi. An early correct evaluation of a suspect's alibi contributes to the prevention of wrongful convictions and wrongful releases. On the one hand, it avoids that the innocent suspect is needlessly held in custody, while the real perpetrator remains at large. Because being involved in a criminal investigation can cause upheaval and for the purpose of an effective truth finding in criminal proceedings, the time that an innocent person is suspected of having committed a crime should be restricted to a minimum. On the other hand, an early correct evaluation of a staged alibi prevents that the perpetrator is erroneously released from police custody. Therefore, any suspect's potential involvement in a crime should be examined at the earliest stages of criminal proceedings.

Given the importance of a valid determination of an alibi's believability, a number of Anglo-Saxon legal psychological studies have been conducted on the topic of alibis initiated by the influential paper of Olson and Wells (2004). The leading principle in the existing research is that the strength of the supportive evidence is the most important determinant to define the alibi believability. Consequently, most of the studies were conducted to understand how the strength of the evidence affects the alibi believability. Although other aspects of alibi believability have been studied as well, albeit to a lesser degree.

In general, three domains of alibi research can be identified: a) alibi generation; b) alibi evaluation; and c) alibi discrimination (Burke et al., 2007; Culhane et al., 2013). In the first domain, it is studied what alibis innocent suspects can present at various moments in the past and what evidence they can present to support their alibi (Culhane, Hosch, \& Kehn, 2008; Culhane et al., 2013; Olson \& Charman, 2012; Olson \& Wells, 2012). In the alibi 
evaluation research, it is determined what factors affect the alibi believability. The alibi believability refers to the extent to which one considers an alibi as truthful. This is the subjective component of the alibi assessment, which is not per se a reflection of whether the alibi is really true or false. In other words, a believable alibi can still be false and an unbelievable alibi can still be truthful. In the last phase - the discrimination phase - it is determined if true and false alibis in fact can be discerned (Culhane et al., 2013; Nahari \& Vrij, 2014; Sakrisvold, Granhag, \& Mac Giolla, 2017; Strömwall, Granhag, \& Jonsson, 2003). The three domains thus align with the process of the assessment of an alibi, from the moment an alibi is generated until a decision has to be taken about its veracity. However, most of the alibi research has focused on the domain of alibi evaluation, while less attention has been paid to alibi generation and discrimination. In addition, predominantly student samples are included in the existing research instead of police and judicial authorities. As a consequence, the current practices on all domains remain underexposed.

\subsection{THE CURRENT THESIS}

The current thesis aims at bridging the gap that exists between alibi research and how the believability of alibis is determined in practice. More alibi research remains imperative in light of the importance of a valid alibi evaluation for an innocent suspect. The results of the present thesis can eventually result in more valid standards with regard to the generation, evaluation and discrimination of an alibi. Science and progress remain essential in this relatively young research domain in the field of legal psychology to ultimately prevent wrongful convictions and wrongful releases. The aim of the present thesis was threefold: 1) to determine what evidence could logically be expected from innocent suspects; 2) to determine what factors influence the alibi believability; and 3) to assess how students and police detectives evaluate alibis.

The research described in this thesis differs from previous research on two aspects that are important to understand the context in which the results should be understood. First, the base rate of innocent suspects' alibis is established and it is studied whether or not all types of supportive evidence are captured in the literature. These steps are essential, 
because the believability of an alibi cannot be determined correctly if it is unknown what alibis can be expected from innocent suspects. Second, to get a grasp of the alibi evaluation in practice, it is studied how alibis are evaluated by police detectives rather than including samples of students as participants. The studies in this thesis do not focus on merely one of the three domains of alibi research, nor solely on the strength of the evidence as a guiding principle for determining the alibi believability. The current thesis rather aims to be overarching to delineate the entire process of determining the alibi believability.

In addition, to date most of the existing studies are exclusively Anglo-Saxon, focusing on the alibi evaluation by (mock) jurors (i.e., undergraduate students). So far, the evaluation of alibis in the early stages of proceedings was ignored in the literature. In most continental countries (including the Netherlands), however, the emphasis of the proceedings, including the evidence gathering, lies in the pre-trial investigation. In addition, in most continental countries the role of police detectives is somewhat different than in countries with a more adversarial system. Because of the predominant inquisitorial character of the pre-trial investigation, the public prosecutor, and by extension the police, looks for both incriminating and exculpatory evidence, while the suspect has a rather passive role. In most Anglo-Saxon countries, on the contrary, the pre-trial investigation is predominantly adversarial, implying that the prosecution service may restrict itself to gathering only incriminating evidence. In addition, the suspect - and the defence lawyer are more active participants in the evidence gathering process (De Smet, 1999; Van den Wyngaert \& De Smet, 2014; Van Koppen \& Penrod, 2003a, 2003b).

Because of the differences between the two legal systems, it can be argued that the alibi evaluation by police detectives also varies depending on the nature of the legal system. When the police are required to search for both accusatory and exculpatory evidence (e.g., an alibi) one could assume that in that case the police pay more attention to the alibi and potential evidence. In contrast, it can be expected that the assessment of the alibi is regarded as the responsibility of the defence in countries with a predominant adversarial system where the police are not required to investigate exculpatory evidence.

The current thesis aims to address the knowledge gap concerning how the determination of the alibi believability occurs in practice outside the Anglo-Saxon context. 
By conducting the research in a non-Anglo-Saxon legal system it can implicitly be determined to what degree the existing research is also applicable to a continental and more inquisitorial context.

More specifically, the following research questions are addressed in this thesis:

1. What is known from previous research on the factors that make an alibi (un)believable? (Chapter 2)

2. What alibis and supportive evidence can be expected from innocent suspects at various moments? (Chapter 3)

3. How do students, laypeople and police detectives evaluate knowledge evidence? (Chapter 4)

4. How is the alibi believability affected when a suspect lies about his alibi to coverup his involvement in a salacious activity? (Chapter 5)

5. To what extent does the alibi generation effect apply to police detectives? (Chapter 6)

6. How accurately can experienced police detectives and naïve undergraduate students discriminate between true and false alibis generated by genuine suspects? (Chapter 7)

\subsection{OVERVIEW OF CHAPTERS}

Each chapter of the current thesis is guided by one of the aforementioned research questions. Chapter 2 consists of a systematic literature review outlining the factors that are most important to determine the alibi believability. From that literature review it became clear that the strength of the supportive evidence is most important to determine the alibi believability. To assess the validity of relying on the strength of the evidence to determine the believability of a true alibi, the base rate of innocent suspects' alibis was established among a large sample of community members in Chapter 3. By determining the base rate, it is studied what alibis and supportive evidence innocent suspects report. Besides asking the participants whether or not they could come up with evidence to support their alibis, either witness, physical or both, they were also asked if there was other evidence to support 
their alibis. A minority of participants reported evidence that could be classified as knowledge evidence. The results from the base rate study suggest that other evidence than witness or physical evidence could support an alibi as well. Therefore, knowledge as supportive alibi evidence was studied in Chapter 4 by conducting three experiments among students, laypeople and detectives.

From the literature review it furthermore became clear that the consistency (Culhane \& Hosch, 2012) and the content of the alibi (e.g., Allison, Mathews, \& Michael, 2012) also can affect the alibi believability, regardless of the strength of the evidence. To date, predominantly the effect of single factors on the alibi believability is studied. Therefore, in Chapter 5 a study is presented in which it is examined how the alibi believability is affected when a suspect lies about his alibi to cover-up his involvement in a salacious activity. By doing so, two recent discovered factors, i.e., the consistency and salaciousness of the alibi, are combined to determine how such a combination of factors affects the alibi believability.

When it comes to the evaluation of an alibi, both mock jurors and police detectives tend to set very high standards for an alibi to be found believable (Dysart \& Strange, 2012). However, when mock jurors become aware of the difficulty to present a believable alibi for an innocent suspect (Olson \& Wells, 2012), they evaluate alibis more realistically compared to when they are unaware of that effect. Therefore, Chapter 6 consists of a study in which it is determined if the so-called alibi generation effect can also help police detectives to come to a more realistic alibi evaluation. In addition, the study aims to determine what factors detectives find important when evaluating an alibi.

Ultimately, an alibi should differentiate between innocent suspects and perpetrators. In Chapter 7, a final study is presented in which police detectives' performance in discriminating between true and false alibi statements, generated by genuine suspects in a remand prison, is compared to the performance of students. To better understand the process of alibi discrimination in these groups, it is furthermore studied what aspects both groups find relevant in order to come to a discrimination between true and false alibis. 
The results of the presented studies and their implications to answer the three main questions that are formulated in this dissertation are discussed in Chapter 8. This Chapter is concluded with recommendations for future research and suggestions for practitioners in order to better determine the alibi believability. 
CHAPTER 1

\subsection{REFERENCES}

Allison, M., Mathews, K. R., \& Michael, S. W. (2012). Alibi believability: The impact of salacious alibi activities. Social Behavior and Personality: an international journal, 40, 605-612. doi:10.2224/sbp.2012.40.4.605

Besters, F. (2009). Gegijzeld door een psychopaat [Hostaged by a psychopath]. Eindhoven: De Boekenmakers.

Burke, T. M., \& Marion, S. B. (2012). Alibi witnesses. In B. L. Cultler (Ed.), Conviction of the innocent. Lessons from psychological research (pp. 239-256). Washington: American Psychological Association.

Burke, T. M., Turtle, J. W., \& Olson, E. A. (2007). Alibis in criminal investigations and trials. In M. P. Toglia, J. D. Read, D. F. Ross, \& R. C. Lindsay (Eds.), The handbook of eyewitness psychology: Memory for events (Vol. 1, pp. 157-192). Mahwah, NJ: Lawrence Erlbaum Associates.

Crozier, W. E., Strange, D., \& Loftus, E. F. (2017). Memory errors in alibi generation: How an alibi can turn against us. Behavioral Sciences and the Law, 35, 6-17. doi:10.1002/bsl.2273

Culhane, S. E., \& Hosch, H. M. (2012). Changed alibis: Current law enforcement, future law enforcement, and layperson reactions. Criminal Justice and Behavior, 39, 958-977. doi:10.1177/0093854812438185

Culhane, S. E., Hosch, H. M., \& Kehn, A. (2008). Alibi generation: Data from U.S. Hispanics and U.S. non-Hispanic whites. Journal of Ethnicity in Criminal Justice, 6, 177-199. doi:10.1080/15377930802243395

Culhane, S. E., Kehn, A., Horgan, A. J., Meissner, C. A., Hosch, H. M., \& Wodahl, E. J. (2013). Generation and detection of true and false alibi statements. Psychiatry, Psychology and Law, 20, 619-638. doi:10.1080/13218719.2012.729018

De Smet, B. (1999). Internationale samenwerking in strafzaken tussen Angelsaksische en continentale landen [International cooperation in criminal cases between AngloSaxon and continental countries]. Antwerpen: Intersentia Rechtswetenschappen.

Dysart, J. E., \& Strange, D. (2012). Beliefs about alibis and alibi investigations: A survey of law enforcement. Psychology, Crime and Law, 18, 11-25. doi:10.1080/1068316X.2011.562867

Garrett, B. L. (2011). Convicting the innocent. Cambridge, Massachusetts: Harvard University Press.

Gilovich, T., Medvec, V. H., \& Savitsky, K. (1998). The illusion of transparency: Biased assessments of others' ability to read one's emotional states. Journal of Personality and Social Psychology, 75, 332-346. doi:10.1037/0022-3514.75.2.332 
Guyll, M., Madon, S., Yang, Y., Lannin, D. G., Scherr, K., \& Greathouse, S. (2013). Innocence and resisting confession during interrogation: Effects on physiologic activity. Law and Human Behavior, 37, 366-375. doi:10.1037//hb0000044

Havinga, E., Hopman, S., Melis, P., Vastenburg, J., Zeeman, M., Nelen, H., \& Van Koppen, P. J. (2008). De dood in het Chinese Restaurant: Een moord met vele verhalen. [The death in the Chinese Restaurant: A murder with many stories]. Den Haag, Boom Juridische Uitgevers.

Kassin, S. (2005). On the psychology of confessions. Does innocence put innocents at risk? American Psychologist, 60, 215-228.

Lerner, M. J. (1980). The belief in a just world: A fundamental delusion. New York: Plenum.

Nahari, G., \& Vrij, A. (2014). Can I borrow your alibi? The applicability of the verifiability approach to the case of an alibi witness. Journal of Applied Research in Memory and Cognition, 3, 89-94. doi:10.1016/j.jarmac.2014.04.005

Olson, E. A., \& Charman, S. D. (2012). 'But can you prove it?' - Examining the quality of innocent suspects' alibis. Psychology, Crime and Law, 18, 453-741. doi:10.1080/1068316x.2010.505567

Olson, E. A., \& Wells, G. L. (2004). What makes a good alibi? A proposed taxonomy. Law and Human Behavior, 28, 157-176. doi:10.1023/B: LAHU.0000022320.47112.d3

Olson, E. A., \& Wells, G. L. (2012). The alibi-generation effect: Alibi-generation experience influences alibi evaluation. Legal and Criminological Psychology, 17, 151-164. doi:10.1111/j.2044-8333.2010.02003.x

Quaedflieg, C. W. E. M., \& Schwabe, L. (2017). Memory dynamics under stress. Memory, 113. doi:10.1080/09658211.2017.1338299

Sakrisvold, M. L., Granhag, P. A., \& Mac Giolla, E. (2017). Partners under pressure: Examining the consistency of true and false alibi statements. Behavioral Sciences and the Law, 35, 75-90. doi:10,1002/bsl.2275

Simon, D. (2012). In doubt: The psychology of the criminal justice process. London: Harvard University Press.

Strange, D., Dysart, J. E., \& Loftus, E. F. (2014). Why errors in alibis are not necessarily evidence of guilt. Zeitschrift für Psychologie, 222, 82-89. doi:10.1027/21512604/a000169

Strömwall, L. A., Granhag, P. A., \& Jonsson, A. C. (2003). Deception among pairs: 'Let's say we had lunch and hope they will swallow it!'. Psychology, Crime \& Law, 9, 109-124. doi:10.1080/1068316031000116238

Sullivan, T. P. (1971). Presentation of the defense. Journal of Criminal Law, Criminology, and Police Science, 62, 153-172.

Thompson-Cannino, J., Cotton, R., \& Torneo, E. (2009). Picking Cotton. New York: St. Martin's Press. 
Van den Wyngaert, C., \& De Smet, B. (2014) Strafrecht en strafprocesrecht in hoofdlijnen [Criminal law and criminal procedure law in general lines]. Antwerpen: Maklu.

Van Koppen, P. J., \& Penrod, S. D. (2003a). Adversarial or inquisitorial: Comparing systems. In P. J. van Koppen \& S. D. Penrod (Eds.), Adversarial versus inquisitorial justice: Psychological perspectives on criminal justice systems (pp. 2-20). New York: Plenum.

Van Koppen, P. J., \& Penrod, S. D. (2003b). The John Wayne and Judge Dee versions of justice. In P. J. van Koppen \& S. D. Penrod (Eds.), Adversarial versus inquisitorial justice: Psychological perspectives on criminal justice systems (pp. 347-368). New York: Plenum.

Wagenaar, W. A. (1986). My memory: A case study of autobiographic memories over six years. Cognitive Psychology, 18, 225-252.

Wells, G. L., Small, M., Penrod, S., Malpass, R. S., Fulero, S. M., \& Brimacombe, C. (1998). Eyewitness identification procedures: Recommendations for lineups and photospreads. Law and Human Behavior, 22, 603-647. 


2

OUR WHEREABOUTS: A REVIEW OF THE LITERATURE ON ALIBIS AND FUTURE AVENUES

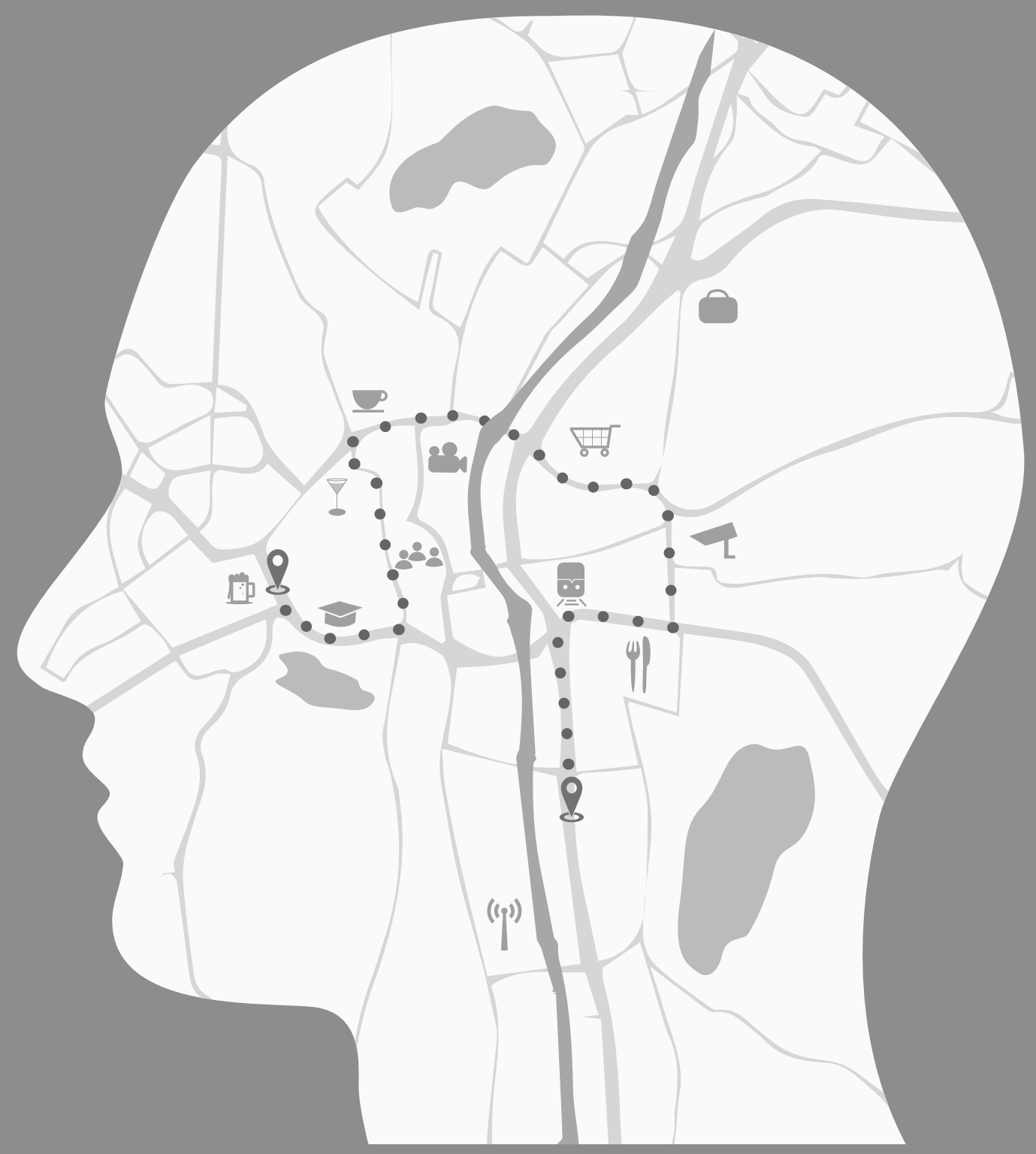

This chapter is a translated and emended version of a Dutch chapter published in a textbook about legal psychology:

Van Koppen, M. V., \& Nieuwkamp, R. (2017). Alibi's [Alibis] in P. J. van Koppen, J. W. de Keijser, R. Horselenberg \& M. Jelicic (Eds.), Routes van het Recht: Over de Rechtspsychologie [Routes of the Law: About Legal Psychology] (pp. 249-260). Den Haag: Boom Juridisch. 



\subsection{INTRODUCTION}

On 16 January 2012 John Travolta was accused of sexually assaulting a male masseur. The masseur claimed that Travolta had grabbed his penis in the Beverly Hills Hotel in Los Angeles. The accusation was reported in the media for the first time on 8 May 2012 (D'Zurilla, 2012). The day after the news broke, Travolta told the media that he had been in New York when the alleged assault took place and therefore could not have committed the assault (Goodhand, 2012).

Mr Travolta's alibi was corroborated with three pieces of physical evidence: a) flight records that indicated that his private jet flew from Los Angeles on 15 January 2012 at 9:00 PM and landed at 4:38 AM in New York on 16 January 2012; b) a receipt printed at 11.38 PM on 16 January at a Chinese restaurant in New York, paid with a credit card and signed by John Travolta (Britney, 2012); and c) at least two photographs of Travolta taken in the Greenwich Hotel in New York at 4:30 PM and at 5:21 PM that same day (D'Zurilla, 2012). These items of physical evidence demonstrated that Travolta was in New York and not in Los Angeles on 16 January 2012. In response to the alibi, the masseur explained to the media that he had been mistaken about the date of the sexual assault (Dillon, 2012). The masseur withdrew his accusations against Travolta a few days later (Sinha-Roy, 2012). This shows that an alibi can lead to the withdrawal of an invalid claim, making prosecution no longer viable.

In a judicial context, an alibi implies that a person cannot have committed the alleged crime because at the time of the crime he was at a location other than where the crime was committed. Although the burden of proof lies with the prosecution, an alibi can be a strong indication that one is in fact innocent, as demonstrated by the Travolta case. Given the importance of an alibi for an innocent suspect, the number of studies on alibis is relatively small. Only during the last decade alibi research has attracted more attention (Allison \& Brimacombe, 2010; Allison, Mathews, \& Michael, 2012; Hosch, Culhane, Jolly, Chavez, \& Shaw, 2011; Jung, Allison, \& Bohn, 2013). Once a person becomes a suspect, he will be asked where he was at the time of the alleged crime and what he was doing there. The suspect will need to consult his memory to answer the questions. This is referred to as 
CHAPTER 2

the reconstruction of the alibi (Burke \& Turtle, 2003). In the next phases, the generation and validation phases, the alibi is presented and the search begins for evidence that supports or refutes the alibi. Based on the presented alibi and the potential supportive evidence, the alibi believability is determined. That evaluation is the basis for making a decision on the veracity of the alibi. Most of the alibi research to date has focused on the determination of the alibi's believability.

\subsection{THE RECONSTRUCTION PHASE: A MEMORY TEST}

When one is asked for their alibi, their autobiographical memory is put to the test (Crozier, Strange, \& Loftus, 2017). In general, people are inept at remembering what they were doing three weeks or even three days ago (Olson \& Charman, 2012). Our memory is not designed to remember everything, which is not a bad thing. If we remembered where we parked our car three months ago as clearly as where we parked our car this morning, we would not be able to locate the car. Recent memories are better recalled than older memories. When the timespan between the event and the recollection increases, the quality of the memory decreases drastically (Burke, Turtle, \& Olson, 2007). The amount of time that passes before the alibi is required determines whether it is possible to recollect the alibi. As time increases, people find it more difficult to find physical evidence, such as CCTV recordings or receipts, to support their alibi. In addition, the probability that the alibi is misremembered increases too and supportive evidence tends to becomes untraceable (Culhane et al., 2013; Olson \& Charman, 2012).

Often people do not have detailed memories about daily or routine activities. That is because we are used to thinking in schemes. Such schemes provide support for our memory: because much of our behaviour is predictable and occurs in a fixed pattern, it is not necessary to remember every detail. A person who worked last Monday will not remember how on that particular day he walked to the train station, took the train, walked the stairs at the office, turned on his computer, had lunch, and took the train home in the evening. Because every regular workday follows that pattern, the person knows the chain of events for last Monday. If a day or event does not go according to the scheme, for 
example if there is a train strike or a teambuilding event at work, this scheme-inconsistent event has to be encoded separately in our memory. If one is asked for their alibi for a certain period of time, it is much easier to report scheme-consistent behaviour than schemeinconsistent behaviour. When the requested period of time was scheme consistent, the alibi is more often accurate (83\%) than when the period of time was scheme inconsistent (11\%; (Leins \& Charman, 2013).

The recollection of an alibi for a particular point in time can be aided with various cues. These cues can give the suspect leads for the when and where aspects of his alibi. Location cues (e.g., where you were on location X) lead to most accurate recollections of the alibi. Time cues (e.g., where you were at time $Y$ ) or the combination of location and time cues (e.g., where you were at location $\mathrm{X}$ at time $\mathrm{Y}$ ) can also help the suspect to reconstruct his memory but are less effective than the location cue (Leins \& Charman, 2013). People have more difficulty determining when they did something compared to what they did (Strange, Dysart, \& Loftus, 2014). The fact that the combination of the two cues does not lead to the most accurate alibi can be explained by the very specific information the two cues represent. The combination is more specific than only the location cue, making it more difficult to recollect information. Wagenaar, for example, put his own memory to the test and took notes over a period of six years and 2400 events about when and where the event occurred and what it was and who was with him (Wagenaar, 1986). The what-cue (i.e., the nature of the event) was the greatest aid for remembering where the event took place, who was with him and when the event occurred.

\subsection{THE VALIDATION PHASE: SUPPORTIVE EVIDENCE FOR THE ALIBI}

It is not enough for a suspect to successfully reconstruct an alibi. The suspect's statement will have to be supported with evidence: who or what can support the alibi? That validation phase entails a search for evidence to support the alibi (Burke et al., 2007). Olson and Wells (2004) created a taxonomy with two types of alibi evidence. First, witnesses can support the suspect's alibi. Alibi witnesses should be able to remember what they were doing at the time of the alleged crime and if the suspect was with them at that moment (Burke \& Marion, 
CHAPTER 2

2012). The second type of alibi evidence is physical evidence, such as CCTV recordings that confirm that the suspect was somewhere else other than the location where the crime occurred. A third type of evidence, not included by Olson and Wells (2004) in the taxonomy, is knowledge as evidence. When a suspect possesses unique knowledge, that he could only have acquired if the alibi is true, that knowledge supports the alibi. An example of a case in which the suspect presented allegedly unique knowledge can be found in the Deventer murder case where the defendant stated that at the time that the victim was killed, he was in a traffic jam. The traffic jam was not reported in the media (Derksen, 2011) and makes the defendant's knowledge about the traffic jam unique knowledge. He could, however, also have obtained that knowledge when passing a viaduct from where the traffic jam was also visible or heard it from other people (Haan, 2009).

Not every suspect is capable of proving his innocence with supportive evidence for his alibi. Compared to reconstructing an alibi, acquiring evidence is not an easy task. It can therefore not be ruled out that the suspect will not make errors in that process. The absence of an alibi or an alibi that is not strongly supported with evidence can never be taken as evidence of the suspect's guilt. This is illustrated by the American Innocence Project that studies possible wrongful convictions. From the analyses of the causes of wrongful convictions in their cases, it appears that many of the wrongly convicted individuals were able to present an alibi that was also supported by witnesses (Garrett, 2011; Simon, 2012; Strange et al., 2014; Wells et al., 1998). The prosecutors and the juries, however, did not believe the presented alibis, which eventually led to the conviction of an innocent person. For a suspect, it is difficult to prove his innocence with an alibi even when he was not involved in the alleged crime. As demonstrated by the case of Travolta, the likelihood that the suspect is the perpetrator decreases if the suspect can present strong evidence for his alibi. The alibi is most believable when there is strong supportive evidence (Olson \& Wells, 2004). 


\subsection{THE EVALUATION PHASE: ALIBI BELIEVABILITY}

After the phases of reconstruction and validation, the alibi and its supportive evidence are evaluated for believability. In the alibi taxonomy Olson and Wells (2004) describe how the strength of the supportive evidence can be determined. The rationale behind the taxonomy is that the alibi becomes more believable as the supportive evidence becomes stronger. A second important aspect of alibi believability is the ease or difficulty by which the supportive evidence can be fabricated.

\subsubsection{Witness Evidence}

The strength of the corroborating alibi witness' statement depends on the relational distance to the suspect (Fawcett, 2015). The closer the relational distance, the weaker the supportive testimony becomes. An alibi witness who is not related to the suspect is to a lesser degree intrinsically motivated to lie in favour of the suspect (Burke \& Marion, 2012). When such a witness confirms the suspect's whereabouts, the testimony, for instance, is considered as stronger evidence compared to the confirming statement of a suspect's family member (Hosch et al., 2011; Olson \& Wells, 2004). Thus, the suspect's neighbour is a more credible alibi witness than the suspect's girlfriend (Culhane \& Hosch, 2004). The girlfriend's testimony has no added value in terms of alibi believability compared to a suspect's statement that is not supported by any witness (Culhane \& Hosch, 2004). Alibis supported by biological family members (e.g., brother or mother) are found to be less believable than alibis supported by other family members (e.g., partner or in-laws). The most believable alibis are those supported by witnesses other than family members (e.g., best friend or neighbour; (Hosch et al., 2011). In short, the closer the social or biological relational distance between the alibi witness and the suspect, the less believable the supportive statements of such witnesses are perceived.

The results on determining the strength of witness evidence implicitly suggest that people who are close to the suspect have a potential motive to lie in favour of the suspect when they talk to the police (Sullivan, 1971). This assumption is, however, not supported in 
CHAPTER 2

experimental studies: people who like each other do not lie more frequently in favour of the suspect compared to people whom they like less (Marion \& Burke, 2013). Also, strangers can be inclined to lie in favour of the suspect. They can lie for them out of fear of the suspect, because they feel sorry for the suspect, or because of an aversion against the police and the judicial system (Dysart \& Strange, 2012). When witnesses are asked to support a false alibi, up to $60 \%$ of the people provide such support (Marion \& Burke, 2017). It is doubtful, however, if a stranger can correctly remember seeing the innocent suspect with whom they interacted. Less than $40 \%$ of strangers can remember having interacted with the suspect 24 hours earlier, and their memories for that interaction are quite vague. Only $7 \%$ of strangers can also recall the time and the nature of the interaction with the suspect (Charman, Reyes, Villalba, \& Evans, 2017).

Besides the relational distance between the suspect and the witness, other factors also determine the alibi's believability. Witnesses who are $100 \%$ certain of their statement are more often believed than witnesses who are $80 \%$ certain that the suspect was with them at the moment the alleged crime was committed (Allison, Jung, Sweeney, \& Culhane, 2014). The witness's age is also important. A young child is more often believed than an adult, regardless of whether it is the suspect's or his neighbour's child (Dahl \& Price, 2012). The confirming testimony of adult children seems to harm more than do good, as in one study where suspects were more likely to be found guilty when their adult son confirmed their alibi than without that testimony (Dahl \& Price, 2012). That the credibility of young children is greater than of adult alibi witnesses can be explained by the tendency of children to be seen as more honest or less capable of lying than adults (Ross, Jurden, Lindsay, \& Keeney, 2003).

\subsubsection{Physical Evidence}

For physical evidence, like witness evidence, the evidence is weaker when the evidence can be easily fabricated or obtained from someone else. For example, a receipt can easily be passed on from one person to another and is therefore weaker evidence than CCTV recordings on which the suspect is clearly recognisable, far away from the crime scene 
where the alleged crime was committed at that time (Olson \& Wells, 2004). Physical evidence is strong when three criteria are met: the evidence needs to a) be directly linked to the suspect; b) contain an indication of time; and c) provide location information (Olson \& Charman, 2012). The recordings of CCTV cameras are a good example of such strong evidence. If the evidence indicates time or location information but cannot be directly linked to the suspect, the evidence is of moderate strength (e.g., a receipt). If the evidence contains none of the three criteria, the evidence is weak (e.g., a receipt where only the total amount of the purchases is displayed).

\subsubsection{Knowledge Evidence}

As illustrated above, aspects that determine the strength of witness or physical evidence have already been set out in the literature. It can be argued that for knowledge evidence, the more difficult it is to falsify the evidence, the stronger the evidence is (M. V. Van Koppen \& Van Koppen, 2010). The more difficult it is for a person to have acquired the knowledge on a previous occasion or from someone else, the stronger the evidence is. The suspect's alibi will be more believable if he can report many details of a movie, at least if the movie was recently released. A suspect who claims to have watched the movie Titanic can say that the plot consists of a ship that sank, but that will probably not be found to be very believable.

\subsubsection{Alibi Believability of Different Types of Supportive Evidence}

The strength of the believability of the supportive evidence varies across types of supportive evidence. There are also differences within these types in the degree of believability that is added to the alibi. Although the taxonomy of Olson and Wells (2004) offers some guidelines on how to determine the strength of evidence, the strength of multiple items within one type of evidence cannot be determined. For example, are two motivated witnesses who support the suspect's alibi more believable than one unmotivated witness? That factor is 
important to address because police detectives find the number of alibi witnesses more important than who those witnesses are (Eastwood, Snook, \& Au, 2016).

In general, physical evidence is thought to be more difficult to fabricate than witness or knowledge evidence; therefore, physical evidence adds more to alibi believability than the other types (Olson \& Wells, 2004). However, the following case study shows that strong physical evidence for an alibi is not always indicative of innocence. On Wednesday 7 November 2001 around 4:00 AM, Brigitte and her two children were killed in their house near to Aalst, Belgium. Quite soon in the investigation, Patrick, the father of the family, became a suspect. But Patrick had an alibi. He was a successful businessman and organised seminars on a regular basis in a conference hotel in Landgraaf, The Netherlands. He said that he was in the hotel from Monday until Thursday during the week that his spouse and children were killed. There is only one entrance to the hotel, which is filmed by a CCTV camera 24 hours a day, 7 days a week. The records from that CCTV camera show that Patrick entered the hotel 7 November at $0.44 \mathrm{AM}$ and left the hotel the following morning at 8.06 AM. The records thus provide strong supportive evidence for Patrick's alibi because the CCTV records show that Patrick did not leave the hotel that night.

His alibi, however, did not set Patrick free. At the crime scene, footprints covered in the victim's blood were found. We know that those footprints belong to Patrick because he has a very specific way of walking. So, Patrick can be placed at the crime scene with a great level of certainty. How can the footprint evidence be brought into agreement with the alibi? To answer that question, it is important to have some additional information about the conference hotel. No tourists were staying in the hotel because the company that organised the seminars rented the entire hotel. All attendees were checked into a room at the reception desk, but the keys of the spare rooms remained in the locks on the outside of the rooms, giving all attendees access to the spare rooms. Patrick had checked into a room on the first floor, B.14. On Wednesday 7 November, the housekeeper noticed that room B.14 had not been used that night. The bed appeared to be untouched; the shower was dry and showed no signs of use. In the room below Patrick's room on the ground floor B.04 the shower was wet, although nobody was registered in that room. Later it became clear that Patrick snuck out of the window in room B.04 on the night of the murder, but used the 
shower in that room after he returned (through the same window) and later exited the hotel at 8.06 AM using the single entrance of the hotel.

\subsubsection{The Effects of Timing, Consistency and Salaciousness on Alibi Believability}

Besides the evidence a suspect can provide to support his alibi, other factors also affect the alibi believability. Not every person can present supportive evidence for his alibi at any time of the day (Culhane, Hosch, \& Kehn, 2008; Culhane et al., 2013; Olson \& Charman, 2012). Some people are also more likely to be able to present supportive evidence than others. A working married father will spend a substantial amount of time with his co-workers, children and partner. He will find it less difficult to find alibi witnesses compared to a single unemployed man who spends a substantial amount of time being at home alone (Burke et al., 2007). For the unemployed man it will be more difficult to present supportive evidence, and thus he is less likely to offer the police a believable alibi compared to the employed man.

Moreover, for a believable alibi it is important that the alibi remains consistent over time. When the suspect presents an alibi and later changes that alibi, regardless of whether the supportive evidence becomes stronger or weaker according to the taxonomy, that change will result in a decrease in the alibi believability (Culhane \& Hosch, 2012). For an innocent suspect it is difficult to prove one's innocence using an alibi. Inconsistencies in alibis appear more often than one might assume (Strange et al., 2014). A suspect changing his alibi or presenting an inconsistent alibi is not always indicative of a false, fabricated alibi. An incomplete or inconsistent alibi does not sufficiently discriminate between a true and a false alibi to be decisive for a conviction. The diagnostic value of an alibi is not sufficiently high for such decision.

Innocent people find it difficult to present a consistent alibi that is supported by strong evidence for both periods in the near past (e.g., three days ago) and in the distant past (e.g., fourteen weeks ago). Most of the innocents are capable of remembering where they have been and what they did without using any external resources. About $10 \%$ of the alibis, however, appear to be incorrect, and about $25 \%$ of the reported supportive evidence 
CHAPTER 2

appears to be non-existent or no longer available (Olson \& Charman, 2012). If innocents are asked again for their alibis one week after their initial statement, about $60 \%$ of them appear to be entirely or partially inconsistent about what they did, and about half of them are inconsistent about who was with them (Strange et al., 2014). The innocents' memories appear more often to be correct when they are more certain about their memories, their memories are more vivid, they relived the memories and when they remembered the events from their own perspective (Strange et al., 2014).

When supportive evidence is lacking, the superficial aspects of the alibi become more important, such as the content of the behaviour in which the suspect states to have been involved during the time the alleged crime was committed. The content of such behaviour can relate to the salaciousness and/or the legality of the behaviour. Salaciousness refers to the sexual content of certain activities in which the suspect might have been involved when the alleged crime was committed (e.g., watching a porn movie) while the legality of the activities indicates if the behaviour was prohibited (e.g., illegally copying DVD's).

Research shows no differences in the alibi believability based on the legality of the behaviour in which the suspect was involved when the alleged crime was committed (Allison et al., 2014). The non-significant differences might be explained by the fact that the displayed behaviour (i.e., illegally making copies of DVD's) is illegal but still more or less accepted within the community. The same goes for salacious alibis, where mixed results have been observed. In the first study on salacious alibis, an increase of the alibi believability was found (Allison et al., 2012). That effect has not been replicated (Allison et al., 2014; Jung et al., 2013) and recently it was shown that salacious alibis can be less believable than nonsalacious alibis (Keeping, Eastwood, Lively, \& Snook, 2017). It remains unclear how the salaciousness of the alibi can affect its believability and it can be questioned if the effect is limited to salacious alibis or can be generalized to the content of shameful behaviour (e.g., cross-dressing).

The mixed results for the salaciousness and the legality of behaviour in alibis can be explained by two important factors. First, in most of the alibi evaluation research the presence and the strength of supportive evidence has been studied in relation to the alibi's 
believability (e.g., Jung et al., 2013; Pozzulo, Pettalia, Dempsey, \& Gooden, 2015). That is not surprising because in their influential paper, Olson and Wells (2004) argued that alibi believability could be best determined based on the presence and strength of the evidence and "not the surface attributes of the alibi itself" (Olson \& Wells, 2004, p. 159). This explains why research on these attributes is relatively scarce compared to other research on alibi believability. Second, it remains unclear how suspects are perceived when they were involved in salacious or illegal behaviour. On the one hand, the suspect might come across as an honest person because he admits his involvement in behaviour that is morally doubtful. On the other hand, it can also be argued that being involved in salacious or illegal behaviour will be indicative of the suspect's participation in other illegal activities. The latter impressions can perhaps explain the mixed results in this relatively new approach of alibi research.

\subsection{WHERE THINGS CAN GO WRONG IN ALIBI RECONSTRUCTION, VALIDATION AND EVALUATION}

\subsubsection{Reconstruction Phase: No or Wrong Memories}

The presentation of an alibi can go wrong at any phase (Olson \& Charman, 2012). During the reconstruction phase, the suspect may have no memories about the time during which he is asked for his alibi. The suspect depends on his own memory in the recollection of his alibi (Crozier et al., 2017). If the suspect is guilty, he will have less difficulty remembering his activities than if he is innocent. It is more likely that the memory of committing a crime is better encoded in our memory compared to the memory of a random other person to whom the involvement in a certain event has no specific value (Friedman, 2004). For an innocent suspect, the moment when the alleged crime was committed is probably equally random as any other moment, unless that moment by chance also has a special meaning for the innocent suspect. The alleged crime can, for example, be committed during the suspect's birthday party or on the first day of work. In general, however, an innocent suspect will have to explain to the police where he has been at a specific moment that has 
no special meaning and is therefore more difficult to recollect (Kassam, Gilbert, Swencionis, \& Wilson, 2009; P. J. Van Koppen, 2011). When in hindsight that specific moment proves to be important, high motivation to recollect the memory has no effect on the recollection of that event (Olson \& Charman, 2012).

The alibi reconstruction can also go wrong when the suspect makes mistakes in his statement. A suspect's interview is a stressful experience for the suspect (Guyll et al., 2013). From research it is known that the recollection of memories under stress can be impaired (Quaedflieg \& Schwabe, 2017; Schonfeld, Ackermann, \& Schwabe, 2014; Schwabe, Joels, Roozendaal, Wolf, \& Oitzl, 2012; Smeets, Otgaar, Candel, \& Wolf, 2008; Wolf, 2009). Given that fact, and taking into account the moderate memory an innocent suspect will have for a random event, the chance of an inconsistent alibi increases. People tend to fill in the gaps in their memory with details that emerge from daily routine (Leins \& Charman, 2013). If an innocent suspect is asked for his alibi on Wednesday evening - his regular training time he will provide a statement in which he speaks about his training according to the regular scheme he has developed in his memory. He might not remember exact details of the training, but he will tell how he cycled to the training, started the training, drank something afterwards and cycled back home, as this is a regular Wednesday evening training for him. While he cannot precisely remember the cycling and drinking on that specific Wednesday evening, he will fill these memory gaps based on the scheme he has for training evenings. Deviations for the scheme on the specific evening, for example, that he went by car due to weather conditions, can easily lead to mistakes in the presented alibi (Leins \& Charman, 2013).

In general, police detectives have little patience for the faltering memory of suspects, as is demonstrated by research from the United States. When the suspect is asked for his alibi 24 hours after the alleged crime was committed, more than $50 \%$ of the police detectives think it is extremely unlikely that a suspect would be mistaken about the alibi. When the suspect is questioned one week after the crime, one in eight police detectives still finds a mistake in the suspect's alibi extremely unlikely. When a suspect changes his initial alibi, $20 \%$ of the police detectives think that the change is due to a misrecollection. The remaining $80 \%$ of them think that the change occurred because the suspect lied in his 
initial statement (Dysart \& Strange, 2012). An inconsistent alibi can thus unfairly be treated as a deceitful statement. How an inconsistent alibi can work against a suspect is demonstrated here in the case of Ronald Cotton.

Ronald Cotton was wrongfully convicted in 1985 for the rape of Jennifer Thompson on 28 July 1984. At that time Ronald was 22 years old and frequently went to numerous parties during the summer holiday. He did not pay much attention to the days and nights and what differentiated between them. When he was asked for his alibi in early August 1984 , he tried to recollect his whereabouts for the $28^{\text {th }}$ of July. He told the police that he went to his brother's home to have some drinks and then went to the Candlelight Club together with a friend. In the club he came across some other friends. Shortly after Ronald had provided the police with this statement, he was allowed to talk to his mother. He told her what he told the police and that it would only be a matter of time before the police would realise they had questioned the wrong man. His mother told Ronald that he was mistaken: on the night of the $28^{\text {th }}$ July he was at her home and slept on the couch. When Ronald realised that he had made a mistake, he panicked that he had provided the police with a wrongful alibi. That mistake, and the recognition of Jennifer of Ronald as being the perpetrator in a badly executed line-up, led to the wrongful conviction of Ronald to a lifetime imprisonment. In 1995, it became clear that Ronald could not have been the rapist because his DNA did not match the DNA found at the crime scene, and he was exonerated (Thompson-Cannino, Cotton, \& Torneo, 2009).

\subsubsection{The Validation Phase: No Evidence}

In the validation phase, the presentation of an alibi can go awry when no witness or physical evidence can confirm the suspect's alibi. This can occur if the innocent suspect was home alone and did not have contact with other people when the alleged crime was committed. In that case the suspect has an alibi in that he was at another location than where the alleged crime occurred and can accurately recall his whereabouts, but his alibi cannot be confirmed by any evidence. As stated above, in such cases the suspect could report 
CHAPTER 2

knowledge evidence to support his alibi, for example: what he was watching on television that night.

\subsubsection{The Evaluation Phase: Alibi Believability}

A suspect depends on the judgement of police detectives, judges or juries in the alibi evaluation phase. Police detectives have an a priori sceptic attitude towards suspects' alibis. In about $80 \%$ of cases, they expect that the suspect will lie to them, and about $50 \%$ of the police officers believe that it is easy to fabricate a false alibi (Dysart \& Strange, 2012). The results of research show that the presumption of guilt, before the alibi is presented, leads to the recall of fewer details of the alibi and a less favourable evaluation of the alibi (Olson, 2013). Those who evaluate alibis underestimate the difficulty an innocent suspect faces to present a believable alibi. That leads judges and juries to be more inclined to convict suspects who present an inconsistent alibi or who can only present weak supportive evidence for their alibis. The suspect therefore needs strong and compelling evidence to have a somewhat believable alibi.

Police detectives, who have to evaluate the believability of an alibi, put high demands on an alibi to be believable (Dysart \& Strange, 2012) possibly because they appear to be unaware of how difficult it can be to present a believable alibi. Asking these evaluators to generate an alibi themselves prior to evaluating a suspect's alibi can make them more aware of the difficulty involved. Previous research with students (Olson \& Wells, 2012) shows that this awareness, known as the alibi generation effect, can lead to more realistic expectations of a suspect's alibi.

\subsection{DIFFERENTIATING BETWEEN TRUE AND FALSE ALIBIS}

A true alibi should differentiate between a guilty and an innocent suspect (Culhane et al., 2013). It is up to detectives and other actors in the criminal justice system to differentiate between true and false alibis. A number of cues can be used to determine the veracity of an alibi. For example, suspects who present a false alibi use more words compared to 
suspects who provide a true alibi (Culhane et al., 2013). This can be explained by the desire of liars to provide as many details as possible to make their alibi more believable (Nahari, Vrij, \& Fisher, 2014). Liars name more details in their alibi, but the details they report are difficult to verify.

To differentiate between true and false alibis, it can therefore be wise to focus on the number of details that can be verified (Nahari \& Vrij, 2014). Suspects can also adjust their alibis to match one another's when they both agree to lie about their alibi, or a suspect can ask a witness to testify in his favour. If two people decide to lie about their alibi, such as by falsely stating that they had lunch together, their alibis are more consistent compared to when two people, who actually had lunch, both provide an alibi about that meeting (Granhag, Strömwall, \& Jonsson, 2003). Pairs of liars are also more consistent when one supports the false alibi of the other (Sakrisvold, Granhag, \& Mac Giolla, 2017). The high level of consistency can be explained by the repeat vs. reconstruct hypothesis which holds that liars repeat their prepared answers on anticipated questions while truth tellers rely on their memories to answer questions about their whereabouts (Granhag et al., 2003).

\subsection{CONCLUSION}

All in all it becomes clear that for non-offenders generating a believable alibi is difficult and that subsequently determining the alibi believability is a complex task for all evaluators. Only focusing on the presence and the strength of the evidence provides a too limited perspective on this complex concept. Although the alibi research has focused predominantly on the effects of the supportive evidence to determine the alibi believability, other surface attributes should be taken into consideration as well to come to a more valid alibi evaluation and discrimination. 
CHAPTER 2

\subsection{REFERENCES}

Allison, M., \& Brimacombe, C. (2010). Alibi believability: The effect of prior convictions and judicial instructions. Journal of Applied Social Psychology, 40, 1054-1084. doi:10.1111/j.1559-1816.2010.00610.x

Allison, M., Jung, S., Sweeney, L., \& Culhane, S. E. (2014). The impact of illegal alibi activities, corroborator involvement and corroborator certainty on mock juror perceptions. Psychiatry, Psychology and Law, 21, 191-204. doi:10.1080/13218719.2013.803275

Allison, M., Mathews, K. R., \& Michael, S. W. (2012). Alibi believability: The impact of salacious alibi activities. Social Behavior and Personality: an international journal, 40, 605-612. doi:10.2224/sbp.2012.40.4.605

Britney, F. (2012). John Travolta sex allegations contradicted by flight records? The Hollywood Gossip. Retrieved from http://www.thehollywoodgossip.com/2012/05/john-travolta-allegationscontradicted-by-flight-records/

Burke, T. M., \& Marion, S. B. (2012). Alibi witnesses. In B. L. Cultler (Ed.), Conviction of the innocent. Lessons from psychological research (pp. 239-256). Washington: American Psychological Association.

Burke, T. M., \& Turtle, J. W. (2003). Alibi evidence in criminal investigations and trials: Psychological and legal factors. The Canadian Journal of Police and Security Services, 1, 286-293.

Burke, T. M., Turtle, J. W., \& Olson, E. A. (2007). Alibis in criminal investigations and trials. In M. P. Toglia, J. D. Read, D. F. Ross, \& R. C. Lindsay (Eds.), The handbook of eyewitness psychology: Memory for events (Vol. 1, pp. 157-192). Mahwah, NJ: Lawrence Erlbaum Associates.

Charman, S. D., Reyes, A., Villalba, D. K., \& Evans, J. R. (2017). The (un)reliability of alibi corroboration: Failure to recognize faces of briefly encountered strangers puts innocent suspects at risk. Behavioral Sciences and the Law, 35, 18-36. doi:10.1002/bsl.2264

Crozier, W. E., Strange, D., \& Loftus, E. F. (2017). Memory errors in alibi generation: How an alibi can turn against us. Behavioral Sciences and the Law, 35, 6-17. doi:10.1002/bsl.2273

Culhane, S. E., \& Hosch, H. M. (2004). An alibi witness's influence on mock jurors' verdicts. Journal of Applied Social Psychology, 34, 1604-1616. doi:10.1111/j.15591816.2004.tb02789.x.

Culhane, S. E., \& Hosch, H. M. (2012). Changed alibis: Current law enforcement, future law enforcement, and layperson reactions. Criminal Justice and Behavior, 39, 958-977. doi:10.1177/0093854812438185 
Culhane, S. E., Hosch, H. M., \& Kehn, A. (2008). Alibi generation: Data from U.S. Hispanics and U.S. non-Hispanic whites. Journal of Ethnicity in Criminal Justice, 6, 177-199. doi:10.1080/15377930802243395

Culhane, S. E., Kehn, A., Horgan, A. J., Meissner, C. A., Hosch, H. M., \& Wodahl, E. J. (2013). Generation and detection of true and false alibi statements. Psychiatry, Psychology and Law, 20, 619-638. doi:10.1080/13218719.2012.729018

D'Zurilla, C. (2012). John Travolta accused by second man in sexual-battery lawsuit. Los Angeles Times. Retrieved from http://articles.latimes.com/2012/may/08/entertainment/le-et-mg-john-travoltasexual-battery-massage/

Dahl, L. C., \& Price, H. L. (2012). “He couldn't have done it, he was with me!": The impact of alibi witness age and relationship. Applied Cognitive Psychology, 26, 475-481. doi:10.1002/acp.2821

Derksen, T. (2011). Leugens over Louwes [Lies about Louwes]. Leusden: ISVW-Uitgevers.

Dillon, N. (2012). John Travolta scandal: First accuser admits he got wrong date of alleged sexual assault as third man steps forward. New York Daily News. Retrieved from http://www.nydailynews.com/entertainment/gossip/john-travolta-scandalaccuser-admits-wrong-date-alleged-sexual-assault-man-steps-article-1.1076518

Dysart, J. E., \& Strange, D. (2012). Beliefs about alibis and alibi investigations: A survey of law enforcement. Psychology, Crime and Law, 18, 11-25. doi:10.1080/1068316X.2011.562867

Eastwood, J., Snook, B., \& Au, D. (2016). Safety in numbers: A policy-capturing study of the alibi assessment process. Applied Cognitive Psychology, 260-269. doi:10.1002/acp.3200

Fawcett, H. (2015). The effect of evidence timing and witness motivation upon juror evaluations of alibi witnesses and defendants. Psychiatry, Psychology and Law, 23, 575-587. doi:10.1080/13218719.2015.1081317

Friedman, W. J. (2004). Time in autobiographical memory. Social Cognition, 22, 591-605.

Garrett, B. L. (2011). Convicting the innocent. Cambridge, Massachusetts: Harvard University Press.

Goodhand, A. (2012). John Travolta's attorney says he has flight \& hotel records proving actor wasn't in LA. Radar Online. Retrieved from http://www.radaronline.com/exclusives/2012/05/john-travolta-attorney-saysproof-he-wasnt-la-time-sexual-harassment-lawsuit/

Granhag, P. A., Strömwall, L. A., \& Jonsson, A. C. (2003). Partners in crime: How liars in collusion betray themselves. Journal of Applied Social Psychology, 33, 848-868.

Guyll, M., Madon, S., Yang, Y., Lannin, D. G., Scherr, K., \& Greathouse, S. (2013). Innocence and resisting confession during interrogation: Effects on physiologic activity. Law and Human Behavior, 37, 366-375. doi:10.1037/Ihb0000044 
Haan, B. (2009). De Deventer Moordzaak. Het complot ontrafeld [The Deventer murder case. The conspiracy unraveled]. Amsterdam: Nieuw Amsterdam Uitgevers.

Hosch, H. M., Culhane, S. E., Jolly, K. W., Chavez, R. M., \& Shaw, L. H. (2011). Effects of an alibi witness's relationship to the defendant on mock jurors' judgments. Law and Human Behavior, 35, 127-142. doi:10.1007/s10979-010-9225-5

Jung, S., Allison, M., \& Bohn, L. (2013). Legal decision-making on crimes involving an alibi. Applied Psychology in Criminal Justice, 9, 45-58. doi:10.1037/t04698-000

Kassam, K. S., Gilbert, D. T., Swencionis, J. K., \& Wilson, T. D. (2009). Misconceptions of memory. The Scooter Libby effect. Psychological Science, 20, 551-552. doi:10.1111/j.1467-9280.2009.02334.x

Keeping, Z., Eastwood, J., Lively, C. J., \& Snook, B. (2017). Don't stop believing: the relative impact of internal alibi details on judgments of veracity. Psychology, Crime \& Law, 1-15. doi:10.1080/1068316x.2017.1338700

Leins, D. A., \& Charman, S. D. (2013). Schema reliance and innocent alibi generation. Legal and Criminological Psychology, 21, 1-16. doi:10.1111/lcrp.12035

Marion, S. B., \& Burke, T. M. (2013). False alibi corroboration: Witnesses lie for suspects who seem innocent, whether they like them or not. Law and Human Behavior, 37, 136-143. doi:10.1037/lhb0000021

Marion, S. B., \& Burke, T. M. (2017). Altruistic lying in an alibi corroboration context: The effects of liking, compliance, and relationship between suspects and witnesses. Behavioral Sciences and the Law, 35, 37-59. doi:10.1002/bsl.2269

Nahari, G., \& Vrij, A. (2014). Can I borrow your alibi? The applicability of the verifiability approach to the case of an alibi witness. Journal of Applied Research in Memory and Cognition, 3, 89-94. doi:10.1016/j.jarmac.2014.04.005

Nahari, G., Vrij, A., \& Fisher, R. P. (2014). The verifiability approach: Countermeasures facilitate its ability to discriminate between truths and lies. Applied Cognitive Psychology, 28, 122-128. doi:10.1002/acp.2974

Olson, E. A. (2013). "You don't expect me to believe that, do you?" Expectations influence recall and belief of alibi information. Journal of Applied Social Psychology, 43, 12381247. doi:10.1111/jasp.12086

Olson, E. A., \& Charman, S. D. (2012). 'But can you prove it?' - Examining the quality of innocent suspects' alibis. Psychology, Crime and Law, 18, 453-741. doi:10.1080/1068316x.2010.505567

Olson, E. A., \& Wells, G. L. (2004). What makes a good alibi? A proposed taxonomy. Law and Human Behavior, 28, 157-176. doi:10.1023/B: LAHU.0000022320.47112.d3

Olson, E. A., \& Wells, G. L. (2012). The alibi-generation effect: Alibi-generation experience influences alibi evaluation. Legal and Criminological Psychology, 17, 151-164. doi:10.1111/j.2044-8333.2010.02003.x 
REVIEW OF THE LITERATURE ON ALIBIS AND FUTURE AVENUES

Pozzulo, J. D., Pettalia, J. L., Dempsey, J. L., \& Gooden, A. (2015). Juvenile offenders on trial: Does alibi corroboration evidence and defendant age interact to influence jurors' perceptions and verdicts? Psychiatry, Psychology and Law, 22, 224-234. doi:10.1080/13218719.2014.937518

Quaedflieg, C. W. E. M., \& Schwabe, L. (2017). Memory dynamics under stress. Memory, 113. doi:10.1080/09658211.2017.1338299

Ross, D. F., Jurden, F. H., Lindsay, R. C., \& Keeney, J. M. (2003). Replications and limitations of a two-factor model of child witness credibility. Journal of Applied Social Psychology, 33, 418-431.

Sakrisvold, M. L., Granhag, P. A., \& Mac Giolla, E. (2017). Partners under pressure: Examining the consistency of true and false alibi statements. Behavioral Sciences and the Law, 35, 75-90. doi:10,1002/bsl.2275

Schonfeld, P., Ackermann, K., \& Schwabe, L. (2014). Remembering under stress: Different roles of autonomic arousal and glucocorticoids in memory retrieval. Psychoneuroendocrinology, 39, 249-256. doi:10.1016/j.psyneuen.2013.09.020

Schwabe, L., Joels, M., Roozendaal, B., Wolf, O. T., \& Oitzl, M. S. (2012). Stress effects on memory: An update and integration. Neuroscience and Biobehavioral Reviews, 36, 1740-1749. doi:10.1016/j.neubiorev.2011.07.002

Simon, D. (2012). In doubt: The psychology of the criminal justice process. London: Harvard University Press.

Sinha-Roy, P. (2012). Masseur drops sexual assault claim against John Travolta. Reuters. Retrieved from http://www.reuters.com/article/2012/05/15/entertainment-usjohntravolta-idUSBRE84E13020120515

Smeets, T., Otgaar, H., Candel, I., \& Wolf, O. T. (2008). True or false? Memory is differentially affected by stress-induced cortisol elevations and sympathetic activity at consolidation and retrieval. Psychoneuroendocrinology, 33, 1378-1386. doi:10.1016/j.psyneuen.2008.07.009

Strange, D., Dysart, J. E., \& Loftus, E. F. (2014). Why errors in alibis are not necessarily evidence of guilt. Zeitschrift für Psychologie, 222, 82-89. doi:10.1027/21512604/a000169

Sullivan, T. P. (1971). Presentation of the defense. Journal of Criminal Law, Criminology, and Police Science, 62, 153-172.

Thompson-Cannino, J., Cotton, R., \& Torneo, E. (2009). Picking Cotton. New York: St. Martin's Press.

Van Koppen, M. V., \& Van Koppen, P. J. (2010). Alibi's [Alibis]. In P. J. Van Koppen, H. Merckelbach, M. Jelicic, \& J. W. De Keijser (Eds.), Reizen met mijn rechter: Psychologie van het Recht [Traveling with my judge: Psychology of the Law] (pp. 439-448). Deventer: Kluwer. 
Van Koppen, P. J. (2011). Overtuigend bewijs: Indammen van rechterlijke dwalingen [Convincing evidence: damming of miscarriages of justice]. Amsterdam: Nieuw Amsterdam Uitgevers.

Wagenaar, W. A. (1986). My memory: A case study of autobiographic memories over six years. Cognitive Psychology, 18, 225-252.

Wells, G. L., Small, M., Penrod, S., Malpass, R. S., Fulero, S. M., \& Brimacombe, C. (1998). Eyewitness identification procedures: Recommendations for lineups and photospreads. Law and Human Behavior, 22, 603-647.

Wolf, O. T. (2009). Stress and memory in humans: Twelve years of progress? Brain research, 1293, 142-154. doi:10.1016/j.brainres.2009.04.013 


\}

THE ILLUSION OF THE PERFECT ALIBI: ESTABLISHING THE BASE RATE OF NON-OFFENDERS' ALIBIS

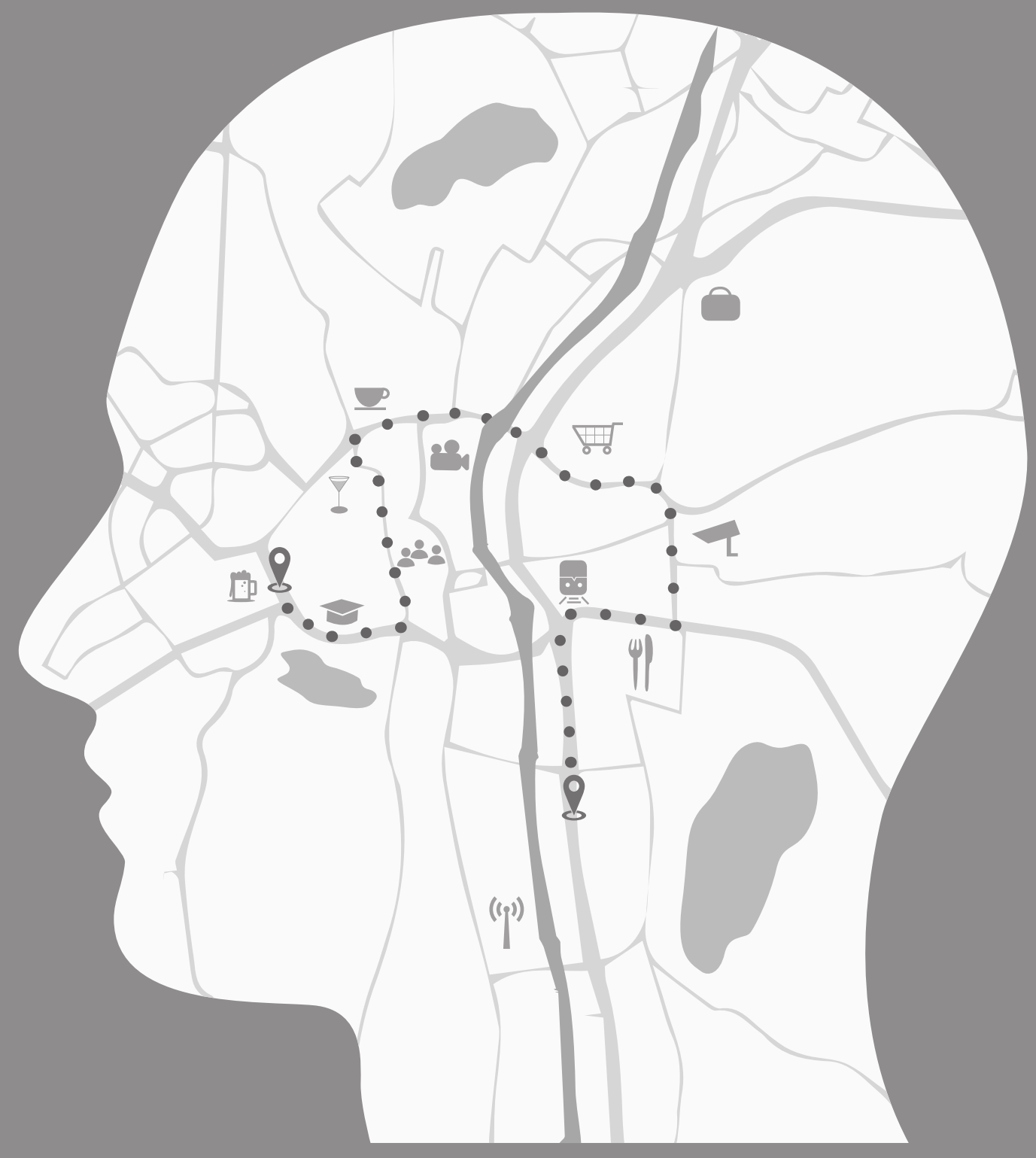

This chapter has been published as:

Nieuwkamp, R., Horselenberg, R., \& Van Koppen, P. J. (2017). The illusion of the perfect alibi: Establishing the base rate of non-offenders' alibis. Journal of Investigative Psychology and Offender Profiling, 14, 23-42. doi:10.1002/jip.1470 



\begin{abstract}
The present study was designed to establish the base rate of alibis and supportive evidence for alibis of non-offenders. That is important because the presence and lack of an alibi are often seen as a clear indicator of innocence and guilt, respectively, of a suspect. A large sample of laypersons ( $N=841$ ) was randomly assigned to one of 32 conditions in which they were asked to generate a true alibi after they were falsely accused of being the perpetrator of a mock robbery. Each condition consisted of either a Tuesday or a Saturday and one of 16 timeframes. In general, the majority of the participants had an alibi (99.5\%) and supportive evidence for their alibis (92.4\%). The supportive evidence often consisted of a combination of supportive evidence rather than one distinct form of supportive evidence (33.3\%). Although it is widely assumed that the alibi believability is determined based on the strength of the supportive evidence, our results show that the type of evidence that can be presented by laypeople depends upon the day and the timeframe wherein the crime has been committed. The results of the study therefore imply that determining alibi believability solely on the strength of the supportive evidence is not a fair measure. We suggest that the believability should also be based on the base rate of alibis and its supportive evidence.
\end{abstract}

Keywords: alibi, base rate, supportive evidence, taxonomy 
CHAPTER 3

\subsection{INTRODUCTION}

Over the years, multiple people have been wrongfully convicted all over the world (e.g., Saks \& Koehler, 2005) of which some had an alibi for the moment that the crime was committed to prove their innocence but were not believed (Burke \& Marion, 2012; Burke, Turtle, \& Olson, 2007; Dahl \& Price, 2012; Simon, 2012). In the criminal justice system, there appears to be an assumption that innocent people can generate an accurate and believable alibi (Olson \& Charman, 2012), which means that the alibi should be correct and be supported by strong evidence. For an innocent person, it can, however, be very difficult to provide such strong evidence as also appears in the cases of wrongfully convicted people where convincing evidence is often lacking (Marion, Kukucka, Collins, Kassin, \& Burke, 2015). If people were not at the crime scene but elsewhere and they can remember where they were at that time and evidence to support their alibis, it is perhaps the best chance to prove their innocence.

The fact that the alibis of wrongful convicted people were not believed can be explained by the sceptical attitude of police detectives towards suspects in general (e.g., Kassin, Goldstein, \& Savitsky, 2003; Meissner \& Kassin, 2002; Vrij, 2008) and to their alibis in particular (Dysart \& Strange, 2012). If a suspect, for example, changes his alibi, about 80\% of the police detectives believe that the suspect lied about the initial alibi and that it is easy for a suspect to fabricate a false alibi (Dysart \& Strange, 2012). According to the police detectives, an alibi should be mentioned at the beginning of the criminal investigation, supported by strong evidence, and remains consistent over time, to be believable (Dysart \& Strange, 2012).

The sceptical attitude towards alibis does not only appear from wrongful convictions cases but also appears from the results of alibi research. These results show that without strong evidence, (mock) jurors find the alibi not believable. When evidence is presented, the strength of the evidence is important because the stronger the evidence, the more believable the alibi becomes (e.g., Hosch, Culhane, Jolly, Chavez, \& Shaw, 2011; Jung, Allison, \& Bohn, 2013). 
Research on alibi evidence and research on alibi believability were boosted by the introduction of alibi taxonomy by Olson and Wells (2004). With the taxonomy, the strength of the supportive evidence can be evaluated. The supportive evidence in the taxonomy consists of only witness evidence, only physical evidence, or a combination of both (Culhane et al., 2013; Fawcett, 2015).

From alibi research, we also know that the impact on alibi believability of physical evidence is larger than of witness evidence. Even the weakest form of physical evidence is still considered stronger evidence than the strongest type of witness evidence (Olson \& Wells, 2004). The rationale is that witnesses can either be motived to lie in favour of the suspect or that they can be mistaken (Burke \& Marion, 2012).

Although recent research also shows that evidence is an influential factor determining alibi believability (e.g., Jung et al., 2013; Pozzulo, Pettalia, Dempsey, \& Gooden, 2015), it is also known that, contrary to what Olson and Wells (2004) argued, other factors affect the alibi believability too. For instance, the consistency of the alibi (Culhane \& Hosch, 2012; Nieuwkamp, Horselenberg, \& Van Koppen, 2016), the context in which the alibi is first presented (Sommers \& Douglass, 2007), and the salaciousness of the alibi (Allison, Jung, Sweeney, \& Culhane, 2014; Allison, Mathews, \& Michael, 2012; Jung et al., 2013; Nieuwkamp et al., 2016).

Thus, in order to present a believable alibi, according to both police detectives and scholars, strong evidence is of the essence. It can, however, be questioned if all genuine alibis of non-offenders can meet these expectations of the "perfect" believable alibi. The alibis that were presented in cases of wrongful conviction show that, despite being true, they were not believed because they were not supported by strong enough evidence (e.g., Wells et al., 1998). Given the importance of strong supportive evidence, we will focus in the present paper on the question if such evidence may be expected from non-offenders when asked for their alibis. To determine how realistic the criteria are for the perfect alibi, three sources of information can be examined: wrongful conviction cases, alibis presented in court, and alibis generated by non-offenders.

First, the examination of alibis presented by convicts who were innocent provides little information, besides that not every defendant presented an alibi (11 out of 40 cases 
in the study by Wells et al., 1998) and that if the defendant did present an alibi, it was not believed (Connors, Lundregan, Miller, \& McEwen, 1996; Garrett, 2011; Simon, 2012; Wells et al., 1998). Because little information is available on the specific alibis in these cases and because these cases only shed a light on the alibis of a specific subpopulation of people (i.e., wrongful convicts), these alibis are not indicative of the alibis of all non-offenders.

Nieuwkamp (2015) illustrated that, in the Netherlands, only three out of 191 alibis presented in court (1.6\%) were found to be believable. That is not surprising because alibis presented in court are found to be less believable than when the same alibi is presented during a police questioning (Sommers \& Douglass, 2007). Furthermore, the alibis presented in court typically are supported by relatively weak witness evidence (Nieuwkamp, 2015).

Because trial-based alibis are seriously biased, that is, believed alibis are not presented there, a third source of information can be examined to answer the question how realistic the criteria for the perfect alibi are. That source of information consists of the alibis that non-offenders can present. By analysing the alibis of innocent people, the base rate of non-offenders' alibis can be determined. In such studies, also referred to as alibi generation studies (Burke et al., 2007), non-offenders are asked to imagine that they are a suspect of a (mock)crime that they did not commit. They are then asked to describe where they were at the time of the (mock)crime and whether they have evidence to support their alibi. Using that method, knowledge can be gained on what alibis and evidence non-offenders are expected to present when police detectives questions them on their involvement in a crime. The results of base rate research have the potential to provide rich information on what true alibis can be given by non-offenders and also provide information on how likely it is to expect strong supportive evidence of a suspect.

The few studies on determining the base rate of non-offenders' alibis until now show three important things. First, most non-offenders (about 95\%) have an alibi, and second, they can support their alibi with evidence (about 90\%; Culhane, Hosch, \& Kehn, 2008; Culhane et al., 2013; Olson \& Charman, 2012). Third, the supportive evidence they present more often consists of witness evidence (about 85\%) than of physical evidence (about 25\%). These findings led researchers to conclude that a discrepancy seems to exist between which alibis can be presented by non-offenders compared to which alibis are 
found to be believable (Culhane et al., 2008). The alibis generated by non-offenders are often supported with evidence that is considered to be relatively weak, while strong evidence is required in order for the alibi to be believable. The question at hand is whether determining the alibi believability mainly on the strength of the supportive evidence is a fair measure. Although these studies on alibi generation indicate a critical issue, three important limitations should be mentioned.

First, in all studies, undergraduate students were asked for their alibi for a certain day and time (Allison, Michael, Mathews, \& Overman, 2011; Culhane et al., 2008; Culhane et al., 2013; Leins \& Charman, 2013; Olson \& Charman, 2012; Olson \& Wells, 2012). The use of undergraduate students in such studies can, however, be problematic for generalizing the results (Culhane et al., 2008; Eastwood, Snook, \& Au, 2016) and to determine which alibis and evidence can be expected by non -offenders in the criminal justice system, because older adults "are more likely to have additional family members (spouse and children) [who could support their alibis] and less likely to spend the same amount of time with friends" (Culhane et al., 2013, p. 627).

In the previous studies on alibi generation, the participants were asked for their alibi mainly in the evening (Allison, Michael, Mathews, \& Overman, 2011; Culhane et al., 2008; Culhane et al., 2013), which is a second limitation for the generalizability of the results. Alibis were seldom asked between 9:00 AM and 5:00 PM because it "would result in a high number of work-related alibis" (Culhane et al., 2013, p. 627). Only information about the alibis in the evening is available and not about alibis for the morning, the afternoon, or the night. However, crimes occur throughout the entire day (e.g., Felson \& Poulsen, 2003), and therefore, establishing the base rate of non-offenders' alibis should cover all times of day on various days because the routines of people may be different on weekdays and in the weekend (Culhane et al., 2008). Next, in all previous studies, the participants were not allowed to use any resources to generate their alibis. Olson and Charman (2012) asked their participants to generate an initial alibi and report possible supportive evidence when they returned to the lab 48 hours later. Between both sessions, the participants were instructed to determine whether or not their alibi was valid or had to be changed, and they were asked to collect the supportive evidence they claimed. About 
$11 \%$ of the participants were mistaken about the presented alibi, and about a quarter of the participants had been mistaken or were unable to collect the reported supportive evidence. Olson and Charman (2012) stated that in practice, police officers might allow suspects to check their personal calendar when asked for their alibi. Olson and Charman (2012) wanted to study the potential memory failures when generating an alibi too, and therefore, the participants in their study were not allowed to use any resources.

Given the limitations, previous alibi studies are perhaps less suited to establish the base rate of alibis and its supportive evidence of the population of non-offenders. Establishing the base rate of alibis is, however, important to determine what the whereabouts of people are at various times and various days, to determine if they can report supportive evidence for it and, if so, what evidence they present. In order to do so, the present study was designed. The first objective of the present study was to establish the base rate of alibis and its supportive evidence of non-offenders. Next, we were in particular interested in what alibis and what types of supportive evidence are reported. Last, we were interested in whether or not one can assume an equal number of alibis and types of supportive evidence among all presented alibis, days, and timeframes.

In line with the results of earlier studies (e.g., Culhane et al., 2013), we first hypothesized that most of our participants would be able to present an alibi. Next, we hypothesized, in accordance with previous research findings, that the participants would more often have witness evidence than physical evidence to support their alibi (e.g., Culhane et al., 2008; Olson \& Charman, 2012). Moreover, we hypothesized that the participants would less often have supportive evidence during the night compared to the other timeframes because most of them are assumed to be asleep. Last, we expected differences in the alibi and supportive evidence between: a) a week and weekend day; and b) between the parts of the day, that is, an interaction between the type of day and the part of the day.

To overcome the limitations of alibi generation research, we have chosen to ask a large sample of people from the community for their alibis to generalize the results to the population of non-offenders. To establish the base rate, we aimed to reach a broader group of participants than only students, although students are also a part of the population of 
non-offenders. Some might furthermore argue that the base rate of alibis could be determined using actual suspects or convicted criminals. However, in our opinion, a true alibi should differentiate between a guilty and an innocent suspect, because by definition, a guilty suspect cannot present a true alibi for the crime that he or she committed. In addition, asking convicted criminals for their alibis about a mock crime is for three reasons less informative than the alibis of community members. First, asking convicted criminals for their alibi in the near past would highly likely result in an alibi as "I was in jail." Second, if they were asked for their alibis in the period before they got arrested, questioned, and eventually convicted, the study would become a memory study rather than an alibi study. Third, because the majority of the innocent people who were wrongfully convicted had an alibi that was not believed (e.g., Culhane et al., 2013; Wells et al., 1998) in the pre-trial investigation, we believe that the alibis of non-offenders should rather be studied than those people who are convicted. Knowledge of the alibis of non-offenders is necessary to learn the discriminative value of alibis, both given by offenders and non-offenders. Therefore, the present study aims at obtaining a more complete view of the alibis of nonoffenders and gaining insight what alibis and evidence are most often reported and as a consequence how likely the perfect alibi is at various days and times.

To address the second limitation in alibi generation research, we decided to ask our participants for their alibis on a wide range of timeframes across days, because crimes can occur throughout an entire day (Felson \& Poulsen, 2003). With regard to the last limitation, in the present study, the participants were explicitly instructed that resources could be used to generate their alibi. In the present study, we are not interested in potential memory errors but only in determining what alibis non-offenders can report and what types of supportive evidence they present. 
CHAPTER 3

\subsection{METHOD}

\subsubsection{Participants}

Participants from the community responded to an online questionnaire. The questionnaire can be found in the Appendix. They received an e-mail with an online link to the questionnaire. At first, friends, colleagues, and family from the first author were sent an e mail with the link. They were in turn asked to send their colleagues and friends the link to the questionnaire because we aimed at a large sample of participants, a similar method as used by Nieuwkamp et al. (2016). In that study, the authors selected two groups of community members. One group was recruited in the same way as in the present study. To control for a possible selection bias, a second group was recruited at a dance school. No differences were found between groups for their demographics and their answers on the dependent variables. Given that outcome, we believe that a possible selection bias in the selection of participants in the present study does not affect the results in another way than when the participants would have been recruited offline.

The questionnaire was completed by 862 participants of whom 21 participants were excluded. Fifteen participants were excluded because they failed to complete the questions about their alibi and supportive evidence. Six other participants were excluded because they did not complete the questionnaire seriously, for instance, by answering each question with an $\mathrm{x}$. Three participants did not report their gender, and 17 participants did not report their highest completed education. They were nevertheless included in the analyses because it would not hamper the outcomes.

In total, 841 participants (261 men, 31.0\%) were included in the analyses. Their ages varied between 17 and 79 years, with a mean age of 30.2, (SD = 12.7) and a median of 25.0 years. Most of the participants were employed and had a partner with whom they were living together (see Table 1, for demographics). Most of the participants in our sample were well educated compared to the average Dutch citizen. Because $65.3 \%$ of the participants in our sample had achieved a bachelor degree either from college or university, 
while only $28.3 \%$ of the Dutch population has such a degree (CBS, 2013), our participants are higher educated compared to the average at the time of data collection.

Table 1

Participant Characteristics (proportions) $n=841$

\begin{tabular}{|c|c|c|}
\hline \multicolumn{3}{|l|}{$\operatorname{Sex}^{1}$} \\
\hline Male & 261 & $(0.31)$ \\
\hline Female & 577 & $(0.69)$ \\
\hline \multicolumn{3}{|l|}{ Relationship status $^{1}$} \\
\hline Single & 259 & $(0.31)$ \\
\hline Partner, not living together & 240 & $(0.29)$ \\
\hline Partner, living together & 339 & $(0.40)$ \\
\hline \multicolumn{3}{|l|}{ Employment status ${ }^{1,3}$} \\
\hline Unemployed & 44 & $(0.05)$ \\
\hline Student & 288 & $(0.34)$ \\
\hline Employed & 506 & $(0.60)$ \\
\hline \multicolumn{3}{|l|}{ Highest completed education ${ }^{2,3}$} \\
\hline Elementary school & 19 & $(0.02)$ \\
\hline Secondary school & 196 & $(0.23)$ \\
\hline Intermediate vocational education & 71 & $(0.08)$ \\
\hline College or university & 538 & $(0.64)$ \\
\hline
\end{tabular}

\subsubsection{Research Design}

We tested our hypotheses using a 2 (day: Tuesday and Saturday) $\times 4$ (time: morning, afternoon, evening, and night) between-subjects factorial design. Two different days (i.e., Tuesday and Saturday) were chosen because the activities of people may vary between weekdays and weekend days (Culhane et al., 2008). Although Culhane et al. (2008) did not find a difference between both days, the authors argued that differences between the days might exist when testing non-student adults. The 4-day parts consisted each of four times: the morning (06:45-10:45 AM), the afternoon (1:45-5:45 PM), the evening (6:45-9:45 PM), and the night (11.45 pm-4:45 AM). The timeframes were chosen based upon when most 
CHAPTER 3

robberies were committed per hour on a single day (Felson \& Poulsen, 2003), because the participants had to present their alibi for a mock robbery. The timespan varied between the day parts because only the highest numbers of robberies were included (Felson \& Poulsen, 2003). The combination of "day" and "time" results in eight conditions, and each condition had a minimum of 80 participants. The responses over the conditions were not equally distributed because for each condition, a new link to the questionnaire was randomly created. It caused an unequal distribution over the timeframes for which we controlled in our analysis (see Table 2, for the number of participants per day and time).

\subsubsection{Materials}

After the participants read an informed consent, they were presented with the questionnaire that consisted of four parts: demographics, case vignette, alibi generation, and last, report possible supportive evidence for it.

The case vignette detailed that a mock robbery was committed last Tuesday or Saturday at one of the timeframes. A robbery was chosen as mock crime comparable to previous studies (e.g., Allison et al., 2014; Allison et al., 2012; Culhane \& Hosch, 2004, 2012; Eastwood et al., 2016; Pozzulo et al., 2015). To increase the ecological validity, we asked the participants to imagine that he or she was a suspect and that the police asked them where they had been during the robbery. In previous studies, the participants were only asked to generate an alibi for a particular day and time (e.g., Culhane et al., 2013). The participants in the present study were asked for their alibis for either last Tuesday or Saturday (range: 1-7 days). A delay not greater than 7 days was chosen because people can remember up to $90 \%$ of the details from a one-time experience about a week ago (Wagenaar, 1986). In addition, they were explicitly instructed that they could use resources (e.g., agenda or diaries) to determine where they had been because the results from memory studies show that participants can reliably reconstruct memories using such cues up to 6 years ago (Odinot \& Wolters, 2006).

Comparable to the method used by Allison, Michael, Mathews, and Overman (2011), the participants were first asked to write down their alibi in an open-ended question 
as detailed as possible. Afterwards, they were asked in a cued-recall question if they could support their alibi with physical evidence (e.g., camera recordings or a receipt). In case they had physical evidence, they were asked of what item(s) the physical evidence consisted. Similar to the method of Culhane, Hosch, and Kehn (2008), participants reported the physical evidence in an open-ended question. Next, they were asked if their alibi could be supported by witness evidence. If they reported witness evidence, they were asked to indicate their relationship with the alibi witness(es) in a cued question listing six types of witnesses. Four types of witnesses were identical to those used in the study by Olson and Charman (2012): "family member," "friend," "acquaintance," and "stranger." A family member is closely related to the suspect and may therefore have a possible motive to lie in favor of the suspect. A friend and a co-worker (Culhane et al., 2008) also might have a possible motive to lie for the suspect but into a lesser degree than a family member. Those types of witnesses are therefore referred to as a motivated familiar other witness (Olson \& Wells, 2004). An acquaintance (e.g., the neighbor) is a type of non-motivated familiar other witness (Culhane et al., 2008; Olson \& Wells, 2004) and is characterized by a large relational distance to the suspect while also being familiar to the suspect and therefore being unlikely to be mistaken about the suspect's identity. A stranger also has no motive to lie but can be mistaken about the suspect's identity and is therefore referred to as a non-motivated stranger (Olson \& Wells, 2004). We added "partner" to the list of possible alibi witnesses as another witness who is a motivated familiar other witness. Last, we asked the participants whether or not they had any other additional supportive evidence that they had not mentioned before to support their alibi. The participants were then thanked for their cooperation and given the opportunity to provide their contact information if they wanted to receive a brief summary of the study results once the data were analyzed.

\subsection{RESULTS}

No differences between men and women are found in the analyses. To avoid redundancy in describing the results, potential differences due to gender are not discussed. 
CHAPTER 3

\subsubsection{Alibis}

If the participant was able to describe where he or she had been, the answer was coded as an alibi. If the participant answered "I don't know" or "I cannot remember," it was coded as no alibi. In general, almost all of the participants were able to report an alibi ( $\mathrm{n}=837$; 99.5\%). The presented alibis of the participants were post hoc categorized into 19 alibi locations (see Table 2, for an overview of the presented alibis).

\subsubsection{Supportive Evidence}

The vast majority of participants reported to have supportive evidence $(n=777 ; 92.4 \%)$ that most often consisted of only witness evidence or a combination of evidence. All the types of evidence are displayed in Table 3.

\subsubsection{Physical Evidence}

About $25 \%$ ( $n=209$ ) of the participants reported to have at least one item of physical evidence, and of them, $37(17.7 \%)$ had more than one item to support their alibi. They described a total of 260 items (range 1-5 items), and these items were post hoc clustered into 19 categories (see Table 4, for an overview). Most of the participants reported a receipt (32\%), one of the weakest items of physical evidence, while only $7 \%$ of the participants who presented physical evidence; and only $2 \%$ of all people - reported video recordings on the items of strong physical evidence. 
Table 2

Alibi Frequency for Tuesday and Saturday per Timeframe (Proportions)

\begin{tabular}{|c|c|c|c|c|c|c|c|c|c|}
\hline \multirow{2}{*}{ Alibi } & \multicolumn{4}{|c|}{ Tuesday } & \multicolumn{4}{|c|}{ Saturday } & \multirow{2}{*}{$\begin{array}{l}\text { Total } \\
\mathrm{n}=841\end{array}$} \\
\hline & $\begin{array}{r}\text { Morning } \\
\mathrm{n}=84\end{array}$ & $\begin{array}{r}\text { Afternoon } \\
n=89\end{array}$ & $\begin{array}{l}\text { Evening } \\
\mathrm{n}=165\end{array}$ & $\begin{array}{r}\text { Night } \\
\mathrm{n}=115\end{array}$ & $\begin{array}{r}\text { Morning } \\
\mathrm{n}=102\end{array}$ & $\begin{array}{r}\text { Afternoon } \\
n=93\end{array}$ & $\begin{array}{c}\text { Evening } \\
n=102\end{array}$ & $\begin{array}{c}\text { Night } \\
\mathrm{n}=91\end{array}$ & \\
\hline No alibi & $1(0.01)$ & $1(0.01)$ & $0(0.00)$ & $1(0.01)$ & $0(0.00)$ & $1(0.01)$ & $0(0.00)$ & $0(0.00)$ & $4(0.01)$ \\
\hline At home & $40(0.48)$ & $33(0.37)$ & $92(0.56)$ & $88(0.77)$ & $66(0.65)$ & $39(0.42)$ & $43(0.42)$ & $66(0.73)$ & $467(0.56)$ \\
\hline At work & $16(0.19)$ & $24(0.27)$ & $5(0.03)$ & $1(0.01)$ & $6(0.06)$ & $10(0.11)$ & 7 (0.07) & $2(0.02)$ & $71(0.08)$ \\
\hline On holiday & $4(0.05)$ & $3(0.03)$ & $0(0.00)$ & $1(0.01)$ & $3(0.03)$ & 4 (0.04) & $7(0.07)$ & $3(0.03)$ & $25(0.03)$ \\
\hline On the go & $9(0.11)$ & $9(0.10)$ & $13(0.08)$ & $3(0.03)$ & $7(0.07)$ & $9(0.10)$ & $1(0.01)$ & $0(0.00)$ & $51(0.06)$ \\
\hline With friends & $1(0.01)$ & $1(0.01)$ & $13(0.08)$ & $0(0.00)$ & $1(0.01)$ & $1(0.01)$ & $7(0.07)$ & $4(0.04)$ & $28(0.03)$ \\
\hline Playing sports & $0(0.00)$ & $2(0.02)$ & 7 (0.04) & $1(0.01)$ & $3(0.03)$ & $4(0.04)$ & $1(0.01)$ & $1(0.01)$ & $19(0.02)$ \\
\hline In class & $6(0.07)$ & $5(0.06)$ & $5(0.03)$ & $1(0.01)$ & $0(0.00)$ & $0(0.00)$ & $0(0.00)$ & $0(0.00)$ & $17(0.02)$ \\
\hline At the hospital & $1(0.01)$ & $1(0.01)$ & $1(0.01)$ & $1(0.01)$ & $0(0.00)$ & $0(0.00)$ & $0(0.00)$ & $0(0.00)$ & $4(0.01)$ \\
\hline At the library & $1(0.01)$ & $1(0.01)$ & $0(0.00)$ & $0(0.00)$ & $0(0.00)$ & $0(0.00)$ & $0(0.00)$ & $0(0.00)$ & $2(0.00)$ \\
\hline With partner & $1(0.01)$ & $3(0.03)$ & $7(0.04)$ & $7(0.06)$ & $1(0.01)$ & $1(0.01)$ & $4(0.04)$ & $3(0.03)$ & $27(0.03)$ \\
\hline At a repetition & $0(0.00)$ & $0(0.00)$ & $3(0.02)$ & $0(0.00)$ & $1(0.01)$ & $0(0.00)$ & $0(0.00)$ & $0(0.00)$ & $4(0.01)$ \\
\hline With family & $1(0.01)$ & $2(0.02)$ & $5(0.03)$ & $2(0.02)$ & $7(0.07)$ & $6(0.07)$ & $11(0.11)$ & $4(0.04)$ & $38(0.05)$ \\
\hline Lunch/diner & $0(0.01)$ & $0(0.00)$ & $7(0.04)$ & $7(0.06)$ & $0(0.00)$ & $3(0.03)$ & $0(0.00)$ & $4(0.04)$ & $32(0.04)$ \\
\hline Outside & $0(0.00)$ & $2(0.02)$ & $2(0.01)$ & $1(0.01)$ & $2(0.02)$ & $4(0.04)$ & $0(0.00)$ & $1(0.01)$ & $12(0.01)$ \\
\hline At the cinema & $0(0.00)$ & $0(0.00)$ & $1(0.01)$ & $0(0.00)$ & $0(0.00)$ & $0(0.00)$ & $1(0.01)$ & $1(0.01)$ & $3(0.00)$ \\
\hline At a reception & $0(0.00)$ & $0(0.00)$ & $4(0.02)$ & $1(0.01)$ & $0(0.00)$ & $0(0.00)$ & $0(0.00)$ & $0(0.00)$ & $7(0.01)$ \\
\hline At a concert or event & $1(0.01)$ & $0(0.00)$ & $0(0.00)$ & $0(0.00)$ & $0(0.00)$ & $4(0.04)$ & $2(0.02)$ & $2(0.02)$ & $13(0.02)$ \\
\hline Shopping & $1(0.01)$ & $2(0.02)$ & $0(0.00)$ & $0(0.00)$ & $5(0.05)$ & $7(0.08)$ & $6(0.06)$ & $0(0.00)$ & $15(0.02)$ \\
\hline With a client & $1(0.01)$ & $0(0.00)$ & $0(0.00)$ & $0(0.00)$ & $0(0.00)$ & $0(0.00)$ & $0(0.00)$ & $0(0.00)$ & $1(0.00)$ \\
\hline At a wedding & $0(0.00)$ & $0(0.00)$ & $0(0.00)$ & $0(0.00)$ & $0(0.00)$ & $0(0.00)$ & $1(0.01)$ & $0(0.00)$ & $1(0.00)$ \\
\hline
\end{tabular}

Note: the proportions in the columns do not consistently count to 1 due to rounding. 
Table 3

Frequencies of Supportive Evidence for Tuesday and Saturday per Timeframe (Proportions)

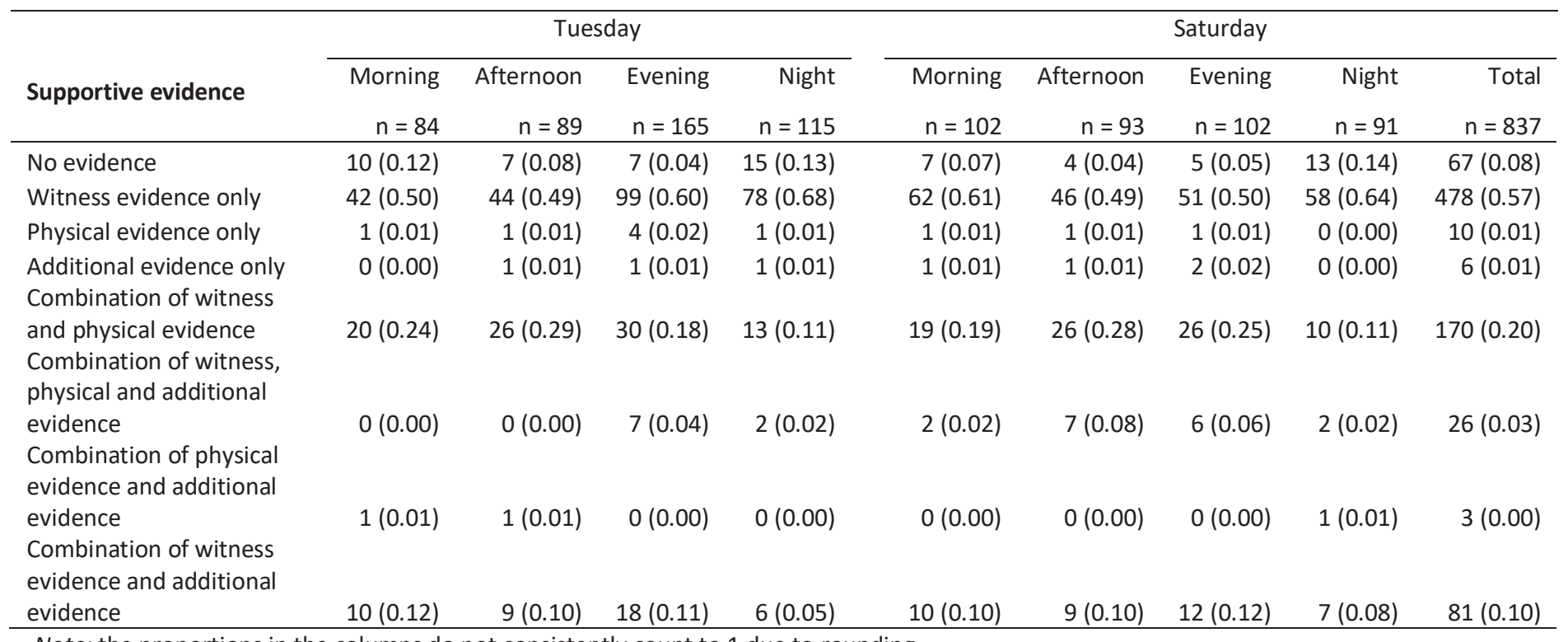

Note: the proportions in the columns do not consistently count to 1 due to rounding. 
Table 4

Frequency of Reported Items Physical Evidence for Tuesday and Saturday per Timeframe (Proportions)

\begin{tabular}{|c|c|c|c|c|c|c|c|c|c|}
\hline & \multicolumn{4}{|c|}{ Tuesday } & \multicolumn{5}{|c|}{ Saturday } \\
\hline & Morning & Afternoon & Evening & Night & Morning & Afternoon & Evening & Night & Total \\
\hline & $\begin{array}{r}n=22 \\
(26.2 \%)\end{array}$ & $\begin{array}{r}n=28 \\
(31.5 \%)\end{array}$ & $\begin{array}{r}n=41 \\
(24.8 \%)\end{array}$ & $\begin{array}{r}n=16 \\
(13.9 \%)\end{array}$ & $\begin{array}{r}n=22 \\
(21.6 \%)\end{array}$ & $\begin{array}{r}n=34 \\
(36.6 \%)\end{array}$ & $\begin{array}{r}n=33 \\
(32.4 \%)\end{array}$ & $\begin{array}{r}n=13 \\
(14.3 \%)\end{array}$ & $\begin{array}{l}n=209 \\
(24.9 \%)\end{array}$ \\
\hline Video recordings & $0(0.00)$ & $2(0.11)$ & $1(0.06)$ & $1(0.06)$ & $2(0.11)$ & $7(0.39)$ & $5(0.28)$ & $0(0.00)$ & $18(0.07)$ \\
\hline Photographs & $3(0.23)$ & $1(0.08)$ & $0(0.00)$ & $1(0.08)$ & $0(0.00)$ & $3(0.23)$ & $5(0.38)$ & $0(0.00)$ & $13(0.05)$ \\
\hline Punch card records & $2(0.29)$ & $2(0.29)$ & $0(0.00)$ & $0(0.00)$ & $1(0.14)$ & $1(0.14)$ & $1(0.14)$ & $0(0.00)$ & $7(0.03)$ \\
\hline Personal public transportation cards & $2(0.13)$ & $3(0.23)$ & $7(0.46)$ & $0(0.00)$ & $1(0.07)$ & $0(0.00)$ & $1(0.07)$ & $1(0.07)$ & $15(0.06)$ \\
\hline Telephone records & $0(0.00)$ & $2(0.18)$ & $3(0.17)$ & $0(0.00)$ & $0(0.00)$ & $1(0.09)$ & $2(0.18)$ & $3(0.17)$ & $11(0.04)$ \\
\hline Computer logs (e.g., e-mails sent) & $5(0.14)$ & $3(0.08)$ & $12(0.33)$ & $7(0.19)$ & $1(0.03)$ & $3(0.08)$ & $3(0.08)$ & $2(0.06)$ & $36(0.14)$ \\
\hline Ticket stubs & $0(0.00)$ & $1(0.13)$ & $1(0.13)$ & $1(0.13)$ & $3(0.38)$ & $1(0.13)$ & $1(0.13)$ & $0(0.00)$ & $8(0.03)$ \\
\hline Receipts & $8(0.10)$ & $9(0.11)$ & $10(0.12)$ & $6(0.07)$ & $7(0.08)$ & $21(0.25)$ & $15(0.18)$ & $7(0.08)$ & $83(0.32)$ \\
\hline Checking in records (e.g., the gym) & $1(0.09)$ & $4(0.36)$ & $3(0.27)$ & $2(0.18)$ & $1(0.09)$ & $0(0.00)$ & $0(0.00)$ & $0(0.00)$ & $11(0.04)$ \\
\hline Video recordings of personal vehicle & $1(0.50)$ & $0(0.00)$ & $0(0.00)$ & $1(0.50)$ & $0(0.00)$ & $0(0.00)$ & $0(0.00)$ & $0(0.00)$ & $2(0.01)$ \\
\hline Airline tickets & $1(0.17)$ & $0(0.00)$ & $1(0.17)$ & $0(0.00)$ & $1(0.17)$ & $1(0.17)$ & $1(0.17)$ & $1(0.17)$ & $6(0.02)$ \\
\hline Reservations & $1(0.09)$ & $0(0.00)$ & $0(0.00)$ & $0(0.00)$ & $1(0.09)$ & $3(0.27)$ & $1(0.09)$ & $4(0.36)$ & $11(0.04)$ \\
\hline Bank transactions & $2(0.50)$ & $1(0.25)$ & $0(0.00)$ & $0(0.00)$ & $1(0.25)$ & $0(0.00)$ & $0(0.00)$ & $0(0.00)$ & $4(0.02)$ \\
\hline Appointment cards (i.e., a family doctor) & $2(1.00)$ & $0(0.00)$ & $0(0.00)$ & $0(0.00)$ & $0(0.00)$ & $0(0.00)$ & $0(0.00)$ & $0(0.00)$ & $2(0.01)$ \\
\hline Timetables & $2(0.33)$ & $1(0.17)$ & $1(0.17)$ & $0(0.00)$ & $2(0.33)$ & $0(0.00)$ & $0(0.00)$ & $0(0.00)$ & $6(0.02)$ \\
\hline Logbooks (e.g., attendance sheet) & $2(0.10)$ & $4(0.20)$ & $4(0.20)$ & $0(0.00)$ & $4(0.20)$ & $4(0.20)$ & $2(0.10)$ & $0(0.00)$ & $20(0.08)$ \\
\hline Stamp on savings card & $0(0.00)$ & $0(0.00)$ & $1(1.00)$ & $0(0.00)$ & $0(0.00)$ & $0(0.00)$ & $0(0.00)$ & $0(0.00)$ & $1(0.00)$ \\
\hline Wristbands (e.g., of a festival attended) & $0(0.00)$ & $0(0.00)$ & $1(0.50)$ & $0(0.00)$ & $0(0.00)$ & $0(0.00)$ & $1(0.50)$ & $0(0.00)$ & $2(0.01)$ \\
\hline Payslips & $0(0.00)$ & $1(0.20)$ & $0(0.00)$ & $0(0.00)$ & $3(0.60)$ & $0(0.00)$ & $0(0.00)$ & $1(0.20)$ & $5(0.02)$ \\
\hline Total items physical evidence & $32(0.12)$ & $34(0.13)$ & $45(0.17)$ & $19(0.07)$ & $28(0.11)$ & $45(0.17)$ & $38(0.15)$ & $19(0.07)$ & $260(1.00)$ \\
\hline
\end{tabular}




\subsubsection{Witness and Additional Evidence}

A total of $757(90.0 \%)$ of the participants reported that at least one witness could support their alibi; however, most of them ( $n=537 ; 63.9 \%)$ reported more than one alibi witness. They reported a total of 1,363 witnesses (see Table 5, for an overview). About $65 \%$ of the participants reported the weakest alibi witness (i.e., a motivated familiar other), while a stronger alibi witness was only reported by $16 \%$ of the participants.

Additional evidence was reported by 117 participants (13.9\%). Besides the classic types of supportive evidence (witness and physical evidence), nine participants (1.1\%) reported a type of evidence that could be categorized as knowledge evidence (e.g., someone who reported to have been at home without witness or physical evidence but the participant reported the content of all the television shows he had watched that evening). The last type of reported was categorized as unclear evidence ( $n=14 ; 1.7 \%$ ). It was categorized as unclear evidence when it could not directly be linked to the presented alibi and/or to the time when the alleged crime took place (e.g., someone who reported to have been running through the forest and said that the mud on his running shoes could support his alibi).

The supportive evidence varied between the presented alibis (see Table 6, for an overview). When the participant had no evidence to support his alibi, he was most often at home. When the participant only had witness evidence, he was most likely to be with friends, at the library, at a repetition, with their families, or at the cinema. Last, the combination of physical and witness evidence was most likely when the participant was at work, in class, or at a concert. Thus, it appears that the presented alibi influences which supportive evidence can be expected. In the next section, the differences among the conditions will be discussed. 


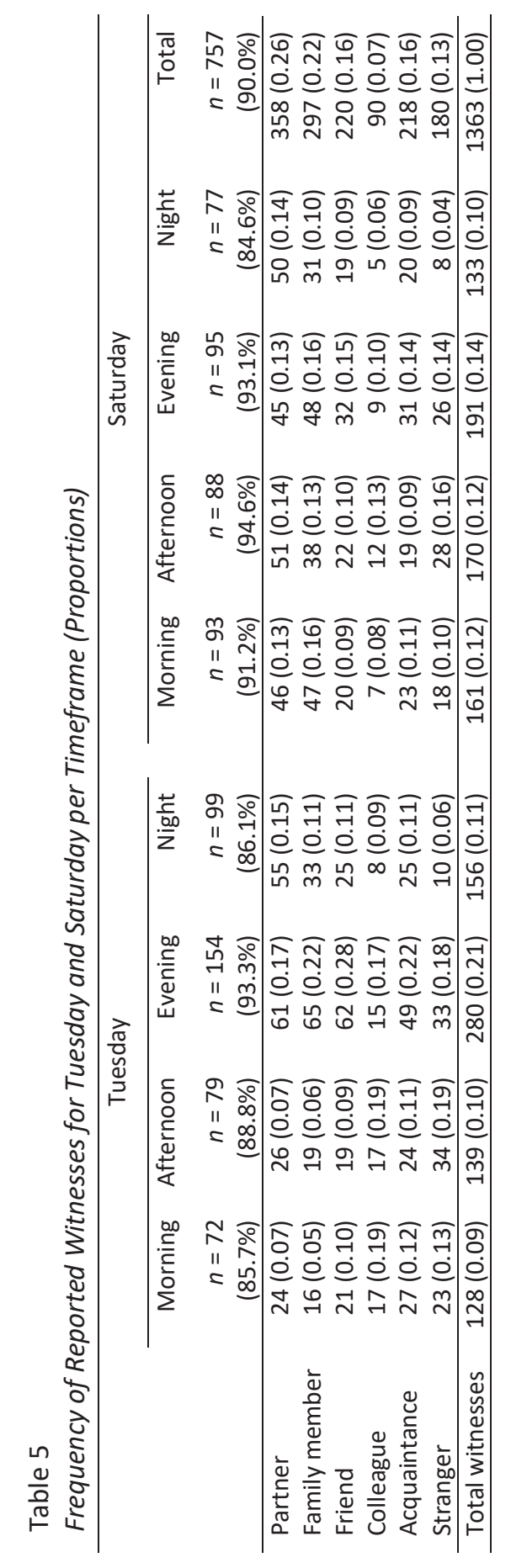




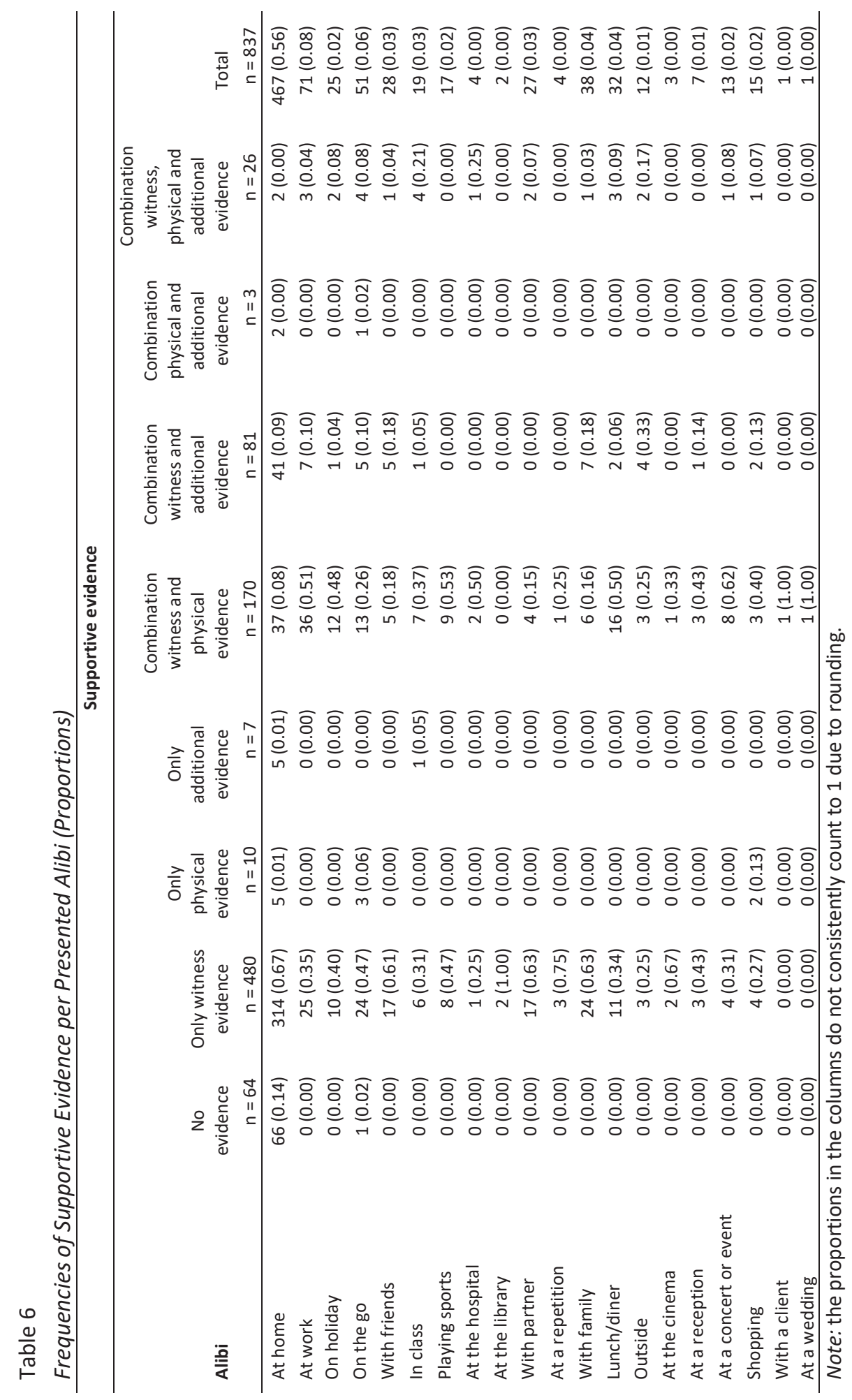




\subsubsection{Differences in Alibis and Supportive Evidence Between the Conditions}

It is interesting to determine if the alibis and evidence of non-offenders differ at various times and between a weekday and the weekend to understand at what time or what day people are most likely to report supportive evidence for their alibis and what type of evidence they can present. In order to do so, binary logistic regression analysis was used because the responses were unequally distributed among the conditions. The baseline for each separate regression was determined with the dependent variable with the lowest overall percentage (see Table 7, for the baselines). For example, if an alibi was least often reported for the afternoon, the afternoon was chosen as the baseline for that variable. In the analysis, we compared the three other timeframes to the baseline and analysed if possible differences exist between the times and days. For each variable, the factors "day" and "time" and the interaction term were stepwise entered forward in the binary logistic regression analysis.

The day and time did not influence whether or not the participants had an alibi but whether supportive evidence was reported, differed between the conditions (model $x 2$ ( 2 , $\mathrm{n}=837)=13.67, \mathrm{p}=.001$, Nagelkerke $\mathrm{R} 2=.038$ ). The participants were 2.59 times more likely to have supportive evidence for their alibi in the evening compared to the night. In addition, on Saturdays, participants were 3.62 times more likely to have supportive evidence in the afternoon compared to the night (see Figure 1).

An alibi in absence of any supportive evidence was 2.83 times more likely to be reported in the night compared to the afternoon (model $\chi 2(2, n=837)=15.31, p<.001$, Nagelkerke R2 $=0.42$ ). In addition, on Tuesday, the participants were 2.46 times more likely to have no supportive evidence for the alibi in the morning compared to the afternoon (see Figure 2). Although the results seem logical and obvious, the general assumption is also supported by the data. In addition, the results contribute to the understanding of what evidence can be expected by non-offenders at various times. The results imply that a perfect alibi can only be seldom expected of non-offenders. Moreover, the evidence that can be expected by non-offenders varies depending on when the crime is committed. 
A combination between witness and physical supportive evidence was 1.80 times more likely to be reported in the afternoon than during the night (model $\chi 2(1, n=774)=$ $8.65, p=.003$, Nagelkerke R2 $=.017$ ). Only witness evidence was 2.25 times more likely for an alibi in the night than in the afternoon (model $\chi 2(2, n=774)=19.07, p<0.001$, Nagelkerke R2 = .033). The combination of witness, physical, and additional evidence was 3.74 times more likely to be reported in the evening than in the morning. In addition, such a combination of supportive evidence was 5.92 times more likely to be reported in the afternoon compared to the morning, but only on Saturday (model $\chi 2(2, n=774)=12.37$ $p=.002$, Nagelkerke R2 $=.062$; see Figure 3 and Table 8 , for the test results). 
Table 7

Frequencies of Alibi and Supportive Evidence per Timeframe (Proportions)

\begin{tabular}{|c|c|c|c|c|c|}
\hline & $\begin{array}{r}\text { Morning } \\
N=186\end{array}$ & $\begin{array}{r}\text { Afternoon } \\
N=182\end{array}$ & $\begin{array}{r}\text { Evening } \\
N=267\end{array}$ & $\begin{array}{r}\text { Night } \\
N=206\end{array}$ & Total \\
\hline Alibi & $185(1.00)$ & $180(0.99)$ & $267(1.00)$ & $205(1.00)$ & 837 \\
\hline Supportive evidence & $17(0.09)$ & $10(0.06)$ & $12(0.05)$ & $28(0.14)$ & 67 \\
\hline Witness evidence only & $168(0.91)$ & $170(0.94)$ & $255(0.96)$ & $177(0.86)$ & 770 \\
\hline Physical evidence only & $103(0.56)$ & $90(0.50)$ & $150(0.56)$ & $135(0.66)$ & 478 \\
\hline Additional evidence only & $2(0.01)$ & $2(0.01)$ & $5(0.02)$ & $1(0.01)$ & 10 \\
\hline Combination of witness and physical evidence & $1(0.01)$ & $1(0.01)$ & $3(0.01)$ & $1(0.01)$ & 6 \\
\hline Combination of witness and additional evidence & $39(0.21)$ & $52(0.29)$ & $56(0.21)$ & $23(0.11)$ & 170 \\
\hline Combination of physical and additional evidence & $20(0.11)$ & $18(0.10)$ & $30(0.11)$ & $13(0.06)$ & 81 \\
\hline Combination of witness, physical and additional evidence & $1(0.01)$ & $1(0.01)$ & $0(0.00)$ & $1(0.01)$ & 3 \\
\hline
\end{tabular}

Note. the proportions displayed in boldface are used as a baseline in the binary logistic regression analysis. 
Table 8

Stepwise Regression of Alibis and Supportive Evidence per Day and Timeframe

\begin{tabular}{|c|c|c|c|c|c|}
\hline & $B$ & $\begin{array}{l}\text { S.E. } \\
(B)\end{array}$ & $\begin{array}{l}\text { Wald } \\
(d f=1)\end{array}$ & $p$ & $\begin{array}{l}\text { Odds } \\
\text { ratio }\end{array}$ \\
\hline \multicolumn{6}{|l|}{ Supportive evidence ${ }^{1}$} \\
\hline \multicolumn{6}{|l|}{ Step 1} \\
\hline Constant & 2.237 & 0.142 & 248.635 & $<0.001$ & 9.364 \\
\hline Evening versus night & 0.820 & 0.328 & 6.255 & 0.012 & 2.269 \\
\hline \multicolumn{6}{|l|}{ Step 2} \\
\hline Constant & 2.103 & 0.147 & 204.996 & $<0.001$ & 8.192 \\
\hline Evening versus night & 0.953 & 0.330 & 8.348 & 0.004 & 2.594 \\
\hline \multicolumn{6}{|l|}{ Afternoon versus night only for } \\
\hline Saturday & 1.287 & 0.605 & 4.523 & 0.033 & 3.621 \\
\hline \multicolumn{6}{|l|}{ No Supportive evidence ${ }^{1}$} \\
\hline \multicolumn{6}{|l|}{ Step 1} \\
\hline Constant & -2.722 & 0.165 & 271.057 & $<0.001$ & 0.066 \\
\hline Night versus evening & 0.878 & 0.262 & 11.214 & 0.001 & 2.405 \\
\hline \multicolumn{6}{|l|}{ Step 2} \\
\hline Constant & -2.887 & 0.191 & 228.866 & $<0.001$ & 0.056 \\
\hline Night versus evening & 1.043 & 0.297 & 13.977 & $<0.001$ & 2.837 \\
\hline \multicolumn{6}{|l|}{ Morning versus evening only for } \\
\hline Tuesday & 0.899 & 0.387 & 5.380 & 0.020 & 2.456 \\
\hline \multicolumn{6}{|c|}{ Combination of witness and physical evidence ${ }^{2}$} \\
\hline \multicolumn{6}{|c|}{ Step 1} \\
\hline Constant & -1.413 & 0.103 & 189.616 & $<0.001$ & 0.243 \\
\hline Afternoon versus night & 0.586 & 0.195 & 8.984 & 0.003 & 1.800 \\
\hline \multicolumn{6}{|l|}{ Only witness evidence ${ }^{2}$} \\
\hline \multicolumn{6}{|l|}{ Step 1} \\
\hline Constant & 0.304 & 0.083 & 13.486 & $<0.001$ & 1.356 \\
\hline Night versus afternoon & 0.809 & 0.193 & 17.675 & $<0.001$ & 2.250 \\
\hline \multicolumn{6}{|c|}{ Combination of witness, physical and additional evidence ${ }^{2}$} \\
\hline \multicolumn{6}{|c|}{ Step 1} \\
\hline Constant & -3.555 & 0.233 & 233.498 & $<0.001$ & 0.029 \\
\hline \multicolumn{6}{|l|}{ Afternoon versus morning only for } \\
\hline Saturday & 1.082 & 0.457 & 5.605 & 0.018 & 2.952 \\
\hline \multicolumn{6}{|l|}{ Step 2} \\
\hline Constant & -4.251 & 0.411 & 106.896 & $<0.001$ & 0.014 \\
\hline Evening versus morning & 1.319 & 0.500 & 6.954 & 0.008 & 3.738 \\
\hline \multicolumn{6}{|l|}{ Afternoon versus morning only for } \\
\hline Saturday & 1.778 & 0.569 & 9.758 & 0.002 & 5.918 \\
\hline
\end{tabular}

Note: the dependent variable is displayed in boldface.

$1: \mathrm{n}=837$.

$2: n=774$. 
Figure 1

Percentages of Supportive Evidence per Days and Timeframe

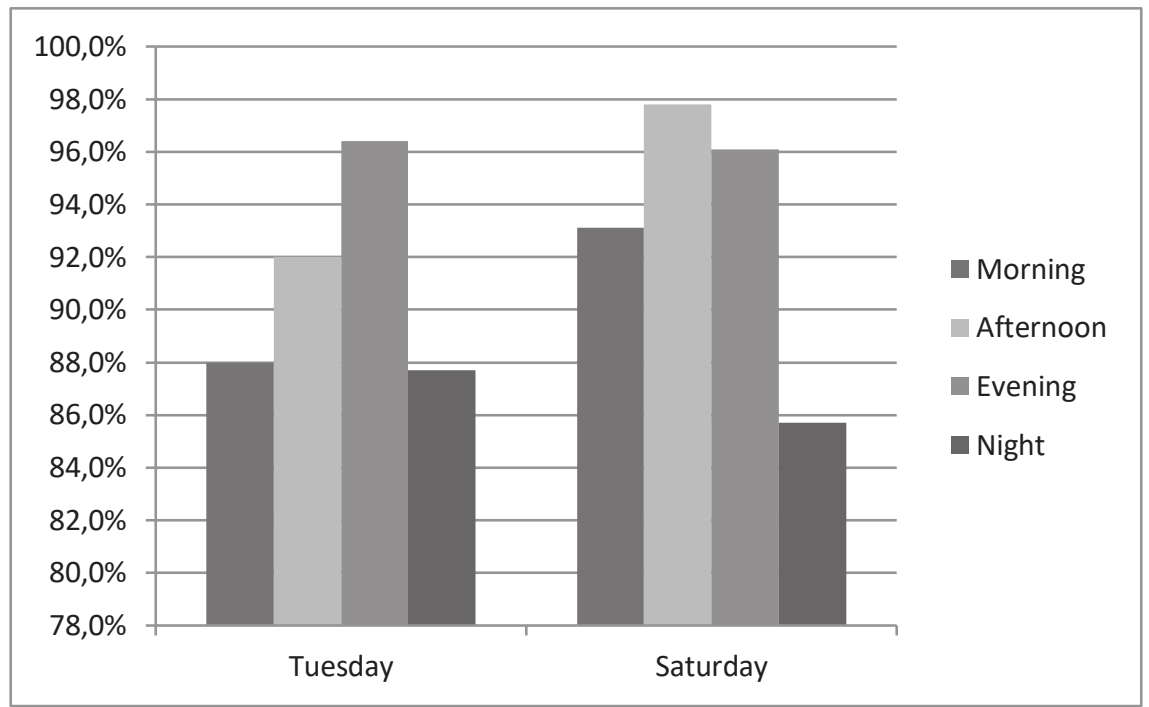

Figure 2

Percentages of no supportive evidence per days and timeframe

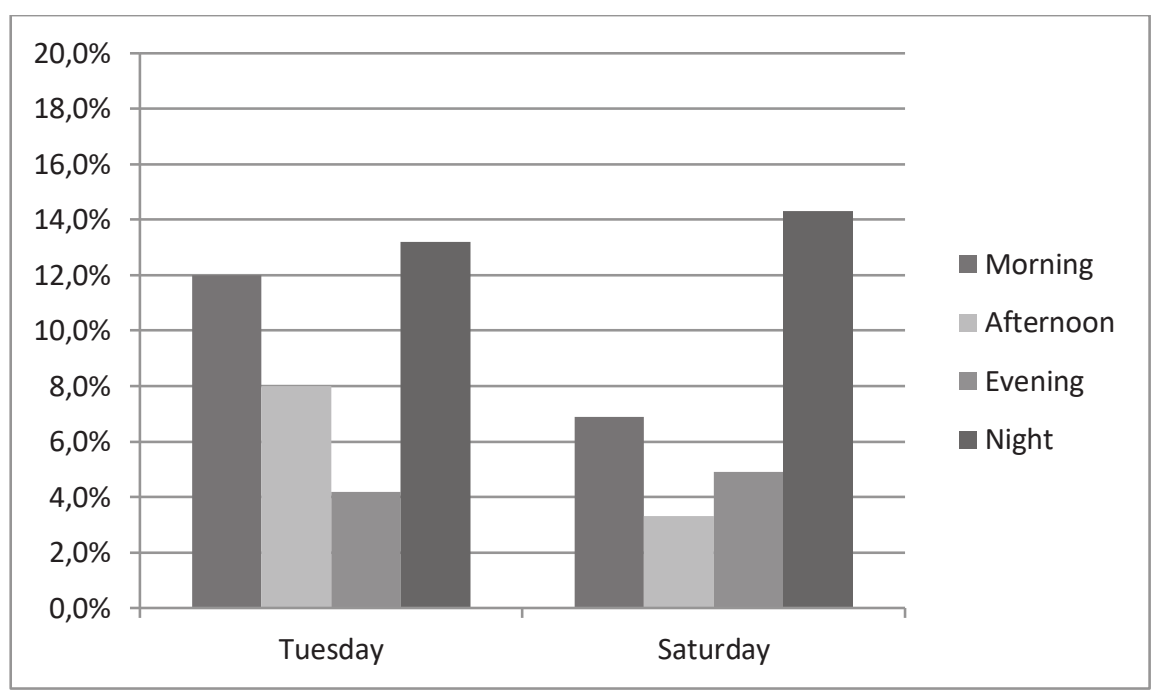




\subsection{DISCUSSION}

The objective of the present study was to establish the base rate of alibis and its supportive evidence of non-offenders. Despite the fact that most non-offenders report an alibi, the vast majority of their alibis do not match the criteria of the perfect alibi by the police because strong evidence is lacking. The reported evidence is more often weak, and the evidence for their alibi differs depending on when the alleged crime was committed (i.e., during the morning, afternoon, evening, or night). In addition, an alibi without supportive evidence - the least believable alibi - is most likely to be expected during the night compared to other timeframes. An alibi supported with evidence is most likely to be expected on Saturday afternoon. The results show that the perfect alibi to which police detectives compare a suspect's alibi is an illusion because only $2 \%$ of innocent people (18 out of the 841 participants) can present strong physical evidence (i.e., video recordings), and therefore, the base rate of alibis should be taken into account when evaluating alibis.

The present study was the first in which participants from a large community sample were asked to generate an alibi. Although the results of the present study are comparable to the results from studies with students as participants (e.g., Culhane et al., 2008), we also analysed the locations of the presented alibis and the reported supportive evidence in more detail than in previous studies. It came to light that different types of evidence can be expected dependent on the reported alibi location. Olson and Wells (2004, p. 159), however, argued that factors other than the strength of the evidence (such as the alibi location) are unimportant to determine the alibi believability. The results of the present study thus show that what evidence can be expected varies depending on the alibi location.

One of the greatest challenges in the study was to classify supportive evidence. A combination of evidence was reported by about one third of the participants. We have therefore chosen to describe the three forms of supportive evidence separately because we did not know how to determine the strength of the combinations of supportive evidence. Previously, Olson and Charman (2012), for example, only reported the strongest form of witness or physical evidence when multiple items of evidence were reported. Because the amount of alibi witnesses is of great influence to determine the alibi believability rather 
than the quality of the relationship between the witness and the suspect (Eastwood et al., 2016), we decided to display all the reported evidence.

It also raises the question whether the strength of supportive evidence can be determined with the taxonomy of Olson and Wells (2004). Although Olson and Wells (2004) have determined the strength of the combination of witness and physical evidence, it remains unclear how the strength of a combination of evidence within one category of supportive evidence should be determined. For instance, are two motivated familiar other witnesses (e.g., the suspect's partner and his mother) equally strong witness evidence as one unmotivated familiar other witness (e.g., the suspect's neighbour)? We suggest conducting more research on how to determine the strength of multiple items of supportive alibi evidence presented by one suspect, especially because about $64 \%$ of our participants reported more than one alibi witness.

Most of the new additional evidence that was reported in our study consisted of witness or physical evidence. However, nine participants reported additional evidence that could be labelled as unique knowledge evidence. Because about $7 \%$ of the participants in earlier studies had an alibi without supportive evidence, it could be the case that they had unique knowledge evidence to support their alibi. In the study by Olson and Charman (2012), the authors provided an example of an uncorroborated alibi:

"An alibi might be of such nature that there is no way to verify it independently, despite its accuracy. For example, a person who accurately recalls watching television alone for the two-hour period during which a crime was committed has no witness and no physical records of his behaviour" (Olson \& Charman, 2012, p.5).

When that person can correctly recall what he or she has watched on television within the 2 hours, it might also be classified as knowledge evidence. More research is needed to determine whether or not the taxonomy of Olson and Wells (2004) could be expanded with knowledge evidence. The first results on how believable the new type of supportive evidence is compared to witness and physical evidence are promising (Nieuwkamp, 
Horselenberg, \& Van Koppen, 2017). In that study, knowledge evidence is rated to be equally believable as an unmotivated familiar other witness among students, laypersons and police detectives.

One of the limitations of the present study is that we did not include all the different age groups of the community equally. The average age of the participants was around 30 years $(m d n=25.0)$, although the range was $17-79$ years. The elderly community members were less represented in the present study than the younger ones. An obvious explanation is that not everyone has access to the Internet and that an online survey is less useful to reach a widespread sample of participants (Dillman, 2002). The results of the present study are therefore less representative for the elderly community members.

A selection bias could be a second limitation of the present study because at first, the friends and family of the first author were asked to fill out and forward the questionnaire. Nieuwkamp et al. (2016) used a similar methodology where a second group of participants (i.e., a sample of community members who were recruited in a dance school) was added to control for a possible selection bias. No difference was observed between both groups of participants for their demographics and their answers on the dependent variables. We therefore believe that the possible effect of a selection bias in the present study would be very small.

A third limitation to the study is that only 2 days were chosen for the participants to present and validate an alibi. We chose a Tuesday and a Saturday: one day during the week and one in the weekend. It could be the case that the alibis are different for other weekdays and Sunday, although we could not find a reason why Tuesday and Saturday would be very different. Last, for practical reasons, we did not ask our participants to send the supportive evidence to us. However, we tried to control for that limitation by providing the participants with the opportunity to use all sorts of cues to generate a valid alibi.

The results of the present study can be beneficial to determine how believable an alibi is. For example, when a suspect is asked for his or her alibi during a night, it is known that the suspect is most likely to report only witness evidence (about $66 \%$ of the nonoffenders). On the one hand, it would be odd to expect strong physical evidence during the night because the base rate indicates that only one person reported to have such evidence 
at that moment. On the other hand, the base rate indicates that on Saturday afternoon, camera recordings can most often be expected. Thus, depending on what time the suspect is asked for his or her alibi can influence the reportable supportive evidence. We therefore argue that besides the strength of the supportive evidence, one should also critically examine how likely it is to expect certain evidence at different moments. In addition, when the location of the presented alibi is studied, the evidence that can be expected to support the alibi also varies. When a person says that he or she was at home, it is most likely that the alibi can be supported with only witness evidence (66\%) or no evidence (14\%). However, when the person says he or she was at a concert or playing sports, a combination between witness and physical evidence is most likely to be expected (62\% and 53\%), which also implies that the person is highly likely to present an item of physical evidence.

In sum, because most of the alibis of non-offenders are supported by (weaker) evidence that police detectives would not find believable, the strict criteria police detectives demand in practice for a believable alibi are based on an illusion. Furthermore, in alibi research, it was assumed that the alibi believability could be determined by assessing the strength of the supportive evidence. The results of the present study show that one cannot assume supportive evidence regardless of the alibi location and day and time of the alleged crime. Accordingly, the strength of the supportive evidence alone is not indicative of the believability of an alibi and in that sense does not allow for differentiating between innocent and guilty suspects. Especially, it is known that also the consistency and salaciousness, for example, need to be taken into account because these factors also affect the alibi believability.

We therefore argue that also the base rate of alibis and its supportive evidence should be taken into consideration to determine the alibi's believability, both in practice and alibi research. 
CHAPTER 3

\subsection{REFERENCES}

Allison, M., Jung, S., Sweeney, L., \& Culhane, S. E. (2014). The impact of illegal alibi activities, corroborator involvement and corroborator certainty on mock juror perceptions. Psychiatry, Psychology and Law, 21, 191-204. doi:10.1080/13218719.2013.803275

Allison, M., Mathews, K. R., \& Michael, S. W. (2012). Alibi believability: The impact of salacious alibi activities. Social Behavior and Personality: an international journal, 40, 605-612. doi:10.2224/sbp.2012.40.4.605

Allison, M., Michael, S. W., Mathews, K. R., \& Overman, A. A. (2011). Brief report: Narrative qualities and perceptions of generated alibis. North American Journal of Psychology, 13, 359-366.

Burke, T. M., \& Marion, S. B. (2012). Alibi witnesses. In B. L. Cultler (Ed.), Conviction of the innocent. Lessons from psychological research (pp. 239-256). Washington: American Psychological Association.

Burke, T. M., \& Turtle, J. W. (2003). Alibi evidence in criminal investigations and trials: Psychological and legal factors. The Canadian Journal of Police and Security Services, 1, 286-293.

Burke, T. M., Turtle, J. W., \& Olson, E. A. (2007). Alibis in criminal investigations and trials. In M. P. Toglia, J. D. Read, D. F. Ross, \& R. C. Lindsay (Eds.), The handbook of eyewitness psychology: Memory for events (Vol. 1, pp. 157-192). Mahwah, NJ: Lawrence Erlbaum Associates.

CBS. (2013). Beroepsbevolking, behaalde onderwijs naar herkomst geslacht en leeftijd. [Workforce, education received at home by sex and age]. Centraal Bureau voor de Statistiek (CBS) [Central Bureau for Statistics]. Retrieved from http://statline.cbs.nl/StatWeb/publication/?VW=T\&DM=SLNL\&PA=71822ned\&LA $=\mathrm{NL}$

Connors, E., Lundregan, T., Miller, N., \& McEwen, T. (1996). Convicted by juries, exonerated by science: Case studies in the use of DNA evidence to establish innocence after trial. Washington, DC: US Department of Justice, National Institute of Justice.

Culhane, S. E., \& Hosch, H. M. (2004). An alibi witness's influence on mock jurors' verdicts. Journal of Applied Social Psychology, 34, 1604-1616. doi:10.1111/j.15591816.2004.tb02789.x

Culhane, S. E., \& Hosch, H. M. (2012). Changed alibis: Current law enforcement, future law enforcement, and layperson reactions. Criminal Justice and Behavior, 39, 958-977. doi:10.1177/0093854812438185

Culhane, S. E., Hosch, H. M., \& Kehn, A. (2008). Alibi generation: Data from U.S. Hispanics and U.S. non-Hispanic whites. Journal of Ethnicity in Criminal Justice, 6, 177-199. doi:10.1080/15377930802243395 
Culhane, S. E., Kehn, A., Horgan, A. J., Meissner, C. A., Hosch, H. M., \& Wodahl, E. J. (2013). Generation and detection of true and false alibi statements. Psychiatry, Psychology and Law, 20, 619-638. doi:10.1080/13218719.2012.729018

Dahl, L. C., \& Price, H. L. (2012). “He couldn't have done it, he was with me!": The impact of alibi witness age and relationship. Applied Cognitive Psychology, 26, 475-481. doi:10.1002/acp.2821

Dillman, D. A. (2002). Presidential address: Navigating the rapids of change: Some observations on survey methodology in the early twenty-first century. Public Opinion Quarterly, 66, 473-494. doi:10.1086/342184

Dysart, J. E., \& Strange, D. (2012). Beliefs about alibis and alibi investigations: A survey of law enforcement. Psychology, Crime and Law, 18, 11-25. doi:10.1080/1068316X.2011.562867

Eastwood, J., Snook, B., \& Au, D. (2016). Safety in numbers: A policy-capturing study of the alibi assessment process. Applied Cognitive Psychology, 260-269. doi:10.1002/acp.3200

Fawcett, H. (2015). The effect of evidence timing and witness motivation upon juror evaluations of alibi witnesses and defendants. Psychiatry, Psychology and Law, 575-587. doi:10.1080/13218719.2015.1081317

Felson, M., \& Poulsen, E. (2003). Simple indicators of crime by time of day. International Journal of Forecasting, 19, 595-601. doi:10.1016/s0169-2070(03)00093-1

Garrett, B. L. (2011). Convicting the innocent. Cambridge, Massachusetts: Harvard University Press.

Hosch, H. M., Culhane, S. E., Jolly, K. W., Chavez, R. M., \& Shaw, L. H. (2011). Effects of an alibi witness's relationship to the defendant on mock jurors' judgments. Law and Human Behavior, 35, 127-142. doi:10.1007/s10979-010-9225-5

Jung, S., Allison, M., \& Bohn, L. (2013). Legal decision-making on crimes involving an alibi. Applied Psychology in Criminal Justice, 9, 45-58. doi:10.1037/t04698-000

Kassin, S. M., Goldstein, C. C., \& Savitsky, K. (2003). Behavioral confirmation in the interrogation room: On the dangers of presuming guilt. Law and Human Behavior, 27, 187-203. doi:10.1023/A:1022599230598

Leins, D. A., \& Charman, S. D. (2013). Schema reliance and innocent alibi generation. Legal and Criminological Psychology, 21, 111-126. doi:10.1111/lcrp.12035

Marion, S. B., Kukucka, J., Collins, C., Kassin, S., \& Burke, T. M. (2015). Lost proof of innocence: The impact of confessions on alibi witnesses. Law and Human Behavior, 40, 65-71. doi:10.1037/lhb0000156.

Meissner, C. A., \& Kassin, S. (2002). "He's guilty!": Investigator bias in judgments of truth and deception. Law and Human Behavior, 26, 469-480. doi:10.1023/A:1020278620751 
Nieuwkamp, R. (2015). De geloofwaardigheid van alibi's [The believability of alibis]. Strafblad, 5, 428-434.

Nieuwkamp, R., Horselenberg, R., \& Van Koppen, P. J. (2016). A lie and a mistress: On increasing the believability of your alibi. Psychiatry, Psychology and Law. doi:10.1080/13218719.2016.1142934

Nieuwkamp, R., Horselenberg, R., \& Van Koppen, P. J. (2017). You don't know: Knowledge as supportive alibi evidence. Manuscript submitted for publication.

Odinot, G., \& Wolters, G. (2006). Repeated recall, retention interval and the accuracyconfidence relation in eyewitness memory. Applied Cognitive Psychology, 20, 973985. doi:10.1002/acp.1263

Olson, E. A., \& Charman, S. D. (2012). 'But can you prove it?' - Examining the quality of innocent suspects' alibis. Psychology, Crime and Law, 18, 453-741. doi:10.1080/1068316x.2010.505567

Olson, E. A., \& Wells, G. L. (2004). What makes a good alibi? A proposed taxonomy. Law and Human Behavior, 28, 157-176. doi:10.1023/B: LAHU.0000022320.47112.d3

Olson, E. A., \& Wells, G. L. (2012). The alibi-generation effect: Alibi-generation experience influences alibi evaluation. Legal and Criminological Psychology, 17, 151-164. doi:10.1111/j.2044-8333.2010.02003.x

Pozzulo, J. D., Pettalia, J. L., Dempsey, J. L., \& Gooden, A. (2015). Juvenile offenders on trial: Does alibi corroboration evidence and defendant age interact to influence jurors' perceptions and verdicts? Psychiatry, Psychology and Law, 22, 224-234. doi:10.1080/13218719.2014.937518

Saks, M. J., \& Koehler, J. J. (2005). The coming paradigm shift in forensic identification science. Science, 309, 892-895. doi:10.2307/3842593

Simon, D. (2012). In doubt: The psychology of the criminal justice process. London: Harvard University Press.

Sommers, S. R., \& Douglass, A. B. (2007). Context matters: Alibi strength varies according to evaluator perspective. Legal and Criminological Psychology, 12, 41-54. doi:10.1348/135532506x114301

Vrij, A. (2008). Detecting lies and deceit: Pitfalls and opportunities. Chichester: John Wiley.

Wagenaar, W. A. (1986). My memory: A case study of autobiographic memories over six years. Cognitive Psychology, 18, 225-252.

Wells, G. L., Small, M., Penrod, S., Malpass, R. S., Fulero, S. M., \& Brimacombe, C. (1998). Eyewitness identification procedures: Recommendations for lineups and photospreads. Law and Human Behavior, 22, 603-647. 


\subsection{APPENDIX: QUESTIONNAIRE}

\section{Informed consent:}

By proceeding to the next page, please be informed that your participation is on a voluntary basis which implies that you can stop filling out the questionnaire at any moment in time. All your answers will be processed anonymously. At the end of the questionnaire you can enter your email address if you like to receive a brief summary of the results once the data collection has been completed. Your email address will be stored in another location, so it cannot be traces back to the answers you provided in the questionnaire. If you do not agree with these terms, please close this window.

\section{General questions:}

1) What is your gender?

Male

Female

2) What is your year of birth?

3) What is your relationship status?

I am single.

I have a partner but we are not living together. I have a partner and we are living together.

4) What is your employment status?

I am (temporarily) unemployed.

I am a student.

I am employed.

5) What is your higher completed education?

Elementary school

Secondary school

Intermediate vocational education

College or University 
CHAPTER 3

\section{Case vignette:}

Now carefully read the following text. Some questions about the text will be asked at a later stage.

Imagine that last Tuesday night at 01.45 AM an armed robbery was committed in your municipality. The robber took the content of the register while pointing a gun at the shop owner. The police have started to look into the robbery and imagine that they have reason to believe you could be a possible suspect in this case. The police therefore want to know where you have been at the time that the aforementioned robbery was committed.

\section{Alibi generation:}

6) Describe as fully as possible where you have been at the time of the aforementioned robbery (use resources such as your agenda or diary when necessary)

\section{Supportive evidence:}

7) Can your alibi be supported with physical evidence (an example of physical evidence is a receipt)

Yes, it consists of:

No

8) Can a witness support your alibi?

No

If yes, how many witnesses can support your alibi?

2345 or more


9) What is your relation to the alibi witness(es) from question 8? Please indicate for each category of alibi witnesses the number of witness(es) that could support your alibi, more than one answer is possible.

Partner Family member Friend Colleague Acquaintance Stranger

10) Is there any other evidence that you have not reported yet that could support your alibi?

No

Yes, it consists of:

You have reached the end of the questionnaire. Thank you very much for your cooperation!

If you wish to receive a brief summary of the results please leave your email address here: 

4

YOU DON'T KNOW: KNOWLEDGE AS SUPPORTIVE ALIBI EVIDENCE

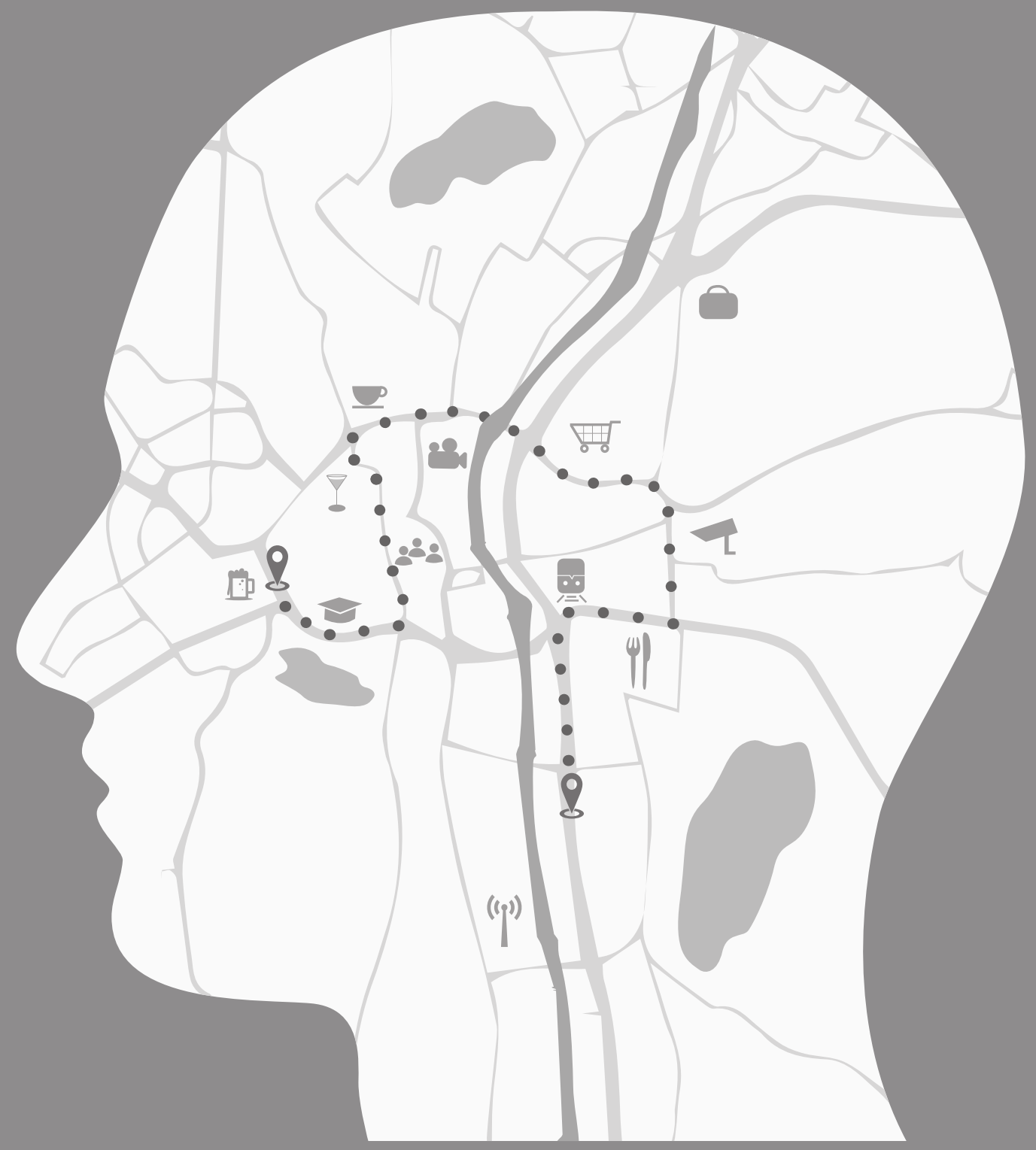

This chapter has been submitted for publication to The International Journal of Evidence and Proof:

Nieuwkamp, R., Horselenberg, R., \& Van Koppen, P. J. You don't know: Knowledge as supportive alibi evidence. Manuscript in revision for publication. 



\begin{abstract}
Until now, supportive evidence for alibis has been conceptualized into two distinct types: witness and physical evidence. The present study examined whether knowledge, as a third type of supportive evidence, can contribute to the understanding of evidence for alibis.

Three experiments were conducted in which police detectives, laypersons and undergraduate students were asked to evaluate four alibis with either: witness, physical, or knowledge supportive evidence, or with no supportive evidence. The results from the three experiments show that knowledge evidence is equally believable as strong witness evidence. We also found that not all items of strong physical evidence are evaluated as equally strong and believable. We therefore suggest adjusting the criteria to determine the strength of physical evidence and conducting more research on knowledge evidence.
\end{abstract}

Keywords: alibi, supportive evidence, knowledge, taxonomy, police detectives 
CHAPTER 4

\subsection{INTRODUCTION}

Previous research on alibi evaluation has concluded that the presence and strength of supportive evidence, categorized as physical or witness evidence, are the most important factors in determining alibi believability (e.g., Jung, Allison, \& Bohn, 2013; Pozzulo, Pettalia, Dempsey, \& Gooden, 2015). In the alibi literature, however, not all types of supportive evidence are captured. In the present paper we focus on a type of supportive evidence not yet studied, namely knowledge evidence. Knowledge evidence refers to information that could only be known to a person if that person was at a certain event.

\subsubsection{Supportive Evidence}

Classically, two types of supporting alibi evidence are studied: witness evidence and physical evidence. The evidence for an alibi can consist of either type or a combination of both types (Culhane et al., 2013; Nieuwkamp, Horselenberg, \& Van Koppen, 2017). To determine the strength of supportive evidence, Olson and Wells (2004) created an alibi taxonomy consisting of the two classic types of supportive evidence. The strength of witness evidence is based on the degree to which the witness might be motivated to lie in the suspect's favour (Sullivan, 1971). It is expected that if the relational distance between the suspect and witness is large (e.g., a previously unknown stranger), the witness is assumed to be the least inclined to lie for the suspect. In the taxonomy, such a witness is referred to as an unmotivated other witness, and is considered the strongest type of witness evidence (Olson \& Wells, 2004). The witness' testimony is viewed as weaker evidence when the relational distance is small (e.g., the suspect's girlfriend) and is referred to as a motivated familiar other witness (Culhane \& Hosch, 2004).

Physical evidence is considered strong supportive evidence when three criteria are met: the evidence a) is linked to the suspect; b) contains an indication of the date and time; c) and contains location information (Olson \& Charman, 2012). That is, the evidence has to place the suspect at a specific place at a specific time other than the crime scene. CCTV recordings are an example of strong physical evidence, as they are hard to alter (Olson \& 
Wells, 2004). In contrast, a receipt is an example of weak physical evidence, for a receipt lacks a solid link to whom purchased the goods. The rationale underlying the three criteria is that the more difficult it is for the suspect to fabricate the physical evidence or to obtain it from someone else, the stronger the evidence is.

The impact of physical evidence cannot be underestimated because weak physical evidence (i.e., a receipt) has a greater positive influence on alibi believability than an unmotivated familiar other witness (Olson \& Wells, 2004). In past studies physical evidence has been little varied until now. Typically, strong evidence consists of the recordings of CCTV cameras and weak evidence consists of a receipt in alibi research (e.g., Allison \& Brimacombe, 2010; Jung, Allison, \& Bohn, 2013), although a credit card receipt or an airline ticket stub are also examples of strong physical evidence (Olson \& Charman, 2012).

A suspect can also present a combination of both types of evidence for his alibi (Culhane et al., 2013; Nieuwkamp et al., 2017). The strength of a combination of supportive evidence can also be determined using the taxonomy of Olson and Wells (2004) in such that it depends on the strength of the witness and physical evidence separately. For example, weak witness evidence combined with weak physical evidence is of equal strength as strong physical evidence without witness evidence (Olson \& Wells, 2004). However, to date it remains unclear how a combination within one type of evidence should be assessed. For example, are two motivated familiar witnesses stronger evidence than one unmotivated stranger witness? That question needs to be addressed in future research.

\subsubsection{Knowledge as Supportive Evidence}

Although the taxonomy helps to understand the evaluation of alibi believability, it is unclear if all types of supportive evidence are captured in the taxonomy. Based on the well-known Dutch Deventer murder case, Van Koppen and Van Koppen (2010) argued that knowledge could be a novel type of supportive alibi evidence. In the Deventer murder case, the defendant presented an alibi supported by evidence that cannot be found in the alibi literature. The defendant said that he could not have committed the murder because he was in a traffic jam around 30 kilometres from the murder site. His knowledge of the traffic 
jam could support his alibi. The police verified that at the time of the murder there was indeed a traffic jam where the defendant reported it to be, and that the jam had not been mentioned in the radio traffic reports. The question that remained was whether the defendant knew about the traffic jam from his own experience or if he got that knowledge through another source (Haan, 2009). Haan (2009) argued that the defendant could have seen the traffic jam from another location or could have talked to colleagues who were stuck in that traffic jam. Regardless of how the defendant obtained the knowledge, the concept of knowledge as supportive evidence for an alibi can be valuable for the alibi literature.

Knowledge evidence can consist of any kind of information that the suspect has to support his alibi for what he was doing at the time the alleged crime was committed. The strength of knowledge evidence could perhaps be assessed based on the same rationale as physical evidence: the more difficult it is to fabricate or obtain, the stronger the evidence is. In contrast, the easier it is to obtain particular knowledge from another source (e.g., talking to someone else) or to base the alibi on prior knowledge of the suspect (e.g., being able to tell the plot of a classic movie alike Titanic that was broadcast on television on the night of the crime), the weaker the evidence is. Unique knowledge evidence is therefore the strongest form of knowledge evidence and can be defined as knowledge that could only be known to the person if that person was present at a certain event.

Knowledge evidence has the potential of being a meaningful addition to the two classical types of supportive alibi evidence. The present paper will examine how knowledge evidence is evaluated by diverse groups of participants.

\subsubsection{Police Detectives as Participants}

Our understanding of alibi evaluation has grown over the years, but most of that research has been conducted with undergraduate students as participants (e.g., Sauerland, Mehlkoph, Krix, \& Sagana, 2016). In practice, the police detectives' role is very important in evaluating alibis in criminal pre-trial investigations. Depending on whether they consider the alibi to be believable, the police officers may invest more or less time and energy 
investigating the suspect's potential involvement in the alleged crime. By doing so, they influence subsequent procedures. Nevertheless, the use of police detectives in alibi evaluation research is rare (Culhane \& Hosch, 2012; Dysart \& Strange, 2012; Eastwood, Snook, \& Au, 2016). Research shows that important differences exist between students and police detectives in alibi evaluation. When both groups of participants are asked to evaluate alibis on five aspects (e.g., the quantity of alibi witnesses and the quality of the relation between the suspect and the alibi witness), police detectives focus on more aspects (2.5 aspects) than students (1.7 aspects; Eastwood et al., 2016). In addition, police detectives find the number of alibi witnesses more important than the relational distance with the suspect (Eastwood et al., 2016). Police detectives also come to more guilty judgements than students (Culhane \& Hosch, 2012), which can be explained by their distrust of suspects in general (e.g., Kassin, Goldstein, \& Savitsky, 2003; Meissner \& Kassin, 2002; Vrij, 2008) and of their alibis in particular (Dysart \& Strange, 2012). When a suspect changes his alibi, for example, about $80 \%$ of the police detectives think that the change is made due to deception rather than error (Dysart \& Strange, 2012), although such misrecollections are common occurrences (Crozier, Strange, \& Loftus, 2017; Strange, Dysart, \& Loftus, 2014).

\subsubsection{Present Studies}

The present experiments were designed to determine how knowledge evidence is evaluated in terms of believability and strength compared to witness, physical and no supportive alibi evidence among police detectives, undergraduate students and laypersons.

In general, we expected an alibi supported by any type of evidence to be more believable than an alibi without supportive evidence (Hypothesis 1) based on earlier research (e.g., Olson \& Wells, 2004). We expected knowledge evidence to be equally strong and believable as witness evidence (Hypothesis 2), but physical evidence to be the strongest and most believable (Hypothesis 3), in line with previous studies (e.g., Pozzulo, Pettalia, Dempsey, \& Gooden, 2015). 
CHAPTER 4

\subsection{EXPERIMENT 1}

\subsubsection{Method}

\subsubsection{Design}

The experiment consisted of a 2 (group: laypersons vs. police detectives) x 4 (evidence: no evidence, witness evidence, physical evidence and knowledge evidence) mixed-factorial design. The between-subjects factor consisted of two groups of participants. The withinsubjects factor was the type of supportive evidence presented.

\subsubsection{Participants}

One group of laypeople and two groups of police detectives were recruited for the experiment. The police detectives consisted of one group of police detectives from the regular police force $(n=48)$ and one group of detectives working for the Dutch Fiscal Information and Investigation Service (FIOD; $n=40$ ). The police detectives from the regular force were recruited during a theme day in the Netherlands. They were between 29 and 59 years old $(M=45.6, S D=7.8)$. The second group was recruited by contacting the FIOD. The FIOD provided a list of 58 employees based somewhere in the country who were highly likely to have experience in evaluating alibis based on their previous position in the police service. A total of 41 FIOD detectives completed an online version of the questionnaire. One participant was excluded because he never had to evaluate an alibi. The age of the 40 remaining FIOD detectives ranged from 35 to 62 years $(M=49.8, S D=6.6)$.

The laypersons $(n=56)$ were recruited in public areas in two average sized cities in the Netherlands. Their ages varied between 19 and 62 years $(M=33.8, S D=14.5)$.

No significant differences were observed between the two groups of police detectives in regard to demographics and their scores on the dependent variables $(p>0.05)$. The two groups of police detectives were therefore combined. Two participants from the group of police detectives had at least one missing value for the alibi evaluation; they were 
excluded from the analysis. Hence, the final group of police detectives consisted of 86 participants (see Table 1 for an overview).

All participants completed the questionnaire individually and received no compensation. The standing ethical committee of the Faculty of Psychology and Neuroscience at Maastricht University approved the study.

Table 1

Participant Characteristics in Percentages

\begin{tabular}{|c|c|c|c|c|}
\hline & \multicolumn{3}{|c|}{ Group of participants } & \multirow[b]{2}{*}{ Average $^{2}$} \\
\hline & $\begin{array}{l}\text { Lay people } \\
\quad(n=56)\end{array}$ & $\begin{array}{c}\text { Police } \\
\text { detectives } \\
\text { specialised in } \\
\text { sexual } \\
\text { delinquency } \\
(n=48) \\
\end{array}$ & $\begin{array}{c}\text { FIOD } \\
\text { detectives } \\
(n=40)\end{array}$ & \\
\hline \multicolumn{5}{|l|}{ Sex } \\
\hline Male & $46.4(26)$ & $41.7(20)$ & $87.5(35)$ & $58.5(81)$ \\
\hline Female & $53.6(30)$ & $58.3(28)$ & $12.5(5)$ & $41.5(63)$ \\
\hline \multicolumn{5}{|l|}{ Highest completed education ${ }^{1}$} \\
\hline Elementary school & $0.0(0)$ & $0.0(0)$ & $5.0(2)$ & $1.7(2)$ \\
\hline Secondary school & $36.4(20)$ & $35.5(17)$ & $40.0(16)$ & $37.3(53)$ \\
\hline $\begin{array}{l}\text { Intermediate vocational } \\
\text { education }\end{array}$ & $14.5(8)$ & $33.3(16)$ & $35.0(14)$ & $27.6(38)$ \\
\hline College or University & $49.0(27)$ & $31.3(15)$ & $20.0(8)$ & $33.4(50)$ \\
\hline \multicolumn{5}{|l|}{ Alibi evaluation in current job } \\
\hline Never & & $0.0(0)$ & $12.5(5)$ & $7.3(5)$ \\
\hline Less than once a month & & $54.2(26)$ & $70.0(28)$ & $61.1(54)$ \\
\hline Less than once a week & & $22.9(11)$ & $10.0(4)$ & $16.5(15)$ \\
\hline About once a week & & $18.8(9)$ & $2.5(1)$ & $10.7(10)$ \\
\hline Two to four times a week & & $2.1(1)$ & $5.0(2)$ & $7.1(3)$ \\
\hline About once a day & & $2.1(1)$ & $0.0(0)$ & $1.1(1)$ \\
\hline
\end{tabular}


CHAPTER 4

\subsubsection{Materials and Procedure}

The FIOD detectives received a digital copy of the questionnaire using www.surveygizmo.com. A digital version was created because the detectives were located throughout the country. Potential participants were contacted via email with the request to independently complete the questionnaire. All other participants completed the questionnaire individually using a paper-and-pencil form.

After consent was received, the participants were asked for some demographics (e.g., gender and age), and the detectives were also asked how often they evaluate an alibi on average per month. All participants were then presented with a short description of a mock armed robbery that was committed the previous Friday at 10:05 AM at a small grocery store at the train station of a Dutch city, Amersfoort. The police arrested four men who all presented the same alibi (i.e., "I took the train at 9:26 AM in Amersfoort to arrive at 10:25 AM in Amsterdam"). ${ }^{2}$ One suspect presented the alibi without supporting evidence, and the other three suspects presented either witness, physical or knowledge supportive evidence. The participants were asked to evaluate the presented alibis in a randomised order to preclude any order effects.

The witness and physical evidence consisted of the strongest type of evidence according to the taxonomy of Olson and Charman (2012). The alibi witness was an unmotivated other witness, namely the ticket collector who recognised the suspect on the train because the suspect often takes the train from Amersfoort to Amsterdam. The physical evidence consisted of the records of the suspect's personal public transportation card, the so-called OV chip card. The Dutch OV chip card is a personal card containing the passenger's name, date of birth and a photograph. A passenger typically checks in with the OV chip card electronically at the departure station and checks out at the arrival station. The records of the suspect's OV chip card show that the card was used at 9:20 AM to check in at Amersfoort central and to check out at 10:31 AM in Amsterdam central station. These records thus fulfil the requirements for strong physical evidence as: a) it is the suspect's personal card and is

\footnotetext{
${ }^{2}$ A journey of about one hour and 62 kilometres. 
directly linked to him; and it also contains b) time; and c) location information. The knowledge evidence in the present experiment consists of unique knowledge evidence. The suspect said that on his train journey someone pulled the emergency brake that resulted in an emergency stop of the train. After standing still for a couple of minutes, the train proceeded and managed to arrive on time in Amsterdam. The Dutch railways never publicised information about the incident.

All alibis and supportive evidence were rated on three dependent measures: a) alibi believability; b) evidence strength; and c) the degree to which the alibi and its supportive evidence contributed to the innocence of the suspect. The participants rated the dependent measures on a Visual Analogue Scale (VAS; Luria, 1975) by marking their answer on a horizontal bar of $10 \mathrm{~cm}$ in length. The VAS consisted of two values below the horizontal bar at the beginning and the end of the bar. The value at the beginning was the lowest value (e.g., 'not at all believable') and the end point consisted of the highest value (e.g., 'completely believable').

We created two scales of dependent measures: one only about the alibi and the other consisting of the average of the other two items referring to the presented evidence. Because the supportive evidence was different in each presented alibi, separate scales (evidentiary value hereafter) were constructed per type of presented evidence. The $\alpha$ 's for the evidentiary value varied between .83 and .93 .

Lastly, the participants were asked which type of supportive evidence for an alibi was most important to them in general. They could choose from four options: witness evidence, physical evidence, knowledge evidence, or that all types of evidence were equally important. They were then fully debriefed and thanked for their participation. Along with the three general formulated hypotheses, we also expected police detectives to attribute lower believability scores to all presented alibis (Hypothesis 4) in line with previous studies (Culhane \& Hosch, 2012). 
CHAPTER 4

\subsubsection{Results}

The data were analysed using general linear model (GLM) repeated measures analyses for the alibi believability measure and the evidentiary value. The within-subjects factor consisted of the supportive evidence, and the between-subjects factor was the group of participants (i.e., police detectives or laypersons). The results of these analyses showed that the assumption of sphericity was violated for the alibi believability measure and the evidentiary value. A Huynh-Feldt correction of the degrees of freedom was therefore applied ( $\varepsilon=.95$ for alibi believability and $\varepsilon=.89$ for the evidentiary value).

For believability, no interaction between the groups and the type of evidence was found. A main effect of evidence was observed, $F(2.85,399.25)=58.51, p<.001, \eta_{p}{ }^{2}=.30$. An alibi without supportive evidence was found to be the least believable compared to alibis with supportive evidence, $p<.001$, supporting Hypothesis 1 . No differences were observed between the types of supportive evidence for the alibi believability, $p>.05$.

No interaction was observed between the groups with regard to evidentiary value, but a main effect of supportive evidence was found, $F(2.68,378.24)=91.70, p<.001, \eta_{p}{ }^{2}=$ .39. Similar to the believability measure, the alibi without supportive evidence obtained the lowest evidentiary value compared to the alibis supported with evidence, $p<.001$. No differences were observed between the types of evidence on the scale $(p>.05)$, meaning Hypotheses 2, 3 and 4 were not supported. See Table 2 for an overview.

Most participants found all types of evidence equally important (44.8\%), although a considerable percentage (34.4\%) indicated that knowledge evidence was most important. A smaller proportion of the participants indicated that they found physical (14.7\%) or witness evidence (6.3\%) the most critical to support an alibi. There were no differences between detectives and laypersons on these ratings. 
KNOWLEDGE AS SUPPORTIVE ALIBI EVIDENCE

Table 2

Mean Scores (M) and Standard Deviation (SD) for the Alibi Believability Measure and the Evidence Scale Measure $(n=144)$

\begin{tabular}{|c|c|c|}
\hline Supportive evidence & $M$ & $S D$ \\
\hline \multicolumn{3}{|l|}{ Believability measure } \\
\hline No evidence ${ }^{1}$ & 3.70 & 2.32 \\
\hline Witness evidence & 6.46 & 2.46 \\
\hline Physical evidence & 6.09 & 2.41 \\
\hline Knowledge evidence & 6.18 & 2.30 \\
\hline \multicolumn{3}{|l|}{ Evidentiary value } \\
\hline No evidence ${ }^{1}$ & 2.19 & 1.76 \\
\hline Witness evidence & 5.82 & 2.68 \\
\hline Physical evidence & 5.21 & 2.60 \\
\hline Knowledge evidence ${ }^{2}$ & 5.09 & 2.41 \\
\hline
\end{tabular}

Note: the dependant variable is displayed in boldface.

1 : significant at $p<.001$ compared to the other forms of supportive evidence.

2: one missing value.

\subsubsection{Discussion}

There was no difference between detectives and laypersons in alibi evaluation and believability. Also, knowledge evidence turned out to be a useful addition to the value of alibis. The results even suggest that knowledge evidence has the same effects on alibi evaluation as the other types of supportive evidence. This was unexpected, as previous research has shown that physical evidence is considered to be stronger supportive evidence than witness evidence (e.g., Allison \& Brimacombe, 2010; Jung et al., 2013). These deviating results could be explained by two limitations.

This is the first alibi evaluation study to include both laypersons and police detectives. Typically, undergraduate students are asked to evaluate the alibis and therefore most of our understanding of alibi evaluation research comes from how students evaluate alibis. The selection of laypersons and police officers in the experiment could possibly explain why our results are not consistent with previous findings. On the one hand, police detectives are thought to have a sceptical attitude towards alibis (Dysart \& Strange, 2012) and come to more guilty judgements than students when evaluating alibis (Culhane \& Hosch, 2012). On the other hand, there is no difference in the assessment of alibi believability when comparing the alibi evaluations of police detectives and students 
(Culhane \& Hosch, 2012). Similar to these results, we did not find any difference in the evaluation of alibis in terms of believability and the evidentiary value between police detectives and laypersons in the present experiment.

Second, the police detectives did not perceive the physical evidence as strong evidence. When they were debriefed, they indicated that although the OV chip card is directly linked to the suspect, it does not necessarily mean that he himself used the card on the day of the robbery. From their experience, they know that the ticket collector is more interested in verifying if the passenger has paid for his journey than if the card truly belongs to the passenger. The police detectives stated that they would have evaluated the alibis differently if CCTV recordings were presented showing that the suspect entered the train in Amersfoort and exited the train in Amsterdam. Their remarks might aid in understanding why the physical evidence was evaluated as weaker than we expected.

\subsection{EXPERIMENT 2}

To control for the first limitation in Experiment 1, we only included students in the second experiment. To control for the second limitation of Experiment 1, half of the participants received another type of strong physical evidence (i.e., CCTV recordings) while the other half of the participants received the same physical evidence as in Experiment 1 (i.e., an OV chip card). CCTV recordings were included based on the feedback of the detectives and also because CCTV recordings are typically used as strong physical evidence in alibi research (Allison \& Brimacombe, 2010; Jung et al., 2013). These two changes were made to make our results more comparable to previous research to determine the added value of knowledge evidence.

For the second experiment, we expected that knowledge evidence would not differ in its believability and the evidentiary value from witness evidence and physical evidence when it consisted of the OV chip card (Hypothesis 1a). When the physical evidence consisted of CCTV recordings, we expected knowledge evidence to be evaluated similarly to witness evidence but yet weaker than the presented physical evidence (Hypothesis 1b). As in Experiment 1, we expected the alibi without supportive evidence to obtain the lowest score 
on both measures (Hypothesis 2). For the physical evidence, we expected CCTV recordings to score higher on both measures compared to the OV chip card (Hypothesis 3) as well as higher on both measures compared to witness evidence (Hypothesis 4).

\subsubsection{Method}

\subsubsection{Design}

The second experiment consisted of a 2 (item of physical evidence: OV chip card vs. CCTV recordings) x 4 (supportive evidence: witness vs. physical vs. knowledge vs. none) mixed factorial design.

\subsubsection{Participants}

The 85 participants were undergraduate students from the Faculty of Psychology and Neuroscience at Maastricht University. They were recruited by means of flyers and received a research credit in return for their participation. Their ages varied between 19 and 53 years $(M=22.08, S D=3.91)$ and most of them were female $(76.5 \%)$. The standing ethical committee of the Faculty of Psychology and Neuroscience at Maastricht University approved the study.

\subsubsection{Materials and Procedure}

The supportive physical evidence was changed for half of the participants compared to the materials used in Experiment 1. Half of the participants received the same materials as in Experiment 1, while the other half of the participants read that the suspect's alibi was supported by CCTV recordings. On the recordings, the suspect was visible on the train platform around 9:20 AM in Amersfoort entering a train, and around 10:30 AM the suspect was again visible on the train platform in Amsterdam exiting a train. All other materials and 
CHAPTER 4

procedures in Experiment 2 were identical to Experiment 1. The $\alpha$ 's for the evidentiary value ranged between .88 and .94 .

\subsubsection{Results}

The data were analysed using general linear model (GLM) repeated measures analyses for the alibi believability measure and the evidentiary value. The within-subjects factor consisted of the supportive evidence, while the between-subjects factor consisted of the item of physical evidence (i.e., OV chip card or CCTV recordings). The assumption of sphericity was violated for both the believability measure and the evidentiary value; thus a Huynh-Feldt correction was applied to the degrees of freedom $(\varepsilon=.90$ for the alibi believability and $\varepsilon=.94$ for the evidentiary value).

\subsubsection{Believability measure}

No interaction was observed, but a main effect of supportive evidence was found, $F(2,58$, $214,31)=56.72, p<.001, \eta_{p}^{2}=.41$. All alibis with supportive evidence were rated to be more believable than the alibi without supportive evidence $(p<.001)$, supporting Hypothesis 2 . In addition, when the supportive evidence consisted of witness evidence, the alibi was rated to be more believable $(M=6.95 ; S D=2.04)$ than when knowledge evidence was reported $(M=6.25 ; S D=2.34), p=.028$. The results of a one-way ANOVA revealed that video recordings and the OV chip card were found to be equally believable: $F(1,83)=.003, p>.05$, which does not support Hypotheses $1 \mathrm{a}$ and b.

\subsubsection{Evidentiary value}

Depending on which physical evidence was presented, the evidence was rated differently by the participants: $F(2,82 ; 234,38)=2.88, p=.040, \eta_{p}{ }^{2}=.03$. The participants rated the evidentiary value of CCTV recordings higher $(M=7.19, S D=2.61)$ than the OV chip card $(M$ $=5.84, S D=2.58), F(1,83)=5.73, p=.019, \eta_{p}{ }^{2}=.07$, supporting the third hypothesis. The 
evidentiary values were therefore compared per item of physical evidence using pairwise comparisons.

When the physical evidence consisted of the OV chip card, an alibi without supportive evidence received the lowest score compared to the alibis with supportive evidence $(p<.001)$. No differences were observed between the types of supportive evidence $(p>.05)$, similar to the results in Experiment 1. Furthermore, the participants rated the alibis supported by knowledge and witness evidence as comparable in evidentiary value, supporting Hypothesis 1 a.

When the physical evidence consisted of CCTV recordings, an alibi without supportive evidence still obtained the lowest score compared to alibis supported with evidence $(p<.001)$, supporting the second hypothesis. However, the participants now rated the evidentiary value of witness and physical evidence higher than knowledge evidence ( $p$ $<.001)$, supporting Hypothesis 1b. Thus, knowledge evidence was considered to be weaker than witness and physical evidence, which leads to partial rejection of Hypothesis $1 \mathrm{~b}$. Furthermore, no difference was observed between witness and physical evidence $(p=.051)$ on the evidentiary value; therefore, Hypothesis 4 is rejected (see Table 3 for an overview).

Most participants found all types of evidence equally important (47.6\%), although a quarter of the participants $(25.0 \%)$ indicated that knowledge evidence was most important. A smaller proportion of the participants indicated that they viewed physical evidence $(17.9 \%)$ or witness evidence $(9.5 \%)$ as the most important to support an alibi. There were no differences between the participants who received the OV card or the CCTV recordings as physical evidence. 
Table 3

Mean scores (M) and Standard Deviation (SD) for the Alibi Believability Measure and the Evidence Scale Measure Displayed for the OV Chip Card and Video Recordings as Supportive Evidence $(N=85)$

\begin{tabular}{|c|c|c|c|c|c|c|}
\hline \multirow[b]{3}{*}{ Supportive evidence } & \multicolumn{4}{|c|}{ Item of physical evidence } & \multicolumn{2}{|c|}{ Average } \\
\hline & \multicolumn{2}{|c|}{ OV chip card } & \multicolumn{2}{|c|}{ Video recordings } & \multirow[b]{2}{*}{$M$} & \multirow[b]{2}{*}{$S D$} \\
\hline & $M$ & $S D$ & $M$ & $S D$ & & \\
\hline \multicolumn{7}{|l|}{ Believability measure } \\
\hline No evidence ${ }^{1}$ & 3.41 & 2.38 & 3.78 & 2.47 & 3.60 & 2.42 \\
\hline Witness evidence ${ }^{2}$ & 7.02 & 2.13 & 6.88 & 1.97 & 6.95 & 2.04 \\
\hline Physical evidence & 6.75 & 2.31 & 6.78 & 2.40 & 6.77 & 2.35 \\
\hline Knowledge evidence & 6.21 & 2.12 & 6.30 & 2.52 & 6.25 & 2.34 \\
\hline \multicolumn{7}{|l|}{ Evidentiary value } \\
\hline No evidence $^{1}$ & 1.80 & 1.62 & 1.96 & 1.82 & 1.88 & 1.72 \\
\hline Witness evidence & 5.95 & 2.46 & 6.00 & 2.41 & 5.97 & 2.42 \\
\hline Physical evidence $^{3}$ & 5.84 & 2.58 & 7.19 & 2.61 & 6.55 & 2.67 \\
\hline Knowledge evidence & 5.36 & 2.48 & 4.84 & 2.76 & 5.09 & 2.63 \\
\hline
\end{tabular}

Note: The dependent variable is displayed in boldface.

${ }^{1}$ : significant at $p<.001$ compared to the other forms of supportive evidence.

2: significant at $p=.028$ compared to knowledge evidence.

3: significant at $p<.001$ compared to knowledge evidence when the physical evidence consisted of the personal public transportation card.

\subsubsection{Discussion}

The aim of the second experiment was to determine if the atypical results in Experiment 1 could be explained by the selection of participants and/or the type of physical evidence that was presented. Although both items of strong physical evidence were equally believable, we found that CCTV recordings obtained a higher evidentiary value compared to the OV chip card. When the physical evidence consisted of the OV chip card, no differences were observed for the alibi evaluation compared to the types of supportive evidence, similar to the results in Experiment 1.

The results of this study show that the students' results are in line with the results in Experiment 1. Students also rated all types of evidence as equally believable. Yet, when the physical evidence consisted of another type of strong evidence, differences between the type of evidence were apparent. Hence, the fact that no differences are observed in the evaluation in Experiment 1 and in the present study when the OV chip card was presented 
can be explained by the selection of the physical evidence in both studies and is less likely due to the selection of participants. One could, however, argue that students are more familiar with public transport and the OV chip card than police detectives, which could have affected the results. As stated in Experiment 1, the role of police detectives is very important in the criminal pre-trial investigation. Depending on whether or not they consider the alibi to be believable, the police officers may invest more or less time and energy investigating the suspect's potential involvement in the alleged crime. By doing so, they influence further procedures. It is therefore important to determine how they evaluate knowledge evidence in relation to CCTV recordings. Therefore, as a final experiment, Experiment 2 was replicated using police detectives.

\subsection{EXPERIMENT 3}

The last study was designed to determine how police detectives would evaluate knowledge evidence compared to both types of physical evidence, witness evidence and no supportive evidence. For this experiment we expected, based on the findings in Experiments 1 and 2, that an alibi without supportive evidence would be the least believable and obtain the lowest evidentiary value (Hypothesis 1). Second, we expected that CCTV recordings would hold a higher evidentiary value compared to the OV chip card. In addition, we expected CCTV recordings to receive a higher evidentiary value than witness evidence, in line with the results of previous research (Hypothesis 3), although no difference was observed between witness and physical evidence in Experiment 2. Third, we expected knowledge evidence to be rated comparable to witness evidence on both measures when the physical evidence consisted of the OV chip card based on the results in Experiment 1 (Hypothesis 4). Furthermore, when the physical evidence consisted of CCTV recordings, we expected a lower evidentiary value for knowledge evidence than for witness evidence based on the results in Experiment 2 (Hypothesis 5). 
CHAPTER 4

\subsubsection{Method}

A total of 402 police detectives were asked to fill out the same questionnaires described in Experiment 2. The questionnaires were handed out to all of the police detectives at a national police conference in April 2014 in Almere, the Netherlands of whom 108 detectives filled out the questionnaire. Five participants had to be excluded as their answers were incomplete. Two additional participants were excluded for they reported to have never evaluated an alibi. The sample thus consisted of 101 police detectives. Fifty-eight participants filled out the questionnaire in which the OV chip card was presented as physical evidence; forty-three participants completed the questionnaire in which the physical evidence consisted of CCTV recordings. The two versions of the questionnaire were randomly distributed among the attendees, however, more people completed the questionnaire in which the OV chip card was reported as physical evidence. The participants' ages varied between 24 and 64 years $(M=42.44, S D=11.94)$, and on average they evaluated an alibi once a month or less (45.5\%) in their present job (see Table 4 for demographics). The $\alpha$ 's for the evidentiary value varied between .80 and 95 .

\subsubsection{Results}

The data were analysed using general linear model (GLM) repeated measures analyses for the alibi believability measure and the evidentiary value. The within-subjects factor was the supportive evidence, and the between-subjects factor consisted of the type of physical evidence (i.e., OV card or CCTV recordings).

For the believability measure, the assumption of sphericity was violated, and therefore the degrees of freedom were adjusted using the Huynh-Feldt correction $(\varepsilon=.97)$. 


\begin{tabular}{lc} 
Table 4 & \\
Participants Characteristics in Percentages & \\
\hline Sex & $50.5(50)$ \\
Male & $49.5(51)$ \\
$\quad$ Female & \\
Highest completed education & $0.0(0)$ \\
$\quad$ Elementary school & $23.8(24)$ \\
Secondary school & $25.7(26)$ \\
Intermediate Vocational Education & $50.5(51)$ \\
College or University & \\
Alibi evaluation in present job ${ }^{1}$ & $0.0(0)$ \\
$\quad$ Never & $50.0(46)$ \\
Less than once a month & $10.9(10)$ \\
Less than once a week & $27.2(25)$ \\
About once a week & $3.3(3)$ \\
Two to four times a week & $5.4(5)$ \\
About once a day & $2.2(2)$ \\
More than once a day & $1.1(1)$ \\
More than three times a day & \\
\hline Note: number of participants (n) are placed in parentheses; the dependant variable is \\
displayed in boldface.
\end{tabular}

\subsubsection{Believability measure}

Similar to the previous experiments, an alibi without supportive evidence was rated to be the least believable compared to those with supportive evidence, $F(2.91,287.74)=64.53$, $p<.001, \eta_{p}{ }^{2}=.40$. No other difference was observed between the types of supportive evidence in terms of believability, supporting Hypothesis 1 . However, the results of a oneway ANOVA revealed that participants rated the CCTV recordings as more believable physical evidence $(M=6.70 ; S D=2.12)$ than the OV chip card $(M=5.42 ; S D=2.11), F(1,99)$ $=9.02, p=.003$.

\subsubsection{Evidentiary value}

Depending on the type of physical evidence that was presented, the evidence was rated differently in evidentiary value: $F(3,297)=7.31, p<.001, \eta_{p}{ }^{2}=.07$. The video recordings obtained a higher evidentiary value $(M=6.92, S D=1.87)$ than the OV chip card $(M=4.65$, 
$S D=2.45), F(1,99)=25.86, p<.001, \eta_{p}{ }^{2}=.21$, supporting Hypothesis 2 . Again, regardless of which type of physical evidence was presented, all alibis supported with evidence obtained a higher score than those without supportive evidence $(p<.001)$. In contrast to Experiment 2, CCTV recordings received a higher score compared to knowledge evidence ( $p$ $=.001)$ and witness evidence $(p=.038)$, while no difference was observed between knowledge and witness evidence. In contrast, no differences were observed between the OV chip card and the other types of supportive evidence, supporting Hypotheses 3 and 4 but not Hypothesis 5. For an overview, see Table 5.

Table 5

Mean Scores (M) and Standard Deviation (SD) for the Alibi Believability Measure and the Evidence Scale Measure Displayed for the OV Chip Card and Video Recordings as Physical Evidence $(n=101)$

\begin{tabular}{|c|c|c|c|c|c|c|}
\hline \multirow[b]{3}{*}{ Supportive evidence } & \multicolumn{4}{|c|}{ Form of physical supportive evidence } & \multicolumn{2}{|c|}{ Average } \\
\hline & \multicolumn{2}{|c|}{ OV chip card } & \multicolumn{2}{|c|}{ Video recordings } & \multirow[b]{2}{*}{$M$} & \multirow[b]{2}{*}{$S D$} \\
\hline & $M$ & $S D$ & $M$ & $S D$ & & \\
\hline \multicolumn{7}{|l|}{ Believability measure } \\
\hline No evidence ${ }^{1}$ & 3.11 & 1.57 & 3.80 & 2.11 & 3.40 & 1.84 \\
\hline Witness evidence & 5.88 & 2.29 & 6.32 & 2.04 & 6.07 & 2.19 \\
\hline Physical evidence ${ }^{2}$ & 5.42 & 2.11 & 6.70 & 2.12 & 5.97 & 2.20 \\
\hline Knowledge evidence & 5.92 & 1.74 & 6.05 & 1.95 & 5.97 & 1.82 \\
\hline \multicolumn{7}{|l|}{ Evidentiary value } \\
\hline No evidence & 1.89 & 1.35 & 2.09 & 1.60 & 1.97 & 1.46 \\
\hline Witness evidence ${ }^{3}$ & 5.23 & 2.33 & 5.80 & 2.34 & 5.47 & 2.34 \\
\hline Physical evidence & 4.65 & 2.45 & 6.92 & 1.87 & 5.62 & 2.48 \\
\hline Knowledge evidence 4 & 4.94 & 2.07 & 5.38 & 2.08 & 5.13 & 2.08 \\
\hline
\end{tabular}

Note: the dependent variable is displayed in boldface.

1 : significant at $p<.001$ compared to the other forms of supportive evidence.

2: significant at $p=.003$ between the personal public transportation card and video recordings.

3: significant at $p=.038$ compared to physical evidence but only when it consisted of video recordings.

4: significant at $p=.001$ compared to physical evidence but only when it consisted of video recordings. 
Most participants found all types of evidence equally important for a believable alibi (55.5\%), although about one in three participants (33.0\%) indicated that knowledge evidence was most important. A smaller proportion of the participants indicated that they found physical evidence $(9.0 \%)$ or witness evidence $(3.0 \%)$ to be the most important to support an alibi. There were no differences between the participants who received the OV card or the CCTV recordings as physical evidence.

\subsubsection{Discussion}

In the third experiment, we found that the alibi evaluation by police officers differed depending on which physical evidence was presented. When the physical evidence consisted of the OV chip card, the physical evidence was evaluated in a similar manner to witness and knowledge evidence. However, when the physical evidence consisted of CCTV recordings, the physical evidence appeared to be more believable and obtained a higher evidentiary value score than the OV chip card. Knowledge evidence was equally believable as witness and both items of physical evidence. In addition, knowledge evidence obtained a similar evidentiary value as witness evidence when the OV chip card was reported. We can conclude that the evaluation of alibis is also affected by which item of physical evidence is presented and that knowledge evidence is a relevant new type of supportive evidence for alibis. Both items of strong physical evidence used in the experiment meet the criteria for strong evidence, yet are evaluated differently.

\subsection{GENERAL DISCUSSION}

In the experiments, laypersons and police detectives rated knowledge evidence to be equally believable as witness and physical evidence. Both students and police detectives evaluated knowledge evidence similarly in regard to its evidentiary value compared to the OV chip card as physical evidence. The results offer a valuable addition of the knowledge evidence to the alibi literature. The results suggest that the Olson and Wells (2004) 
taxonomy could be expanded to include the new type of evidence in addition to witness and physical evidence.

If knowledge evidence is added to the taxonomy, criteria have to be established to determine the relative strength of knowledge evidence. For physical evidence, the strength is determined by the ease by which it can be fabricated or obtained from someone else. For knowledge evidence, the strength could perhaps be determined based on the uniqueness of the knowledge (i.e., how easily the suspect could have obtained the knowledge from another source). It can be argued that having knowledge of a well-known movie's plot like 'Titanic' can be expected to be weaker evidence than the knowledge of a new movie that was released a week ago in the theatre. That assumption should be tested in future studies to determine if knowledge evidence could be added to the existing alibi taxonomy (Olson \& Charman, 2012; Olson \& Wells, 2004).

Besides adjusting the taxonomy by adding knowledge evidence, the taxonomy could possibly be improved by revising the criteria to determine the strength of physical evidence. In the present studies, all types of supportive evidence were chosen based on the strongest items of evidence according to the taxonomy (Olson \& Wells, 2004), using the criteria of Olson \& Charman (2012). According to the criteria, strong physical evidence “[...] contains time and place information and could be linked to the specific participant (such as a time card from an employer, a credit card receipt, or an airline ticket stub)" (Olson \& Charman, 2012, p. 9). To our surprise, the OV chip card records are weaker supportive evidence than CCTV recordings, although both items meet the academic criteria for strong physical evidence. The police detectives argued that the records of the OV chip card do not necessarily confirm that the suspect used that card. A suspect's friend could have used the card to provide the suspect with evidence for the false alibi.

The police detectives' argument also applies to the examples of strong supportive evidence provided by Olson and Charman (2012). The purchases registered on the suspect's credit card on the day and time of the alleged crime do not necessarily imply that the suspect himself used the card at that moment. At present, physical evidence is classified into three categories: strong; moderate; and weak. The OV chip card records seem to fall between strong and moderate evidence. 
Furthermore, there is little variation in the presented items of physical evidence in alibi evaluation research to date. In most studies, CCTV recordings are used as strong physical supportive evidence (e.g., Allison \& Brimacombe, 2010; Olson \& Wells, 2004). In only a few studies the presented physical evidence consisted of weaker evidence, such as a receipt or a time-stamped movie ticket (e.g., Jung et al., 2013; Pozzulo et al., 2015). In addition, there is a lack of studies in which a combination of evidence is reported (e.g., Dahl, Brimacombe, \& Lindsay, 2009; Hosch, Culhane, Jolly, Chavez, \& Shaw, 2011; Sargent \& Bradfield, 2004), although in reality one-third of non-offenders offer a combination of evidence when asked for their alibi (Nieuwkamp et al., 2017). Given the impact of physical evidence on the evaluation of an alibi (Olson \& Wells, 2004), we suggest conducting more research on the evaluation of different items of physical evidence.

\subsubsection{Further Research}

It should be noted that the students in Experiment 2 evaluated CCTV recordings as equally believable as the OV chip card, while the police detectives considered the CCTV recordings to be more believable than the OV chip card. It could therefore be concluded that perhaps the criteria to determine the strength of the supportive evidence only applies for students and not for police detectives. It raises doubt as to how valid the criteria of the taxonomy are for determining the strength of physical evidence in practice. As stated above, most of the research on alibis has been conducted using students as participants, although recent results suggest that alibi evaluation differs between police detectives and students (Culhane \& Hosch, 2012; Dysart \& Strange, 2012; Eastwood et al., 2016). The results of the present experiments add to those recent findings. We therefore call for more alibi research involving police detectives as participants in order to better understand how they evaluate alibis in practice, especially because they are the first to encounter and evaluate the alibis in practice (Culhane \& Hosch, 2012). Taking these reflections into account, further research should focus on adapting the criteria for determining the strength of physical evidence to correspond to the way in which alibis are evaluated in practice. 


\subsubsection{Limitations}

In the present three experiments, the same methodology was applied in which the four suspects reported the same alibi, but the alibis were supported with a different type of supportive evidence or no supportive evidence at all. A limitation could therefore be that the alibis were too similar, which could have affected the alibi evaluation. We tried to minimise that limitation by randomising the reported alibis among all participants. In addition, because we wanted to determine the added value of knowledge evidence, our experiments were inspired by a study by Olson and Wells (2004) in which the alibis were kept constant and only the supportive evidence varied among the suspects.

\subsubsection{Conclusion}

We found that the taxonomy does not align with how alibis are evaluated in practice because certain items of physical evidence police detectives come across in practice do not fully fit today's taxonomy. In addition, the set criteria to determine the strength of evidence do not align with how alibis are evaluated in practice. This raises doubts about the applicability of the alibi taxonomy in practice and how applicable our knowledge is to the field. Therefore, more refinement is needed to determine how various items of physical evidence are evaluated both in the lab and in practice. Furthermore, our results demonstrate the value of adding knowledge evidence to the alibi evaluation literature. Jeremy Bentham once stated: "The field of evidence is no other than the field of knowledge" (Bentham, 1843). Based on the results of these experiments, we can conclude that the opposite also seems to be true for the evaluation of alibis: the field of knowledge is no other than the field of evidence. 
KNOWLEDGE AS SUPPORTIVE ALIBI EVIDENCE

\subsection{REFERENCES}

Allison, M., \& Brimacombe, C. (2010). Alibi believability: The effect of prior convictions and judicial instructions. Journal of Applied Social Psychology, 40, 1054-1084. doi: 10.1111/j.1559-1816.2010.00610.x.

Bentham, J. (1843). The Works of Jeremy Bentham. [Vol 6]. Retrieved from http://oll.libertyfund.org/titles/1923-If0872-06_label_187.

Crozier, W. E., Strange, D., \& Loftus, E. F. (2017). Memory errors in alibi generation: How an alibi can turn agaist us. Behavioral Sciences and the Law, 35, 6-17. doi:10.1002/bsl.2273

Culhane, S. E., \& Hosch, H. M. (2004). An alibi witness's influence on mock jurors' verdicts. Journal of Applied Social Psychology, 34, 1604-1616. doi: 10.1111/j.15591816.2004.tb02789.x.

Culhane, S. E., \& Hosch, H. M. (2012). Changed alibis: Current law enforcement, future law enforcement, and layperson reactions. Criminal Justice and Behavior, 39, 958-977. doi: 10.1177/0093854812438185.

Culhane, S. E., Kehn, A., Horgan, A. J., Meissner, C. A., Hosch, H. M., \& Wodahl, E. J. (2013). Generation and detection of true and false alibi statements. Psychiatry, Psychology and Law, 20, 619-638. doi: 10.1080/13218719.2012.729018.

Dahl, L. C., Brimacombe, C. A., \& Lindsay, D. S. (2009). Investigating investigators: How presentation order influences participant-investigators' interpretations of eyewitness identification and alibi evidence. Law and Human Behavior, 33, 368380. doi: 10.1007/s10979-008-9151-y.

Dysart, J. E., \& Strange, D. (2012). Beliefs about alibis and alibi investigations: A survey of law enforcement. Psychology, Crime and Law, 18, 11-25. doi: 10.1080/1068316X.2011.562867.

Eastwood, J., Snook, B., \& Au, D. (2016). Safety in numbers: A policy-capturing study of the alibi assessment process. Applied Cognitive Psychology, 260-269. doi: 10.1002/acp.3200.

Haan, B. (2009). De Deventer Moordzaak. Het complot ontrafeld [The Deventer murder case. The conspiracy unraveled]. Amsterdam: Nieuw Amsterdam Uitgevers.

Hosch, H. M., Culhane, S. E., Jolly, K. W., Chavez, R. M., \& Shaw, L. H. (2011). Effects of an alibi witness's relationship to the defendant on mock jurors' judgments. Law and Human Behavior, 35, 127-142. doi: 10.1007/s10979-010-9225-5.

Jung, S., Allison, M., \& Bohn, L. (2013). Legal decision-making on crimes involving an alibi. Applied Psychology in Criminal Justice, 9, 45-58. doi: 10.1037/t04698-000. 
CHAPTER 4

Kassin, S. M., Goldstein, C. C., \& Savitsky, K. (2003). Behavioral confirmation in the interrogation room: On the dangers of presuming guilt. Law and Human Behavior, 27, 187-203. doi:10.1023/A:1022599230598.

Luria, R. E. (1975). The validity and reliability of the visual analogue mood scale. Journal of Psychiatric Research, 12, 51-57.

Meissner, C. A., \& Kassin, S. (2002). "He's guilty!": Investigator bias in judgments of truth and deception. Law and Human Behavior, 26, 469-480. doi:10.1023/A:1020278620751.

Nieuwkamp, R., Horselenberg, R., \& Van Koppen, P. J. (2017). The illusion of the perfect alibi: Establishing the base rate of non-offenders' alibis. Journal of Investigative Psychology and Offender Profiling, 14, 23-42. doi:10.1002/jip.1470.

Olson, E. A., \& Charman, S. D. (2012). 'But can you prove it?' - Examining the quality of innocent suspects' alibis. Psychology, Crime and Law, 18, 453-741. doi: 10.1080/1068316x.2010.505567.

Olson, E. A., \& Wells, G. L. (2004). What makes a good alibi? A proposed taxonomy. Law and Human Behavior, 28, 157-176. doi: 10.1023/B: LAHU.0000022320.47112.d3.

Pozzulo, J. D., Pettalia, J. L., Dempsey, J. L., \& Gooden, A. (2015). Juvenile offenders on trial: Does alibi corroboration evidence and defendant age interact to influence jurors' perceptions and verdicts? Psychiatry, Psychology and Law, 22, 224-234. doi:10.1080/13218719.2014.937518.

Sargent, M. J., \& Bradfield, A. L. (2004). Race and information processing in criminal trials: Does the defendant's race affect how the facts are evaluated? Personality and Social Psychology Bulletin, 30, 995-1008. doi: 10.1177/0146167204265741.

Sauerland, M., Mehlkoph, S., Krix, A. C., \& Sagana, A. (2016). Deceiving suspects about the content of their alibis: Consequences for truthful and untruthful suspects. Journal of Forensic Practice, 18, 143-154. doi: 10.1108/JFP-10- 2014-0042

Strange, D., Dysart, J. E., \& Loftus, E. F. (2014). Why errors in alibis are not necessarily evidence of guilt. Zeitschrift für Psychologie, 222, 82-89. doi:10.1027/21512604/a000169.

Sullivan, T. P. (1971). Presentation of the defense. Journal of Criminal Law, Criminology, and Police Science, 62, 153-172.

Van Koppen, M. V., \& Van Koppen, P. J. (2010). Alibi's [Alibis]. In P. J. Van Koppen, H. Merckelbach, M. Jelicic, \& J. W. De Keijser (Eds.), Reizen met mijn rechter: Psychologie van het Recht [Traveling with my judge: Psychology of the Law] (pp. 439-448). Deventer: Kluwer.

Vrij, A. (2008). Detecting lies and deceit: Pitfalls and opportunities. Chichester: John Wiley. 


5

A LIE AND A MISTRESS: ON INCREASING THE BELIEVABILITY OF YOUR ALIBI

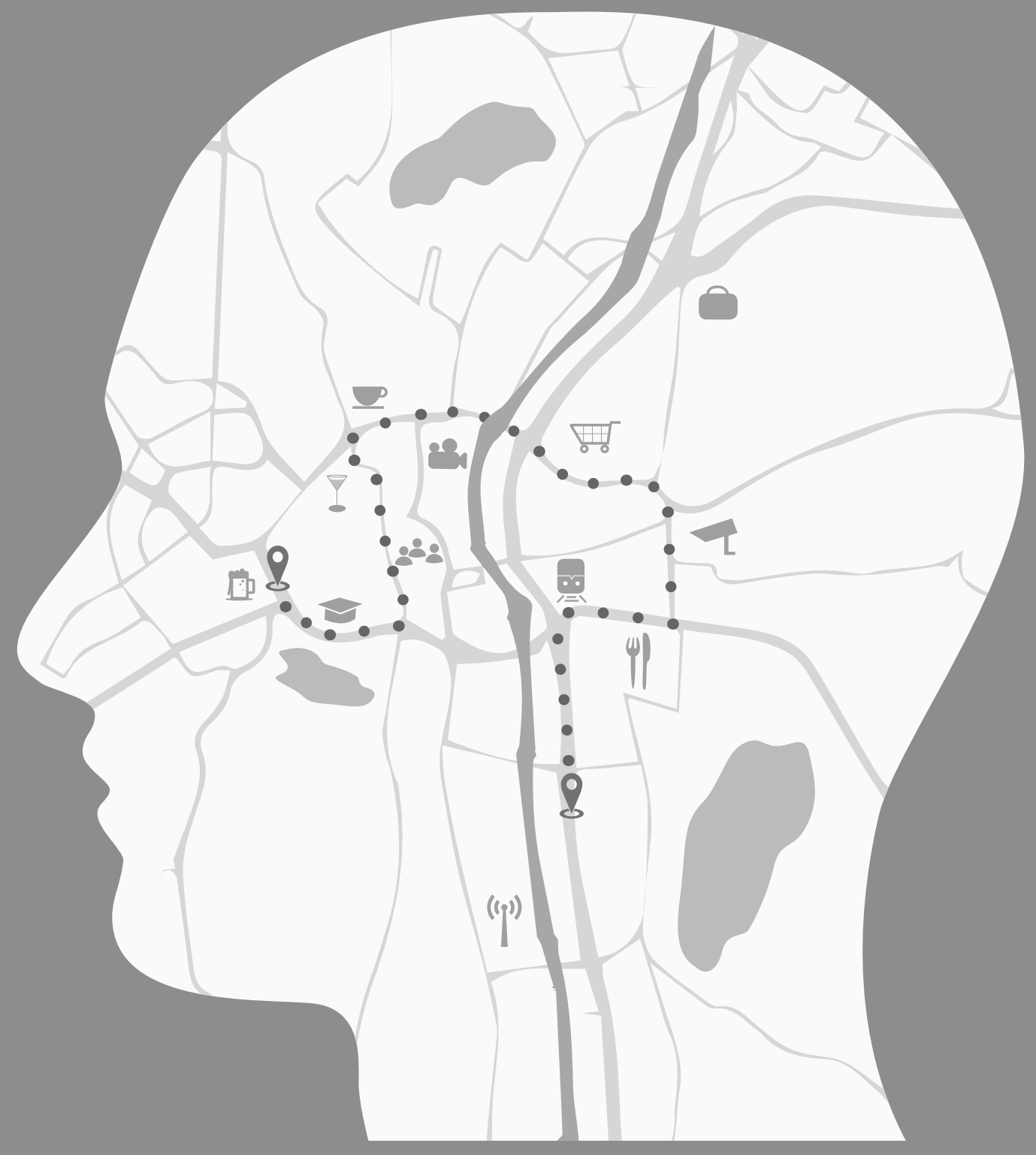

This chapter has been published as:

Nieuwkamp, R., Horselenberg, R., \& Van Koppen, P. J. (2016). A lie and a mistress: On increasing the believability of your alibi. Psychiatry, Psychology and Law, 23, 733-745. doi: 10.1080/13218719.2016.1142934 



\begin{abstract}
The present study was designed to assess whether or not the presentation method and the salaciousness of an alibi affect its evaluation. Community participants $(n=150)$ were asked to evaluate a salacious or a non-salacious alibi of a crime suspect. The alibi was either presented immediately after arrest by the suspect or was changed after the initial alibi turned out to be incorrect. The incorrect alibi was due to either a misrecollection or a deliberate lie. We found that when the initial alibi was changed into a salacious alibi, the believability increased. That effect was larger when the initial alibi was a lie than when it was a misrecollection. The results of the present study demonstrate that, contrary to common belief, a changed salacious alibi can lead to an increase of the alibi believability.
\end{abstract}

Keywords: alibi believability; changed alibis; salaciousness 
CHAPTER 5

\subsection{INTRODUCTION}

An alibi is the claim that a suspect could not have committed an alleged crime since he or she was somewhere else at the time it took place (Olson \& Wells, 2004). Most of the research conducted on alibis to date has addressed the evaluation of suspects' alibis. In such studies, undergraduate students are asked to take on the role of a juror and rate the guilt of a defendant who presented an alibi and potential supportive evidence for it (Allison \& Brimacombe, 2010; Allison, Mathews, \& Michael, 2012; Culhane \& Hosch, 2004; Hosch, Culhane, Jolly, Chavez, \& Shaw, 2011; Jung, Allison, \& Bohn, 2013; Lindsay, Lim, \& Marando, 1986; McAllister \& Bregman, 1989; Sargent \& Bradfield, 2004). The results of these studies are consistent with the taxonomy of Olson and Wells (2004), showing that the stronger the supportive evidence, the less guilty the participants rated the defendant. It was first thought that only the strength of the supportive evidence was of importance in determining alibi believability (Olson \& Wells, 2004). However, it has become clear that also other factors can affect alibi believability, such as the context in which the alibi is first presented (Sommers \& Douglass, 2007), the race of the defendant (Sargent \& Bradfield, 2004), prior convictions of the defendant (Allison \& Brimacombe, 2010), whether or not the presented alibi is salacious (Allison et al., 2012; Allison, Jung, Sweeney, \& Culhane, 2014; Jung et al., 2013), and whether or not the presented alibi remains unchanged (Culhane \& Hosch, 2012). When an alibi or the supportive evidence for it is changed, this leads to a decrease in alibi believability, even when the supportive evidence becomes stronger according to the taxonomy of Olson and Wells (2004), compared to when the strength of the evidence is maintained (Culhane \& Hosch, 2012).

We can distinguish two phases that precede the evaluation of an alibi: presentation and validation with supporting evidence. Presentation refers to the suspect's statement in which it is stated that he or she could not have committed the crime on the basis of having been somewhere else at the time it was committed (Burke, Turtle, \& Olson, 2007). The suspect can subsequently validate the alibi by reporting supporting evidence for his or her alibi. The supportive evidence can consist of three forms of supportive evidence: witness, physical, or knowledge evidence (Nieuwkamp, Horselenberg, \& van Koppen, 2017b). From 
the results of alibi presentation and validation studies we know that about $95 \%$ of people can present an alibi and about $90 \%$ of them can report supportive evidence for it (Culhane et al., 2013; Culhane, Hosch, \& Kehn, 2008; Nieuwkamp, Horselenberg, \& van Koppen, 2017a; Olson \& Charman, 2012). The results of these studies show that witness evidence (about $80 \%$ ) is much more common than physical evidence (about 25\%). The impact of the believability of physical evidence is larger than the impact of witness evidence (Olson \& Wells, 2004), meaning that innocent suspects can more often present supportive alibi evidence that is less likely to be believed than evidence that is more likely to be believed. In fact, the presence of supportive alibi evidence depends upon the day, timeframe and presented alibi, so therefore the base rate of alibis and supportive evidence should also be taken into account to determine its believability (Nieuwkamp et al., 2017a).

\subsubsection{Changed Alibis}

Laypeople, undergraduate students, and police officers believe that a true alibi should remain consistent over time (Burke et al., 2007; Culhane \& Hosch, 2012; Dysart \& Strange, 2012). However, in several cases an innocent man has been convicted merely based upon reporting a false alibi due to misrecollection. For instance, Ronald Cotton reported a false alibi due to misrecollection for the sexual assault on Jennifer Thompson (ThompsonCannino, Cotton, \& Torneo, 2009); the alibi he presented was truthful, but he described what he was doing on a day different from the day on which the sexual assault had taken place. This mistake, combined with multiple errors in the eyewitness identification, led to a wrongful conviction.

Not only case studies but also the results of empirical studies suggest that alibis or the supportive evidence for them from innocent people are more often changed than we might think (Olson \& Charman, 2012). Olson and Charman (2012) found that when participants were asked to provide an alibi in the distant past, a change in the alibi or the supportive evidence was more likely to occur (about $24 \%$ of the time) than in the near past (about 4\%). People are quite accurate in determining what they were doing three weeks ago but less accurate when they did it that particular day (Strange, Dysart, \& 
Loftus, 2014). Strange et al. (2014) have therefore claimed that inconsistencies in alibis are the norm rather than the exception. Their claim is supported by the finding of Leins and Charman (2013), who found that when innocent suspects present an alibi, they heavily rely on schemas (i.e., what they would normally be doing at the time and day for which they are asked to present an alibi) rather than relying on their actual memory.

In addition, we know that police interrogations are often quite stressful for suspects (Guyll et al., 2013) and that the retrieval of information can be impaired under stress (Smeets, Otgaar, Candel, \& Wolf, 2008). An innocent suspect may therefore report a schema-consistent yet incorrect alibi. Also, an innocent suspect may just have no memory of what he or she was doing, simply because of being unaware that a crime was committed at that particular time (Kassam, Gilbert, Swencionis, \& Wilson, 2009).

If a suspect reports an incorrect alibi and changes his or her alibi or the supportive evidence, it always results in a decrease in alibi believability (Culhane \& Hosch, 2012). The reasons why a suspect changes an alibi can be diverse. The suspect can simply be mistaken due to relying on schemas rather than memory or the suspect can be lying. To date, research has not been conducted on whether or not the reason why a suspect changes an alibi can affect the evaluation of the alibi. The vast majority of senior law enforcement personnel (about $80 \%$ ) believe that if an alibi changes, the suspect must have been lying previously rather than simply being mistaken (Dysart \& Strange, 2012).

\subsubsection{Salacious Alibis}

Although it was thought that the alibi story does not influence its believability, it was recently found that the salaciousness of the presented alibi does have an effect. Allison et al. (2012) found that a salacious alibi (watching a pornographic movie) was rated as being more believable compared to a non-salacious alibi (watching a normal movie). In a followup study, however, the effect of the alibi salaciousness on believability was not replicated (Allison et al., 2014). In the second study, the suspect was accused of sexually assaulting a woman, instead of being accused of a robbery, a crime that is typically described in alibi research (Allison \& Brimacombe, 2010; Allison et al., 2012; Culhane \& Hosch, 2004). Thus, 
in the 2014 study both the presented alibi and the mock crime were salacious. The authors noted that the type of mock crime chosen might explain the inconsistency between the findings of both studies. Differences in alibi believability can therefore be explained by contextual factors (e.g., the type of crime) that affect alibi evaluation (Sommers \& Douglass, 2007). However, in another study, the type of mock crime (i.e., sexual assault, physical assault or theft) did not affect alibi believability when a salacious alibi was presented (Jung et al., 2013). To date, it therefore remains unclear why a salacious alibi might sometimes increase alibi believability.

In the current study the participants were presented with either a salacious or a non-salacious alibi. These alibis were either presented immediately (unchanged) or presented after the suspect provided an incorrect alibi (changed). Besides an honest mistake as a reason for changing the initial alibi (Culhane \& Hosch, 2012), we have added a lie as a second reason why the initial alibi was incorrect. A lie was chosen because most of the senior law enforcement personnel believe that a change in the suspect's alibi means that the suspect was lying before (Dysart \& Strange, 2012). We expected that the unchanged salacious alibi would be rated as more believable compared to the unchanged non-salacious alibi (Allison et al., 2012). When the alibi was changed, we expected the changed alibi to be less believable, regardless of the reason why it was changed, compared to when the alibi was unchanged. We had no prior expectations for the interactions between salaciousness and the reason why the alibi was changed in terms of alibi believability.

\subsection{METHOD}

\subsubsection{Participants}

A total of 150 participants ( 37 men) from a community sample were recruited for the present study. Of these, 100 participants filled out an online version of the questionnaire using Survey Gizmo (http://www.surveygizmo.com). The participants who filled out the 
online version were friends and acquaintances of the first author. They were in turn asked to send the link to the questionnaire to their family, friends and colleagues.

To check for a possible selection bias of participants, a second group of 50 participants from the community was asked to fill out a paper version of the questionnaire. These participants were recruited at a dance school in Belgium. No differences were observed between the two groups of participants and they were therefore combined.

The participants were between 18 and 74 years old $(M=31.01, S D=12.9)$. Most of them were employed and had a partner with whom they were living (for demographics, see Table 1). The participants in our sample were most often well-educated compared to the average Dutch and Belgian citizen. In our sample, $75.3 \%$ of the participants had achieved a bachelor degree either from college or university, while only $28.3 \%$ of the Dutch population has such a degree (Centraal Bureau voor de Statistiek, 2013) or 32.7\% of the Belgian population (Federale Overheidsdienst Werkgelegenheid, Arbeid en Sociaal Overleg, 2012).

Table 1

Participants Characteristics $(n=150)$

\begin{tabular}{|c|c|c|}
\hline & $\%$ & \\
\hline \multicolumn{3}{|l|}{ Sex } \\
\hline Male & 24.7 & 37 \\
\hline Female & 75.3 & 113 \\
\hline \multicolumn{3}{|l|}{ Relationship status } \\
\hline Single & 30.0 & 45 \\
\hline Partner, not living together & 18.0 & 27 \\
\hline Partner, living together & 52.0 & 78 \\
\hline \multicolumn{3}{|l|}{ Employment status ${ }^{1}$} \\
\hline Unemployed & 5.4 & 8 \\
\hline Student & 25.5 & 38 \\
\hline Employed & 69.1 & 103 \\
\hline \multicolumn{3}{|l|}{ Highest completed education } \\
\hline Elementary school & 0.7 & 1 \\
\hline Secondary school & 24.0 & 36 \\
\hline Intermediate vocational education & 0 & 0 \\
\hline College or university & 75.3 & 113 \\
\hline
\end{tabular}

Note: ${ }^{1}$ : there was one missing value for this characteristic, the valid percentages are displayed. 


\subsubsection{Research Design}

The design of the present study consisted of a 2 (salacious, non-salacious) $\times 3$ (immediate, lied before, mistaken before) mixed factorial design. The participants were randomly assigned to one of the six conditions.

The participants who were asked to evaluate the suspect's changed alibi were first presented with the initial, incorrect alibi. After they had evaluated the incorrect alibi, they were asked to evaluate the second alibi presented by the suspect. They then read the same salacious or non-salacious alibi as used with the immediate group.

\subsubsection{Materials}

At the beginning of the questionnaire the participants read an informed consent form. After the participants agreed to fill out the questionnaire, they were asked five demographic questions: gender, year of birth, relational status, employment status, and level of education. The participants read a case vignette of a mock crime describing that last Monday there was a burglary at a restaurant around 10:30 PM. Because Monday is the closing day of the restaurant, the revenues from the weekend (€5000) were stolen. One of the suspects was Mark, aged 28, who lived nearby with his wife and two children.

The salacious alibi was similar to the salacious alibi presented by Jung et al. (2013); the suspect was at a hotel with his mistress. In the present study, both the salacious and non-salacious alibis could be supported by a witness: the suspect's cousin. In the salacious alibi, the suspect said that he bumped into his cousin in the hotel lobby; in the non-salacious alibi, the suspect said he was helping his cousin to move out of his apartment.

The participants were then asked to evaluate the alibi on four dependent variables: 1) believability; 2) strength of the supportive evidence; 3) the degree to which the alibi sup ported the suspect's claim of innocence; and 4) how easy the alibi would have been to fabricate. The participants were asked to score these aspects using a $10 \mathrm{~cm}$ Visual Analogue Scale (VAS) (Luria, 1975). The VAS had two labels at the beginning and the end of the bar. The label at the beginning had the lowest value (for example, extremely unbelievable) and 
the label at the end had the highest value (for example, extremely believable). For the online version, a slider of $10 \mathrm{~cm}$ was used with the same labels.

In the remaining four conditions the participants were asked to rate two alibis. The suspect initially and incorrectly claimed that he had been working that evening and had left work at about 9:00 PM. He said that the records of his punch card would show the time at which he left work. The police investigation, however, showed that the exit time registered on the card was 7:30 PM rather than 9:00 PM. With that information, the participants were asked to evaluate the incorrect alibi and the supportive evidence on the same four dependent variables.

On a new page, the participants in these four conditions read that the suspect was questioned for a second time about the crime. In a second interrogation, the suspect was confronted with the results of the police investigation. Depending on the condition, the suspect either then said he then realized that he had made a mistake or the suspect admitted that he had lied about his initial alibi. He then presented either a salacious or nonsalacious alibi identical to those described above.

After the participants read the second alibi, they were asked to evaluate the changed alibi on the same four dependent variables. Next, all the participants were asked in an open-ended question if they would ask for additional evidence in order to believe the suspect's changed alibi and, if so, what kind of supportive evidence they would require. Lastly, they were thanked and dismissed. The participants could give their email addresses to receive the results after the data analysis.

\subsection{RESULTS}

All the analyses were conducted with a criterion for significance that was set at $\alpha=.05$ and Bonferroni corrections were applied for multiple testing. 


\subsubsection{Immediate Salacious and Non-salacious Alibis}

The answers of the participants who read the salacious or non-salacious alibi immediately were analysed using a univariate analysis of variance (ANOVA) for each dependent variable. For the four analyses only the alibi believability was rated differently between the two conditions: $\left(F(1,48)=12.17, p=.001\right.$, partial $\left.\eta^{2}=.20\right)$. Contrary to expectations, a nonsalacious alibi was rated as being more believable $(M=5.62 ; S D=1.88)$ than the salacious alibi $(M=3.73 ; S D=1.95)$. No differences between the groups were observed for their demographics.

\subsubsection{Changed Salacious and Non-salacious Alibis}

The answers of the remaining four groups of participants, who read a changed salacious or non-salacious alibi, were analysed using a repeated measures ANOVA. The results on the dependent variables were tested in the model over time in combination with the two independent variables: the salaciousness of the alibi and why the initial alibi was changed.

An interaction was observed between the believability measures and the salaciousness of the alibi over time: $F(1,96)=5.67, p=.019$, partial $\eta^{2}=.06$. The alibi believability increased over time depending on the salaciousness of the alibi. Therefore the simple effects were analysed by reference to the level of the salaciousness of the alibi over time. These analyses revealed that when a salacious alibi was presented, the alibi believability increased over time, $F(1,96)=13.36, p<.001$, partial $\eta^{2}=.12$. When a nonsalacious alibi was presented, the alibi believability did not change statistically. The interaction between the salaciousness and the presentation method was not statistically significant over time $(p=.084)$. A main effect was found for why the initial alibi was changed: $F(1,96)=5.35, p=.023$, partial $\eta^{2}=.05$. An alibi that was changed because of a lie was rated as being more believable $(M=3.92, S D=2.30)$ compared to when the alibi was a misrecollection ( $M=3.09, S D=2.73$; see Table 2 for an overview of the mean scores).

An interaction was observed between the perceived strength of the supportive evidence and the reason why the initial alibi was changed over time: $F(1,96)=5.72, p=$ 
.019 , partial $\eta^{2}=.06$. The perceived strength of the supportive evidence diminished over time depending on why the initial alibi was changed. Therefore the simple effects were analysed per level of why the initial alibi was changed over time. These analyses showed that the impact of the decline was greater when the initial alibi was a misrecollection $(F(1$, $96)=30.03, p<.001$, partial $\left.\eta^{2}=.24\right)$ compared to when the alibi presented was a lie $(F(1$, $96)=4.40, p=.039$, partial $\left.\eta^{2}=.04\right)$. In addition, a main effect was found for the salaciousness of the alibi: $F(1,96)=15.35, p<.001$, partial $\eta^{2}=.14$. The supportive evidence for a salacious alibi was rated as being to be stronger $(M=4.78, S D=2.53)$ compared to when the alibi was non-salacious $(M=3.39, S D=2.70)$.

An interaction was observed between the degree to which the alibi contributed to the suspect's claim of innocence measures and the salaciousness of the alibi over time: $F(1$, $96)=4.70, p=.033$, partial .05. The contribution to the suspect's claim of innocence increased over time depending on whether or not the presented alibi was salacious. Therefore the simple effects were analysed per level of the alibi salaciousness over time. These results show that the contribution only increased for a salacious alibi over time, $F(1$, $96)=6.55, p=.012$, partial $\eta^{2}=.06$. When the alibi was non-salacious, the contribution did not become larger. No other effects were observed.

The alibi's ease of fabrication decreased over time regardless of the salaciousness or the reason why the alibi was changed: $F(1,96)=12.23, p=.001$, partial $\eta^{2}=.12$. No other effects were observed. See Table 2 for an overview of all the scores for each dependent variable.

\subsubsection{The Influence of the Presentation Method and Salaciousness on Alibi Believability}

The possible interactions of both independent variables (presentation method and alibi salaciousness) were tested on the dependent variables, although the participants who read the alibi immediately evaluated fewer alibis than the other participants. The results were therefore analysed per level of the presentation method. The salacious and non-salacious alibis were identical for all participants regardless of the presentation method. The 
salaciousness and the presentation method (i.e., immediate, lied before, mistaken before) were therefore included in a univariate ANOVA for each of the dependent variables.

Table 2

Mean Scores (M) and Standard Deviations (SD) on Time 1 and 2 ( $n=100)$

\begin{tabular}{|c|c|c|c|c|c|c|c|c|}
\hline \multirow{4}{*}{ Presentation Method } & \multicolumn{4}{|c|}{ Time 1} & \multicolumn{4}{|c|}{ Time 2} \\
\hline & \multicolumn{8}{|c|}{ Salaciousness } \\
\hline & \multicolumn{2}{|c|}{ Non-salacious } & \multicolumn{2}{|c|}{ Salacious } & \multicolumn{2}{|c|}{ Non-salacious } & \multicolumn{2}{|c|}{ Salacious } \\
\hline & $M$ & $S D$ & $M$ & $S D$ & $M$ & $S D$ & $M$ & $S D$ \\
\hline \multicolumn{9}{|l|}{ Believability } \\
\hline Mistaken before & 3.24 & 2.54 & 2.06 & 1.47 & 2.84 & 1.94 & 4.22 & 2.78 \\
\hline Lied before & 2.69 & 2.56 & 4.31 & 2.76 & 3.34 & 1.95 & 5.35 & 2.61 \\
\hline Average & 2.96 & 2.54 & 3.19 & 2.47 & 3.09 & 1.94 & 4.78 & 2.73 \\
\hline \multicolumn{9}{|c|}{ Strength of the evidence } \\
\hline Mistaken before & 4.82 & 2.85 & 6.29 & 2.53 & 2.51 & 2.03 & 2.87 & 2.12 \\
\hline Lied before & 3.30 & 3.12 & 5.93 & 2.80 & 2.94 & 2.39 & 4.10 & 2.57 \\
\hline Average & 4.06 & 3.06 & 6.11 & 2.65 & 2.72 & 2.21 & 3.48 & 2.41 \\
\hline \multicolumn{9}{|l|}{$\begin{array}{l}\text { Contribution to claim of } \\
\text { innocence }\end{array}$} \\
\hline Mistaken before & 3.52 & 2.39 & 1.88 & 1.50 & 2.66 & 2.11 & 3.03 & 2.54 \\
\hline Lied before & 2.32 & 1.83 & 3.40 & 2.73 & 2.76 & 1.82 & 4.30 & 2.48 \\
\hline Average & 2.92 & 2.20 & 2.61 & 2.32 & 2.71 & 1.95 & 3.67 & 2.51 \\
\hline \multicolumn{9}{|l|}{ Ease of fabrication } \\
\hline Mistaken before & 3.92 & 2.98 & 3.34 & 2.82 & 2.73 & 2.92 & 1.92 & 1.97 \\
\hline Lied before & 3.30 & 2.47 & 3.86 & 2.52 & 1.50 & 1.39 & 3.72 & 3.33 \\
\hline Average & 3.61 & 2.73 & 3.60 & 2.66 & 2.11 & 2.35 & 2.82 & 2.86 \\
\hline
\end{tabular}

Note: the dependent variables are displayed in boldface.

For the alibi believability, an interaction was observed between the presentation method and the salaciousness of the alibi, $F(2,144)=11.17, p<.001$, partial $\eta^{2}=.13$, so the simple effects were analysed per level of presentation method because it was not identical for all participants. For all three levels of presentation method, statistically significant differences exist for the alibi believability depending upon the salaciousness of the alibi: immediate, $F$ $(1,144)=9.09, p=.003$, partial $\eta^{2}=.06$; mistaken before, $F(1,144)=4.83, p=.030$, partial $\eta^{2}=.03$; and change because of a lie: $F(1,144)=10.32, p=.002$, partial $\eta^{2}=.07$. As discussed above, when the alibi was presented immediately the non-salacious alibi was rated as being more believable than the salacious alibi. When the first alibi was a misrecollection, the 
salacious alibi was rated as being more believable $(M=4.22, S D=2.78)$ than the nonsalacious alibi $(M=2.84, S D=1.94)$. When the alibi was a lie, the salacious alibi was rated as being more believable $(M=5.35, S D=2.61)$ than the non-salacious alibi $(M=3.34, S D=$ 1.95). See Table 3 and Figure 1 for an overview

For the strength of the evidence and the alibi's contribution to the suspect's claim of innocence, no differences were observed among all the participants. For the alibi's ease of fabrication, an interaction was observed between the presentation method and the alibi salaciousness: $F(2,133)=5.13, p=.007$, partial $\eta^{2}=.07^{3}$. Therefore the simple effects were analysed per level of presentation method. Only when the initial alibi was a lie were differences observed for this aspect, $F(1,133)=10.08, p=.002$, partial $\eta^{2}=.07$. When the alibi was salacious it was rated as being easier to fabricate $(M=3.72, S D=3.33)$ than the non-salacious alibi $(M=1.50, S D=1.39$; see Figure 2$)$.

\footnotetext{
3 The ease with which the alibi could be fabricated was answered by 39 out of the 50 participants who read the alibi immediately; therefore the degrees of freedom differ from those in the previous analysis.
} 
Table 3

Mean Scores (M) and Standard Deviations (SD) for the Dependent Variables at Time 2 $(n=150)$

\begin{tabular}{lcccc}
\hline Presentation method & \multicolumn{5}{c}{ Salaciousness } \\
\hline & $M$ & $S D$ & $M$ & $S D$ \\
\cline { 2 - 5 } & & & & \\
Believability & 5.62 & 1.88 & 3.73 & 1.95 \\
$\quad$ Immediate & 2.84 & 1.94 & 4.22 & 2.78 \\
$\quad$ Mistaken before & 3.34 & 1.95 & 5.35 & 2.61 \\
$\quad$ Lied before & 3.93 & 2.25 & 4.43 & 2.53 \\
$\quad$ Average & & & & \\
Strength of the evidence & 3.68 & 2.18 & 2.75 & 1.65 \\
$\quad$ Immediate & 2.51 & 2.03 & 2.87 & 2.12 \\
$\quad$ Mistaken before & 2.94 & 2.39 & 4.10 & 2.57 \\
$\quad$ Lied before & 3.04 & 2.23 & 3.24 & 2.20 \\
$\quad$ Average & & & & \\
Contribution to claim of innocence & 3.62 & 2.04 & 3.12 & 1.92 \\
$\quad$ Immediate & 2.66 & 2.11 & 3.03 & 2.54 \\
$\quad$ Mistaken before & 2.76 & 1.82 & 4.30 & 2.48 \\
$\quad$ Lied before & 3.02 & 2.01 & 3.49 & 2.37 \\
$\quad$ Average & & & & \\
Ease of fabrication ${ }^{1}$ & 2.51 & 2.33 & 2.33 & 2.35 \\
$\quad$ Immediate & 2.73 & 2.92 & 1.92 & 1.97 \\
$\quad$ Mistaken before & 1.50 & 1.39 & 3.72 & 3.33 \\
$\quad$ Lied before & 2.23 & 2.33 & 2.69 & 2.72 \\
$\quad$ Average & & & & \\
\hline Note: the dependent varianyyyyy
\end{tabular}

Note: the dependent variables are displayed in boldface.

1: there were 11 missing value for this characteristic, the valid percentages are displayed.

Table 4

Number of Items (n) and Percentages (\%) of the Wanted Additional Physical Supportive Evidence

\begin{tabular}{lrr}
\hline Type of physical evidence & $n$ & $\%$ \\
\hline Camera recordings & 60 & 55.0 \\
Registration/payment hotel & 28 & 25.7 \\
Telecom (i.e., sent text messages) & 6 & 5.5 \\
Photos & 5 & 4.6 \\
Forensic material (e.g., fingerprints, DNA) & 5 & 4.6 \\
Receipt rental truck/drinks hotel & 4 & 3.7 \\
Moving boxes & 1 & 0.9 \\
Total & 109 & 100.0 \\
\hline
\end{tabular}


CHAPTER 5

Figure 1

Mean Scores for Alibi Believability

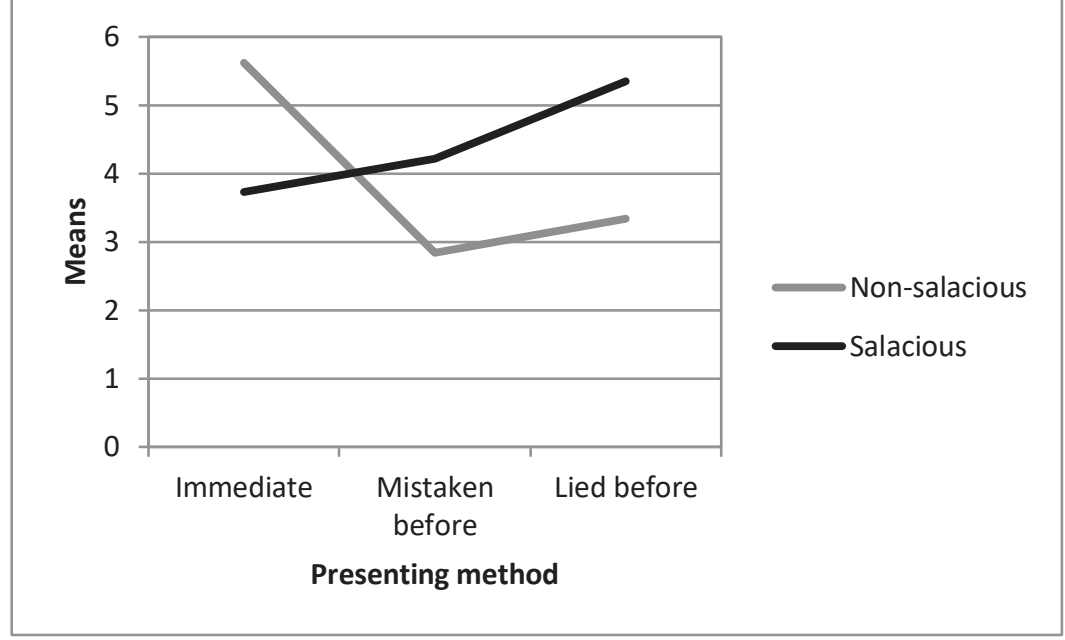

Figure 2

Mean Scores for the Alibi's Ease of Fabrication

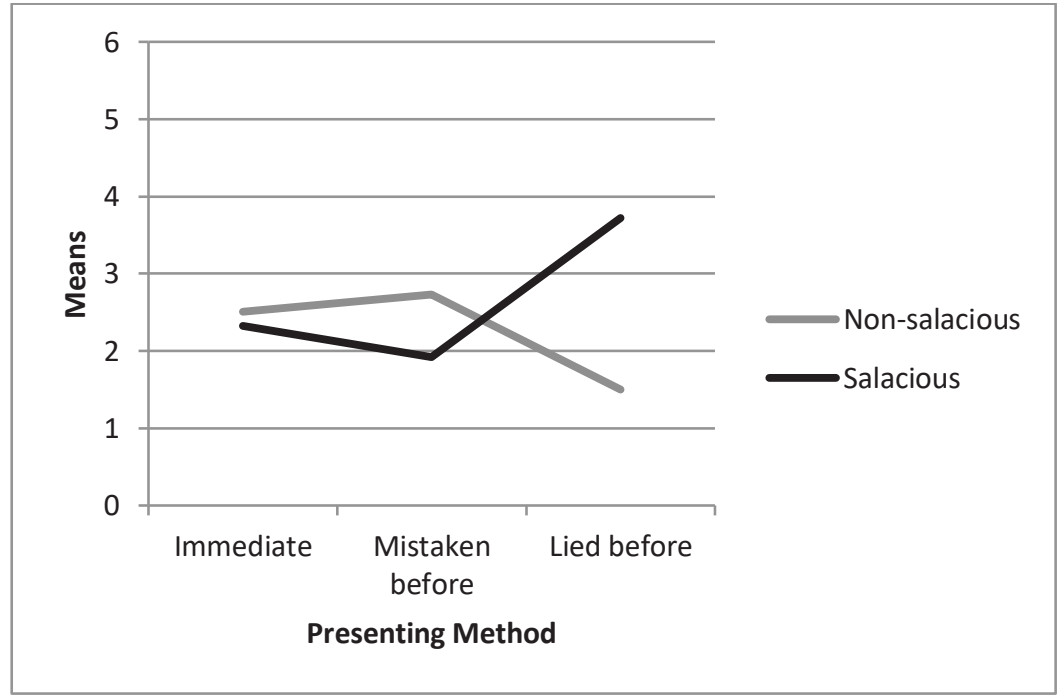


THE EFFECT OF ALIBI CONSISTENCY AND SALACIOUSNESS ON ALIBI BELIEVABILITY

\subsubsection{Additional Evidence}

After the participants evaluated the suspect's alibis, they were asked if they would need additional evidence if they were to believe the alibi. Most of the participants $(90.0 \%)$ wanted additional evidence. It was the case that 90 participants (60.0\%) wanted additional physical evidence, of whom 18 more wanted more than one item of physical evidence. Furthermore, 72 participants (48.0\%) wanted additional witness evidence, of whom 8 wanted more than one witness (see Tables 4 and 5 for an overview of the types of required additional evidence).

To test whether the proportions of required additional evidence were different among the groups, $\chi^{2}$ tests of were conducted for each type of supportive evidence (only physical evidence, only witness evidence, both witness and physical evidence). These tests were conducted for both the salaciousness of the presented alibis and whether or not the alibi was presented immediately or changed. When the participants evaluated a salacious alibi on the one hand, a higher number of participants required additional physical evidence only $\left(n_{0}=38\right)$ than would be expected by chance $\left(n_{e}=32.2\right)$. When the participants evaluated a non-salacious alibi on the other hand, a lower number of participants required additional physical evidence only $\left(n_{0}=25\right)$ than would be expected by chance $\left(n_{e}=30.8\right)$. According to the $\chi^{2}$ test of independence, the difference is statistically significant, $\chi^{2}(1, n=$ $135)=4.01, p=.045, \phi=.17$, so it can be inferred that people prefer physical evidence when they are asked to evaluate a salacious alibi.

In addition, when the participants evaluated an alibi that was initially a misrecollection, a higher number required additional physical evidence $\left(n_{o}=28\right)$ than would expected by chance $\left(n_{e}=21.0\right)$. When the participants evaluated an alibi that was presented immediately or was initially a lie, a lower number required additional physical evidence (immediately, $n_{o}=15$; lie, $\left.n_{o}=20\right)$ than would be expected by chance $\left(n_{e}=21.0\right)$. According to the $\chi^{2}$ test of independence, the difference is statistically significant, $\chi^{2}(2, n=135)=7.68$, $p=.022$, Cramer's $V=.24$. It can therefore be inferred that people prefer physical evidence when they evaluate an alibi that was a misrecollection rather than when it was presented immediately or was initially a lie. 
On the contrary, when the participants evaluated an alibi that was presented immediately, a higher number required additional witness evidence $\left(n_{0}=22\right)$ than would be expected by chance $\left(n_{e}=15.0\right)$. When the participants evaluated an alibi that was initially a misrecollection or a lie, a lower number required additional witness evidence (misrecollection, $n_{0}=11$; lie, $n_{0}=12$ ) than would be expected by chance $\left(n_{e}=15.0\right)$. According to the $\chi^{2}$ test of independence, the difference is statistically significant, $\chi^{2}(2, n=$ $135)=7.40, p=.025$, Cramer's $V=.23$ It can therefore be inferred that people are more likely to want witness evidence when they evaluate an alibi which was presented immediately rather than when the alibi was changed, whether due to a misrecollection or a lie.

Table 5

Number of Items (n) and Percentages (\%) of Wanted Additional Witness Supportive Evidence

\begin{tabular}{lrr}
\hline Type of witness evidence & $n$ & $\%$ \\
\hline Neutral witness & 30 & 37.5 \\
Mistress & 14 & 17.5 \\
Nephew & 13 & 16.3 \\
Neighbours & 12 & 15.0 \\
Unclear (i.e., 'witnesses') & 6 & 7.5 \\
Parents & 2 & 2.5 \\
Colleagues & 2 & 2.5 \\
Stranger & 1 & 1.3 \\
Total & 80 & 100.0 \\
\hline
\end{tabular}

\subsection{DISCUSSION}

In part, the results of the present study are counterintuitive. It has been thought that alibi believability is merely determined by the strength of the supportive evidence (Olson \& Wells, 2004). The strength of the supportive evidence is still an important factor in determining alibi believability (Jung et al., 2013), but we now know that other factors also play a role. Recently, it came to light that the salaciousness of the alibi and whether or not the alibi has been changed also affect its believability, regardless of the strength of the evidence (Allison et al., 2012; Culhane \& Hosch, 2012). The results of the present study show 
that the relationship is even more complex. Changes in the alibi interact with the alibi's salaciousness on its believability measures. These results imply that a change in alibi does not always have to lead to a decrease in its believability, but in fact can cause an increase. In practice this implies that a changed alibi does not necessarily mean that the suspect has been lying, although more than $80 \%$ of the senior law enforcement personnel believe that suspects change their alibi because they lied initially (Dysart \& Strange, 2012).

The salaciousness of an alibi in relation to its believability has now been addressed in four studies, including the present one (Allison et al., 2012, 2014; Jung et al., 2013). It was first found that a salacious alibi was more believable than a non-salacious one (Allison et al., 2012). In two later studies, the salaciousness had no effect on the believability (Allison et al., 2014; Jung et al., 2013). In the present study, it was found that an immediately presented non-salacious alibi is more believable than an immediately presented salacious alibi. In all studies apart from the present one, students were used as participants. It can be argued that this difference in participants explains these contrary findings. However, no important differences seem to exist in the evaluation of alibis between students, laypeople and police detectives as participants (Culhane \& Hosch, 2012; Nieuwkamp et al., 2017b).

Rather than changing the witness evidence to support the alibi (Culhane \& Hosch, 2012), we changed the alibi narrative. This narrative change interacted with the salaciousness of the alibi on the alibi believability measures. Only for the salacious alibis were the changed alibis rated as being more believable and this effect was the largest when the initial alibi was a lie. Although these results are partially contrary to previous findings, they can be explained. A suspect who lied about his initial alibi hoping that his affair with his mistress would remain undiscovered makes more intuitive sense than a suspect who lied about his initial alibi because he did not want to report that he was helping his cousin move out. The effect sizes of the difference between a lie and a misrecollection were, however, both quite small (.06 and .03, respectively). It can therefore be argued that it does not matter very much whether the initial alibi was a misrecollection and a lie when the suspect gives a salacious alibi afterwards.

Besides introducing a narrative change to the alibis, the present study was the first in which participants were asked what evidence they would require in order to believe the 
CHAPTER 5

presented alibis. In line with the impact of the supportive evidence from alibi evaluation studies (i.e., the impact of physical evidence is greater than witness evidence for alibi believability; Olson \& Wells, 2004), the participants in our study more often required additional physical evidence to support an alibi that was either salacious or a misrecollection. In addition, within the required physical evidence, camera recordings were most often requested. According to the taxonomy, camera recordings are one of the strongest forms of supportive evidence for an alibi. Police detectives also find alibis supported with physical evidence more believable than alibis supported with witness evidence (Dysart \& Strange, 2012). In contrast, we know from the base rate of alibis that only about $2 \%$ of people report having camera recordings to support their alibis (Nieuwkamp et al., 2017a). This finding adds to the assertion of Culhane (2008) that we expect strong evidence in order to believe an alibi, even though it is unrealistic to request such evidence from innocent people.

While most of our participants requested strong evidence in order to believe the presented alibis, the results of the present study equally demonstrate that the content of the presented alibis is also important in relation to the reason why the alibi was changed. Without taking these others factors into consideration together with the strength of the supportive evidence, it is very difficult to fully assess alibi believability. The new insights gained in recent years in combination with the results of the present study suggest that alibi believability needs to be assessed in terms of more than just the strength of the supportive evidence in order to obtain a realistic evaluation. Although the strength of the supportive evidence remains an important aspect of alibi believability, the base rate of alibis cannot be ignored. Whether an innocent suspect has supportive evidence for his or her alibi and what type of evidence can be expected depends on various factors; therefore the base rate needs to be taken into account when evaluating an alibi (Nieuwkamp et al., 2017a). It would thus be too simple to disbelieve an alibi simply due to the absence of strong supportive evidence. The results of the present study also show that the reason why an alibi was changed needs to be taken into account in combination with the content of the revised alibi. Again, it would be too simple to state that every change in an alibi or the evidence for it would render it less believable. In particular cases, such as a suspect lying in an attempt to keep his or her 
affair a secret, makes intuitive sense and the results of this study show that if a person is wrongfully accused of having committed a crime, lying to conceal having a mistress might positively contribute to finding the truth due to the real alibi being more convincing once it has been revealed. 
CHAPTER 5

\subsection{REFERENCES}

Allison, M., \& Brimacombe, C. (2010). Alibi believability: The effect of prior convictions and judicial instructions. Journal of Applied Social Psychology, 40, 1054-1084. doi: 10.1111/j.1559-1816.2010.00610.x

Allison, M., Jung, S., Sweeney, L., \& Culhane, S. E. (2014). The impact of illegal alibi activities, corroborator involvement and corroborator certainty on mock juror perceptions. Psychology and Law, 21, 191-204. doi: 10.1080/13218719.2013.803275

Allison, M., Mathews, K. R., \& Michael, S. W. (2012). Alibi Believability: The Impact of Salacious Alibi Activities. Social Behavior and Personality: an international journal, 40, 605-612. doi: 10.2224/sbp.2012.40.4.605

Burke, T. M., Turtle, J. W., \& Olson, E. A. (2007). Alibis in criminal investigations and trials. In M. P. Toglia, J. D. Read, D. F. Ross, \& R. C. Lindsay (Eds.), The handbook of eyewitness psychology: Memory for events (Vol. 1, pp. 157-192). Mahwah, NJ: Lawrence Erlbaum Associates.

Centraal Bureau voor de Statistiek. (2013). Beroepsbevolking, behaalde onderwijs naar herkomst geslacht en leeftijd. [Workforce, education received at home by sex and age]. Centraal Bureau voor de Statistiek. Retrieved from http://statline. cbs.nl/StatWeb/publication/?VW=T\&DM=SLNL\&PA=71822ned\&LA=NL.

Culhane, S. E., \& Hosch, H. M. (2004). An alibi influence on mock verdicts. Journal of Applied Social Psychology, 34, 1604-1616. doi: 10.1111/j.1559-1816.2004.tb02789.x

Culhane, S. E., \& Hosch, H. M. (2012). Changed alibis: Current law enforcement, future law enforcement, and layperson reactions. Criminal Justice and Behavior, 39, 958-977. doi: $10.1177 / 0093854812438185$

Culhane, S. E., Hosch, H. M., \& Kehn, A. (2008). Alibi generation: Data from U.S. Hispanics and U.S. non-Hispanic Whites. Journal of Ethnicity in Criminal Justice, 6, 177-199. doi: 10.1080/15377930802243395

Culhane, S. E., Kehn, A., Horgan, A. J., Meissner, C. A., Hosch, H. M., \& Wodahl, E. J. (2013). Generation and detection of true and false alibi statements. Psychiatry, Psychology and Law, 20, 619-638. doi: 10.1080/13218719.2012.729018

Dysart, J. E., \& Strange, D. (2012). Beliefs about alibis and alibi investigations: A survey of law enforcement. Psychology, Crime and Law, 18, 11-25. doi: 10.1080/1068316X.2011.562867

Federale Overheidsdienst Werkgelegenheid, Arbeid en Sociaal Overleg (2012). Statistieken [Statistics]. Federale Overheidsdienst Werkgelegenheid, Arbeid en Sociaal Overleg. Retrieved from http://www.werk.belgie.be/moduleDefault.aspx?id=21166AutoAncher6 
Guyll, M., Madon, S., Yang, Y., Lannin, D. G., Scherr, K., \& Greathouse, S. (2013). Innocence and resisting confession during interrogation: Effects on physiologic activity. Law and Human Behavior, 37, 366-375. doi: 10.1037/lhb0000044

Hosch, H. M., Culhane, S. E., Jolly, K. W., Chavez, R. M., \& Shaw, L. H. (2011). Effects of an alibi witness's relationship to the defendant on mock jurors' judgments. Law and Human Behavior, 35, 127-142. doi: 10.1007/s10979-010-9225-5

Jung, S., Allison, M., \& Bohn, L. (2013). Legal decision-making on crimes involving an alibi. Applied Psychology in Criminal Justice, 9, 45-58. doi: 10.1037/t04698-000

Kassam, K. S., Gilbert, D. T., Swencionis, J. K., \& Wilson, T. D. (2009). Misconceptions of memory. The Scooter Libby effect. Psychological Science, 20, 551-552. doi: 10.1111/j.1467-9280.2009.02334.x

Leins, D. A., \& Charman, S. D. (2013). Schema reliance and innocent alibi generation. Legal and Criminological Psychology, 111-126. doi: 10.1111/lcrp.12035

Lindsay, R. C., Lim, R., \& Marando, D. C. (1986). Mock-juror evaluations of eyewitness testimony: A test of metamemory hypotheses. Journal of Applied Social Psychology, 16, 447-459. doi: 10.1111/j.1559-1816.1986.tb01151.x

Luria, R. E. (1975). The validity and reliability of the visual analogue mood scale. Journal of Psychiatric Research, 12, 51-57.

McAllister, H. A., \& Bregman, M. J. (1989). Juror underutilization of eyewitness nonidentifications: A test of the disconfirmed expectancy explanation. Journal of Applied Social Psychology, 19, 20-29. doi: 10.1111/j.1559-1816.1989.tb01218.x

Nieuwkamp, R., Horselenberg, R., \& Van Koppen, P. J. (2017a). The illusion of the perfect alibi: Establishing the base rate of non-offenders' alibis. Journal of Investigative Psychology and Offender Profiling, 14, 23-42. doi:10.1002/jip.1470

Nieuwkamp, R., Horselenberg, R., \& Van Koppen, P. J. (2017b). You don't know: Knowledge as supportive alibi evidence. Manuscript submitted for publication.

Olson, E. A., \& Charman, S. D. (2012). 'But can you prove it?' - Examining the quality of innocent suspects' alibis. Psychology, Crime and Law, 18, 453 741. doi: 10.1080/ 1068316x.2010.505567

Olson, E. A., \& Wells, G. L. (2004). What makes a good alibi? A proposed taxonomy. Law and Human Behavior, 28, 157-176. doi: 10.1023/B: LAHU.0000022320.47112.d3

Sargent, M. J., \& Bradfield, A. L. (2004). Race and information processing in criminal trials: Does the defendant's race affect how the facts are evaluated? Personality and Social Psychology Bulletin, 30, 995-1008. doi: 10.1177/0146167204265741

Smeets, T., Otgaar, H., Candel, I., \& Wolf, O. T. (2008). True or false? Memory is differentially affected by stress-induced cortisol elevations and sympathetic activity at consolidation and retrieval. Psychoneuroendocrinology, 33, 1378-1386. doi: 10.1016/j.psyneuen.2008.07.009 
CHAPTER 5

Sommers, S. R., \& Douglass, A. B. (2007). Context matters: Alibi strength varies according to evaluator perspective. Legal and Criminological Psychology, 12, 41-54. doi: $10.1348 / 135532506 \times 114301$

Strange, D., Dysart, J. E., \& Loftus, E. F. (2014). Why errors in alibis are not necessarily evidence of guilt. Zeitschrift für Psychologie, 222, 82-89. doi: 10.1027/21512604/a000169

Thompson-Cannino, J., Cotton, R., \& Torneo, E. (2009). Picking Cotton. New York: St. Martin's Press. 


6

ALIGNING EXPECTATIONS WITH REALITY: NO ALIBI GENERATION EFFECT AMONG POLICE DETECTIVES

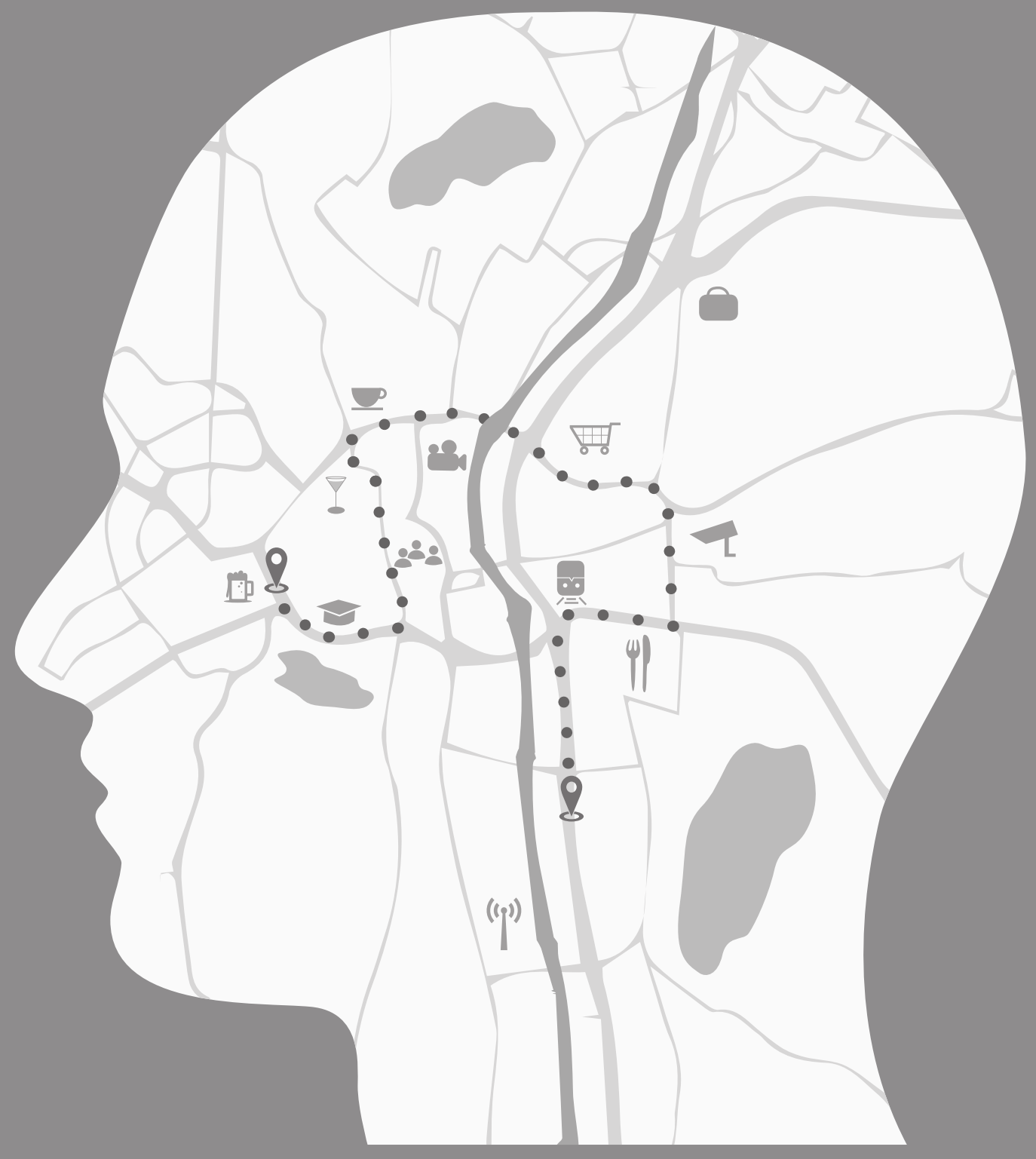

This chapter has been submitted for publication to Legal and Criminological Psychology:

Nieuwkamp, R., Horselenberg, R., \& Van Koppen, P. J. Aligning expectations with reality: No alibi generation effect among police detectives. Manuscript in revision for publication. 



\section{ABSTRACT}

Purpose. Police detectives in evaluating alibis put high demands on an alibi to be believable. That may be due to a lack of awareness of how difficult it can be to present a believable alibi. Asking these evaluators to generate an alibi themselves prior to evaluating a suspect's alibi can make them more aware of the difficulties inherent in presenting a believable alibi. A previous study with students has shown that such awareness, known as the alibi generation effect, can lead to more realistic alibi evaluations.

Methods. The present study is a replication of Olson and Wells (2012) using 60 experienced police detectives. Participants were asked to generate an alibi themselves either prior to or following the evaluation of a suspect's alibi.

Results. None of the effects that were found in the original study were replicated in our study. Close examination of the detectives' alibis, however, shows that they more often report physical evidence (about 76\%) compared to laypeople (about 33\%).

Conclusions. Although we did not replicate the results from the original study, an important difference was observed in the number of police detectives who reported physical evidence compared to laypeople. The data suggest that police officers are more aware of the

presence of that type of evidence (e.g., GPS data from their mobile phones) than laypeople are. These results might offer some insight into the alibi generation effect not being seen in police detectives and their expectations of such strong evidence from laypeople.

Keywords: alibi generation; alibi evaluation; police detectives. 
CHAPTER 6

\subsection{INTRODUCTION}

Police detectives and mock jurors typically require strong evidence for an alibi to be believable (e.g., Dysart \& Strange, 2012; Jung, Allison, \& Bohn, 2013; Pozzulo, Pettalia, Dempsey, \& Gooden, 2015). However, research has found that non-offenders can present strong evidence for an alibi in only $2 \%$ of cases (Nieuwkamp, Horselenberg, \& Van Koppen, 2017). A non-believed true alibi remains an important cause of wrongful convictions (Crozier, Strange, \& Loftus, 2017), and therefore more research is needed on how practitioners evaluate alibis. To create a more realistic alibi evaluation, three simple selfevaluation questions could be used: where was I when the alleged crime was committed; what type of evidence can I present; and would I find my own alibi believable as a police detective or a juror? Answering these questions prior to the evaluation of a suspect's alibi leads to a more realistic alibi evaluation than when the suspect's alibi is immediately evaluated, or referred to as the alibi generation effect (Olson \& Wells, 2012). The present study was designed to determine if the alibi generation effect also holds for police detectives. If the effect is replicated, this simple and practical step could help practitioners to make a more realistic alibi evaluation.

\subsubsection{Alibi Evaluation}

To date, most of the alibi research has focused on determining what factors make an alibi (un)believable, which is known as the alibi evaluation. In such research, typically mock jurors are asked to evaluate the defendant's alibi. Various aspects of the alibi are manipulated to determine which are the most and least believable alibis. To structure the alibi research, Olson and Wells (2004) created an alibi taxonomy by which the strength of the supportive alibi evidence can be assessed. According to the authors, the strength of the evidence is crucial to determine the alibi's believability. Currently, the strength of the supportive evidence remains one of the best predictors of how believable the alibi will be considered (Jung et al., 2013). 
Olson and Wells (2004) present two types of evidence in their taxonomy: witness and physical evidence. Witness evidence consists of a corroborating witness statement confirming the suspect's alibi, whereas physical evidence refers to tangible evidence (e.g., a receipt or CCTV recordings). For both witness and physical evidence, the rule of thumb applies that the more difficult it is to fabricate the evidence, the stronger the evidence is perceived to be (Olson \& Wells, 2004).

For witness evidence, the relational distance between the suspect and the witness also determines the strength of the corroborating statement. Witnesses who are close to the suspect (e.g., family, partner) are expected to have a motivation to lie in favour of the suspect (Sullivan, 1971) and are therefore less trustworthy witnesses compared to strangers and acquaintances (Culhane \& Hosch, 2004). A stranger is the least inclined to lie in favour of the suspect, but a stranger is unlikely to recognise the suspect even when they briefly have interacted with each other (Charman, Reyes, Villalba, \& Evans, 2017). As a result, an acquaintance is considered as the strongest type of witness evidence.

Physical evidence is strong when three criteria are met: a) it needs to be linked to the suspect; and contain b) time; and c) location information. CCTV recordings are commonly used in alibi research as a form of strong physical evidence (e.g., Allison \& Brimacombe, 2010; Olson \& Wells, 2004). A receipt is an example of weak evidence because it is not linked to the suspect and does not always contain time or location information. Like the strength of the evidence, the alibi should also not be changed over time. If the alibi is changed, its believability decreases, even when the supportive evidence becomes stronger than it initially was (Culhane \& Hosch, 2012). Thus, an alibi should contain strong evidence and remain unchanged in order to be found believable.

\subsubsection{Alibi Generation}

Usually a person generates an alibi and presents supportive evidence when he is asked for it. Compared to the research on alibi evaluation, research on alibi generation is nascent (Culhane, Hosch, \& Kehn, 2008; Nieuwkamp et al., 2017; Olson \& Charman, 2012). In general, it can be concluded that most people are able to recollect their whereabouts and 
also to present supportive evidence. The presented evidence is, however, more often weak than strong. As described above, CCTV recordings are the strongest type of evidence an innocent person can present. Yet, only $2 \%$ of non-offenders report such evidence (Nieuwkamp et al., 2017). As Culhane et al. (2008) noted, there is an irony in what evidence people find believable and what evidence non-offenders can actually present. Police detectives (Dysart \& Strange, 2012) and mock jurors (e.g., Jung et al., 2013) both expect stronger evidence from non-offenders than what can be realistically provided.

Furthermore, Olson and Charman (2012) found that 1 in 10 generated true alibis appeared to be incorrect and about $25 \%$ of the reported evidence was incorrect or no longer available. A mistake about one's whereabouts is not always indicative of guilt because people have more difficulties in determining when they did something rather than what they did (Strange, Dysart, \& Loftus, 2014). Being asked for an alibi tests autobiographical memory (Crozier et al., 2017) and, in general, people are inept at remembering what they were doing three weeks or even three days ago (Olson \& Charman, 2012). Furthermore, when the timespan between the events and the recollection increases, the quality of the memory decreases drastically (Burke, Turtle, \& Olson, 2007). In addition, the probability that the alibi is misremembered and/or that the supportive evidence is no longer existent increases (Culhane et al., 2013; Nieuwkamp, Horselenberg, \& Van Koppen, 2016; Olson \& Charman, 2012). Taken together, it can be argued that alibi evaluators have too little knowledge about the functioning of human memory, which might explain why they set unrealistic expectations in alibi evaluation. Innocent people simply do not possess strong evidence for their alibis seven days a week, 24 hours a day, and our memory does not always generate valid memories.

\subsubsection{Research with Practitioners}

Despite their knowledge and experiences, police detectives, who have to evaluate the believability of an alibi in practice, are seldom included in alibi research. Police detectives were included in only two studies. The results of the first study shows that police detectives are sceptical about alibis (Dysart \& Strange, 2012). In about 80\% of cases, they expect that 
the suspect will lie to them, and about half of them believe that it is easy to fabricate a false alibi (Dysart \& Strange, 2012). Furthermore, detectives have little patience for the faltering memory of suspects. When the suspect is asked for his alibi 24 hours after the alleged crime was committed, more than $50 \%$ of the police detectives think it is extremely unlikely that a suspect would be mistaken about the alibi. When the suspect is questioned one week after the crime, 1 in 8 police detectives still find a mistake in the suspect's alibi extremely unlikely. When a suspect changes his initial alibi, $20 \%$ of the police detectives think that the change is due to an erroneous recollection. The remaining $80 \%$ believe that the change occurred because the suspect lied in his initial statement (Dysart \& Strange, 2012). Furthermore, more recently it was demonstrated that police detectives differ from laypeople when it comes to the factors they consider to be important when evaluating an alibi (Eastwood, Snook, \& Au, 2016). Police detectives, for example, find the quantity of alibi witnesses more important than the quality of their relationship. These results might affect how police detectives evaluate alibis in practice, which might not be in line with the findings of previous research that used student samples. Given their expertise and experience, it might well be that police officers focus on other aspects during the alibi evaluation than students do. Therefore, the police detectives' expertise and experience can help scholars to conduct more ecologically valid research on alibis that would be more applicable to law enforcement practice. In addition, this would allow for an enhanced incorporation of the knowledge of scholars in current practices.

\subsubsection{Present Study}

Thirteen years after the pioneering paper by Olson and Wells (2004), and given the knowledge that scholars have acquired since, it is time to start building bridges between practitioners and scholars in alibi research. Although police detectives could be valuable resources for alibi research, their evaluation is not flawless. As stated above, a non-believed true alibi appears to be an important factor in wrongful convictions (Simon, 2012; Wells et al., 1998). Both mock jurors and police detectives set unrealistic expectations for what constitutes a believable alibi. An easily applicable method to increase awareness of these 
high standards, and the difficulty a non-offender faces to present a believable alibi, can be found in the alibi generation effect (Olson \& Wells, 2012). Olson and Wells (2012) found that participants evaluated the defendant's alibi as more believable when they first generated a personal alibi (i.e., generate first condition) compared to when the participants first evaluated the defendant's alibi prior to generating a personal alibi (i.e., evaluate first condition).

The present study is a replication of Experiment 1 as described in the paper of Olson and Wells (2012), but with the inclusion of experienced police detectives as participants. This change was made to determine if detectives can also benefit from the alibi generation effect. We expected that the police detectives in the generate first condition would evaluate the suspect's alibi as more believable compared to the detectives in the evaluate first condition.

\subsection{METHOD}

\subsubsection{Participants}

Experienced police detectives ( 50 males, 10 females, $M_{\text {age }}=50.1$, age range: $24-64$ years) participated in the study. They had an average of 28 years of experience within the police force (experience range: 6-46 years), little alibi contact during their daily job (40\% did so about once a month), and only $17 \%$ of them had received some training on alibi evaluation. They were recruited at two police stations in the Netherlands. Their participation was on a voluntary basis, and they received no compensation for their participation. The standing ethical committee of a university in the Netherlands and the chiefs of the police stations granted permission for this study. 


\subsubsection{Materials and Procedure}

The participants were first asked either to generate an alibi prior to the evaluation of an alibi (generate first condition) or to first evaluate the alibi prior to the generation of their alibi (evaluate first condition).

The materials used by Olson and Wells (2012) in their experiment 1 were translated and used for the replication study. The questionnaire consisted of two parts: demographics and the original questionnaire on alibi generation and evaluation measures. The presented demographics differed slightly because of the test population. Three questions were added: the number of years of service in the police force; how often they evaluate alibis; and whether they received specific training on alibi evaluation. In the original study, participants were asked to generate an alibi for either 3 or 30 days ago. Because no latency effect was reported by Olson and Wells (2012), the participants in the present study were only asked to generate an alibi for three days ago.

\subsubsection{Generation Measures}

All participants were prompted by an open-ended question to generate their alibi for three days ago between $10 \mathrm{AM}$ and 12 PM. They were then asked seven follow-up questions on their alibi and supportive evidence. First, they were asked how certain they were that they could produce supportive evidence for their alibis on an 11-point Likert scale ranging from $0 \%$ (certainly not) to $100 \%$ (certainly). Second, they were asked what type of supportive evidence they had: physical evidence, witness evidence, a combination of physical and witness evidence, another type of evidence (open-ended answer), or no evidence. Next they were asked in an open-ended question to describe, if applicable, the physical evidence. Fourth and fifth, they were asked in two forced-choice questions whether the evidence contained a date and an indication of time. The sixth question relates to witness evidence, asking the participants who could support their alibi (i.e., their partner; a family member; a friend, an acquaintance, or a stranger). Last, they were asked to indicate on an 11-point Likert scale how believable they think another police detective or juror/judge would 
CHAPTER 6

consider their alibi to be, ranging from $0 \%$ (certainly not believable) to $100 \%$ (certainly believable).

\subsubsection{Evaluation Measure}

In addition to generating an alibi, the participants were asked to evaluate a suspect's alibi. He was asked for his whereabouts one month after an armed robbery of a convenience store had occurred. The suspect presented an alibi with supportive evidence of moderate strength: a friend who corroborates the alibi (the suspect's full statement can be found in the appendix). After reading the suspect's alibi, the participants answered three questions on an 11-point Likert scale. They were first asked to what degree they believed the suspect's alibi, from 0 (not at all) to 10 (completely). In the second and third question, the participants were asked how strong they thought the supportive evidence was, from 0 (very weak) to 10 (very strong) as well as how easily the supportive evidence could be fabricated, with 0 indicating very easily and 10 meaning very difficult. These two questions were included because the alibi believability appears to be determined primarily by the strength of the evidence and on how easily the alibi can be fabricated (Olson \& Wells, 2004). Last, the participants answered two open-ended qualitative questions identical to those in the original study: "what aspects made you believe the alibi?" and "what aspects made you disbelieve the alibi?".

\subsubsection{Procedure}

All participants were tested individually in the police station. The participants were randomly assigned to one of the two conditions. After giving their consent, the participants completed the questionnaire. After completion, the participants were fully debriefed, thanked for their cooperation, and dismissed. 


\subsection{RESULTS}

The three evaluation measures were moderately correlated $(r=.63)$. Because the test results for the averaged items did not differ from those for the single items, the single items are discussed for clarity. All analyses were conducted using univariate analyses of variance (ANOVA) where the condition was the independent variable. For all analyses, a confidence level of $95 \%$ was used, and a Bonferroni correction was applied to correct for multiple testing.

\subsubsection{Alibi Evaluation}

No difference was observed between the conditions on how believable they found the alibi: $F(1,58)=0.10, n s, \eta_{p}{ }^{2}=.002$, how strong they perceived the presented supportive evidence: $F(1,58)=0.15, n s, \eta_{p}{ }^{2}=.003$, or how easily the supportive evidence could be fabricated: $F(1,58)=.20, n s, \eta_{p}{ }^{2}=.003$. See Table 1 for the mean scores. Thus, we did not replicate the alibi generation effect.

Table 1

Alibi Evaluation Scores per Condition

\begin{tabular}{lcccccc}
\hline & \multicolumn{3}{c}{ Generate first } & \multicolumn{3}{c}{ Evaluate first } \\
Measure & $n$ & $M(S D)$ & $95 \% \mathrm{Cl}$ & $n$ & $M(S D)$ & $95 \% \mathrm{Cl}$ \\
\hline Alibi believability & 30 & $4.97(2.25)$ & {$[4.13,5.81]$} & 30 & $4.80(1.83)$ & {$[4.12,5.48]$} \\
Evidence strength & 30 & $4.00(2.42)$ & {$[3.10,4.90]$} & 30 & $4.23(2.27)$ & {$[3.39,5.08]$} \\
Evidence ease of & 30 & $4.00(3.02)$ & {$[2.87,5.13]$} & 30 & $3.67(2.82)$ & {$[2.61,4.72]$} \\
fabrication & & & & & & \\
\hline
\end{tabular}

\subsubsection{Qualitative Measures}

The answers on the two qualitative questions (i.e., believable and less believable aspects of the alibi) were studied in more detail to determine why the effect was not replicated. The answers were post-hoc categorised into 22 categories by two independent coders. They had 
an agreement of $77.5 \% .{ }^{4}$ In cases where no accordance was obtained, these were discussed and resolved. The two most important reasons to believe the suspect's alibi were either a witness confirming the suspect's story $(30.9 \%)$ or the possibility of retrieving physical evidence (21.0\%). The two most important reasons not to believe the suspect's alibi were the relational distance between the witness and the suspect (i.e., his friend, $28.7 \%$ ) and the need for more investigative action (e.g., asking the suspect about details of what he saw on television, 16.5\%). Table 2 provides an overview.

Table 2

Reasons to (Dis)believe the Suspect's Alibi

\begin{tabular}{lrr} 
& $\mathrm{n}$ & $\%$ \\
Reasons to believe the alibi & 10 & 12.3 \\
Not been able to interview the suspect; more investigative acts are & & \\
needed & 25 & 30.9 \\
Presence of witness evidence; friend confirms the alibi & 17 & 21.0 \\
Possible presence of physical evidence & 7 & 8.6 \\
Alibi seems believable; no reason to disbelieve the alibi & 12 & 14.8 \\
A timeline is presented & 4 & 4.9 \\
Superficial alibi & 1 & 1.2 \\
Number of details in the alibi & 5 & 6.2 \\
Possibility to verify the alibi & 81 & 100.0 \\
Subtotal & & \\
Reasons to disbelieve the alibi & 19 & 16.5 \\
Not been able to interview the suspect; more investigative acts are & & \\
needed & 4 & 3.5 \\
Witness evidence is not verified & 13 & 11.3 \\
No physical evidence presented & 33 & 28.7 \\
Relation between the witness and the suspect (i.e., the witness is a friend) & 12 & 10.4 \\
Superficial alibi; alibi is too easy & 2 & 1.7 \\
Suspect was at the crime scene & 17 & 14.8 \\
Too much time has passed & 8 & 7.0 \\
Too little verifiable details & 3 & 2.6 \\
Choice of language in alibi: "had been planning on watching a football & & \\
game" & & \\
Suspect can recall his whereabouts after one month & 1 & 0.9 \\
He became a suspect for a reason & 3 & 2.6 \\
Subtotal & 115 & 100.0 \\
\hline
\end{tabular}

\footnotetext{
${ }^{4}$ It was not possible to calculate Cohen's kappa because the cell displaying the misses, according to the signal detection theory, had no observations, therefore the percentage is displayed (items of agreement: 152 out of 196 items $=77.5 \%)$.
} 


\subsubsection{Generation Measures}

One participant could not remember what he did three days ago; the other 59 participants were: at home (42.4\%), at work (30.5\%), alone outside (e.g., fishing: $13.6 \%)$, outside with others (e.g., shopping with their family: $10.2 \%$ ) or playing sports (3.4\%), and no difference in the reported alibis was observed between the conditions. The participants were asked to indicate how certain (range $0-100 \%$ ) they were that they could find supportive evidence. Eight in ten participants were very sure (range of answers: $80-100 \%$ ) that they could find supportive evidence for their alibis, and most participants ( $n=53,89.9 \%$ ) did indeed have supportive evidence for their alibis. The evidence most often consisted of a combination of witness and physical evidence (79.2\%). The other alibis were supported by witness evidence only $(20.8 \%)$. Forty-one participants $(75.9 \%)$ presented a total of 69 items of physical evidence. This evidence consisted of: phone records (34.8\%); computer data (e.g., emails sent: $30.4 \%)$; camera recordings (14.5\%); receipts (10.1\%); entries in an online agenda (5.8\%); or photographs (4.3\%). All participants reported having at least one alibi witness. Eighty-one witnesses were claimed. A partner (32.1\%) and an acquaintance (32.1\%) were the most often named witnesses compared to a family member (17.4\%), a stranger (15.9\%), or a friend $(8.7 \%)$.

\subsubsection{Alibi Believability}

All participants were very confident that another detective, judge or juror would find their presented alibi believable. No difference was observed between the conditions on how confident they were that their alibi would be (dis)believed: $F(1,58)=1.60, p=.21$. Of those who presented an alibi, 71\% were very confident (range: $80-100 \%$ ) that others would find their alibi believable. Most confident were those participants who reported that an acquaintance, the strongest type of witness evidence according to the taxonomy of Olson and Wells (2004), could support their alibi. The least confident were those who had no supportive evidence for their alibi at all (see Table 3). 
Table 3

Self-rated Alibi Believability over $80 \%$

\begin{tabular}{lcc}
\hline Alibi and/or supportive evidence & Number of people (n) & Percentage (\%) \\
\hline All alibis & $42 / 59$ & 71.2 \\
Alibi, without supportive evidence & $2 / 17$ & 28.6 \\
Alibi, supported by evidence & $41 / 53$ & 77.4 \\
Alibi, supported by any type of physical evidence & $38 / 42$ & 82.3 \\
Alibi supported by strong physical evidence (i.e., & $8 / 10$ & 80.0 \\
CCTV recordings) & & 77.4 \\
Alibis supported by any alibi witness & $41 / 53$ & 92.3 \\
Alibis supported by strong witness evidence (i.e., an & $24 / 26$ & \\
acquaintance) & & \\
Note: the number of people represents all the persons who rated their alibi to be over $80 \%$ believable \\
when others would evaluated their alibi.
\end{tabular}

\subsubsection{Differences in Alibi Generation between Police Detectives and Laypeople}

Both in alibi generation research as in police practice, suspects more often report witness evidence than physical evidence (Culhane et al., 2008; Culhane et al., 2013; Olson \& Charman, 2012), this was not the case in the present study. Furthermore, the police detectives reported a large number of items of physical evidence to support their alibi compared to previous studies. Based on these atypical results, their data were compared to the alibis and supportive evidence reported by laypeople $(n=43)$ collected during a previous study. ${ }^{5}$ Both groups of participants report to have an alibi and evidence that supports it equally often. The type of reported evidence is, however, different. Police detectives more often report physical evidence $(75.9 \%$ vs. $33.3 \%): \chi^{2}(1, n=92)=19.70, p<.001$, Cramer's V $=.46$; and a combination of physical and witness evidence $(75.9 \%$ vs. $30.8 \%): \chi^{2}(1, n=92)=$ $21.78, p<.001$, Cramer's V = .49. Laypeople more often report only witness evidence $(66.7 \%$ vs. $20.8 \%): \chi^{2}(1, n=92)=19.70, p<.001$, Cramer's $V=.46$. Police detectives also report more items of physical evidence than laypeople (1.6 vs. 0.5): $F(1,80)=42.78, p<.001, \eta_{p}{ }^{2}=$ .35 , while laypeople report more alibi witnesses (3.0 vs. 1.5$): F(1,90)=33.79, p<.001, \eta_{p}{ }^{2}=$ .27. Police detectives more often report having computer data $\left(34.0 \%\right.$ vs. $2.6 \% ; \chi^{2}(1, n=$

${ }^{5}$ The data was collected before the current study was conducted. The data of 43 people were selected who were asked to generate an alibi for the same timeframe as in this study. Laypeople (17 males, 26 females, $M_{\text {age }}=30.8$, age range: $20-64$ years) participated in that study for the same timeframe (Chapter 3). 
$92)=13.52, p<.001$, Cramer's $V=.38)$ and telephone data $\left(47.2 \%\right.$ vs. $0 \% ; \chi^{2}(1, n=92)=$ 22.57, $p<.001$, Cramer's $V=.50$. Although laypeople reported more witnesses, no differences were observed between the groups on what type of witness supported their alibi. Table 4 provides an overview.

Table 4

Differences in the Reported Evidence Between Police Detectives and Laypeople

\begin{tabular}{|c|c|c|c|c|}
\hline & \multicolumn{2}{|c|}{ Police detectives $(n=60)$} & \multicolumn{2}{|c|}{ Laypeople $(n=43)$} \\
\hline & $\mathrm{n}$ & $\%$ & $\mathrm{n}$ & $\%$ \\
\hline Evidence & 53 & 89.8 & 39 & 90.7 \\
\hline Physical** & 42 & 79.2 & 13 & 33.3 \\
\hline Witness ${ }^{* *}$ & 53 & 100.0 & 38 & 97.4 \\
\hline $\begin{array}{l}\text { Combination: physical and } \\
\text { witness }^{* *}\end{array}$ & 42 & 79.2 & 12 & 30.8 \\
\hline Physical only & 0 & 0.0 & 1 & 2.6 \\
\hline Witness only & 11 & 20.8 & 26 & 66.7 \\
\hline Number of items & $M(S D)$ & $95 \% \mathrm{Cl}$ & $M(S D)$ & $95 \% \mathrm{Cl}$ \\
\hline Physical* & $1.60(.12)$ & {$[1.36,1.84]$} & $.46(.13)$ & {$[.21, .72]$} \\
\hline Witness* & $1.56(.13)$ & {$[1.30,1.81]$} & $3.03(.26)$ & {$[2.49,3.55]$} \\
\hline
\end{tabular}

Note: $:^{*} p<.05 ;{ }^{* *}: p<.001$.

\subsection{DISCUSSION}

The aim of the present study was to determine whether or not police detectives could also benefit from the alibi generation effect to obtain more realistic alibi evaluations. However, that phenomenon does not seem to occur in police detectives. Along with the absence of that effect, most police detectives wanted to conduct more investigative acts (e.g., interviewing the suspect, determining if CCTV recordings are available) to make a profound evaluation of the friends' supportive testimony. This can explain why all evaluation scores are rather neutral instead of pointing in the direction of (dis)belief. Furthermore, closer examination of their generated alibis shows that police detectives report physical evidence more often than laypeople. That result might explain why police detectives demand strong evidence for alibis (Dysart \& Strange, 2012) even though it is known that non-offenders seldom possess such strong evidence (Culhane et al., 2008). 
Over the past decades, knowledge of the criteria that make an alibi believable has increased. The alibi generation effect has the power to raise awareness of how difficult it is for a non-offender to present a believable alibi. That effect is, however, deceiving because police detectives already evaluate alibis in a realistic manner, and therefore the alibi generation effect does not apply to them. The police detectives wanted to conduct more investigative acts. They wanted to question the suspect, for example, to ask him what details of the game he could remember. In that sense, the believability of the suspect's alibi was determined by the information supporting or refuting the suspect's alibi, rather than the strength of the reported evidence.

This finding is in agreement with the study by Eastwood et al. (2016) where the strength of the supportive evidence was also less important than the amount of information available. Taken together, police detectives appear more interested in the information a suspect can present instead of how strong the reported evidence is according to the taxonomy. Promising research is currently being conducted on the verifiability of suspect's accounts in order to improve the differentiation between truth tellers and liars (Harvey, Vrij, Nahari, \& Ludwig, 2017). That approach shows that truth tellers are more inclined to report information that is verifiable (e.g., I called my friend Kris yesterday evening), while liars will present information that is more difficult to verify (e.g., when I walked to my house, I saw a black Audi). That approach also appears to be effective to differentiate true from false alibis (Nahari \& Vrij, 2014) and shares similarities with the formulated subsequent investigative acts that the police detectives wanted to perform in this study. However, the verifiability approach has only been tested once in alibi research, using undergraduate students. Future research should be aimed at applying the verifiability approach to alibi research in collaboration with practitioners.

One of the most important limitations in the present study is related to the suspect's alibi that was presented. Although we used the same materials as in the original study by Olson and Wells (2012) to allow for comparison, most of the detectives found the alibi evaluation difficult due to a lack of details. In particular, they did not believe the corroborating witness statement and wanted to investigate the alibi in more detail (e.g., interviewing the suspect and witness). Interestingly, $21 \%$ of the arguments for believing the 
alibi refer to the potential presence of physical evidence, although the suspect did not report such evidence. The participants in the present study wanted to know if the grocery store had CCTV surveillance cameras and to recover those records, if still available, from the day of the robbery. Other detectives wondered if it would be possible to locate the suspect's mobile phone records for that day to determine if his mobile phone had been near the crime scene. Their own generated alibis contained more physical supportive evidence for their alibi (75.9\%) than laypeople (33.3\%). In particular, they more often reported the presence of telephone data (e.g., phone calls and GPS data on the location of their telephone; 47.2\%) compared to the group of laypeople, which reported no such evidence.

Our data suggest that police detectives either more often have physical evidence to support their alibis or are more aware of the possible presence of such evidence. However, the locations of their whereabouts are not different from laypeople. It therefore seems unlikely that police detectives more frequently visit places where their presence is registered by CCTV cameras, for example. Most of their presented evidence consisted of telephone data (e.g., calls made and GPS triangulation data where their phone was located at various times). Furthermore, a substantial number of police detectives wanted to investigate whether or not the suspect's alibi could be supported by physical evidence, CCTV recordings and telephone data in particular. Taken together, we argue that police detectives are more aware than laypeople of the presence of physical evidence that may support an alibi. Those reflections might explain why the police officers in the present study did not believe the suspect's alibi, but also why they often expect physical evidence from a nonoffender. For police detectives it is also important to realize that laypeople are less often aware of the potential presence of physical evidence they could report to support their alibis. The non-offenders asked if their alibi could be supported by physical evidence such as CCTV footage or receipts. Despite that instruction they less often present physical evidence compared to police detectives who in general seem to be more aware of the potential presence of such evidence.

Our results, combined with the knowledge that police detectives take other aspects into account during the alibi evaluation (Eastwood et al., 2016), suggest that the findings from laboratory research with undergraduate students cannot be translated to 
CHAPTER 6

practice on a one-to-one basis. Future research should therefore include the legal authorities. In addition, legal authorities could increase their collaboration with scholars on alibi research in order to determine how true alibis can be better distinguished from false ones, thus helping to prevent wrongful convictions in the future. 


\subsection{REFERENCES}

Allison, M., \& Brimacombe, C. (2010). Alibi believability: The effect of prior convictions and judicial instructions. Journal of Applied Social Psychology, 40, 1054-1084. doi:10.1111/j.1559-1816.2010.00610.x

Burke, T. M., Turtle, J. W., \& Olson, E. A. (2007). Alibis in criminal investigations and trials. In M. P. Toglia, J. D. Read, D. F. Ross, \& R. C. Lindsay (Eds.), The handbook of eyewitness psychology: Memory for events (Vol. 1, pp. 157-192). Mahwah, NJ: Lawrence Erlbaum Associates.

Charman, S. D., Reyes, A., Villalba, D. K., \& Evans, J. R. (2017). The (un)reliability of alibi corroborators: Failure to recognize faces of briefly encountered strangers puts innocent suspects at risk. Behavioral Sciences and the Law, 35, 18-36. doi:10.1002/bsl.2264

Crozier, W. E., Strange, D., \& Loftus, E. F. (2017). Memory errors in alibi generation: How an alibi can turn agaist us. Behavioral Sciences and the Law, 35, 6-17. doi:10.1002/bsl.2273

Culhane, S. E., \& Hosch, H. M. (2004). An alibi witness's influence on mock jurors' verdicts. Journal of Applied Social Psychology, 34, 1604-1616. doi:10.1111/j.15591816.2004.tb02789.x.

Culhane, S. E., \& Hosch, H. M. (2012). Changed alibis: Current law enforcement, future law enforcement, and layperson reactions. Criminal Justice and Behavior, 39, 958-977. doi:10.1177/0093854812438185

Culhane, S. E., Hosch, H. M., \& Kehn, A. (2008). Alibi generation: Data from U.S. Hispanics and U.S. non-Hispanic whites. Journal of Ethnicity in Criminal Justice, 6, 177-199. doi:10.1080/15377930802243395

Culhane, S. E., Kehn, A., Horgan, A. J., Meissner, C. A., Hosch, H. M., \& Wodahl, E. J. (2013). Generation and detection of true and false alibi statements. Psychiatry, Psychology and Law, 20, 619-638. doi:10.1080/13218719.2012.729018

Dysart, J. E., \& Strange, D. (2012). Beliefs about alibis and alibi investigations: A survey of law enforcement. Psychology, Crime and Law, 18, 11-25. doi:10.1080/1068316X.2011.562867

Eastwood, J., Snook, B., \& Au, D. (2016). Safety in numbers: A policy-capturing study of the alibi assessment process. Applied Cognitive Psychology, 260-269. doi:10.1002/acp.3200

Harvey, A. C., Vrij, A., Nahari, G., \& Ludwig, K. (2017). Applying the verifiability approach to insurance claims settings: Exploring the effect of the information protocol. Legal and Criminological Psychology, 22, 47-59. doi:10.1111/Icrp.12092 
Jung, S., Allison, M., \& Bohn, L. (2013). Legal decision-making on crimes involving an alibi. Applied Psychology in Criminal Justice, 9, 45-58. doi:10.1037/t04698-000

Nahari, G., \& Vrij, A. (2014). Can I borrow your alibi? The applicability of the verifiability approach to the case of an alibi witness. Journal of Applied Research in Memory and Cognition, 3, 89-94. doi:10.1016/j.jarmac.2014.04.005

Nieuwkamp, R., Horselenberg, R., \& Van Koppen, P. J. (2016). A lie and a mistress: On increasing the believability of your alibi. Psychiatry, Psychology and Law, 23, 733745. doi:10.1080/13218719.2016.1142934

Nieuwkamp, R., Horselenberg, R., \& Van Koppen, P. J. (2017). The illusion of the perfect alibi: Establishing the base rate of non-offenders' alibis. Journal of Investigative Psychology and Offender Profiling, 14, 23-42. doi:10.1002/jip.1470

Olson, E. A., \& Charman, S. D. (2012). 'But can you prove it?' - Examining the quality of innocent suspects' alibis. Psychology, Crime and Law, 18, 453-741. doi:10.1080/1068316x.2010.505567

Olson, E. A., \& Wells, G. L. (2004). What makes a good alibi? A proposed taxonomy. Law and Human Behavior, 28, 157-176. doi:10.1023/B: LAHU.0000022320.47112.d3

Olson, E. A., \& Wells, G. L. (2012). The alibi-generation effect: Alibi-generation experience influences alibi evaluation. Legal and Criminological Psychology, 17, 151-164. doi:10.1111/j.2044-8333.2010.02003.x

Pozzulo, J. D., Pettalia, J. L., Dempsey, J. L., \& Gooden, A. (2015). Juvenile offenders on trial: Does alibi corroboration evidence and defendant age interact to influence jurors' perceptions and verdicts? Psychiatry, Psychology and Law, 22, 224-234. doi:10.1080/13218719.2014.937518

Simon, D. (2012). In doubt: The psychology of the criminal justice process. London: Harvard University Press.

Strange, D., Dysart, J. E., \& Loftus, E. F. (2014). Why errors in alibis are not necessarily evidence of guilt. Zeitschrift für Psychologie, 222, 82-89. doi:10.1027/21512604/a000169

Sullivan, T. P. (1971). Presentation of the defense. Journal of Criminal Law, Criminology, and Police Science, 62, 153-172.

Wells, G. L., Small, M., Penrod, S., Malpass, R. S., Fulero, S. M., \& Brimacombe, C. (1998). Eyewitness identification procedures: Recommendations for lineups and photospreads. Law and Human Behavior, 22, 603-647. 


\subsection{APPENDIX: THE SUSPECT'S PRESENTED ALIBI}

“B. L. claimed that he had been at a friend's house on the day of the robbery. He insisted he had nothing to do with the crime. He said that he and his friend had been planning on watching a football game that day, and he was going to bring snacks. So he left his house on foot at around 11:30, stopped at a nearby grocery store and bought snacks and beer, and continued on to his friend's house, intending to be there by kickoff at noon. I contacted the friend, who confirmed that B. L. was at his house for the football game that day, and they watched the entire game." 



\section{7}

TRUE AND FALSE ALIBIS AMONG PRISONERS AND ITS DETECTION BY POLICE DETECTIVES

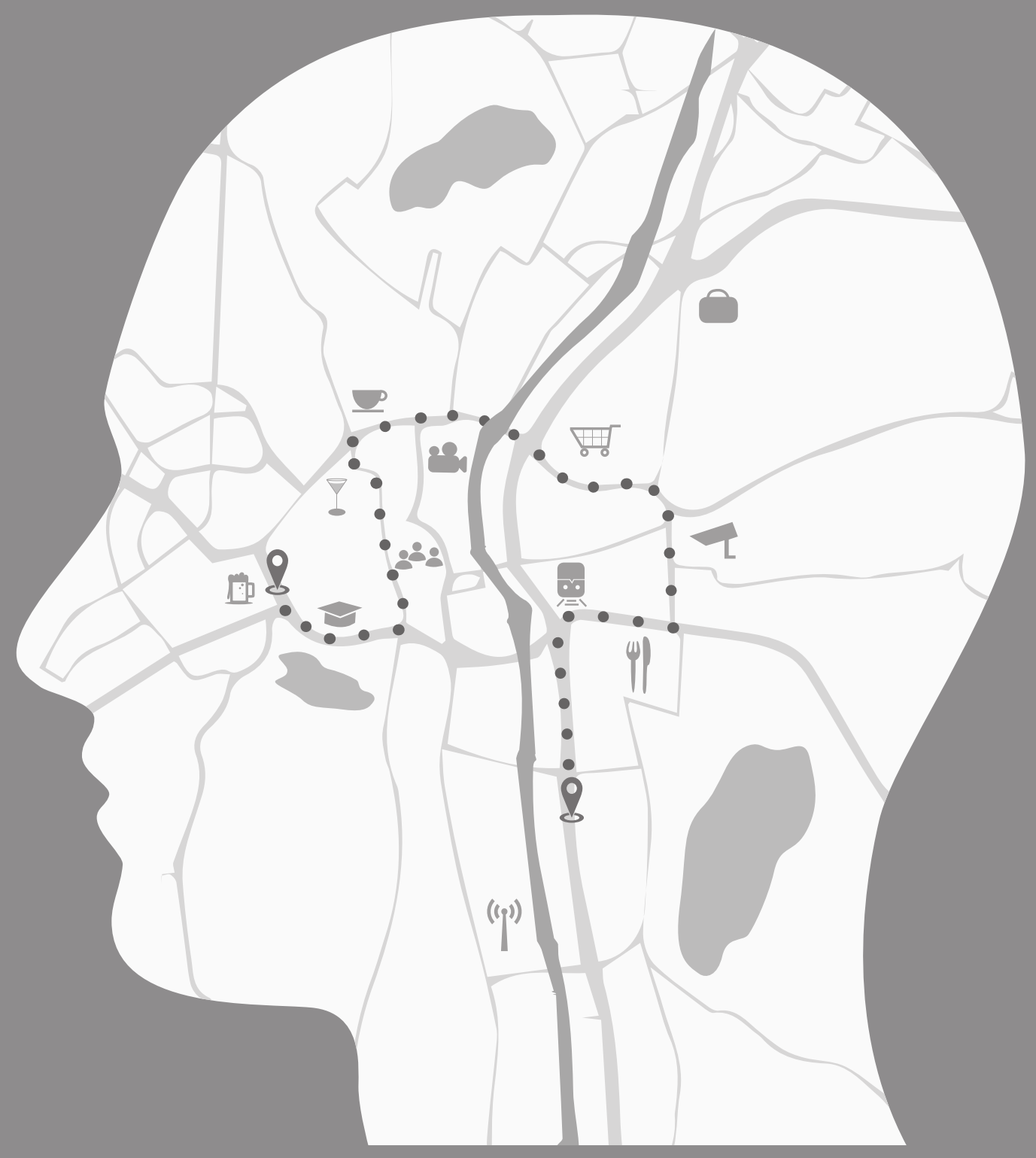

This chapter has been submitted for publication to Psychiatry, Psychology and Law:

Nieuwkamp, R., Horselenberg, R., \& Van Koppen, P. J. True and false alibis among prisoners and its detection by police detectives. Manuscript submitted for publication. 



\begin{abstract}
The present study was designed to determine whether differences exist between true and false alibis and how accurate police detectives and lay people are in determining the veracity of alibis. The present paper provides a replication of the research by Culhane et al. (2013) with more representative participants. In the first study, real suspects in a remand prison generated true or false alibis. In the second study, a subset of those alibis were written out and provided to experienced police officers and students for alibi evaluation and discrimination. Our results show that differentiating between true and false alibis is difficult even when more representative materials and participants are included, the accuracy did not exceed $60 \%$. Interestingly we found that students and police officers focus on other aspects during the alibi discrimination. Thus, research using student participants cannot be, directly, used in alibi discrimination studies.
\end{abstract}


CHAPTER 7

\subsection{INTRODUCTION}

The research on discrimination between true and false alibis is scarce (Culhane et al., 2013; Nahari \& Vrij, 2014; Porter \& Yuille, 1996; Strömwall, Granhag, \& Jonsson, 2003). The present paper describes two experiments aiming for more representative alibi discrimination research using real suspects and police detectives as a sample.

One of the most important limitations in all studies on alibis is the lack of representative samples of participants (e.g., Eastwood, Snook, \& Au, 2016). The experiments in the present paper are inspired by the article of Culhane et al. (2013), in which the authors first asked students to generate either true or false alibis. A subset of these alibis was then video-recorded and subsequently shown to another group of students who were asked to make two piles: those who were true and those who were false. In real life, police detectives are the first to evaluate the alibis. Given the fact that a wrongful classification of the veracity of a suspect's alibi has been an important factor in the review of wrongful conviction cases (e.g., Simon, 2012; Wells et al., 1998), there is an urgent need to conduct research on this topic with a representative sample of participants. This is the main aim of the present paper.

\subsubsection{Alibi Research}

Three broad domains can be identified in the research on alibis: generation, evaluation and discrimination of alibis (Burke, Turtle, \& Olson, 2007; Culhane et al., 2013). In alibi generation studies, non-offenders are asked to generate an alibi and supportive evidence for a specific period in time. The veracity of the alibi is determined in the alibi discrimination domain. In alibi evaluation studies, often mock jurors determine the alibi believability based on the overall believability, strength and ease by which the evidence can be fabricated (e.g., Jung, Allison, \& Bohn, 2013).

In the criminal justice system there appears to be an assumption that innocent people usually generate an accurate and believable alibis (Olson \& Charman, 2012). This means that the alibi should be correct and supported by strong evidence. True alibis can, 
however, also be inaccurate because of various reasons (Crozier, Strange, \& Loftus, 2017). It has been demonstrated that the larger the time gap between the alleged crime and the moment of interviewing, the more errors occur in the alibi statement of non-offenders (e.g., Olson \& Charman, 2012). Furthermore, a suspect might be simply mistaken about his whereabouts when at the time of the alleged crime he was involved in a less common event (e.g., Strange, Dysart, \& Loftus, 2014). Lastly, a suspect may also lie about his alibi to conceal his involvement in another, but shameful situation (Nieuwkamp, Horselenberg, \& Van Koppen, 2016). The assumption that non-offenders are able to present strong supportive evidence for their alibis has proven to be incorrect (Culhane, Hosch, \& Kehn, 2008; Culhane et al., 2013; Olson \& Charman, 2012). In fact, only 2\% of the non-offenders can present strong evidence for their alibis (Nieuwkamp, Horselenberg, \& Van Koppen, 2017).

\subsubsection{Supportive Evidence}

The strength of the supportive evidence can be determined using the alibi taxonomy of Olson and Wells (2004). In the taxonomy, two types of evidence to support an alibi are distinguished: witness evidence and physical evidence. According to the taxonomy, the testimony of an alibi witness is strong supportive evidence when the relational distance between the witness and the suspect is large (e.g., the suspect's neighbour or other unmotivated witness; Olson \& Wells, 2004). The witness' testimony is weaker evidence when the relational distance is small (e.g., the suspect's girlfriend; Culhane \& Hosch, 2004). The rationale behind determining the strength of the witness evidence based on relational closeness is that the closer the relational distance between the suspect and the witness, the more inclined the witness may be to have a motive to lie in favour of the suspect. Police officers, however, focus more on the number of witnesses supporting an alibi than on the relational distance between the witnesses and the suspect (Eastwood, Snook, \& Au, 2016).

Physical evidence is considered strong supportive evidence when three criteria are met. The evidence needs to: a) be linked to the suspect; b) contain time information; and c) contain location information (Olson \& Charman, 2012). That is, it has to locate the suspect at a specific place at a specific time. An example of strong evidence is CCTV-footage from a 
security camera (Olson \& Wells, 2004). A receipt is an example of weak physical evidence, because a receipt usually lacks a link to the one who purchased the goods. The rationale behind the three criteria is that the more difficult it becomes for the suspect to fabricate the physical evidence or to obtain it from someone else, the stronger the evidence becomes. The impact of physical evidence cannot be underestimated because weak physical evidence (i.e., a receipt) has a greater positive influence on the alibi believability than strong witness evidence (i.e., an unmotivated familiar other witness; Olson \& Wells, 2004).

A suspect can also have a combination of witness and physical evidence for his alibi (Culhane et al., 2013; Nieuwkamp et al., 2017). The strength of a combination of supportive evidence can also be determined using the taxonomy of Olson and Wells (2004). The strength of the combination depends on the strength of the witness and physical evidence separately. For example, weak witness evidence combined with weak physical evidence is equally strong as having strong physical evidence without witness evidence (Olson \& Wells, 2004).

\subsubsection{The Studies by Culhane et al. (2013)}

Having knowledge about non-offender's alibis is fundamental to differentiate between true and false alibis as argued by Olson and Charman (2012, p. 12): "The perception in the legal system that alibis have diagnostic value is critically dependent on the assumption that innocent people should be able to produce relatively strong and accurate alibis; otherwise, alibis would be useless as tools to differentiate the innocent from the guilty." Besides the generated alibi that needs to be correct, the presence and strength of the evidence are the most important factors for a believable alibi (Pozzulo, Pettalia, Dempsey, \& Gooden, 2015). As stated above, the research on alibi generation shows that non-offenders are more likely to present weak supportive evidence rather than strong supportive evidence (e.g., Culhane et al., 2013). That makes distinguishing between true and false alibis difficult. It leads scholars to conclude that a discrepancy exists between what alibis non-offenders can present and what alibis are found to be believable (Culhane et al., 2008). 
The most important limitation of alibi research in general and in particular in the field of alibi generation studies is the use of undergraduate students (Eastwood et al., 2016) because older adults "are more likely to have additional family members (spouse and children) [who could support their alibis] and less likely to spend the same amount of time with friends" (Culhane et al., 2013, p. 627). In the present study, we tested alibi generation with a sample of non-students, namely recently arrested male suspects, generating true and false alibis. So, we tested whether the results found by Culhane et al. (2013) among undergraduate students also hold for genuine suspects and police officers using their general methodology for the experiments in the present paper. In order to do so, a short overview of the study by Culhane et al. (2013) is provided, followed by the most important adaptations in the present paper. The rationale behind these decisions is explained per experiment below.

In the paper of Culhane et al. (2013) two experiments are described, one on alibi generation and the other one on alibi discrimination. In the first study, students were asked to provide an either true or false alibi for an evening either five or 12 days ago. All participants were subsequently asked to collect all the reported evidence for their alibis and to return the lab 48 hours later. Inconsistencies in the alibis were observed in $6.5 \%$ of the cases and truth tellers are most often at home with friends or family. Those who reported a false alibi all reported at least one friend as a witness. In addition, false alibis consisted of more words compared to true alibis. The delay had no effect on the results besides that liars reported more witnesses when the delay increased.

Six true and six false statements were subsequently video-recorded and used as materials in the second study. In the second study, another group of students was shown the videotaped alibis and was asked to differentiate between the true and false alibis. A low accuracy (43.3\%) was found, where true alibis were more often classified correctly (57.4\%) than false alibis (29.1\%). While males were better at detecting false alibis, females were better at detecting true alibis.

In the current studies we wanted to increase the ecological validity by improving the selection of participants for the studies. In the first study, in which alibi generation was studied, we asked recently arrested suspects to present a true or a false alibi. In the second 
CHAPTER 7

study we compared the performance of police detectives to student in accurately discriminating between true and false alibis. Police detectives were chosen as participants because their role is very important in the criminal pre-trial investigation. Depending on whether they consider the alibi to be believable or not, the police officers may invest more or less time and energy investigating the suspect's potential involvement in the alleged crime. By doing so, they influence the further procedure.

\subsection{EXPERIMENT 1: ALIBI GENERATION}

The research question we addressed in the first study was whether differences could be observed between true and false alibis generated by real suspects. We expected that truth tellers would report to be more often at home than those who lie, similar to the results from Culhane et al. (2013). Second, we expected that liars would less often mention supportive evidence than truth tellers. Concurrently, when liars mention evidence, the evidence would more often be a testimony of a motivated witness than an unmotivated witness. Third, we expected that truth tellers would report more often physical evidence than liars because it is more difficulty for a liar to fabricate fake physical evidence.

\subsubsection{Method}

\subsubsection{Participants}

Fifty male suspects from a Dutch remand prison participated in the study. Their ages varied between 20 and 60 years $(M d n=34.5)$. Most of them were single, unemployed prior to their arrest and had the Dutch nationality. The suspects were recently arrested by the police and were in pre-trial detention waiting further questioning by the police. Due to privacy regulations, we were only allowed to ask them for their basic demographics 


\subsubsection{Research Design}

The participants were randomly assigned to a condition in which they were either asked to generate a true or a false alibi for two days prior to their arrest by the police. The time between the testing and their alibi varied between 3 and 14 days $(M=10.1, S D=2.9)$.

\subsubsection{Procedure and Materials}

The study was conducted in a Dutch remand prison that was visited on 11 occasions in the period between February 2014 and December 2014. The participants had to meet strict criteria in order to participate in the study. They had to be suspects in a criminal investigation waiting further interviewing by the police and they were not arrested longer than 14 days before participating. That time period was chosen to ensure that most participants could report an alibi (Culhane et al., 2013; Olson \& Charman, 2012) without shifting the study to a memory experiment. The results from alibi generation research show that by increasing the time span between the critical event and the testing results more often in error that require a change in the alibi and the supportive evidence (e.g., Olson \& Charman, 2012). That finding is important but the main focus of the present study is to determine potential differences between true and false alibis. In addition, the only observed effect of an increased delay up to 12 days resulted in liars reporting more witnesses (Culhane et al., 2013); we therefore did not include a difference in the delay.

Ideally we would visit our participants 48 hours after they generated their initial alibi and to come up with supportive evidence in order to verify their statement, but given the context of being in prison that was impossible. It can therefore be argued that the veracity of the alibis cannot be verified. However, inconsistent alibis were only observed in $6.5 \%$ of the generated alibis in the study of Culhane et al. (2013). In our opinion, the limitation of not being able to verify the evidence does not outweigh the benefits of including suspects in the alibi generation research.

With the help of the Bureau Selection and Detention, in the remand prison, suspects were selected for participation based upon their arrival date in prison. To 
guarantee the participant's anonymity, we were only given the cell number when visiting the prison for the study. If the suspect wanted to participate, he was brought to a private room. After consent, the participants read a mock crime report.

The mock crime report was a case description of a robbery, in which the police believes the participant, could be a suspect and wherein the suspect is asked for his alibi on the day and time of the alleged crime. The participant was subsequently asked, in an openended question, to describe as detailed as possible where he had been. Half of the participants were instructed to lie about the alibi, the other half was asked to be truthful. We used the same instruction as Culhane et al. (2013) provided to the lying participants: they were asked to fabricate an alibi that they would tell to the police in order to convince them of their innocence. The other half of the participants was asked to describe their true alibi of where they had been when the alleged crime was committed.

After the participants wrote down their alibis, they were asked if they had supportive evidence (both physical and witness evidence). The participants were asked to describe their physical evidence in an open-ended question, similar to the method used by Culhane et al. (2008). If a witness could support the alibi, the participants were asked in a cued-question what their relation to the witness was. They could choose from six possible witnesses: friend, co-worker, acquaintance, stranger, partner and family member. Afterwards the participants were asked in an open-ended question if they had any other unreported evidence that could support their alibi. The participants were then thanked, received a written debriefing, offered the possibility to receive the results of the study when the data were collected and brought back to their cell.

\subsubsection{Results}

\subsubsection{Alibis}

The participants generated 24 false and 25 true alibis. One participant refused to report a false alibi because he would never talk to the police. The generated alibis were post hoc categorized into 11 categories. The participants reported most often to be at home (40.8\%), 
at a friend's house; alone outside (e.g., jogging); or in a bar with friends (all scores: 12.2\%), Table 1 provides an overview. No difference between the conditions was observed for which alibi location was reported, although five participants said to be in a bar with friends when telling the truth compared to one participant in the lie condition: $\chi^{2}(1, n=49)=2.86$, $p=.09$, Cramer's $V=.24$. In addition, there was no difference between the conditions as to the number of words in the suspect's statement $\left(M_{\text {true }}=74.44, S D=10.93, M_{\text {false }}=71.36\right.$, $S D=16.51) ; F(1,48)=.61$, ns. No support was thus found for our first hypothesis because both truth tellers and liars reported equally often to be at home.

Table 1

Reported Alibis by Truth Tellers and Liars

\begin{tabular}{lrrrrrr}
\hline Location & \multicolumn{2}{c}{ Truth tellers } & \multicolumn{2}{c}{ Liars } & \multicolumn{2}{c}{ Total } \\
\hline & $\mathrm{n}$ & $\%$ & $\mathrm{n}$ & $\%$ & $\mathrm{n}$ & $\%$ \\
\cline { 2 - 7 } At home & 10 & 50.0 & 10 & 50.0 & 20 & 40.8 \\
Shopping & 1 & 100.0 & 0 & 0.0 & 1 & 2.0 \\
In transit & 1 & 100.0 & 0 & 0.0 & 1 & 2.0 \\
With friends & 2 & 33.3 & 4 & 66.7 & 6 & 12.2 \\
Abroad & 1 & 100.0 & 0 & 0.0 & 1 & 2.0 \\
Alone outside & 2 & 33.3 & 4 & 66.7 & 6 & 12.2 \\
With family & 3 & 75.0 & 1 & 25.0 & 4 & 8.2 \\
In a bar with friends & 5 & 83.3 & 1 & 16.7 & 6 & 12.2 \\
With partner & 0 & 0.0 & 2 & 100.0 & 2 & 4.1 \\
At a party & 0 & 0.0 & 1 & 100.0 & 1 & 2.0 \\
At the cinema & 0 & 0.0 & 1 & 100.0 & 1 & 2.0 \\
\hline Total & 25 & 51.0 & 24 & 49.0 & 49 & 100.0
\end{tabular}

\subsubsection{Supportive Evidence}

Forty-four participants (about 90\%) mentioned to have supportive evidence for their alibis and there was no difference between the conditions: $\chi^{2}(1, n=49)=.27, p=.60$, Cramer's $V$ $=.07$. That leads us to reject our second hypothesis that truth tellers would more often report supportive evidence compared to liars. The evidence consisted of only physical evidence (6.8\%), only witness evidence (40.9\%), or a combination of physical and witness evidence (52.3\%). No difference between the conditions was observed whether evidence was presented and which evidence was presented, although 15 truth tellers compared to 
eight liars reported a combination of evidence: $\chi^{2}(1, \mathrm{n}=44)=3.24, p=.07$, Cramer's $V=.27$. Therefore, the individual categories of supportive evidence were examined.

Twenty-four participants (49.0\%) reported to have physical evidence for their alibis. No difference was observed between the truth tellers (62.5\%) and liars (37.5\%) if they reported physical evidence: $\chi^{2}(1, \mathrm{n}=44)=2.48, p=n s$, Cramer's $V=.23$, which leads us to reject our third hypothesis that truth tellers would more often report physical evidence compared to liars. They reported 30 items of physical evidence and again there was no difference between the conditions and the number of items mentioned: $F(1,22)=0.08, p=$ .ns. The items of physical evidence were post-hoc clustered into 15 categories, Table 2 provides an overview. No differences were observed between the categories and the conditions, largest $\chi^{2}(1, \mathrm{n}=24)=0.83, p=.36$, Cramer's $V=.19$.

Witness evidence was reported by 41 participants (93.2\%) and no difference was found between the conditions whether witness evidence was reported: $\chi^{2}(1, n=44)=0.46$, $p=. n s$, Cramer's $V=.10$. They reported a total of 105 witnesses $^{6}$ and again no difference was observed between the conditions and the number of witnesses reported: $F(1,39)=$ $0.12, p=. n s$. A friend was most often mentioned to be able to support the participant's alibi $(\mathrm{n}=44)$ while no participant mentioned a co-worker as a witness. An acquaintance and a stranger can be classified as unmotivated witnesses and a partner while a family member and friend can be classified as motivated witnesses. In total, 91 motivated witnesses (86.7\%) were mentioned compared to 14 unmotivated witnesses (13.3\%). No differences were found for the number of motivated witnesses between the conditions: $F(1,39)=0.14, p=$ $n s$, which leads us also to reject the hypothesis that liars would more often report a witness with a potential motive to lie compared to truth tellers.

Five participants in the truth condition reported additional supportive evidence compared to zero participants in the lie condition: $\chi^{2}(1, n=49)=5.35, p=.02$, Cramer's $V=$ .33. Two participants mentioned physical evidence (unreported telephone records), one

${ }^{6}$ The participants could choose between six categories to indicate the number of witnesses: none, one, two, three, four, five or more. In case the latter option was ticked, we used the lower bound (i.e., five) to calculate the number of witnesses. 
participant reported witness evidence (his neighbour) and two participants reported unclear evidence (e.g., dirty hands caused by working on a friend's scooter).

Table 2

Reported Physical Evidence by Truth Tellers and Liars

\begin{tabular}{lrrrrrr}
\hline Item of physical evidence & \multicolumn{2}{c}{ Truth tellers } & \multicolumn{2}{c}{ Liars } & \multicolumn{2}{c}{ Total } \\
\hline & $\mathrm{n}$ & $\%$ & $\mathrm{n}$ & $\%$ & $\mathrm{n}$ & $\%$ \\
\cline { 2 - 7 } Phone records & 2 & 50.0 & 2 & 50.0 & 4 & 13.3 \\
Bank transaction & 2 & 100.0 & 0 & 0.0 & 2 & 6.7 \\
Receipt & 4 & 50.0 & 4 & 50.0 & 8 & 26.7 \\
CCTV footage & 4 & 80.0 & 1 & 20.0 & 5 & 16.7 \\
Photos & 2 & 100.0 & 0 & 0.0 & 2 & 6.7 \\
Groceries & 1 & 50.0 & 1 & 50.0 & 2 & 6.7 \\
Fresh paint on the wall & 1 & 100.0 & 0 & 0.0 & 1 & 3.3 \\
Computer logs & 1 & 50.0 & 1 & 50.0 & 2 & 6.7 \\
Fresh tattoo & 1 & 100.0 & 0 & 0.0 & 1 & 3.3 \\
Used condom & 0 & 0.0 & 1 & 100.0 & 1 & 3.3 \\
Movie ticket & 0 & 0.0 & 1 & 100.0 & 1 & 3.3 \\
Laundry after playing sports & 0 & 0.0 & 1 & 100.0 & 1 & 3.3 \\
\hline \multicolumn{1}{c}{ Total } & 18 & 60.0 & 12 & 40.0 & 30 & 100.0
\end{tabular}

\subsubsection{Discussion}

The aim of the first study was to determine whether differences can be observed between true and false alibis generated by actual suspects. However, no differences were observed between the true and false alibis. Additional evidence was the only factor that differentiated between true and false statements.

Two downsides may have caused the absence of differences between the groups. First, the participants wrote down their statements because we were not allowed to bring any recording devices into the facility. Audio recordings might have resulted in alibis that were richer in details. Second, the participants are actual suspects and they might be familiar with generating alibis compared to inexperienced students. That may have taken away differences between true and false alibis.

The results show that alibi discrimination based on the type, quantity and quality of the supportive evidence makes the discrimination very difficult. To determine if 
CHAPTER 7

professionals are better at discriminating between true and false alibis, a second experiment was conducted.

\subsection{EXPERIMENT 2: ALIBI DISCRIMINATION AND EVALUATION}

Given the assumption that innocent people can generate accurate alibis supported with strong evidence (Olson \& Charman, 2012) it logically leads to conclude that those who are not innocent cannot generate accurate alibis with strong supportive evidence. However, as described above, there are various reasons why non-offenders would not report an accurate alibi (Crozier et al., 2017). In addition, alibi generation research shows that the strength of the supportive evidence cannot be used solely to determine the believability of an alibi because most non-offenders do not have such strong evidence although they are innocent (e.g., Nieuwkamp et al., 2017). It has lead scholars more recently to study whether any differences can be distinguished between true and false alibis rather than only focusing on the strength of the evidence (Culhane et al., 2013). In alibi discrimination, the evaluators try to differentiate between true and false statements. To understand the research on alibi discrimination, a short and to the point overview is provided of lie detection research.

\subsubsection{Verbal and Non-Verbal Cues for Lie Detection}

In general, one can either apply non-verbal techniques for deception detection or one can use verbal techniques for it. Using non-verbal techniques, more attention is being paid to the non-verbal behaviour (e.g., gaze, body movement) rather than the content of someone's statement. From lie detection research it is known that when using videorecorded statements, people tend to focus on non-verbal cues (e.g., movements and posture) rather than verbal cues (i.e., the speech content) (e.g., Vrij, 2008). A meta-analysis on verbal and non-verbal cues of deception showed that the non-verbal cues of deception are especially weak and unreliable (DePaulo et al., 2003). More support for the use of verbal cues can be found in the Undeutsch hypothesis (Stellar, 1989) where it is stated that true statements can be distinguished from fabricated statements because they consist of 
different verbal characteristics (Van Koppen \& Van Koppen, 2010). The results of research on topic of discrimination between true and false statements show increased accuracy when the evaluators only have access to written or audio statements and when only verbal cues are available compared to when also non-verbal cues are available (Bond \& DePaulo, 2006; Burgoon, Blair, \& Strom, 2008; DePaulo, Rosenthal, Green, \& Rosenkrantz, 1982; Lindholm, 2008). More specifically, when the evaluator focuses on a cluster of verbal cues the accuracy in the discrimination could increase up to $80 \%$ (Vrij, 2008).

However, not all verbal cues are diagnostic to differentiate between true and false statements. The cues that have been found to be diagnostic are: plausibility, level of detail, logical structure, length and the number of contradictions (DePaulo et al., 2003; Vrij, 2005, 2008). Furthermore, Hartwig and Bond (2011) found that the strongest cue for deception detection is the global impression of the statement. The authors therefore argue that a variety of cues can be better predictors than an evaluation on individual cue level (Hartwig \& Bond, 2011).

Regardless of the research on lie detection, it is worth mentioning that during a police interview, interviewers tend to focus more attention on non-verbal cues rather than on verbal cues (Vrij, Granhag, Mann, \& Leal, 2011). In order to better differentiate between true and false statements the use of verbal cues is therefore preferred over non-verbal cues (Vredeveldt, Van Koppen, \& Granhag, 2014; Vrij, 2008), which for example can be achieved by providing a written statement. It is therefore advised to focus more on what is being said rather than how it is being said (e.g., Vredeveldt et al., 2014).

\subsubsection{Alibi Discrimination}

In all studies on alibi discrimination, the participants were undergraduate students. To make a decision whether the alibis presented to them were true or false, students are typically shown a videotaped statement (Culhane et al., 2013; Strömwall et al., 2003) or statements written out on paper (Nahari \& Vrij, 2014; Porter \& Yuille, 1996). From that type of research it is known that true alibis are found to be more coherent (Porter \& Yuille, 1996) and more often supported by evidence and details that can be verified compared to false alibis (Nahari 
\& Vrij, 2014). False alibis more often consist of statements in which people report to be at home where a witness can support their alibi compared to true alibis (Culhane et al., 2013). These researchers also found that untruthful alibis consist of more words than true alibis.

Students find the discrimination between true and false alibis difficult, with a modest accuracy of $66 \%$. True alibis are more often classified correctly (about $71 \%$ ) than false alibis (about 62\%). The non-representative materials and participants in the research can, perhaps, explain the modest results. The present study aims at narrowing the gap between laboratory studies and fieldwork. Ten of the alibis generated in study 1 were presented to experienced police detectives to determine if they are better at discriminating between true and false alibis than students.

The research question that was investigated in the second study is whether police detectives can make a better decision on alibi discrimination than students. Second, we were interested in which criteria both groups of participants use to discriminate between the alibis. We first expected the overall accuracy would be around $66 \%$ (based on the results of previous research). Because the introduction of police detectives in the research on alibi discrimination is new, we had no concrete expectation on their performance but we expected that, based on their expertise, their performance would be better compared to students. Second, we expected that true alibis will be evaluated as: more believable, contain more details, have a more logical structure, shorter and contain fewer contradictions compared to false alibis based on previous findings in lie detection (DePaulo et al., 2003; Vrij, 2005, 2008). In addition, we know that both police detectives and students expect strong evidence for a true and believable alibi (Dysart \& Strange, 2012; Jung et al., 2013) we therefore expected that for both groups the presence of strong (i.e., physical) evidence would be important when they discriminate between alibis. However, given their expertise, it might be that police detectives focus on additional aspects of the alibis in the process of alibi generation. We will explore the factors influencing the decision about the alibis in both groups. 


\subsubsection{Method}

\subsubsection{Participants}

A total of 46 police detectives ( 26 males) ${ }^{7}$ and 47 undergraduate students (11 males) were recruited for the study. The detectives' ages varied between 24 and 63 years ( $M d n=45.0)$. On average, they worked for more than 20 years for the police and had about 14 years of interview experience. Only five police detectives $(11.4 \%)^{8}$ received some training in deception detection or on how to evaluate alibis. Most of the police detectives evaluate an alibi less than once a month in criminal cases they encounter jobwise. The students' ages varied between 19 and 27 years $(M d n=21.0)$. Two gift cards of 10 euros were raffled among each group of participants.

\subsubsection{Research Design}

The design of the study consisted of a 2 (police detective, student) x 2 (true, false alibi) mixed factorial design.

\subsubsection{Procedure and Materials}

From the 24 false alibis generated in prison, five alibis were randomly selected using www.randomnumbergenerator.com and five true alibis were selected from the 25 true alibis using the same procedure. The 10 selected alibis were written out in the format of an official police report (see attachment). The statements were written out because the results of lie detection research show that verbal cues of a statement are more effective to differentiate between true and false statements than non-verbal cues (Vredeveldt et al., 2014; Vrij, 2008). The participants were subsequently provided with a random set of five alibis out of the 10 alibis selected for the study. The presented set of five alibis could thus

${ }^{7}$ Four participants did not report their gender.

8 Two missing values, only valid percentage is reported. 
consist of five true alibis, five false alibis, or five alibis of which some were true and some were false.

\subsubsection{Pilot Study}

Because the statements generated in study 1 were quite short and the number of details was quite low, we wanted to know if the a priori selected statements would be suitable for the second study. To assess whether the generated alibis in prison were suitable for the present study, a researcher (different from the authors), asked 10 laypeople to provide either a true or false alibi following the same instructions given to the participants in study 1. When the new statements were collected, the participants were asked follow-up questions (e.g., what did you do prior to 8.30 PM) and questions to generate more details (e.g., could you describe what you have watched on the television?) after their free recall. These statements were verbatim transcribed in question-answer format. The length of the laypeople's statements consisted of 496 words on average $\left(M_{\text {true }}=441.6, M_{\text {false }}=551.0\right)$ and the statements from study 1 consisted of 73 words on average $\left(M_{\text {true }}=74.44, M_{\text {false }}=71.36\right)$. The 10 alibis selected a priori for the second experiment and the 10 alibis generated by laypeople were provided to 10 scholars from the KU Leuven University in Belgium. They were asked to classify the statements in two piles: true and false. No difference was observed in their accuracy between the groups despite the longer and more detailed statements from laypeople. We therefore kept the alibis generated by the suspects to increase the ecological validity of the materials.

\subsubsection{Procedure and Materials Continued}

In the present study, the student participants could register for participating in the study by applying via the SONA system or by contacting the researcher via contact information on posters throughout the faculty. The police detectives were contacted through personal contacts. The participants completed the questionnaire individually. A researcher was always present in case clarification was needed. In a minority of cases, a detective 
completed the questionnaire at a later moment after s/he was called away for an emergency.

The participants had to fill in seven separate forms. After completing the informed consent and demographics form they read a crime report containing the mock crime scenario identical to the one used in Study 1. In that report it was also stated that multiple suspects were arrested and that all of them presented an alibi. Because it was unclear whether the arrested suspects were involved in that crime, it could be the case that all alibis were true, that all alibis were false or that some alibis were true and some false, similar to the method used by Culhane et al. (2013). The participants were then presented with five alibis. After reading each alibi, the participants received an evaluation form.

On the evaluation form, the participants were first asked in a forced choice question whether the alibi was true or false (i.e., alibi discrimination). The participants then evaluated the alibis (i.e., alibi evaluation) on criteria that have been proven to be effective in differentiating between true and false statements from the lie detection literature (e.g., the number of contradictions) and alibi evaluation (e.g., alibi believability). A variety of cues was presented because such variety can be a better predictor than single cue indicators (Hartwig \& Bond, 2011; Vrij, 2008). In addition, the participants were asked to evaluate all the reported supportive evidence on three aspects per type of reported evidence: the difficulty of fabrication, the strength, and the believability. The participants were also asked to score the verifiability of all presented evidence. The number of questions on the evaluation forms thus varied between seven and 17 questions depending on whether the alibi was supported with evidence and what type of evidence was reported. When an alibi was presented without supportive evidence, the participant answered seven questions. When the three types of supportive evidence were reported, the participants answered 17 questions.

Besides the forced choice question at the beginning of the evaluation form, the participants were asked to mark their answers on a $100 \mathrm{~mm}$ Visual Analogue Scale (VAS: $0=$ not at all believable; $100=$ completely believable) (Luria, 1975). 
Last, the participants were asked to divide 100 points over the 12 aspects of the evaluation form ${ }^{9}$ indicating which of the aspects are most important for them to determine the veracity of each alibi. Using that method, we hoped to receive more information on which aspects are important to the participants in alibi discrimination. After the participants completed all forms, they received a written debriefing, were offered the possibility to receive the results of the study and were able to write down their email address to participate in the raffle of gift cards.

\subsubsection{Results}

\subsubsection{Accuracy}

First, the proportion of the accuracy was calculated. The overall accuracy was moderate $(M d n=.60)$, however, for the police officers, their accuracy scores for the true alibis were non-normally distributed, with skewness of-1.61 (SE=.43) and kurtosis of $2.23(S E=.85)$. The police data for the false alibis were also non-normally distributed with skewness of .11 $(S E=.12)$ and kurtosis of-1.67 (SE=.92). Therefore separate analyses were conducted to determine the accuracy of the true and false alibis. A Mann-Whitney test indicated that the detection of true alibis was higher for police detectives $(M d n=1.00)$ than for students $(M d n=.67), U=506.0, p=.020, r=.24$. No such difference was observed for the false alibis, $U=983.0, p=.073, r=.20$. Examining the proportions, it appears that a substantial number of all participants either have all correct or non-correct. For example, when only one true alibi was presented and the participant classified the alibi correctly, it can be concluded that all true alibis were classified correctly. To control for that, we selected the participants (29 police officers and 31 students) who at least evaluated either two true or two false alibis. In that case, police officers are still better at classifying true alibis $(M d n=1.00)$ over students (Mdn=.67), $U=303.5, p=.025, r=.29$. With regard to false alibis that were classified

${ }^{9}$ For the alibi: the ease by which it can be fabricated, the clearness, the believability, the number of details, the length and the number of contradictions. For the evidence: the presence/absence of physical, witness and additional evidence, the ease by which the evidence can be fabricated, the believability and the verifiability. 
correctly, students perform better than police, although the median of the proportion false alibis classified correctly is identical for both groups ( $M d n=.50)$, officers: $U=621.5, p=.023$, $r=.29$.

When we examine the cases in which the participants are presented with at least two true and true false alibis, all significant differences disappear, due to a very small sample of participants (15 police officers and 14 students). We can therefore conclude that police detectives are better at detecting true alibis than students, while students are better at detecting false alibis when at least two false alibis are presented. The performance of police officers was not influenced by whether or not they were more or less experienced within the police force or in conducting interviews, highest $U=257, p=.210, r=.20$. The results leads us to carefully accept our hypothesis that the accuracy would be around 66\% although important differences between police detectives and students are shown.

\subsubsection{Alibi Evaluation}

All the data on the alibi evaluation aspects were normally distributed, apart from the clearness of the alibi. The police officers' scores on that variable were non-normally distributed; with skewness of $0.75(S E=.16)$ and kurtosis of-1.22 (SE=.32). The students' scores were also non-normally distributed with skewness of-.08 $(S E=.16)$ and kurtosis of$1.03(S E=.16)$. The results show that while no difference is observed between the true and the false alibis, a difference is observed between the groups of participants. For both true and false alibis students found the alibis more clear $(M d n=5.2)$ than the police officers $(M d n=4.7), U=31174.0, p=.001, r=.16$.

The other variables were analysed using multivariate analyses of variance. An alpha level of .05 was used in each of the analyses. All significant effects were examined applying a Bonferroni adjustment for multiple testing. The results revealed that police detectives came to their decision more rationally $(M=5.50 ; S D=2.80)$ than students $(M=4.76$, $\left.S D=2.46 ; F(1,455)=9.17, p=.003, \eta_{p}{ }^{2}=.020\right)$ and police detectives found the alibis to contain fewer contradictions $(M=2.49, S D=2.17)$ than students $(M=2.99, S D=2.38 ; F(1,455)$ $\left.=5.01, p=.011, \eta_{p}^{2}=.011\right)$. Furthermore, true alibis were also found to be more difficult to 
fabricate $(M=3.61, S D=2.77)$, believable $(M=5.48, S D=2.30)$, detailed $(M=3.81, S D=2.74)$ and contain fewer contradictions $(M=2.99, S D=2.38)$ than false alibis. ${ }^{10}$

Although the true alibis were, for example, found to be more believable than false alibis, the mean scores are relatively low (5.48 on a 10-point scale). These low scores could possibly be explained by the modest overall accuracy (60\%). Therefore, we examined if the average scores on these aforementioned aspects were more related to the participants' evaluation (true or false) than the ground truth of the alibis, using Generalized Estimating Equation (GEE) analyses (Hanley, Negassa, Edwardess, \& Forrester, 2003).

\subsubsection{GEE Analysis}

In the present study the participants rated the same aspects of all alibis. The five measurements of believability, for example, are dependent within-subjects factors and produce correlated data. To control for such a dependency, separate GEE analyses were conducted for each aspect per group of participants. In the analyses it was determined whether the score on each aspect was more related to the ground truth of the alibi (hereafter: ground truth) or more to the evaluation of the alibi (hereafter: evaluation). For example, the students score on the aspect 'the number of details' the intercept consists of 1.77 points, which is the expected score when a false alibi is evaluated as false. The betascore for ground truth is 0.81 points, thus when the alibi is true the expected score for this aspect increases with 0.81 points and that increase is significant. When the alibi is evaluated as true, the score increases with 2.22 points, which is again a significant increase. Thus, when the alibi is true and is evaluated as true, the expected score increases significantly by $0.81+2.22$ points $=4.80$ points; see Table 3 for the test results.

\footnotetext{
${ }^{10}$ Respectively: $\left(M=4.98, S D=2.32 ; F(1,455)=6.39, p=.012, \eta_{p}^{2}=.014\right) ;(M=2.76, S D=2.66 ; F(1,454)$ $\left.=11.20, p=.001, \eta_{p}^{2}=.024\right) ;\left(M=4.65, S D=2.34 ; F(1,455)=13.85, p<.001, \eta_{p}^{2}=.030\right) ;(M=2.69$, $\left.S D=2.59 ; F(1,455)=19.73, p<.001, \eta_{p}^{2}=.042\right)$ and $\left(M=2.49, S D=2.17 ; F(1,455)=16.48, p<.001, \eta_{p}{ }^{2}\right.$ $=.035)$.
} 


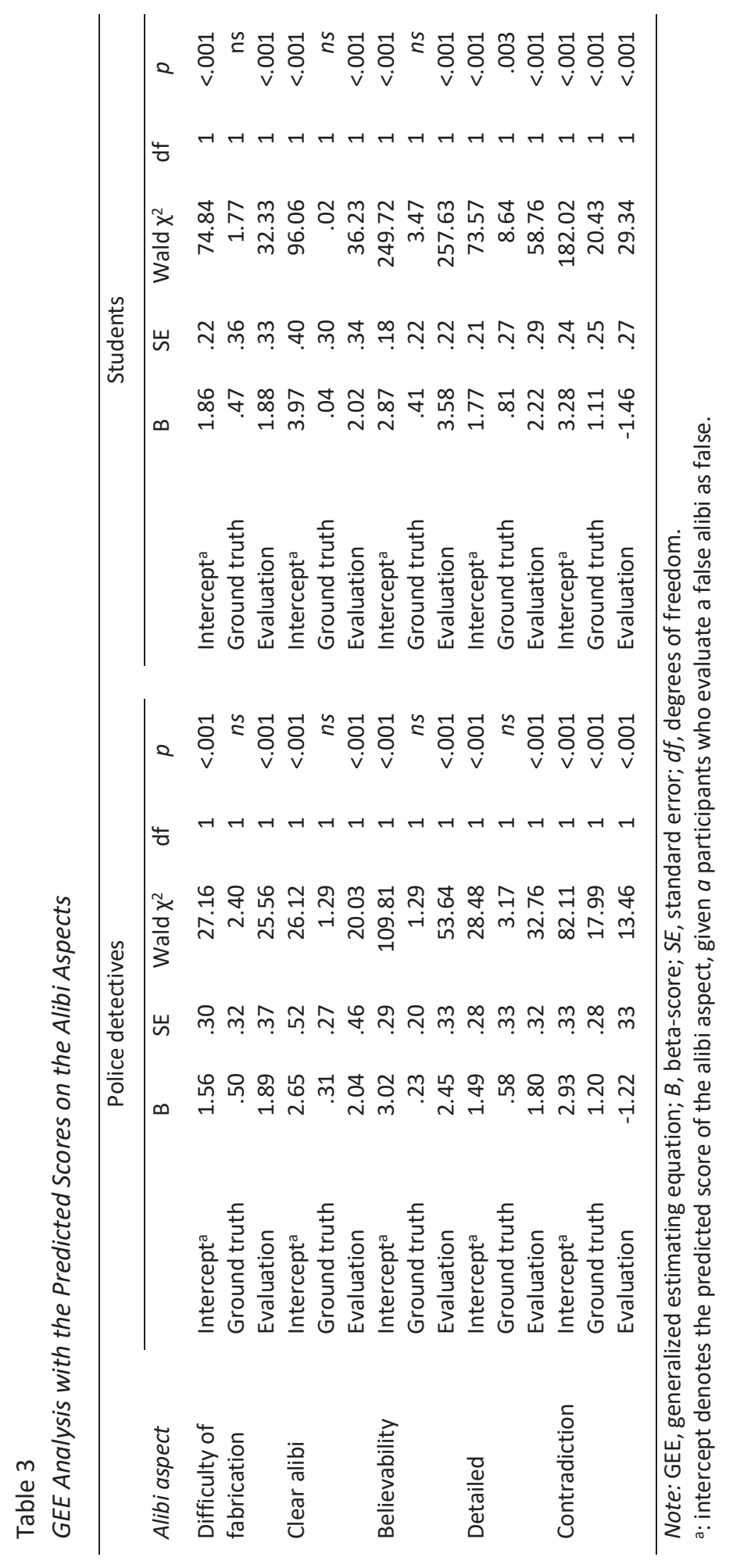


For both groups of participants the results show that the scores on all dependent measures were significantly related to the evaluation of the alibi, apart from the police officers' score on the rationality of their decision. Besides the aspect 'contradiction' all aspects obtained a positive beta-score indicating a higher score on the dependent measures when the alibi was evaluated as true compared to false (i.e., the value of the intercept). The aspect contradiction received a negative beta score for the evaluation. That is, when the alibi is evaluated as true, the number of contradictions decreases. For both groups, the results show that the scores on the number of contradictions were significantly related to the ground truth of the alibi. In the student data the ground truth of the number of details was also significantly related to their scores. All three aspects had a positive beta score indicating that when the alibi is true, the expected score on the dependent measures would increase. In sum, the scores on the dependent measures are more often related to the evaluation of the alibi than to the ground truth of the alibi. It can be concluded that when the alibi is evaluated as true, higher scores are observed for the difficulty of fabrication, its believability, the number of details and the clearness of the alibi, while the number of contradictions decreases. Based on the results, our second hypothesis is partly rejected. True alibis are found to be more difficult to fabricate, believable, detailed and contain fewer contradictions but are no difference in the number of words has been observed.

\subsubsection{Supportive Evidence}

Similar to the analyses conducted for the alibi evaluation, the analyses of the strength, ease of fabrication and believability of the supportive evidence resulted in counter intuitive results. For example, the physical evidence for a false alibi is more believable than for a true alibi. As stated above, given the modest accuracy in detecting the veracity of statements, it should be determined if the scores on the dependent measures of the supportive evidence relate more to the decision whether the alibi is true than its ground truth. Therefore linear regression analyses were conducted and the results are displayed in Table 4.

Based on the participants' decision, it can be concluded that both groups of participants gave significant higher scores for alibis they evaluated to be true compared to 
alibis they classified as false on all evidence aspects (i.e., strength, believability and difficulty of fabrication), besides the strength of additional evidence by police officers. These scores are positive and imply that when an alibi is evaluated as true, the score increases compared to when the alibi is evaluated as false. For the ground truth of the alibis, most of the participants' scores were significantly lower than the constant in the model. In such cases the values were negative implies that if the alibi is true, lower scores on the aspects are observed. 
Table 4

Evaluation of the Supportive Evidence by Police Detectives and Students

\begin{tabular}{|c|c|c|c|c|c|c|c|c|c|c|c|c|c|c|}
\hline \multirow[b]{2}{*}{ Evidence } & \multicolumn{7}{|c|}{ Police detectives } & \multicolumn{7}{|c|}{ Students } \\
\hline & & $B$ & $S E$ & B & $T$ & $p$ & $R^{2}$ & & $B$ & $S E$ & b & $T$ & $p$ & $R^{2}$ \\
\hline \multirow{3}{*}{$\begin{array}{l}\text { Physical } \\
\text { Strength }\end{array}$} & Constant $^{a}$ & 2.68 & .93 & & 2.88 & .005 & .17 & Constant $^{\mathrm{a}}$ & 4.49 & .84 & & 5.82 & $<.001$ & .17 \\
\hline & Decision & 2.90 & .81 & .37 & 3.60 & .001 & & Decision & 1.71 & .66 & .26 & 2.60 & .011 & \\
\hline & Ground truth & -1.11 & .62 & -.18 & -1.79 & ns & & Ground truth & -1.74 & .64 & -.27 & -2.73 & .008 & \\
\hline \multirow[t]{3}{*}{ Believability } & Constanta & 2.24 & .90 & & 2.49 & .015 & .20 & Constant ${ }^{\mathrm{a}}$ & 5.19 & .71 & & 7.35 & $<.001$ & .22 \\
\hline & Decision & 3.55 & .78 & .43 & 4.58 & $<.001$ & & Decision & 1.98 & .55 & .35 & 3.59 & .001 & \\
\hline & Ground truth & -.25 & .61 & -.04 & -.41 & $n s$ & & Ground truth & -1.40 & .54 & -.25 & -2.62 & .010 & \\
\hline \multirow{3}{*}{$\begin{array}{l}\text { Difficulty of } \\
\text { Fabrication }\end{array}$} & Constanta & 3.56 & 1.00 & & 3.54 & .001 & .12 & Constant ${ }^{\mathrm{a}}$ & 3.24 & .85 & & 3.81 & $<.001$ & .09 \\
\hline & Decision & 2.16 & .87 & 2.6 & 2.48 & .015 & & Decision & 2.18 & .67 & .34 & 3.81 & $<.001$ & \\
\hline & Ground truth & -1.44 & .67 & -.23 & -2.15 & .034 & & Ground truth & .36 & .65 & .06 & .56 & $n s$ & \\
\hline \multirow[t]{2}{*}{ Witness } & Constant ${ }^{\mathrm{a}}$ & 2.53 & .42 & & 5.96 & $<.001$ & .20 & Constant ${ }^{\mathrm{a}}$ & 3.41 & .35 & & 9.62 & $<.001$ & .15 \\
\hline & Decision & 2.85 & .43 & .46 & 6.64 & $<.001$ & & Decision & 2.11 & .36 & .40 & 5.95 & $<.001$ & \\
\hline Strength & Ground truth & -.03 & .37 & -.01 & -.09 & $n s$ & & Ground truth & -.21 & .35 & -.04 & -.60 & $n s$ & \\
\hline \multirow[t]{3}{*}{ Believability } & Constant $^{\mathrm{a}}$ & 3.00 & .38 & & 7.86 & $<.001$ & .20 & Constant $^{\mathrm{a}}$ & 3.28 & .31 & & 10.59 & $<.001$ & .19 \\
\hline & Decision & 2.57 & .39 & .46 & 6.67 & $<.001$ & & Decision & 2.06 & .31 & .44 & 6.61 & $<.001$ & \\
\hline & Ground truth & -.38 & .33 & -.78 & -1.14 & $n s$ & & Ground truth & .40 & .41 & .09 & 1.30 & $n s$ & \\
\hline \multirow{3}{*}{$\begin{array}{l}\text { Difficulty of } \\
\text { Fabrication }\end{array}$} & Constant ${ }^{\mathrm{a}}$ & 2.22 & .44 & & 5.01 & $<.001$ & .11 & Constant ${ }^{\mathrm{a}}$ & 2.71 & .38 & & 7.16 & $<.001$ & .06 \\
\hline & Decision & 2.18 & .45 & .35 & 4.85 & $<.001$ & & Decision & 1.28 & .38 & .24 & 3.39 & .001 & \\
\hline & Ground truth & -.08 & .39 & -.01 & -.20 & $n s$ & & Ground truth & .56 & .37 & .11 & 1.49 & ns & \\
\hline
\end{tabular}


Table 4 continued

Evaluation of the Supportive Evidence by Police Detectives and Students

\begin{tabular}{|c|c|c|c|c|c|c|c|c|c|c|c|c|c|c|}
\hline \multirow[b]{2}{*}{ Evidence } & \multicolumn{7}{|c|}{ Police detectives } & \multicolumn{7}{|c|}{ Students } \\
\hline & & $B$ & $S E$ & b & $t$ & $p$ & $R^{2}$ & & $B$ & $S E$ & b & $t$ & $p$ & $R^{2}$ \\
\hline Additional & Constant ${ }^{\mathrm{a}}$ & 4.39 & .89 & & 4.91 & $<.001$ & .23 & Constant $^{a}$ & 4.48 & .81 & & 5.55 & $<.001$ & .37 \\
\hline \multirow[t]{2}{*}{ Strength } & Decision & 1.48 & .79 & .21 & 1.87 & ns & & Decision & 2.96 & .70 & .42 & 4.25 & $<.001$ & \\
\hline & Ground truth & -2.15 & .61 & -.41 & -3.55 & .001 & & Ground truth & -1.82 & .52 & -.35 & -3.51 & .001 & \\
\hline \multirow[t]{3}{*}{ Believability } & Constant $^{\mathrm{a}}$ & 3.87 & .87 & & 4.43 & $<.001$ & .21 & Constant $^{\mathrm{a}}$ & 5.18 & .86 & & 6.03 & $<.001$ & .24 \\
\hline & Decision & 2.02 & .77 & .30 & 2.62 & .012 & & Decision & 2.13 & .74 & .32 & 2.87 & .005 & \\
\hline & Ground truth & -1.60 & .59 & -.31 & -2.70 & .009 & & Ground truth & -1.62 & .55 & -.32 & -2.93 & .005 & \\
\hline Difficulty of & Constanta & 2.43 & 1.01 & & 2.41 & .019 & .10 & Constanta & 3.92 & .94 & & 4.19 & $<.001$ & .29 \\
\hline \multirow[t]{2}{*}{ Fabrication } & Decision & 2.07 & .89 & .29 & 2.33 & .023 & & Decision & 2.69 & .81 & .35 & 3.34 & .001 & \\
\hline & Ground truth & -.86 & .68 & -.16 & -1.27 & $n s$ & & Ground truth & -1.90 & .60 & .34 & -3.16 & .002 & \\
\hline \multirow{3}{*}{$\begin{array}{l}\text { Verifiability all } \\
\text { evidence }\end{array}$} & Constant ${ }^{\mathrm{a}}$ & 5.20 & .43 & & 12.22 & $<.001$ & .08 & Constant ${ }^{\mathrm{a}}$ & 4.58 & 3.37 & & 12.28 & $<.001$ & .01 \\
\hline & Decision & -1.44 & .43 & -.25 & -3.34 & .001 & & Decision & -.78 & .37 & -.15 & -2.09 & .038 & \\
\hline & Ground truth & -.84 & .37 & -.17 & -2.25 & .026 & & Ground truth & -.01 & .37 & -.00 & -.01 & ns & \\
\hline
\end{tabular}

Note: $B$, beta-score; $S E$, standard error; $B$, standardized beta; $R^{2}$, determination coefficient (percentage of dependent variable which is explained by the linear model with the independent variables (ground truth and evaluation).

a: constant denotes the predicted score of the aspect, given $a$ participants who evaluate an actual false alibi (ground truth = false) and the participant correctly classifies the alibi as false (evaluation $=$ false). 
CHAPTER 7

\subsubsection{Which Aspects are Important for Alibi Discrimination?}

After the participants evaluated the alibis they were for each alibi asked to divide 100 points over 12 aspects to determine what aspects in the alibi were found to be important to decide whether the alibi was true or false. Out of the 465 evaluated alibis, the points of 409 alibis could be used. Other cases had to be removed either due to missing values $(n=14)$ or due to participants who allocated more than 100 scores to the 12 aspects $(n=42)$. The data were non-normally distributed causing the average or median score not to be usable in the analyses due to higher number of cases in which 0 points were attributed to the aspects. We therefore created four levels of scores per aspect points to obtain a normal distribution of scores: 0; scores between 1 and 5; scores between 5 and 10; and scores more than 10. These ordinal categories of scores were compared between the groups.

The results show that students more often attribute more than 10 points on whether or not physical evidence was reported $(n=34)$ compared to police officers $(n=11$; $\left.\chi^{2}(2, n=151)=11.90, p=.003, \tau_{b}=.227, p=.003\right)$. Police officers more often assigned 10 or more points on the length of the alibi $(n=15)$ than students $\left(n=4 ; \chi^{2}(2, n=108)=11.79, p=\right.$ $\left..003, \tau_{b}=-.296, p=.002\right)$. In addition, police officers more often assigned 10 or more points to the verifiability of the evidence $(n=67)$ than students $\left(n=37 ; \chi^{2}(2, n=250)=33.17, p<.001\right.$, $\left.\tau_{\mathrm{b}}=-.302, p<.001\right)$. Comparing the column proportions with a $z$-test applied with a Bonferroni correction for multiple comparisons, showed that all proportions were also significant different from each other $(p<.05)$. It can therefore be concluded that when discriminating between alibis, students find the presence of physical evidence most important, while police officers more often focus on the length of the statement and in particular on how easy the alibi can be verified. The data leads us to reject the third hypothesis because only students found the presence of strong supportive evidence one of the most important aspects in the alibi discrimination process. 


\subsubsection{Discussion}

By providing written statements of real suspects to professionals, we observed accuracy rates of $60 \%$ comparable to previous findings (Culhane et al., 2013; Granhag, Strömwall, \& Jonsson, 2003; Nahari \& Vrij, 2014; Porter \& Yuille, 1996). We found that police officers are better at detecting true alibis and that students are better at detecting false alibis. That is, when their sample consisted of minimal two false statements. As expected, true alibis are found to be more difficult to fabricate, more believable, detailed and contain fewer contradiction than false alibis. The data show that police officers come to their decision more rationally than students when evaluating an alibi while students find the alibis to contain more inconsistencies than police officers. Most importantly, however, is that professionals and students focus on different aspects of the alibi when deciding whether the alibi is true or false. Whereas students focus on the presence of physical evidence, police detectives pay more attention to the length of the statement and whether or not the alibi can be verified in general. The present study adds to the discussion that more research should be conducted with representative samples of participants (e.g., Eastwood et al., 2016), especially because students differently discriminate between statements compared to professionals.

One of the most important downsides of the study is the used material. The police officers expressed that they would have liked an opportunity to see the suspect when he told his alibi or to be provided with the possibility to ask follow-up questions to each suspect. That is common limitation when case vignettes are used, however, it guarantees that all participants were provided with the same information because one can imagine that the follow-up question would vary a lot depending on the interest of the participant.

\subsection{GENERAL DISCUSSION}

The goal of the present studies was to apply the general methodology of Culhane et al. (2013) on generating and discriminating between true and false alibis with different groups of participants. Different groups of participants were included to increase the ecological 
validity of the research. Our results are nevertheless comparable with the findings reported by of Culhane et al. (2013). One of the most interesting findings in our results is the knowledge that police detectives focus on other aspects during the alibi discrimination process compared to students. That is an important finding for future research and adds to the argumentation that the results of alibi research using students as participants cannot be translated on a one-to-one basis in practice (e.g., Culhane et al., 2008; Nieuwkamp et al., 2017).

In general it can be concluded that differentiation between true and false alibis is a complex matter. Examining differences between true and false statements (e.g., the alibi, the presence of supportive evidence) did not result in any differences in Study 1, besides the presence of additional evidence is more often reported by truth tellers than by liars. In addition, the results of Study 2 show that the discrimination between true and false alibis neither appears to be easy, with a modest accuracy of $60 \%$. Our results therefore add to the little research on alibi discrimination that the discrimination is difficult (Culhane et al., 2013; Granhag et al., 2003; Nahari \& Vrij, 2014; Porter \& Yuille, 1996). We expected the professionals to outperform the students based on their rich experience in investigating crimes, but this was not the case. Although the accuracy scores in the present study are slightly better compared to Culhane et al. (2013), they do not approach the accuracy rates in the verbal lie detection domain where up to $80 \%$ accuracy scores are reported (Vrij, 2008). However, an alibi is a different type of statement compared to the ones normally used in (verbal) lie detection. Alibis go often hand in hand with reported supportive evidence and the presence and strength of such evidence. Both highly influence the alibi believability (e.g., Jung et al., 2013). Based on the relatively weak evidence non-offenders can present in general (e.g., Nieuwkamp et al., 2017; Olson \& Charman, 2012), and likewise observed in Study 1, the weak evidence might have affected the overall impression of the alibi. Knowing that global impression of a statement is the strongest predictor of its veracity (Hartwig \& Bond, 2011), the alibis might have been negatively affected by that weak evidence.

Although the accuracy rates in the present study do not differ much from previous findings from alibi discrimination research, it is interesting to know that police officers are 
better at detecting true alibis compared to students. Although it has been argued that police officers display a guilty bias towards suspects (e.g., Meissner \& Kassin, 2002), it could be the case that the opposite happens with alibis. That is, police officers believe the suspect's alibi. During the debriefing, the police officers also expressed that, although they had limited information, until the alibi can be verified they tended to believe the suspect bearing in mind the presumption of innocence.

The students were better at detecting false alibis than police officers. That result is unexpected because previous studies found out that students are better at detecting true alibis than false alibis (Culhane et al., 2013). The current result might be explained by two factors. First, normally only students are included in the research on alibi discrimination. In the present study we compared two different groups of participants to each other. The variation in the comparison group might explain the unexpected results. Second, the participants were provided with alibis generated by real suspects rather than fellow students. One could argue that the social life and daily activities of students differ from those of potential criminals and therefore differences occur in alibi supportive evidence. Future research is needed to answer that question.

Most of our knowledge on alibis originates from research on undergraduate students. Reporting an alibi without strong supportive evidence for it, is one of the most stable finding in all alibi research (e.g., Jung et al., 2013; Pozzulo et al., 2015). Such strong evidence most often consists of physical evidence. In fact, even the weakest type of physical evidence is still stronger evidence than the strongest type of witness evidence (Olson \& Wells, 2004). Not only do students find the presence and the strength of physical evidence a diagnostic factor in alibi evaluation, our results also show that student focus on the presence of physical evidence in discriminating between true and false alibis. If professionals would focus on the same aspects as students, then we would have gained important knowledge over the past years of research in the field of alibis.

Unfortunately that is not the case because professionals do not focus most on whether or not physical evidence is reported. They are rather interested in the verifiability of the alibi. Research on the verifiability approach is growing in various kinds of research domains. For example, whether an insurance claim is truthful (Harvey, Vrij, Nahari, \& 
Ludwig, 2017; Nahari, Leal, Vrij, Warmelink, \& Vernham, 2014; Vrij, Nahari, Isitt, \& Leal, 2016), whether one is honest about his or her occupation (Jupe, Vrij, Nahari, \& Leal, 2016), in lie detection in general (Nahari \& Vrij, 2015; Nahari, Vrij, \& Fisher, 2014a, 2014b), but also in alibi discrimination (Nahari \& Vrij, 2014). The approach is based on two assumptions: a) truth tellers will include more details in their statement compared to liars; and b) liars will avoid including details in their statement and will give vague statements instead (Nahari, Vrij, et al., 2014a). For example, a liar is more likely to state "I saw a black Audi" rather than "I called my friend Kris at 10:30 AM this morning". The details of the latter statement can be more easily verified compared to the first statement. Using the verifiability technique, an accuracy of up to $88 \%$ in lie detection can be achieved. Our data show that the verifiability of the alibis is most important for professionals. Future research in the domain of the verifiability approach on alibi discrimination is therefore strongly recommended.

The present paper offers new insights in the domain of alibi generation and discrimination using more representative samples of participants. Although the results are comparable with previous studies, the present paper shows that police detectives perceive an alibi as true until proven wrong and offers a new scope on the guilty bias of police officers. Furthermore, the data show that the research on alibis conducted with students cannot be translated on a one-to-one basis to professionals. That is an important finding to bear in mind for the future alibi research. 
DETERMINING THE VERACITY OF ALIBIS

\subsection{REFERENCES}

Bond, C. F., \& DePaulo, B. M. (2006). Accuracy of deception judgments. Personality \& social psychology Review, 10, 214-234. doi:10.1207/s15327957pspr1003_2

Burgoon, J. K., Blair, J. P., \& Strom, R. E. (2008). Cognitive biases and nonverbal cue availability in detecting deception. Human Communication Research, 34, 572-599. doi:10.1111/j.1468-2958.2008.00333.x

Burke, T. M., Turtle, J. W., \& Olson, E. A. (2007). Alibis in criminal investigations and trials. In M. P. Toglia, J. D. Read, D. F. Ross, \& R. C. Lindsay (Eds.), The handbook of eyewitness psychology: Memory for events (Vol. 1, pp. 157-192). Mahwah, NJ: Lawrence Erlbaum Associates.

Crozier, W. E., Strange, D., \& Loftus, E. F. (2017). Memory errors in alibi generation: How an alibi can turn against us. Behavioral Sciences and the Law, 35, 6-17. doi:10.1002/bsl.2273

Culhane, S. E., \& Hosch, H. M. (2004). An alibi influence on mock verdicts. Journal of Applied Social Psychology, 34, 1604-1616. doi: 10.1111/j.1559-1816.2004.tb02789.x

Culhane, S. E., Hosch, H. M., \& Kehn, A. (2008). Alibi generation: Data from U.S. Hispanics and U.S. non-Hispanic whites. Journal of Ethnicity in Criminal Justice, 6, 177-199. doi:10.1080/15377930802243395

Culhane, S. E., Kehn, A., Horgan, A. J., Meissner, C. A., Hosch, H. M., \& Wodahl, E. J. (2013). Generation and detection of true and false alibi statements. Psychiatry, Psychology and Law, 20, 619-638. doi:10.1080/13218719.2012.729018

DePaulo, B. M., Lindsay, J. J., Malone, B. E., Muhlenbruck, L., Charlton, K., \& Cooper, H. (2003). Cues to deceptions. Psychological Bulletin, 129, 74-118. doi:10.1037/00332909.129.1.74

DePaulo, B. M., Rosenthal, R., Green, C. R., \& Rosenkrantz, J. (1982). Diagnosing deceptive and mixed messages from verbal and nonverbal cues. Journal of Experimental Social Psychology, 18, 433-446. doi:10.1016/0022-1031(82)90064-6

Dysart, J. E., \& Strange, D. (2012). Beliefs about alibis and alibi investigations: A survey of law enforcement. Psychology, Crime and Law, 18, 11-25. doi:10.1080/1068316X.2011.562867

Eastwood, J., Snook, B., \& Au, D. (2016). Safety in numbers: A policy-capturing study of the alibi assessment process. Applied Cognitive Psychology, 260-269. doi:10.1002/acp.3200

Granhag, P. A., Strömwall, L. A., \& Jonsson, A. C. (2003). Partners in crime: How liars in collusion betray themselves. Journal of Applied Social Psychology, 33, 848-868. 
Hanley, J. A., Negassa, A., Edwardess, M. D. B., \& Forrester, J. E. (2003). Statistical analysis of correlated data using generalized estimating equattions: An orientation. American Journal of Epidemiology, 157, 364-375. doi:10.1093/aje/kwf215

Hartwig, M., \& Bond, C. F. (2011). Why do lie-catchers fail? A lens model meta-analysis of human lie judgement. Psychological Bulletin, 137, 643-659. doi:10.1037/a0023589

Harvey, A. C., Vrij, A., Nahari, G., \& Ludwig, K. (2017). Applying the verifiability approach to insurance claims settings: Exploring the effect of the information protocol. Legal and Criminological Psychology, 22, 47-59. doi:10.1111/lcrp.12092

Jung, S., Allison, M., \& Bohn, L. (2013). Legal decision-making on crimes involving an alibi. Applied Psychology in Criminal Justice, 9, 45-58. doi:10.1037/t04698-000

Jupe, L., Vrij, A., Nahari, G., \& Leal, S. (2016). The lies we live: Using the verifiability approach to detect lying about occupation. Journal of Articles in Support of the Null Hypothesis, 13, 1-13.

Lindholm, T. (2008). Who can judge the accuracy of eyewitness statements? A comparison of professionals and lay-persons. Applied Cognitive Psychology, 22, 1301-1314. doi:10.1002/acp.1439

Luria, R. E. (1975). The validity and reliability of the visual analogue mood scale. Journal of Psychiatric Research, 12, 51-57.

Meissner, C. A., \& Kassin, S. (2002). "He's guilty!": Investigator bias in judgments of truth and deception. Law and Human Behavior, 26, 469-480. doi:10.1023/A:1020278620751

Nahari, G., Leal, S., Vrij, A., Warmelink, L., \& Vernham, Z. (2014). Did somebody see it? Applying the verifiability approach to insurance claim interviews. Journal of Investigative Psychology and Offender Profiling, 11, 237-243. doi:10.1002/jip.1417

Nahari, G., \& Vrij, A. (2014). Can I borrow your alibi? The applicability of the verifiability approach to the case of an alibi witness. Journal of Applied Research in Memory and Cognition, 3, 89-94. doi:10.1016/j.jarmac.2014.04.005

Nahari, G., \& Vrij, A. (2015). Can someone fabricate verifiable details when planning in advance? It all depends on the crime scenario. Psychology, Crime \& Law, 21, 987999. doi:10.1080/1068316X.2015.1077248

Nahari, G., Vrij, A., \& Fisher, R. P. (2014a). Exploiting liars' verbal strategies by examining the verifiability of details. Legal and Criminological Psychology, 19, 227-239. doi:10.1111/j.2044-8333.2012.02069.x

Nahari, G., Vrij, A., \& Fisher, R. P. (2014b). The Verifiability Approach: Countermeasures facilitate its ability to discriminate between truths and lies. Applied Cognitive Psychology, 28, 122-128. doi:10.1002/acp.2974

Nieuwkamp, R., Horselenberg, R., \& Van Koppen, P. J. (2016). A lie and a mistress: On increasing the believability of your alibi. Psychiatry, Psychology and Law, 23, 733745. doi:10.1080/13218719.2016.1142934 
Nieuwkamp, R., Horselenberg, R., \& Van Koppen, P. J. (2017). The illusion of the perfect alibi: Establishing the base rate of non-offenders' alibis. Journal of Investigative Psychology and Offender Profiling, 14, 23-42. doi:10.1002/jip.1470

Olson, E. A., \& Charman, S. D. (2012). 'But can you prove it?' - Examining the quality of innocent suspects' alibis. Psychology, Crime and Law, 18, 453-741. doi:10.1080/1068316x.2010.505567

Olson, E. A., \& Wells, G. L. (2004). What makes a good alibi? A proposed taxonomy. Law and Human Behavior, 28, 157-176. doi:10.1023/B: LAHU.0000022320.47112.d3

Porter, S., \& Yuille, J. C. (1996). The language of deceit: An investigation of the verbal cues to deception in the interrogation context. Law and Human Behavior, 20, 443-458. doi:10.1007/BF01498980

Pozzulo, J. D., Pettalia, J. L., Dempsey, J. L., \& Gooden, A. (2015). Juvenile offenders on trial: Does alibi corroboration evidence and defendant age interact to influence jurors' perceptions and verdicts? Psychiatry, Psychology and Law, 22, 224-234. doi:10.1080/13218719.2014.937518

Simon, D. (2012). In doubt: The psychology of the criminal justice process. London: Harvard University Press.

Stellar, M. (1989). Recent developments in statement analysis. In J. C. Yuille (Ed.), Credibility assessment (pp. 135-154). Dordrecht, the Netherlands: Kluwer.

Strange, D., Dysart, J. E., \& Loftus, E. F. (2014). Why errors in alibis are not necessarily evidence of guilt. Zeitschrift für Psychologie, 222, 82-89. doi:10.1027/21512604/a000169

Strömwall, L. A., Granhag, P. A., \& Jonsson, A. C. (2003). Deception among pairs: 'Let's say we had lunch and hope they will swallow it!'. Psychology, Crime \& Law, 9, 109-124. doi:10.1080/1068316031000116238

Van Koppen, M. V., \& Van Koppen, P. J. (2010). Alibi's [Alibis]. In P. J. Van Koppen, H. Merckelbach, M. Jelicic, \& J. W. De Keijser (Eds.), Reizen met mijn rechter: Psychologie van het Recht [Traveling with my judge: Psychology of the Law] (pp. 439-448). Deventer: Kluwer.

Vredeveldt, A., Van Koppen, P. J., \& Granhag, P. A. (2014). The inconsistent suspect: A systematic review of different types of consistency in truth tellers and liars. In R. Bull (Ed.), Investigative interviewing (pp. 183-202). New York: Springer.

Vrij, A. (2005). Criteria-Based Content Analysis: A qualitative review of the first 37 studies. Psychology, Public Policy and Law, 11, 3-41. doi:10.1037/1076-8971.11.1.3

Vrij, A. (2008). Detecting lies and deceit: Pitfalls and opportunities. Chichester: John Wiley.

Vrij, A., Granhag, P. A., Mann, S., \& Leal, S. (2011). Outsmarting the liars: Toward a cognitive lie detection approach. Current Directions in Psychological Science, 20, 28-32. doi:10.1177/0963721410391245 
Vrij, A., Nahari, G., Isitt, R., \& Leal, S. (2016). Using the verifiability lie detection approach in an insurance claim setting. Journal of Investigative Psychology and Offender Profiling, 13, 183-197. doi:10.1002/jip.1458

Wells, G. L., Small, M., Penrod, S., Malpass, R. S., Fulero, S. M., \& Brimacombe, C. (1998). Eyewitness identification procedures: Recommendations for lineups and photospreads. Law and Human Behavior, 22, 603-647. 


\subsection{APPENDIX: STATEMENT FORM}

Police Northern Holland

Detectives division

Document number: PL1234/09-765432

WRITTEN STATEMENT OF SUSPECT'S INTERVIEW

On Monday March 29th 2015, at 12:29PM

Detective,

POLMAN, SARA,

Detective

JANSEN, NIELS,

In the police station located at Marnixstraat 148 in

Amsterdam we interviewed a suspect who claims to be:

M. A.

After the suspect has been informed of his possible

involvement in the alleged crime and that he is not obliged to answer our questions he stated:

SUSPECT'S STATEMENT

(Please note that the suspect's statement has been removed due to privacy regulations. The copies of the statements can be requested by contacting the first author).

After the suspect read this written statement, he confirmed the content of it and signed the written statement

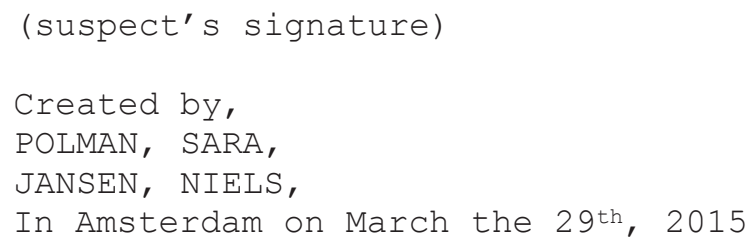



8

THE BIGGER PICTURE AND BUILDING BRIDGES IN ALIBI RESEARCH

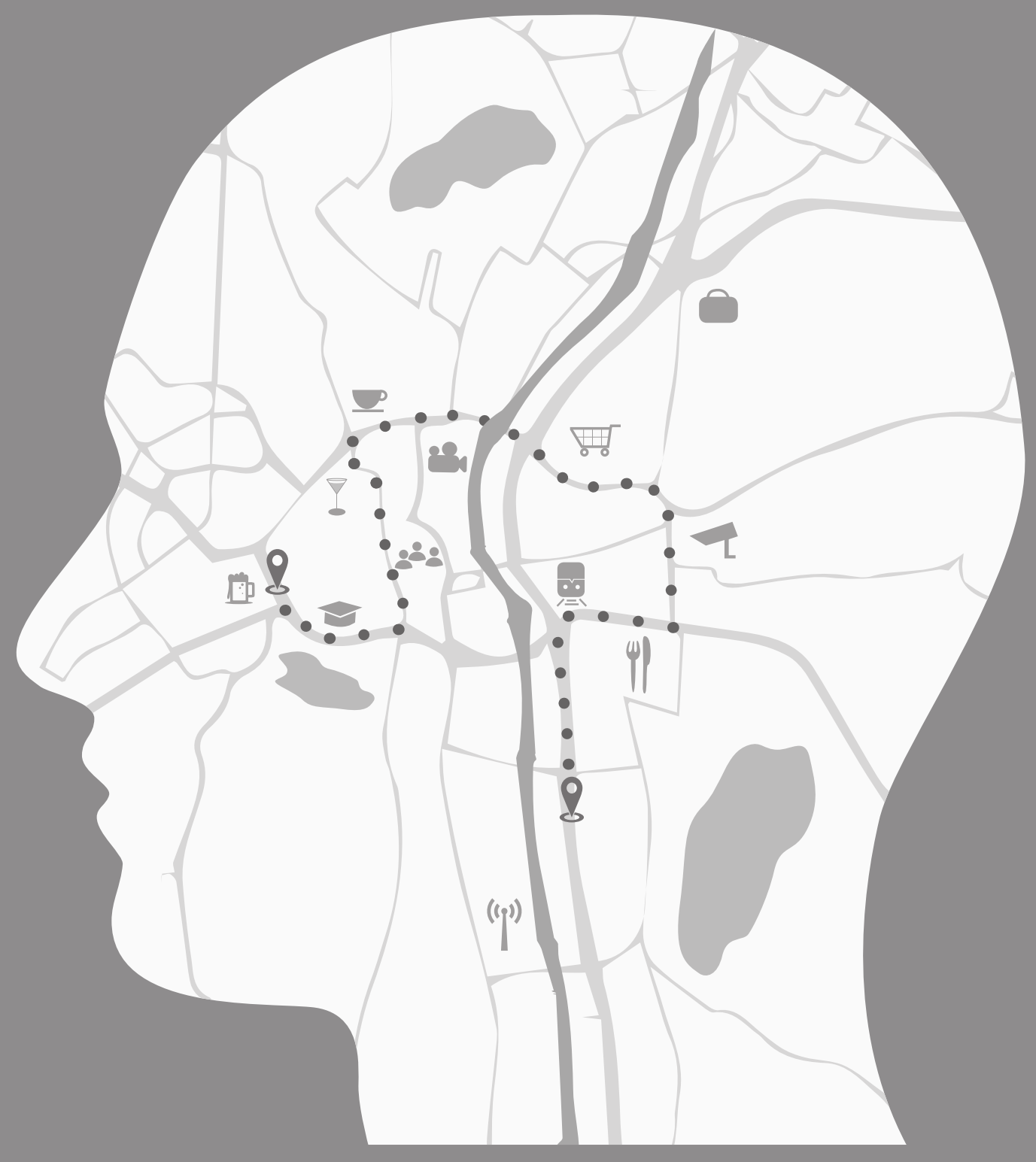





\subsection{INTRODUCTION}

For an alibi to be considered believable, strong supportive evidence is needed from innocent suspects and defendants. Police and judicial authorities tend to set high standards to determine whether an alibi is sufficiently supported with evidence to be believable.

In this dissertation, alibis and the various types of supportive evidence were examined. Furthermore, the evaluation of alibis by practitioners was discussed, taking into account aspects other than the strength of the evidence. More specifically, I focused on the factors that carry most weight in the evaluation of the believability of a suspect's alibi. The results of the studies in this dissertation show that concerns can be raised about the representativeness of the alibi research that is predominantly conducted with students as participants. In addition, the comprehensiveness and utility of the alibi taxonomy of Olson and Wells (2004) can be called into question due to its strong reliance on the strength of the evidence when evaluating an alibi. Although the results of this thesis indicate that laypeople do not provide the evidence that is expected by police detectives to consider an alibi as believable, it appears that police detectives do not evaluate an alibi merely based on the strength of the evidence. Other factors also affect alibi believability and should be taken into account as well.

In the remainder of this chapter, the findings of the six studies are summarized in terms of their effect on our knowledge of alibis. I will then discuss the scope and generalizability of the results of the studies. Then, I will present opportunities for future studies in this relatively young field of research. The chapter will conclude with various practical implications and suggestions for practitioners.

\subsection{SUMMARY OF FINDINGS}

\subsubsection{Influential Factors Affecting Alibi Believability}

The studies presented in this dissertation are not limited to one of the three classical research domains on alibis: alibi generation, evaluation or discrimination (Culhane et al., 
CHAPTER 8

2013). In the first study (Chapter 3) I focused on the domain of alibi generation by determining the base rate of non-offenders' alibis, and the final study (Chapter 7) was about alibi discrimination. In the remaining studies the topic of alibi evaluation was addressed. The entirety of the chapters captures the full process from alibi generation through discrimination. Moreover, in Chapter 6 and 7, more than one domain is addressed, combining various factors to capture the complexity of alibi generation in relation to either evaluation or discrimination. These studies go beyond the pre-existing boundaries of the alibi domains in order to better understand how to determine alibi believability.

Chapter 2 offers a systematic literature review of the factors that are considered to be the most important for determining alibi believability in research and to identify the gaps in the existing literature. The most important factor by far is the presence and the strength of the supportive evidence. However, it was more recently noted that the content of the alibi (e.g., Allison, Mathews, \& Michael, 2012) and its consistency (Culhane \& Hosch, 2012) also affects alibi believability. The strong focus on the supportive evidence can be explained by the finding that in most wrongful convictions where an alibi was presented, the alibi was supported by no or weak evidence. That led Olson and Wells (2004) to conclude that the presence and strength of the evidence are most important for determining alibi believability. Simply put: alibis supported by strong evidence that remain consistent over time are found to be believable by students (Jung, Allison, \& Bohn, 2013) and police detectives (Dysart \& Strange, 2012). The case of John Travolta (see Chapter 2) shows that having strong supportive evidence for an alibi can exculpate a suspect at an early stage of the investigation or even before an investigation is initiated.

However, having such strong evidence is rather unusual. That became clear in the study in which the base rate of non-offenders' alibis was established (Chapter 3 ). In that study, a large sample of laypeople was asked for their alibis. In three other studies, it had been demonstrated that a discrepancy exists between which alibis can be expected and which alibis are thought to be believable (Culhane, Hosch, \& Kehn, 2008; Culhane et al., 2013; Olson \& Charman, 2012). Yet, all those studies are conducted with students. These students were often only asked for their alibis for the evening hours. Crimes are, however, not limited to occurring during the evening (Felson \& Poulsen, 2003). In addition, the 
students were not asked for their alibis for other timeframes, as that would have led to a high number of work-related alibis (Culhane et al., 2013).

Scholars acknowledge that students are not the most representative group of participants for establishing the base rate of non-offenders' alibis, because laypeople's routines might vary and they may have additional alibi witnesses (e.g., children; Culhane et al., 2013). To increase the ecological validity of any statements about a person's alibi, we established the base rate among laypeople. The results show that only $2 \%$ of laypeople can report strong physical evidence, which implies that only these $2 \%$ of non-offenders can report an alibi that would be found believable. In Chapter 6 it became clear that police detectives report physical evidence more often than laypeople when asked to generate an alibi. The reported alibi activities do not differ between the groups, but the police detectives in particular report GPS and telephone data more often than laypeople. It can therefore be argued that police detectives are more aware of the presence of physical evidence when they are asked for their whereabouts, which might explain why they put such stringent requirements on a suspect's alibi before they find it believable (Dysart \& Strange, 2012).

Interestingly, a minority of the participants in Chapter 3 reported evidence that could be labelled as knowledge evidence, which is a type of evidence that had not yet been captured in the literature. When a suspect possesses knowledge that he could only have acquired if the alibi was true, that knowledge supports the alibi. Knowledge evidence could be a relevant addition to the existing types of supportive alibi evidence, because it can lead to alibis that are supported by evidence. Traditionally, based on the two classical types of evidence, an alibi supported by knowledge evidence would be treated as an alibi without evidence. For that reason, the value of adding knowledge evidence to the alibi literature was examined (Chapter 4). Based on the study, it appears that this novel type of evidence is equally believable as the strongest type of witness evidence, regardless of whether it is being evaluated by students, laypeople or police detectives. The alibi taxonomy could therefore be expanded with this novel type of evidence.

Recently, as previously mentioned, factors other than the strength of the supportive evidence were also studied to determine their effect on alibi believability. It was shown, for instance, that salacious alibis sometimes are more believable than non-salacious 
alibis (Allison et al., 2012). To be believable, an alibi should also remain consistent over time (Culhane \& Hosch, 2012). However, little mercy is shown when memory is absent or mistakes are made when a suspect generates an incorrect alibi (Crozier, Strange, \& Loftus, 2017; Strange, Dysart, \& Loftus, 2014).

In the light of the memory errors that can occur when recollecting one's whereabouts, one should take into account that the suspect might simply be mistaken, although $80 \%$ of detectives assume that a change in an alibi is indicative of deceit (Dysart \& Strange, 2012). As was demonstrated in Chapter 5 by the case of Ronald Cotton, such mistakes can lead to disbelief in the alibi and ultimately to a wrongful conviction (Thompson-Cannino, Cotton, \& Torneo, 2009). The findings discussed in Chapter 5 show that an alibi can become more believable when the initial alibi is changed. This is especially true when the suspect lied about his initial alibi, then later admitted that he was involved in a salacious activity.

The study was inspired by a Dutch case that caused controversy. In that case, it was assumed that a young girl was forced to prostitute herself by a so-called loverboy. Customers claimed to have not been aware that she was only 16 years old, instead of 18 years as they were told. The prosecutor said to the media that they would search for all the customers and prosecute them for having sexual relations with a minor. The prosecutor added to his statement that police would pick up the suspects at their residences and that he did not care if their spouse opened the door and learned of the accusations. Soon after that announcement, two suspects committed suicide (Klompenhouwer, 2015). Inspired by that case, we reasoned that in some cases suspects might initially lie to the police about their whereabouts and then admit only later that they were involved in salacious behaviour. Our results show that when the change in the initial alibi makes sense - in the study lying about your alibi to hide an affair - such changes in the alibi can even lead to an increase in the alibi's believability.

At this point, the results described in Chapters 3 to 5 show that the criteria by which to evaluate the merits of the alibi are not as black and white as was assumed in previous studies: one should not expect only strong evidence from non-offenders because: a) it is not realistic that all of them could produce such evidence; b) not all types of 
supportive evidence have been captured in the literature, which was illustrated by the valuable addition of knowledge evidence; and c) not every change in an alibi necessarily indicates a decrease in believability. Based on these results, a more tailor-made approach is preferred when determining alibi believability.

\subsubsection{The Evaluation of Alibis by Students and Police Detectives}

The second part of this dissertation consists of a study on how various groups of evaluators determine alibi believability. In practice, police detectives are the ones to create a first impression of the suspect's alibi's believability. The initial suspect interviews are a key investigative act in the criminal investigation (Baldwin, 1993; Norfolk \& Stark, 2011; Walsh, King, \& Griffiths, 2017). The gathered information in those interviews is crucial for the further development of the investigation in the light of the evidence being gathered; for example: when CCTV footage is available, those tapes should be collected as soon as possible to reduce the risk that the tapes will no longer be available.

Despite their important first impression, police detectives are rarely included in alibi research (Dysart \& Strange, 2012; Eastwood, Snook, \& Au, 2016). One of the aims of this dissertation was to bridge the gap between practitioners and academics in regard to alibi evaluation. In order to start building bridges, one first needs to identify the process of determining alibi believability and to know which aspects are important during the alibi evaluation. As discussed above, scholars have often asked students to evaluate alibis. The results of such studies show that students find the presence and strength of the evidence most important in determining alibi believability (e.g., Jung et al., 2013; Pozzulo, Pettalia, Dempsey, \& Gooden, 2015). In such studies, (e.g., Allison \& Brimacombe, 2010; Hosch, Culhane, Jolly, Chavez, \& Shaw, 2011), the strength of the reported evidence is manipulated based on the alibi taxonomy (Olson \& Wells, 2004). Although the efficacy of the taxonomy has been proven when students were included as participants, its efficacy has not yet been demonstrated with practitioners.

In the study described in Chapter 4, laypeople, students and police detectives evaluated various types of strong supportive evidence, using the most recent alibi taxonomy 
CHAPTER 8

(Olson \& Charman, 2012). Counterintuitive results were observed for police detectives, who did not consider physical evidence to be strong. The presented evidence consisted of the records from a personal card for public transportation. Those records fulfil the criteria for strong physical evidence as described by Olson and Charman (2012), as the records are directly linked to the suspect and contain time and location information. The detectives, however, reasoned that those records do not guarantee that the suspect himself travelled with that card. If the evidence had consisted of CCTV recordings, they would find that evidence stronger and the alibi more believable. In a follow-up study with students and another group of detectives, students did not differentiate between the records of the public transportation card and CCTV recordings in terms of believability, while police detectives did rate the CCTV recordings as stronger and more believable. The results thus show that the alibi taxonomy works in a laboratory setting when students evaluate alibis, but not necessarily in practice.

Recently, it was also demonstrated that police detectives focus on more, but also different, aspects of the alibi than students do when evaluating alibis (Eastwood et al., 2016). Police detectives do not focus only on the presence and strength of the supportive evidence, but also on the number of alibi witnesses. Interestingly, we also found that police officers are less interested in the strength of the supportive evidence and focus more on the verifiability of the alibi and the reported supportive evidence (Chapters 6 and 7). We came to that conclusion by determining how true and false alibis can be discerned by asking students and experienced detectives which aspects of alibis they focus on in their evaluation. While students focus on the strength of the evidence, the detectives find the verifiability of the evidence and the length of the suspect's statement more important. In addition, compared to students, police detectives evaluated more alibis to be truthful. During the debriefing, they stated that unless proven otherwise, detectives tend to believe a suspect's alibi.

This finding is in contrast to previous research on detectives' attitudes in the criminal investigation (e.g., Meissner \& Kassin, 2002). Typically, in such studies a guilty bias is observed in which the detective is convinced of the suspect's guilt and only seeks incriminating evidence. Our findings suggest that when evaluating a suspect's alibi, this bias 
does not seem to be present. Furthermore, in the study reported in Chapter 6, it was revealed that police detectives report physical evidence more often than laypeople do when they are asked to generate an alibi. This, however, does not seem disadvantageous for suspects: when the detectives were presented with a suspect's alibi, most of them wanted to conduct more investigative acts prior to determining the alibi's believability. In particular, the detectives wanted to actively search for additional evidence (e.g., CCTV recordings, interviewing witnesses) to verify whether or not the presented alibi was truthful.

The results thus have two implications. On the one hand, police detectives appear to be more aware of the potential presence of physical evidence than laypeople, which might explain why their standards are so high for a believable alibi. On the other hand, police detectives tend to evaluate alibis as true until proven false, which might explain why they are more interested in the verifiability of the evidence rather than the strength of the evidence.

\subsection{SCOPE AND GENERALIZABILITY}

\subsubsection{The Context of the Conducted Research}

The aim of the present thesis was threefold: to determine a) what factors determine an alibi's believability; b) what evidence could logically be expected to be provided by nonoffenders; and c) how students and police detectives evaluate alibis. The research described in this thesis differs from previous research in two aspects that are important to understanding the context in which the results should be interpreted.

First, most previous research has been conducted in the United States of America or Canada, where mock jurors (i.e., undergraduate students) were asked to evaluate the defendant's alibi. In general, two types of legal systems can be identified in which the pretrial investigation is embedded: an inquisitorial or an adversarial system. In most continental countries in Western Europe (including the Netherlands), the pre-trial investigation has a predominant inquisitorial character whereby the public prosecutor, and by extension the police, looks for both incriminating and exculpatory evidence while the 
suspect has a rather passive role. In countries where the pre-trial investigation is embedded in an adversarial system, the prosecution service may restrict itself to gathering only incriminating evidence, and the suspect-and his lawyer-are more active participants in the evidence-gathering process (De Smet, 1999; Van den Wyngaert \& De Smet, 2014; P. J. Van Koppen \& Penrod, 2003a, 2003b). As an active participant in the criminal investigation, the suspect then has to organize his own defence (Baldwin, 1993; Norfolk \& Stark, 2011). Given the predominantly inquisitorial character of the pre-trial investigation in the Netherlands, the role of police detectives is crucial and cannot be neglected.

The scope of this dissertation is limited to the investigative stages of the criminal proceedings. Consequently, alibis that are presented in court are not included, and neither is its evaluation by prosecutors, judges and lawyers. There is, however, a primary focus on alibi evaluation by police detectives in this dissertation because of the predominant inquisitorial character of the pre-trial investigation and the fact that the focus of criminal proceedings in the Netherlands increasingly rests on the pre-trial investigation.

Second, a number of important findings are contradictory to what has been previously established in alibi research. These results could be explained by differences in the legal systems studied. However, the current findings are also in line with the results in a recent Canadian study (Eastwood et al., 2016) that compared alibi evaluation from detectives to those of students. In both studies it was observed that the strength of the evidence is not most important in the detectives' evaluation. It can therefore be argued that the variation in results is more likely to be explained by the inclusion of police detectives rather than the legal system in which the study is conducted.

\subsubsection{The Inclusion of Police Detectives}

Aside from the differences in the legal systems, the inclusion of practitioners in alibi research is rather novel (Culhane \& Hosch, 2012; Dysart \& Strange, 2012; Eastwood et al., 2016). Given the importance of the detectives' role in the investigative stages of the criminal proceedings, the aim of the dissertation was to bridge the gap between practitioners and 
scholars by including an ecologically representative sample of participants to better understand how alibis are evaluated by detectives rather than solely by students in the lab.

Nevertheless, the alibi studies in which students participated were of vital importance for the development of this nascent field of research. In order to structure the alibi research, Olson and Wells (2004) have created an alibi taxonomy by which the strength of the evidence, and subsequently the alibi believability, could be determined. After the introduction of the taxonomy, alibi research has grown and much understanding was gained on the importance of the strength of supportive evidence in alibi evaluation. Those studies have been very valuable in gaining insight into how students evaluate alibis in the lab. Yet, based on recent findings (Eastwood et al., 2016) and those of this dissertation, the limitations and generalizability of the results in research with student samples cannot be underestimated.

Both students and detectives have unrealistic expectations about what criteria need to be fulfilled in order to believe the suspect's alibi. While student evaluations can become more realistic through the alibi generation effect (Olson \& Wells, 2012), such an effect does not occur when it comes to police detectives (Chapter 6). In their evaluation, police detectives focus on the verifiability and the length of the alibi rather than the strength of the evidence. Furthermore, as previously mentioned, detectives display a truth bias when discriminating between true and false alibis, while in prior studies a guilty bias was observed (Meissner \& Kassin, 2002). These outcomes add to recent findings (Eastwood et al., 2016) that police detectives do not find the strength of the evidence as important as students do when evaluating alibis.

It remains unclear if evidence that is considered to be strong by scholars and students is also considered to be strong by detectives. For physical evidence to be strong, the evidence needs to be linked to the suspect and contain time stamps and information such as credit card receipts or CCTV footage (Olson \& Charman, 2012; Olson \& Wells, 2004). However, the detectives focus less on these criteria and more on the question as to whether or not an alternative explanation can be found for the presence of the evidence. For example, the presence of credit card transactions at the time of the alleged crime can be either explained as indicating that the suspect used the card at that moment or that 
someone else used the card to provide evidence for a false alibi. The detectives find evidence stronger when such alternative explanations are unlikely. For example, this is the case when the suspect reports having been in another town than where the alleged was committed. His alibi can be supported by CCTV footage in that town. When the CCTV footage is examined, it is of high quality and clearly showing a person who could very well be the suspect. The most probable scenario is that the suspect is innocent because he was in another town. Except when the suspect has a twin sibling, it is unlikely that a look-alike of the suspect was in that other town and the suspect knew that this doppelgänger would be in that particular town at the moment that the crime was committed.

Lastly, when detectives are asked to generate an alibi, they more often report physical evidence compared to laypeople. The reported alibi locations do not differ from those of laypeople, and therefore it can be assumed that detectives are more aware of the presence of physical evidence. This finding has two important implications. First, it might explain why police detectives set high demands for believing a suspect's alibi and also why they expect physical evidence given their frame of reference when generating an alibi. Second, it clarifies why the alibi generation effect was not observed. When detectives define their whereabouts prior to evaluating the suspect's alibi, it will not be beneficial for the suspect because they will still be expecting physical evidence to support the suspect's alibi.

Taking together these differences in various studies, it can be argued that this dissertation provides new insights into how alibis are evaluated based on results that are generalizable to police practice. In comparison with students, the detectives' evaluations are more profound and based on fewer simple heuristics (e.g., if the supported evidence is weak, then the alibi is unbelievable and false). One could therefore argue that the performance of police detectives is quite good. That is true, although it cannot be disregarded that the misclassification of the veracity of alibis remains an important factor in wrongful conviction cases and further training remains necessary. 


\subsubsection{Beyond the Strength of the Existing Alibi Evidence}

\subsubsection{Focus on Evidence Strength}

Although the strength of the evidence is of lesser importance to police detectives than it is to students when evaluating alibis, most of the alibi research until now has focused on the strength of the evidence. This strong focus on the evidence can be explained by the influential paper of Olson and Wells (2004, p. 159) in which it is stated: "what distinguished one alibi from another is the level of proof that can be produced to support the alibi, not the surface attributes of the alibi itself". That paper has led to a rise in alibi research, in which the role of strong supportive alibi evidence is highlighted. Other factors that can affect alibi believability, however, have also been identified: the suspect's criminal record (Allison \& Brimacombe, 2010), the content of the presented alibi (e.g., Allison et al., 2012) and the consistency of the alibi evidence (Culhane \& Hosch, 2012). The strength of the evidence still remains the most important aspect for students in determining alibi believability (Jung et al., 2013). However, the base rate of alibis of non-offenders stipulates the importance of studying other factors that affect alibi believability, especially because most non-offenders report evidence that could be classified as weak. The strength of the evidence is thus not diagnostic for differentiating between true and false alibis. Therefore, the research conducted in this dissertation aimed to go beyond the strength of the two classical types of alibi evidence by studying other factors that may influence alibi believability.

\subsubsection{Content and Consistency of an Alibi}

More recently, salacious and inconsistent alibis have been studied as alibi surface attributes. With regard to salacious alibis, mixed results are found. Initially, it was found that a salacious alibi is associated with higher levels of suspect honesty and subsequently led to a more believable alibi compared to non-salacious alibis (Allison et al., 2012). However, that effect has not been replicated (Allison, Jung, Sweeney, \& Culhane, 2014; Jung 
et al., 2013). Keeping, Eastwood, Lively, and Snook (2017) found that a salacious alibi even led to disbelieving the suspect. Those findings are congruent with the results described in Chapter 5 .

When the reported alibi evidence is inconsistent between two questioning sessions, such discrepancies always lead to a decrease in alibi believability (Culhane \& Hosch, 2012). A decrease even occurred when the evidence became stronger over time according to the alibi taxonomy. The results in Chapter 5 show that not every change in the alibi and supportive evidence leads to a decrease in alibi believability. When the change makes sense, it increases the alibi believability. Thus, alibi evaluation is not a process that can be achieved by if-then clauses. For example, when the suspect does not report strong evidence, then the alibi is viewed as unbelievable, or when the alibi is changed, it then becomes less believable than the initially presented alibi. The process of alibi evaluation is more complex, and multiple aspects should be taken into account.

\subsubsection{Starting Afresh: The Base Rate of Alibis and Knowledge Evidence}

If alibi believability needs to be determined, the base rate of the alibi needs to be established. One cannot decide whether or not an alibi of a suspect is believable without knowing what alibis and supportive evidence non-offenders can present at various days and times. Such data were, however, lacking. Some studies were conducted in which students were asked for their alibis during the evening, but the sample size and the type of sample used were insufficient to determine the base rate of various alibis. To establish the base rate, a large sample of people should be asked for their whereabouts: where are nonoffenders during different times and days and what kind of supportive evidence can they present? This provides helpful insights about where people tend to be and what evidence can be expected from them to support their alibi. Most importantly, such data are necessary to determine alibi believability. In that regard, the results presented in Chapter 3 are pioneering and an important first step in the evaluation of alibis. Moreover, the results show that the taxonomy is difficult to apply in determining alibi believability, because it remains unclear how multiple items of one type of evidence should be assessed. For example, the 
question at hand is whether two motivated familiar witnesses are as equally strong as one unmotivated familiar witness.

Furthermore, the participants in the base rate study reported knowledge as a novel type of evidence that was not yet included in the alibi taxonomy. As mentioned before, knowledge evidence was also reported in a well-known murder case, but has been ignored thus far in the literature (M. V. Van Koppen \& Van Koppen, 2010). Our results show that students, laypeople and police detectives acknowledge the added value of knowledge as supportive evidence. In addition, the current taxonomy (Olson \& Charman, 2012) could be expanded with this new type of evidence. It can be argued that the same rule applies for physical evidence as for knowledge evidence: the easier it is to obtain the knowledge through another source or at another moment, the weaker the evidence becomes. For example, being able to recount the plot of an improvisational theatre play from the previous night will be stronger evidence than being able to describe the plot of Romeo and Juliet that was performed the same evening by the local theatre group.

\subsection{IMPLICATIONS FOR FUTURE RESEARCH AND POLICE PRACTICE}

\subsubsection{Future Research}

\subsubsection{The Verifiability Approach}

The verifiability approach is a novel form of verbal lie detection, which has proven to be effective in various settings (e.g., Harvey, Vrij, Leal, Lafferty, \& Nahari, 2017; Harvey, Vrij, Nahari, \& Ludwig, 2017; Jupe, Vrij, Nahari, \& Leal, 2016). The technique is based on the principle that liars will report details in their account that cannot be verified, while truth tellers will report aspects that can be verified. For example, a liar can state that while commuting he saw a black Audi, while a truth teller can state that on that journey he called his friend Kris. Telephone records can more easily verify whether or not the suspect actually called his friend, while the verifiability of seeing a black Audi in town is almost non-existent. In alibi research, only one study has used this technique to determine the veracity of alibi 
statements (Nahari \& Vrij, 2014). This technique should be further tested within the context of alibi research because other attempts to classify alibis according to their veracity are around chance level (Culhane et al., 2013 and Chapter 7 of this dissertation).

Furthermore, when two people decide to lie about their alibi, the consistency in their statements is higher than when truth tellers report their activities (Sakrisvold, Granhag, \& Mac Giolla, 2017; Strömwall, Granhag, \& Jonsson, 2003). With the help of the verifiability approach, the veracity of such statements could possibly be increased, perhaps in combination with increasing the cognitive load during such interviews (e.g., asking unanticipated questions; Lancaster, Vrij, Hope, \& Waller, 2013; Vrij et al., 2009). The verifiability approach is of particular interest given the fact that police detectives tend to focus on the verifiability of the alibi and the evidence (Chapter 6 and 7). However, given the results in Chapter 3, it appears that most non-offenders present witness evidence, consisting of witnesses who might have a reason to lie in the suspect's favour. Even when the evidence is verifiable, evaluators may still perceive such supportive testimonies with scepticism. Therefore, more research on this approach is needed, preferably with the help of practitioners to determine how various types of evidence are evaluated. This is important given that an alibi and its supportive evidence always should be evaluated in light of the ongoing criminal investigation, taking into account other exculpatory and incriminating evidence available. Future research could therefore focus on how alibis and supportive evidence relate to the other evidence available when it comes to the evaluation of an alibi's believability.

In this dissertation interview techniques and the questions to be asked to generate, evaluate and discriminate between alibis were not addressed. However, the verifiability approach may support police officers in fully capturing the suspect's alibi and all the available evidence. This is especially relevant because police detectives are more aware of the presence of physical evidence compared to laypeople (Chapter 6). It could be beneficial for the suspect if police detectives would explicitly ask whether or not he carried his mobile phone with him and whether or not he used his phone shortly before or shortly after the alleged crime was committed. This could stimulate an innocent suspect to provide more evidence to support his alibi. Thus, it would be valuable to study the current practices of 
how police detectives interview the suspect when an alibi is presented. The results of such studies may lead to recommendations on what techniques and questions can be used to map the alibi and its supportive evidence. Future research could provide valuable insights on the use of interview techniques in relation to alibi generation, evaluation and discrimination

\subsubsection{Updating the Alibi Taxonomy}

The alibi taxonomy of Olson and Wells (2004) was initially found to be effective for structuring alibi research. In 2012 the taxonomy was updated (Olson \& Charman, 2012), and given the results from this dissertation study, a second update is advised for four reasons.

First, the current taxonomy does not allow for assessing the strength of multiple items of evidence within one category. It can, for example, be questioned whether the testimonies of two motivated familiar alibi witnesses are equally strong as one testimony of an unmotivated familiar other witness.

Second, despite the impact of physical evidence on alibi believability, little variation was used in the items presented in alibi research. Most often CCTV footage is used as an example of strong evidence (Allison \& Brimacombe, 2010; Sargent \& Bradfield, 2004), while receipts are used to represent weak evidence (Allison \& Brimacombe, 2010; Allison et al., 2012; Dahl, Brimacombe, \& Lindsay, 2009; Maeder \& Dempsey, 2013; Pozzulo et al., 2015). However, as demonstrated in Chapter 3, non-offenders can report various items of physical evidence of which the strength cannot be determined using the taxonomy. The taxonomy includes three levels of strength of physical evidence (Olson \& Charman, 2012, pp. 8-9): weak (no time or place information, e.g., a CD that was burned on a computer at the time of the alleged crime); moderate (time or place information available but that cannot be directly linked to the suspect, e.g., phone record or cash receipt); and strong (time and place information that can be linked to the suspect, e.g., time card from an employer, credit card receipt, airline ticket). Based on the feedback of the detectives presented in Chapter 4, it is unclear whether or not an additional layer is preferred between items of moderate strength and strong evidence. For example, when a suspect is clearly 
visible on CCTV footage, this is without doubt strong evidence. However, credit card receipts, for example, are linked to the suspect, but it cannot be ruled out that someone else may have used the suspect's card to create supporting evidence for a false alibi. That line of thinking aligns with the feedback of the detectives regarding the public transportation card records and CCTV footage. It should be noted that our student sample of participants did not rate both items of physical evidence differently, but such a difference between credit card records and CCTV footage still seems logical to expect.

Third, it is valuable to test various items of physical evidence (e.g., the reported items in Chapter 3 of this dissertation) for their believability using a bottom-up approach. Preferably, that should be achieved by comparing a student sample with a sample of police detectives. Applying such a methodology would allow for testing of the applicability of the existing criteria to evaluate the strength of physical evidence (Olson \& Charman, 2012) and to determine if students and practitioners have different views on what items of physical evidence are thought to be strong or weak.

Fourth, knowledge evidence is not yet included in the alibi taxonomy but is still relevant for the literature. Alibis not supported by witness or physical evidence are thought to be the least believable (Olson \& Wells, 2004); however, with the addition of knowledge evidence, those individuals could potentially support their alibis with evidence. More studies should be conducted in which various items of knowledge evidence are assessed (e.g., thorough interviewing seeking potential supportive evidence, examining the suspect's computer search history). Once the strength of various items of knowledge evidence is established from the bottom up, the alibi taxonomy could perhaps be expanded with this novel type of evidence.

Taking these four reflections and answers to the future research questions into account, a better taxonomy can be developed. Such taxonomy should be useful for practitioners to increase the number of correct alibi determinations instead of only serving an academic debate. 


\subsubsection{Salacious and Other Shameful Alibis}

Besides addressing the alibi's content through the verifiability approach, more research is needed to understand the effect of salacious alibis. To date, the results are still mixed; whereas initially it was found that a salacious alibi would be more believable than a nonsalacious alibi (Allison et al., 2012), no such effect was found in follow-up studies (Allison et al., 2014; Jung et al., 2013) or salacious alibis were found to be even less believable than a non-salacious alibi (Keeping et al., 2017; Chapter 6 of this dissertation). The mixed results might be explained by the fact that all of the salacious alibis were different (e.g., watching a porn movie, having an affair) and that the presented mock-crime varied (e.g., armed robbery, sexual assault). A classical replication study of the initial study on salacious alibis (Allison et al., 2012) might be useful, comparing various types of salacious alibis to determine what behaviour results in more believable or less believable alibis.

For the purpose of our study, it was hypothesized that admitting to having been involved in salacious behaviour would lead to a more positive impression of the suspect and would in turn lead to a more positive alibi evaluation. It could, however, also be determined whether this effect is limited to salacious activities or also applied to other behaviour that might be considered shameful (e.g., visiting a gay bar, cross-dressing). Nonetheless, all studies on alibi content should be regarded as valuable as they shed light on factors that may influence the believability of an alibi other than the strength of the evidence.

\subsubsection{The Implications of Studies Using Student Samples}

Without a doubt, the studies that used student samples in alibi research have been valuable. However, as mentioned previously, one needs to be aware of the limitations of student samples when generalising the results to police practice. Outside the alibi research domain, such generalizability issues have already been documented (e.g., Gainsbury, Russell, \& Blaszczynski, 2014). In this dissertation, it has been shown that detectives report more physical evidence when generating an alibi and that, when evaluating an alibi, they focus on more and other factors than students do. Furthermore, the alibi taxonomy's importance 
has been demonstrated in various studies, including this dissertation, but the practical relevance is ambiguous because what scholars believe to be strong evidence is not directly applicable for police detectives. While scholars believe that all items that are linked to the suspect and contain time and location information are thought to be strong evidence, police detectives scrutinise the evidence considering multiple scenarios.

As a consequence, the results of studies in which student samples are used may not be representative or useful for the evaluation of alibis in practice. It is therefore recommended to include practitioners in future research samples. In this dissertation, samples of practitioners consisted of police detectives as they play a leading role in pre-trial investigations in the Netherlands. In a predominantly inquisitorial investigation, police detectives are the first to evaluate the believability of a suspect's alibi.

Depending on the nature of the criminal proceedings and the role of the police and judicial authorities within the system, future research should also include other practitioners, such as prosecutors, judges, jurors and lawyers, when studying alibis. Furthermore, expanding the scope of future research to practitioners other than police detectives can be recommended, regardless of the nature of the criminal proceedings. For instance, given that judges or jurors ultimately decide upon the guilt of the defendant, it is valuable to study to what extent the presence of an alibi and the evidence, or lack thereof, to support that alibi play a role in their decision-making process. In addition, it should be studied whether and how defence lawyers use the presence or absence of an alibi in the defence strategy and to what extent they actively pursue evidence to prove that alibi. This is of particular importance in legal systems with a pre-trial investigation that is more adversarial and in which the suspect and his defence lawyer play an active role in gathering the evidence. 


\subsubsection{Suggestions for Practitioners}

\subsubsection{Suggestions to Enhance Valid Alibis During the Alibi Generation Process}

Despite the increase in ecological validity with the inclusion of police detectives in alibi research, their evaluation is not flawless either. It cannot be disregarded that misjudgements of alibis occur in a substantial number of documented wrongful conviction cases. Especially when a suspect changes the alibi, detectives often see such inconsistencies as an indication of deceit (Dysart \& Strange, 2012; Thompson-Cannino et al., 2009). Such inconsistencies are more likely to be caused by memory mistakes (Crozier et al., 2017; Strange et al., 2014), in particular when more time has lapsed between the alleged crime and the suspect interview (Olson \& Charman, 2012). In addition, time cues (i.e., where were you at $X$ date and $Y$ time?) are least effective for retrieving the memory for that event (Wagenaar, 1986). Therefore, it is advised to allow the suspect to check his agenda, for example, to activate the location cue that will lead to more valid memories than the time cue. When a suspect generates an alibi, it is important to take the base rate into consideration (Chapter 3) and to remember that detectives are more aware of the presence of physical evidence than laypeople when generating an alibi (Chapter 6). What evidence to expect depends on the alibi location and the time of day.

From the results in Chapter 6 and 7, it also became clear that the detectives received little training in evaluating alibis. It is therefore recommended that detectives be trained in assessing an alibi and its supportive evidence. Moreover, such training can incorporate the aforementioned recommendations to minimize memory errors and unrealistic expectations regarding the presence of physical evidence to support an alibi. Although these hands-on suggestions do not guarantee a perfect and valid alibi evaluation, they may help to enhance the evaluation of alibis in practice. 


\subsubsection{Thinking in Scenarios}

A relatively easy and effective measure to evaluate alibis realistically is formulating multiple scenarios about the alibi. When it comes to evaluating alibis, there are at least two possible scenarios when interviewing a suspect: (a) the suspect is guilty and a false alibi is presented (the guilty scenario), and (b) the suspect is innocent and a true alibi is presented (the alternative scenario) (P. J. Van Koppen, 2011).

The investigator should make his initial (assumed) hypothesis explicit (e.g., the suspect is guilty), and then try to find support for his alternative hypothesis (e.g., the suspect is innocent). How the scenarios are evaluated depends on the information in the case. These data should be used in order to discriminate between the scenarios. If the alternative hypothesis can be rejected based on incoming facts, then the probability of the initial hypothesis increases. For instance, imagine the suspect is questioned about his alibi on Tuesday night. The suspect reports having been asleep at home, and his spouse can confirm his alibi. Alternatively, the suspect is guilty and his spouse falsely supports his alibi. She is regarded as a motivated alibi witness, the weakest type of witness evidence. Knowing that the spouse has a potential motive to lie and given that her testimony is seen as weak supportive evidence adds probability to the guilty scenario. However, taking the base rate into account, since $77 \%$ of people are at home on a Tuesday night and witness evidence is the most likely to be presented for that time period $(68 \%)$, with the suspect's partner to be the most probable alibi witness at that time (56\%), the suspect's alibi is in line with one that most non-offenders can report at that time. This is evidence that supports the alternative scenario.

Further steps could consist of questioning both the suspect and the witness about their activities that night, what they possibly watched on television, and investigating GPS data from their mobile phones to determine if their phones were constantly at the residence. From the results in Chapter 7, it appears that such a mechanism might implicitly already be in place; a truth bias towards a suspect's initial alibi was observed, indicating that an alibi is seen as truthful until incriminating evidence is found. To facilitate and warrant 
such an open attitude, it is advised to construct at least two scenarios to determine which one the evidence supports.

\subsection{CONCLUSION}

An alibi is the best opportunity to prove one's innocence because it simply implies that the suspect was somewhere other than at the location where the alleged crime was committed. However, it is not an easy task for an innocent suspect to present a believable alibi. Both mock jurors (Jung et al., 2013) and police detectives (Dysart \& Strange, 2012) expect a consistent alibi that is supported by strong evidence in order to consider the alibi as believable. Such evidence can, however, only be presented by $2 \%$ of non-offenders (Chapter 3). It is furthermore not uncommon to report an alibi that needs alterations because of memory errors (Dysart \& Strange, 2012). Besides memory errors, in certain circumstances the suspect may decide to lie about the initial alibi to conceal involvement in shameful or embarrassing behaviour. This, however, also complicates the alibi evaluation and discrimination between true and false alibis during police investigations. Such discrimination is nevertheless of vital importance in the pre-trial investigation because it affects the decisions made about potential further investigative acts to collect evidence that may be indicative of either the guilt or innocence of the suspect. Moreover, the correct evaluation of an innocent suspect's alibi should exculpate the suspect and ensure he is not detained longer than strictly necessary.

Most alibi research has focused on the presence and the strength of supportive evidence because in most wrongful conviction cases in which an alibi was presented, the alibi was supported by weak or no evidence (Garrett, 2011; Wells et al., 1998). As demonstrated by the case of John Travolta, having strong evidence can lead to a quick exculpation as a suspect, but the case of Patrick also shows that only focusing on the strength of the evidence can be misleading. The introduction of the alibi taxonomy of Olson and Wells (2004) has been of vital importance in initiating and structuring alibi research. However, the current version of the taxonomy works best in a laboratory setting with students and with certain types of supportive evidence. The present dissertation shows that 
its application in practice is not straightforward and that not all types of supportive evidence have been included. Although the taxonomy's value for alibi research cannot be neglected, a number of adjustments are recommended to improve this important tool for both research and practice.

In addition, there is a need for police detectives to become more aware of the difficulties that may arise when an innocent suspect is asked for his alibi. Detectives are more aware of the presence of physical evidence than laypeople are, but it cannot be expected that laypeople will spontaneously offer such evidence. Therefore, a number of hands-on suggestions have been formulated for practitioners in order to enhance the evaluation of a suspect's alibi. On the one hand, an alibi supported by weak evidence is not necessarily indicative of a staged alibi, and an alibi supported by strong evidence should not immediately lead to the exculpation of that suspect on the other. The evidence should be evaluated in a broader context and in light of what evidence can be expected from an innocent suspect during that timeframe. As police detectives tend to focus more on the verifiability of the alibi (Eastwood et al., 2016), the verifiability approach in alibi research needs to be further explored, especially because this approach is a promising technique to discriminate between true and false alibis (Nahari \& Vrij, 2014). Although that technique has been further developed in other domains of the legal psychological arena (e.g., Harvey et al., 2017; Jupe et al., 2016), the application in alibi research could be further explored, ideally in collaboration with police detectives. In general, collaboration between scholars and various groups of practitioners (i.e., detectives, prosecutors, lawyers and jurors) would increase the ecological validity of alibi research, especially in the domains of alibi evaluation and discrimination.

For practitioners, it is important to remember that, for a suspect, the generation of a believable alibi is a difficult task. When a suspect changes the alibi or the supportive evidence, it should not be treated as an indication of deceit as it is according to today's standard (Dysart \& Strange, 2012). Memory errors can occur, especially when a suspect experiences stress (Quaedflieg \& Schwabe, 2017), or a suspect can have a reason to lie about the initial alibi. Therefore, potential alterations in the alibi should be examined and should not directly lead to disbelief in the suspect's alibi. A suspect's alibi can be the start 
of an alternative scenario. An alibi evaluation taking into account the content of the alibi, the feasibility of (strong) supportive evidence and the fallibility of the suspect's memory can lead to a more realistic alibi evaluation, ultimately enhancing the truth-finding process. 
CHAPTER 8

\subsection{REFERENCES}

Allison, M., \& Brimacombe, C. (2010). Alibi believability: The effect of prior convictions and judicial instructions. Journal of Applied Social Psychology, 40, 1054-1084. doi:10.1111/j.1559-1816.2010.00610.x

Allison, M., Jung, S., Sweeney, L., \& Culhane, S. E. (2014). The impact of illegal alibi activities, corroborator involvement and corroborator certainty on mock juror perceptions. Psychiatry, Psychology and Law, 21, 191-204. doi:10.1080/13218719.2013.803275

Allison, M., Mathews, K. R., \& Michael, S. W. (2012). Alibi believability: The impact of salacious alibi activities. Social Behavior and Personality: an international journal, 40, 605-612. doi:10.2224/sbp.2012.40.4.605

Baldwin, J. (1993). Police interview techniques. Establishing truth or proof? The British Journal of Criminology, 33, 325-352.

Crozier, W. E., Strange, D., \& Loftus, E. F. (2017). Memory errors in alibi generation: How an alibi can turn against us. Behavioral Sciences and the Law, 35, 6-17. doi:10.1002/bsl.2273

Culhane, S. E., \& Hosch, H. M. (2012). Changed alibis: Current law enforcement, future law enforcement, and layperson reactions. Criminal Justice and Behavior, 39, 958-977. doi:10.1177/0093854812438185

Culhane, S. E., Hosch, H. M., \& Kehn, A. (2008). Alibi generation: Data from U.S. Hispanics and U.S. non-Hispanic whites. Journal of Ethnicity in Criminal Justice, 6, 177-199. doi:10.1080/15377930802243395

Culhane, S. E., Kehn, A., Horgan, A. J., Meissner, C. A., Hosch, H. M., \& Wodahl, E. J. (2013). Generation and detection of true and false alibi statements. Psychiatry, Psychology and Law, 20, 619-638. doi:10.1080/13218719.2012.729018

Dahl, L. C., Brimacombe, C. A., \& Lindsay, D. S. (2009). Investigating investigators: How presentation order influences participant-investigators' interpretations of eyewitness identification and alibi evidence. Law and Human Behavior, 33, 368380. doi:10.1007/s10979-008-9151-y

De Smet, B. (1999). Internationale samenwerking in strafzaken tussen Angelsaksische en continentale landen [International cooperation in criminal cases between AngloSaxon and continental countries]. Antwerpen: Intersentia Rechtswetenschappen.

Dysart, J. E., \& Strange, D. (2012). Beliefs about alibis and alibi investigations: A survey of law enforcement. Psychology, Crime and Law, 18, 11-25. doi:10.1080/1068316X.2011.562867

Eastwood, J., Snook, B., \& Au, D. (2016). Safety in numbers: A policy-capturing study of the alibi assessment process. Applied Cognitive Psychology, 260-269. doi:10.1002/acp.3200 
Felson, M., \& Poulsen, E. (2003). Simple indicators of crime by time of day. International Journal of Forecasting, 19, 595-601. doi:10.1016/s0169-2070(03)00093-1

Gainsbury, S. M., Russell, A., \& Blaszczynski, A. (2014). Are psychology university student gamblers representative of non-university students and general gamblers? A comparative analysis. Journal of Gambling Studies, 30, 11-25. doi:10.1007/s10899012-9334-9

Garrett, B. L. (2011). Convicting the innocent. Cambridge, Massachusetts: Harvard University Press.

Harvey, A. C., Vrij, A., Leal, S., Lafferty, M., \& Nahari, G. (2017). Insurance based lie detection: Enhancing the verifiability approach with a model statement component. Acta Psychologica, 174, 1-8. doi:10.1016/j.actpsy.2017.01.00100016918

Harvey, A. C., Vrij, A., Nahari, G., \& Ludwig, K. (2017). Applying the Verifiability Approach to insurance claims settings: Exploring the effect of the information protocol. Legal and Criminological Psychology, 22, 47-59. doi:10.1111/lcrp.12092

Hosch, H. M., Culhane, S. E., Jolly, K. W., Chavez, R. M., \& Shaw, L. H. (2011). Effects of an alibi witness's relationship to the defendant on mock jurors' judgments. Law and Human Behavior, 35, 127-142. doi:10.1007/s10979-010-9225-5

Jung, S., Allison, M., \& Bohn, L. (2013). Legal decision-making on crimes involving an alibi. Applied Psychology in Criminal Justice, 9, 45-58. doi:10.1037/t04698-000

Jupe, L., Vrij, A., Nahari, G., \& Leal, S. (2016). The lies we live: Using the verifiability approach to detect lying about occupation. Journal of Articles in Support of the Null Hypothesis, 13, 1-13.

Keeping, Z., Eastwood, J., Lively, C. J., \& Snook, B. (2017). Don't stop believing: The relative impact of internal alibi details on judgments of veracity. Psychology, Crime \& Law, 1-15. doi:10.1080/1068316x.2017.1338700

Klompenhouwer, L. (2015). Zedenzaak Valkenburg: Maatregelen na zelfmoord 2e verdachte [Sex offence Valkenburg: Measures after suicide $2^{\text {nd }}$ suspect]. Retrieved from http://www.nrc.nl/nieuws/2015/03/17/tweede-verdachte-pleegt-zelfmoord-inloverboy-zaak-valkenburg/

Lancaster, G. L. J., Vrij, A., Hope, L., \& Waller, B. (2013). Sorting the liars from the truth tellers: The benefits of asking unanticipated questions on lie detection. Applied Cognitive Psychology, 27, 107-114. doi:10.1037/0033-295X.98.2.224

Maeder, E. M., \& Dempsey, J. L. (2013). A likely story? The influence of type of alibi and defendant gender on juror decision-making. Psychiatry, Psychology and Law, 20, 543-552. doi:10.1080/13218719.2012.727066

Meissner, C. A., \& Kassin, S. (2002). "He's guilty!": Investigator bias in judgments of truth and deception. Law and Human Behavior, 26, 469-480. doi:10.1023/A:1020278620751 
Nahari, G., \& Vrij, A. (2014). Can I borrow your alibi? The applicability of the verifiability approach to the case of an alibi witness. Journal of Applied Research in Memory and Cognition, 3, 89-94. doi:10.1016/j.jarmac.2014.04.005

Norfolk, G. A., \& Stark, M. M. (2011). Fitness to be interviewed. In M. M. Stark (Ed.), Clinical forensic medicine. A physician's guide (pp. 341-356). New York: Springer.

Olson, E. A., \& Charman, S. D. (2012). 'But can you prove it?' - Examining the quality of innocent suspects' alibis. Psychology, Crime and Law, 18, 453-741. doi:10.1080/1068316x.2010.505567

Olson, E. A., \& Wells, G. L. (2004). What makes a good alibi? A proposed taxonomy. Law and Human Behavior, 28, 157-176. doi:10.1023/B: LAHU.0000022320.47112.d3

Olson, E. A., \& Wells, G. L. (2012). The alibi-generation effect: Alibi-generation experience influences alibi evaluation. Legal and Criminological Psychology, 17, 151-164. doi:10.1111/j.2044-8333.2010.02003.x

Pozzulo, J. D., Pettalia, J. L., Dempsey, J. L., \& Gooden, A. (2015). Juvenile offenders on trial: Does alibi corroboration evidence and defendant age interact to influence jurors' perceptions and verdicts? Psychiatry, Psychology and Law, 22, 224-234. doi:10.1080/13218719.2014.937518

Quaedflieg, C. W. E. M., \& Schwabe, L. (2017). Memory dynamics under stress. Memory, 113. doi:10.1080/09658211.2017.1338299

Sakrisvold, M. L., Granhag, P. A., \& Mac Giolla, E. (2017). Partners under pressure: Examining the consistency of true and false alibi statements. Behavioral Sciences and the Law, 35, 75-90. doi:10,1002/bsl.2275

Sargent, M. J., \& Bradfield, A. L. (2004). Race and information processing in criminal trials: Does the defendant's race affect how the facts are evaluated? Personality and Social Psychology Bulletin, 30, 995-1008. doi:10.1177/0146167204265741

Strange, D., Dysart, J. E., \& Loftus, E. F. (2014). Why errors in alibis are not necessarily evidence of guilt. Zeitschrift für Psychologie, 222, 82-89. doi:10.1027/21512604/a000169

Strömwall, L. A., Granhag, P. A., \& Jonsson, A. C. (2003). Deception among pairs: 'Let's say we had lunch and hope they will swallow it!'. Psychology, Crime \& Law, 9, 109-124. doi:10.1080/1068316031000116238

Thompson-Cannino, J., Cotton, R., \& Torneo, E. (2009). Picking Cotton. New York: St. Martin's Press.

Van den Wyngaert, C., \& De Smet, B. (2014) Strafrecht en strafprocesrecht in hoofdlijnen [Criminal law and criminal procedure law in general lines]. Antwerpen: Maklu.

Van Koppen, M. V., \& Van Koppen, P. J. (2010). Alibi's [Alibis]. In P. J. Van Koppen, H. Merckelbach, M. Jelicic, \& J. W. De Keijser (Eds.), Reizen met mijn rechter: Psychologie van het Recht [Traveling with my judge: Psychology of the Law] (pp. 439-448). Deventer: Kluwer. 
Van Koppen, P. J. (2011). Overtuigend bewijs: Indammen van rechterlijke dwalingen [Convincing evidence: damming of miscarriages of justice]. Amsterdam: Nieuw Amsterdam Uitgevers.

Van Koppen, P. J., \& Penrod, S. D. (2003a). Adversarial or inquisitorial: Comparing systems. In P. J. van Koppen \& S. D. Penrod (Eds.), Adversarial versus inquisitorial justice: Psychological perspectives on criminal justice systems (pp. 2-20). New York: Plenum.

Van Koppen, P. J., \& Penrod, S. D. (2003b). The John Wayne and Judge Dee versions of justice. In P. J. van Koppen \& S. D. Penrod (Eds.), Adversarial versus inquisitorial justice: Psychological perspectives on criminal justice systems (pp. 347-368). New York: Plenum.

Vrij, A., Leal, S., Granhag, P. A., Mann, S., Fisher, R. P., Hillman, J., \& Sperry, K. (2009). Outsmarting the liars: The benefit of asking unanticipated questions. Law and Human Behavior, 33, 159-166. doi:10.1007/s10979-008-9143-y

Wagenaar, W. A. (1986). My memory: A case study of autobiographic memories over six years. Cognitive Psychology, 18, 225-252.

Walsh, D., King, M., \& Griffiths, A. (2017). Evaluating interviews which search for the truth with suspects: But are investigators' self-assessments of their own skills truthful ones? Psychology, Crime \& Law, 23, 647-665. doi:10.1080/1068316x.2017.1296149

Wells, G. L., Small, M., Penrod, S., Malpass, R. S., Fulero, S. M., \& Brimacombe, C. (1998). Eyewitness identification procedures: Recommendations for lineups and photospreads. Law and Human Behavior, 22, 603-647. 

9

THE MANDATORY CHAPTER: WHY THIS RESEARCH IS IMPORTANT

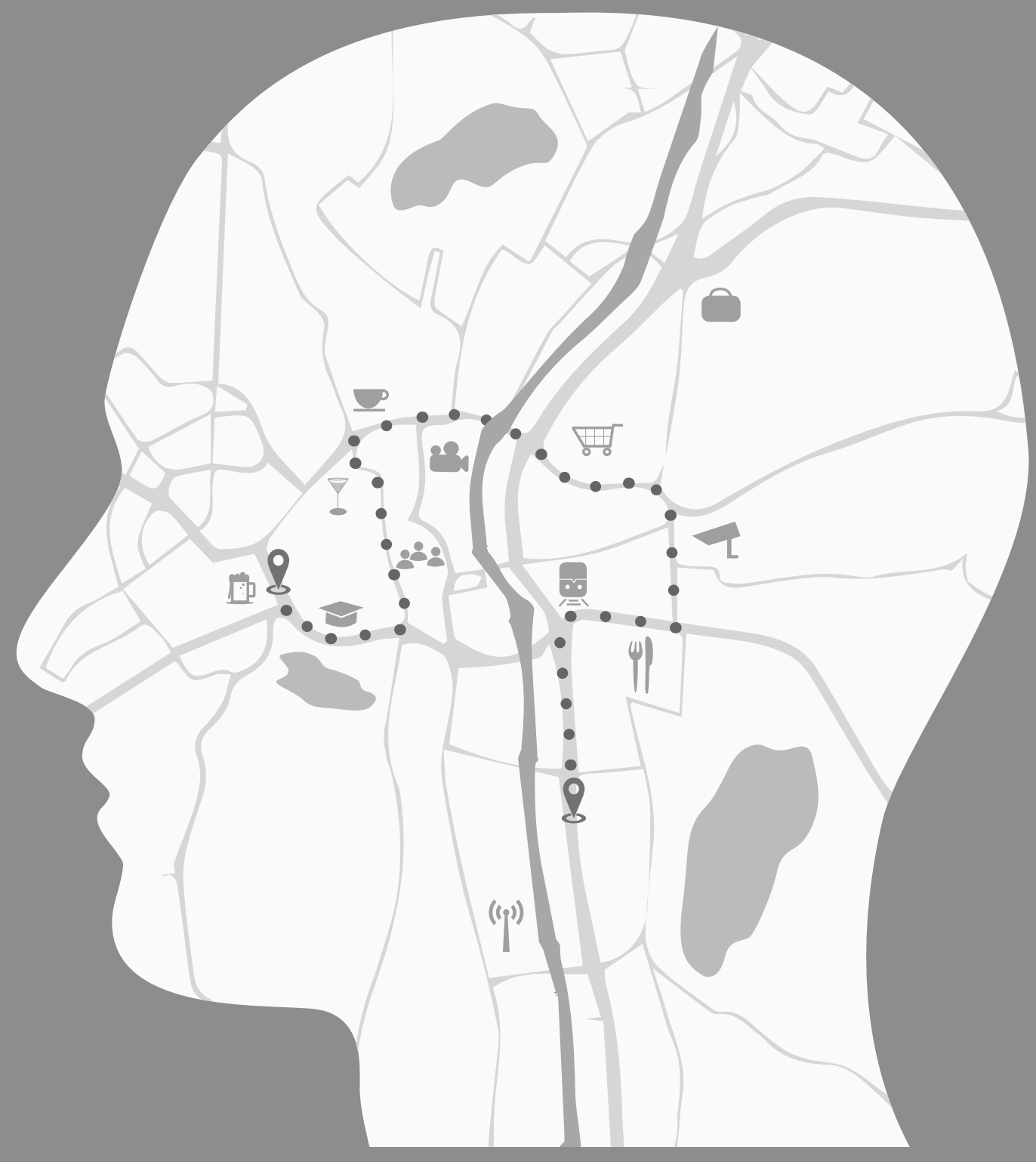



WHY THIS RESEARCH IS IMPORTANT

\subsection{RELEVANCE}

The existence of non-believed true alibis reported in various wrongful conviction cases all over the world (Burke \& Marion, 2012; Burke, Turtle, \& Olson, 2007; Simon, 2012; Wells et al., 1998) demonstrates the importance of a valid alibi assessment. On the one hand, the stakes are high for the innocent suspect whose alibi is not believed. A correct alibi evaluation avoids that the innocent suspect is needlessly held in custody, while the real perpetrator remains at large. Because being involved in a criminal investigation can cause upheaval and for the purpose of an effective truth finding in criminal proceedings, the time that an innocent person is suspected of having committed a crime should be restricted to a minimum. On the other hand, an early correct evaluation of a staged alibi prevents that the perpetrator is erroneously released from police custody. A valid alibi assessment thus contributes to the prevention of both wrongful convictions and wrongful releases. Reducing such errors to an absolute minimum is of course beneficial for everyone, because it contributes to the quality of a state's criminal justice system. In turn, it may prevent that citizens' trust in the legal system becomes impaired because of such errors.

The material truth about (the circumstances of) an alleged crime is, however, mostly unknown during criminal investigations. The police and judicial authorities predominantly have to rely on the statements provided by the suspect and potential witnesses, who may or may not confirm the suspect's statement. In addition, most of the alibis are supported by no or weak evidence (e.g., a motivated familiar other witness who supported the alibi). Physical evidence is not always available. Therefore, the importance of a thorough generation and evaluation of an alibi cannot be underestimated. Such generation can, however, be hampered by memory errors, mistakes and lies, while police detectives and jurors expect unrealistically strong evidence for all suspects' and defendants' alibis (Dysart \& Strange, 2012; Olson \& Wells, 2004). Consequently, a true alibi is often not assessed properly on its veracity. Given that a valid alibi assessment is crucial but complex, the importance of research examining current practices to enhance alibi assessments cannot be neglected. 
CHAPTER 9

\subsection{TARGET GROUPS}

The research findings presented in the thesis are relevant for several groups. The first target group consists of police detectives, because they are the first to assess the suspect's presented alibi. They, however, receive little training in this assessment (see Chapter 6 and 7 of this thesis). Based on the findings of the thesis, police detectives may establish more realistic expectations about a believable alibi. In addition, the thesis may offer insights on several factors that can be taken into account to enhance a valid assessment of an alibi's believability early in the criminal investigation. As such, persons involved in a criminal investigation - in particular innocent suspects - are a second target group. They also benefit from an early valid and effective assessment of alibis because it contributes to the reduction of the amount of wrongful arrests and releases.

A third target group consists of defence lawyers and (investigative) judges. On the one hand, this thesis provides defence lawyers insight about the importance of thoroughly generating a suspect's alibi. Knowledge of the factors that may influence the believability of an alibi may therefore contribute to an effective defence. Insights on what realistically can be expected from an alibi to be believable on the other hand may be valuable for (investigative) judges who have to decide upon extending a suspect's arrest or the defendant's guilt.

Last, scholars may also benefit from the results presented in this thesis. Alibi research is relatively scarce in comparison to other field of research in legal psychology. Since the introduction of the alibi taxonomy of Olson and Wells (2004), the alibi research was boosted in particular in the domain of alibi evaluation. However, the other domains did not benefit from the introduction of the taxonomy as much as the evaluation domain. In most of the subsequent studies, the strength of the supportive evidence remained the primary focus, which led scholars to conclude that a believable alibi is an alibi supported by strong evidence. In this dissertation, I gave the alibi research a fresh start by determining the base rate of alibis. From the results of this study it became clear that only $2 \%$ of the people can report such strong evidence, which would result in only $2 \%$ of believable alibis 
while all alibis were generated by non-offenders. Furthermore, knowledge evidence was introduced as a novel type of supporting evidence to be added to the literature.

In addition, the findings presented in the thesis demonstrate that one cannot underestimate the implications of using student samples in alibi research, but also possibly other fields of legal psychological research as well. Given their important role in assessing alibis in the beginning of a criminal investigation, police detectives were included in multiple studies in this dissertation. The results indicate that detectives are more aware of the presence of physical evidence than laypeople are and that they focus on other aspects compared to students to evaluate an alibi or to discriminate between true and false alibis. While students predominantly focus on the strength of the evidence, detectives find the verifiability of the alibi and the evidence more important. It is therefore recommended to conduct more research in collaboration with police detectives, for example, to update the alibi taxonomy that was developed to determine the alibi believability based on the strength of the evidence. By including practitioners in alibi research, new research findings will in turn be more beneficial to better discriminate between innocent and guilty suspects in practice as well.

\subsection{ACTIVITIES AND PRODUCTS}

At the beginning of my $\mathrm{PhD}$ research, I conducted some interviews with police detectives to understand how they evaluate alibis. As expected, many questions resulted in answers alike: it depends from case to case. One detective stated that the same evidence can have a different value in the criminal investigation depending on the person. He gave the example of a receipt. When a suspect would be questioned and would state that he believed to have been shopping and would subsequently find a receipt matching the critical day and time in his wallet in a pile of other receipts, that evidence is stronger than when another suspect would quickly state that he was shopping and would present the only receipt in his wallet. Such answers made me realise that one cannot simply state that without strong supportive evidence an alibi is unbelievable. To get a grasp of how alibis are documented in case files, a number of case files were examined. One analysis resulted in the description of Patrick's 
false alibi in Chapter 2, showing that an alibi can still be false when having CCTV recordings as supportive alibi evidence. The research was furthermore prompted by, at the time, current events. Two studies were inspired by real cases, i.e., the salacious nature of the Valkenburgse Loverboy case and the knowledge evidence presented in the Deventer murder case.

To valorise my research findings, the studies were as much as possible submitted to and published in open-access journals, both national as international. In addition, I presented the findings of my studies at national and international conferences and I organised a symposium in collaboration with other scholars on the latest findings of alibi research at the latest EAPL conference (2017). Furthermore, we wrote a chapter about the importance of alibi research in the Dutch textbook on legal psychology. To share my acquired knowledge I also gave various presentations for police detectives and lectures to undergraduate students to inspire them about the field of legal psychology and especially the alibi research. Last, the study on inconsistent and salacious alibis was described in the Dutch popular science magazine Quest to reach a broad audience.

\subsection{INNOVATION}

The present dissertation is innovative on various aspects. First, the research described in this thesis differs from previous research on two aspects that are important to understand the context in which the results should be understood. On the one hand, the base rate of innocent suspects' alibis is established and it is studied whether or not all types of supportive evidence are captured in the literature. These steps are essential, because the believability of an alibi cannot be determined correctly if it is unknown what alibis can be expected from innocent suspects. On the other hand, to get a grasp of the alibi evaluation in practice, it is studied how alibis are evaluated by police detectives rather than including samples of students as participants.

Second, the studies in this thesis do not focus on merely one of the three domains

of alibi research, nor solely on the strength of the evidence as a guiding principle for determining the alibi believability. The current thesis rather aims to be overarching to 
delineate the entire process of determining the alibi believability during the pre-trial investigation.

Third, to date most of the existing studies are exclusively Anglo-Saxon, focusing on the alibi evaluation by (mock) jurors (i.e., undergraduate students). So far, the evaluation of alibis in the early stages of proceedings was mostly ignored in the literature. In most continental countries (including the Netherlands), however, the emphasis of the proceedings, including the evidence gathering, lies in the pre-trial investigation. In addition, in most continental countries the role of police detectives is somewhat different than in countries with a more adversarial system. Because of the predominant inquisitorial character of the pre-trial investigation, the public prosecutor, and by extension the police, looks for both incriminating and exculpatory evidence, while the suspect has a rather passive role. In most Anglo-Saxon countries, on the contrary, the pre-trial investigation is predominantly adversarial, implying that the prosecution service may restrict itself to gathering only incriminating evidence. In addition, the suspect - and the defence lawyer are more active participants in the evidence gathering process (De Smet, 1999; Van den Wyngaert \& De Smet, 2014; Van Koppen \& Penrod, 2003a, 2003b). By focusing on police detectives in the Netherlands, this dissertation adds to the knowledge on the assessment of an alibi's believability in a different legal context compared to most of the existing alibi literature. 
CHAPTER 9

\subsection{REFERENCES}

Burke, T. M., \& Marion, S. B. (2012). Alibi witnesses. In B. L. Cultler (Ed.), Conviction of the innocent. Lessons from psychological research (pp. 239 - 256). Washington: American Psychological Association.

Burke, T. M., Turtle, J. W., \& Olson, E. A. (2007). Alibis in criminal investigations and trials. In M. P. Toglia, J. D. Read, D. F. Ross, \& R. C. Lindsay (Eds.), The handbook of eyewitness psychology: Memory for events (Vol. 1, pp. 157-192). Mahwah, NJ: Lawrence Erlbaum Associates.

De Smet, B. (1999). Internationale samenwerking in strafzaken tussen Angelsaksische en continentale landen [International cooperation in criminal cases between AngloSaxon and continental countries]. Antwerpen: Intersentia Rechtswetenschappen.

Dysart, J. E., \& Strange, D. (2012). Beliefs about alibis and alibi investigations: A survey of law enforcement. Psychology, Crime and Law, 18, 11-25. doi:10.1080/1068316X.2011.562867

Olson, E. A., \& Wells, G. L. (2004). What makes a good alibi? A proposed taxonomy. Law and Human Behavior, 28, 157-176. doi:10.1023/B: LAHU.0000022320.47112.d3

Simon, D. (2012). In doubt: The psychology of the criminal justice process. London: Harvard University Press.

Van den Wyngaert, C., \& De Smet, B. (2014) Strafrecht en strafprocesrecht in hoofdlijnen [Criminal law and criminal procedure law in general lines]. Antwerpen: Maklu.

Van Koppen, P. J., \& Penrod, S. D. (2003a). Adversarial or inquisitorial: Comparing systems. In P. J. van Koppen \& S. D. Penrod (Eds.), Adversarial versus inquisitorial justice: Psychological perspectives on criminal justice systems (pp. 2-20). New York: Plenum.

Van Koppen, P. J., \& Penrod, S. D. (2003b). The John Wayne and Judge Dee versions of justice. In P. J. van Koppen \& S. D. Penrod (Eds.), Adversarial versus inquisitorial justice: Psychological perspectives on criminal justice systems (pp. 347-368). New York: Plenum.

Wells, G. L., Small, M., Penrod, S., Malpass, R. S., Fulero, S. M., \& Brimacombe, C. (1998). Eyewitness identification procedures: Recommendations for lineups and photospreads. Law and Human Behavior, 22, 603-647. 


SUMMARY

SAMENVATTING

DANKWOORD

CURRICULUM VITAE

PUBLICATIES EN PRESENTATIES

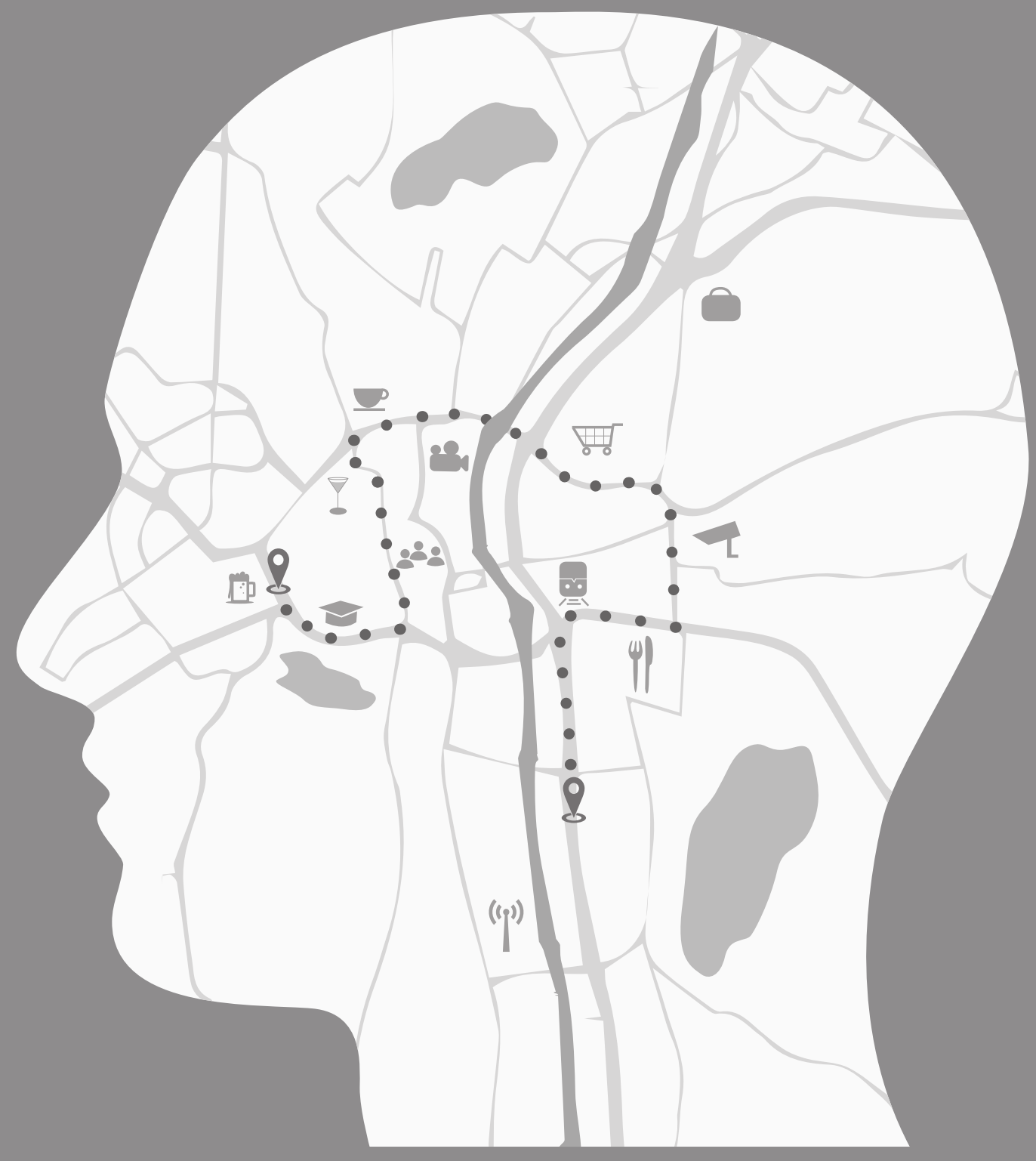





\section{SUMMARY}

A correct alibi evaluation has the potential of accurately differentiating between innocent people and potential suspects at the beginning of the police investigation. However, such evaluations are not flawless. From wrongful conviction cases it became clear that an alibi's veracity is not always properly assessed. Both police detectives and mock jurors expect a consistent alibi that is supported by strong evidence in order to consider the alibi as believable. In addition, it is not uncommon to report an alibi that needs alterations because of, for example, memory errors. A suspect can also report a false alibi, which may lead to a wrongful release from police custody (Chapter 1).

The research on topic of alibis is scarce in comparison to other domains of legal psychological research (e.g., false confessions or lie detection). In the existing alibi research, predominately students are included as participants rather than police detectives to determine how an alibi's believability is assessed, whereas the police are in practice the first to assess the suspect's alibi's believability. The aim of the present thesis is therefore threefold: 1) to determine what evidence could logically be expected from innocent suspects; 2) to determine what factors influence the alibi believability; and 3) to assess how students and police detectives evaluate alibis.

A systematic literature review outlining the factors that are most important to determine the alibi believability was conducted in Chapter 2. From that literature review it became clear that the strength of the supportive evidence is most important to determine the alibi believability. To assess whether or not relying on the strength of the evidence is a valid method to determine the believability of a true alibi, first the base rate of innocent suspects' alibis was established among a large sample of community members in Chapter 3. By determining the base rate, it is studied what alibis and supportive evidence innocent suspects report. The results show that most people can report an alibi which is also supported by evidence. The evidence, however, most often consists of witness evidence, the weaker type of supportive evidence compared to physical evidence. The strongest type of supportive evidence (i.e., CCTV recordings) is only reported by $2 \%$ of the people. That 
implies that only these $2 \%$ of non-offenders can report an alibi that would be found believable when one would only rely on this invalid assessment.

Besides asking the participants whether or not they could come up with evidence - either witness, physical or both - to support their alibis, they were also asked if there was other evidence to support their alibis. Interestingly, a minority of the participants reported evidence that could be labelled as knowledge evidence, which is a type of evidence that had not yet been captured in the literature. When a suspect possesses knowledge that he could only have acquired if the alibi was true, that knowledge supports the alibi. Traditionally, based on the two classical types of evidence, an alibi supported by knowledge evidence would be treated as an alibi without evidence. For that reason, the value of adding knowledge evidence to the alibi literature was examined (Chapter 4). Based on the study, it appears that this novel type of evidence is equally strong and believable as the strongest type of witness evidence, regardless of whether it is being evaluated by students, laypeople or police detectives.

From the literature review it also became clear that the consistency and the content of the alibi also affect the alibi believability, regardless of the strength of the evidence. To date, predominantly the effect of single factors on the alibi believability is studied. Therefore, in Chapter 5 a study is presented in which it is examined how the alibi believability is affected when a suspect lies about his alibi to cover-up his involvement in a salacious activity. By doing so, two recently discovered factors that can affect the alibi believability, i.e., the consistency and salaciousness of the alibi, are combined to determine how such a combination of factors affects the alibi believability. The findings show that an alibi can become more believable when the initial alibi is changed. This is especially true when the suspect lied about his initial alibi, but later admitted that he was involved in a salacious activity. Thus, when a change in the initial alibi makes sense - in the study lying about your alibi to hide an affair - such changes in the alibi can even lead to an increase in the alibi's believability.

As stated above, in practice, police detectives are the first to assess the suspect's alibi's believability. The initial suspect interviews are a key investigative act in the criminal investigation. Despite their important first assessment, police detectives are rarely included 
in alibi research. One of the aims of this dissertation was to bridge the gap between practitioners and academics in regard to alibi evaluation. In order to start building bridges, one first needs to identify the process of determining alibi believability and to know which aspects are important during the alibi evaluation. When it comes to the evaluation of an alibi, both mock jurors and police detectives tend to set very high standards for an alibi to be found believable. However, when mock jurors become aware of the difficulty to present a believable alibi for an innocent suspect, they evaluate alibis more realistically compared to when they are unaware of that effect. Therefore, Chapter 6 consists of a study in which it is determined if this so-called alibi generation effect can also help police detectives to come to a more realistic alibi evaluation. That was not the case, but surprisingly the results reveal that police detectives report physical evidence more often than laypeople do when they are asked to generate an alibi. This, however, does not seem disadvantageous for suspects: when the detectives were presented with a suspect's alibi, most of them wanted to conduct more investigative acts prior to determine the alibi's believability. In particular, the detectives wanted to actively search for additional evidence (e.g., CCTV recordings, interviewing witnesses) to verify whether or not the presented alibi was truthful.

Ultimately, an alibi should differentiate between innocent suspects and perpetrators. In Chapter 7, a final study is presented in which police detectives' performance in discriminating between true and false alibi statements, generated by genuine suspects in a remand prison, is compared to the performance of students. To better understand the process of alibi discrimination in these groups, it is furthermore studied what aspects both groups find relevant in order to come to a discrimination between true and false alibis. In line with recent findings, the data show that police detectives do not focus only on the presence and strength of the supportive evidence, but also on the number of alibi witnesses. Interestingly, while students focus on the strength of the evidence, we found that police officers are less interested in the strength of the supportive evidence and focus more on the verifiability of the alibi, the length of the suspect's statement and the reported evidence. In addition, compared to students, police detectives evaluate more alibis to be truthful. During the debriefing of the study, they stated that unless proven otherwise, detectives tend to believe a suspect's alibi. 
The results of the presented studies and their implications to answer the three main questions that are raised in this dissertation are discussed in Chapter 8. The present dissertation shows that both generating a believable alibi and subsequently determining an alibi's believability in practice are a difficult task. Relying on the strength of the evidence does not seem to be sufficient to assess an alibi. The validity of an alibi's assessment may therefore benefit from taking into account the content of the alibi, the feasibility of (strong) supportive evidence and the fallibility of the suspect's memory. In addition, the alibi and the supportive evidence should be evaluated in the broader context of the case and in light of what evidence can be expected from an innocent suspect during that timeframe. Future research, consisting of a collaboration between scholars and various groups of practitioners, remains needed to further enhance the assessment of an alibi in practice in order to prevent wrongful convictions and releases. 




\section{SAMENVATTING}

Wanneer de geloofwaardigheid van een alibi op correcte wijze wordt beoordeeld, kunnen onschuldigen en mogelijke verdachten reeds bij aanvang van een politioneel onderzoek van elkaar worden onderscheiden. De beoordeling van de geloofwaardigheid van alibi's is echter niet onfeilbaar. Zaken waarin zich een gerechtelijke dwaling heeft voorgedaan, tonen immers aan dat de waarachtigheid van een alibi niet steeds correct wordt ingeschat. Zowel studenten - die werden gevraagd om zich de rol van jurylid in een rechtszaak in te beelden - als rechercheurs als blijken een alibi namelijk slechts geloofwaardig te vinden wanneer het consistent blijft doorheen de tijd en wordt ondersteund door sterk bewijs. Het komt echter wel vaker voor dat een alibi moet worden aangepast door bijvoorbeeld geheugenfouten. Een verdachte kan bovendien een vals alibi vertellen, wat ertoe kan leiden dat hij onterecht in vrijheid wordt gesteld (hoofdstuk 1).

Het onderzoek naar alibi's is schaars te noemen in vergelijking met andere onderzoeksgebieden binnen de rechtspsychologie (zoals bijvoorbeeld het onderzoek naar valse bekentenissen of leugendetectie). Hoewel de geloofwaardigheid van een alibi in de praktijk primair door rechercheurs wordt beoordeeld, wordt in het bestaande alibionderzoek hoofdzakelijk beroep gedaan op studenten, en niet op rechercheurs, om in kaart te brengen hoe de geloofwaardigheid van een alibi wordt bepaald. Het doel van dit proefschrift is dan ook drieledig: 1) het in kaart brengen welk bewijs van onschuldige verdachten kan worden verwacht; het in kaart brengen van de factoren die geloofwaardigheid van een alibi beïnvloeden; en 3) bepalen hoe studenten en rechercheurs de geloofwaardigheid van een alibi beoordelen.

In hoofdstuk 2 werd aan de hand van een systematische literatuurstudie beschreven welke factoren bepalend zijn bij de beoordeling van de geloofwaardigheid van een alibi. Uit deze literatuurstudie blijkt dat de sterkte van ondersteunend bewijs hiervoor de meest bepalende factor is. Om te toetsen of het louter uitgaan van de sterkte van het bewijs een valide methode is om de geloofwaardig van een alibi te beoordelen, werd in hoofdstuk 3 in eerste instantie de base rate van alibi's van een grote groep onschuldige personen uit de samenleving in kaart gebracht. Door de base rate te bepalen kan namelijk 
een inschatting worden gemaakt welke alibi's en welk bewijs kunnen worden verwacht van onschuldige verdachten. De resultaten van dit onderzoek tonen aan dat de meesten wel een alibi kunnen noemen dat bovendien is ondersteund door bewijs. Dat bewijs bestaat doorgaans echter uit getuigenbewijs, de zwakkere vorm van bewijs in vergelijking met fysiek bewijs. De sterkste vorm van alibibewijs (bijvoorbeeld bewakingsbeelden) wordt slechts door $2 \%$ van de onschuldigen genoemd, wat impliceert dat slechts deze $2 \%$ van de onschuldige verdachten een alibi kan verstrekken dat geloofwaardig zou worden geacht wanneer men zich louter zou baseren op deze niet valide methode om de geloofwaardigheid van een alibi te beoordelen.

Aanvullend op het in kaart brengen van welk bewijs onschuldigen voor hun alibi noemen - zijnde fysiek en/of getuigenbewijs - werden de respondenten van de base ratestudie tevens gevraagd naar de aanwezigheid van ander bewijs om hun alibi te ondersteunen. Opmerkelijk was dat een minderheid van de deelnemers bewijs noemde dat gecategoriseerd kan worden als kennisbewijs, een vorm van bewijs die nog niet in de bestaande literatuur is opgenomen. Wanneer een verdachte over kennis beschikt die hij enkel kan hebben verkregen wanneer het alibi waarachtig is, kan die kennis zijn alibi ondersteunen. Uitgaande van de twee klassieke vormen van bewijs zou een dergelijk alibi, ondersteund met kennisbewijs, worden beschouwd als een alibi zonder bewijs. De meerwaarde van kennisbewijs als aanvulling op de bestaande vormen van bewijs in de alibiliteratuur werd dan ook onderzocht in hoofdstuk 4. De resultaten van dit onderzoek tonen aan dat deze nieuwe vorm van bewijs even sterk en geloofwaardig wordt geacht als de sterkste vorm van getuigenbewijs, ongeacht of het bewijs werd beoordeeld door studenten, leken of rechercheurs.

Uit de literatuurstudie kwam eveneens naar voren dat, ongeacht de sterkte van het bewijs, ook de consistentie en de inhoud van het alibi de geloofwaardigheid van dat alibi kunnen beïnvloeden. Tot op heden werd telkens hoofdzakelijk de invloed van één afzonderlijke factor op de geloofwaardigheid van een alibi onderzocht. Vanuit deze vaststelling omvat hoofdstuk 5 een studie waarin werd onderzocht op welke wijze de geloofwaardigheid van een alibi wordt beïnvloed wanneer een verdachte over zijn initiële alibi liegt om zijn betrokkenheid in seksueel getint gedrag te verdoezelen. Op deze manier 
werden twee factoren waarvan het effect op de geloofwaardigheid van een alibi recent werd aangetoond, namelijk de consistentie en de seksueel getinte aard van het alibi, gecombineerd om na te gaan in hoeverre een dergelijke combinatie de geloofwaardigheid van een alibi beïnvloedt. Uit de resultaten blijkt dat een alibi geloofwaardiger kan worden wanneer het oorspronkelijke alibi wordt aangepast. Dit geldt met name wanneer de verdachte over zijn initiële alibi loog, maar later toegeeft dat hij had gelogen om zijn betrokkenheid in seksueel getint gedrag te verdoezelen. Wijzigingen in een alibi kunnen bijgevolg gunstig zijn voor de geloofwaardigheid van een alibi wanneer een dergelijke wijziging zinvol wordt geacht, zoals het geval was in de studie beschreven in hoofdstuk 4 waarbij werd gelogen om een affaire te verbergen.

Zoals eerder vermeld, wordt de geloofwaardigheid van het alibi van een verdachte in de praktijk primair door rechercheurs beoordeeld. De eerste verdachtenverhoren zijn hierbij een sleutelmoment in het politioneel onderzoek. Ondanks hun belangrijke eerste oordeel, worden rechercheurs echter maar zelden in alibionderzoek betrokken. Eén van de doelstellingen van dit proefschrift was dan ook om de kloof tussen de praktijk en academici, met betrekking tot de beoordeling van de geloofwaardigheid van alibi's, te verkleinen. Om op dit vlak bruggen te kunnen slaan, dient in eerste instantie in kaart te worden gebracht op welke manier de geloofwaardigheid van een alibi wordt bepaald in de praktijk en welke aspecten hierbij van belang worden geacht.

Wat de beoordeling van een alibi betreft, blijkt dat zowel studenten - die worden gevraagd om zich de rol van jurylid in een rechtszaak in te beelden - als rechercheurs zeer hoge eisen stellen aan een geloofwaardig alibi. Wanneer dergelijke studenten zich er evenwel bewust van worden dat het lastig is om aan deze eisen te voldoen als onschuldige verdachte, beoordelen zij een alibi meer realistisch dan wanneer zij dit besef niet hebben. Hoofdstuk 6 omvat dan ook een studie waarin werd nagegaan of dit zogenaamde alibi generation effect ook bij rechercheurs tot een meer realistische beoordeling van een alibi leidt. Dat blijkt echter niet het geval te zijn, maar opmerkelijk genoeg blijken rechercheurs wel vaker fysiek bewijs te vermelden om hun alibi te ondersteunen dan anderen wanneer zij worden gevraagd om een alibi te verstrekken. Dit is echter niet nadelig voor verdachten, aangezien de rechercheurs bij voorkeur eerst meer onderzoekshandelingen willen stellen 
alvorens de geloofwaardigheid van het alibi van een verdachte te beoordelen. De rechercheurs willen in het bijzonder actief op zoek gaan naar bijkomend bewijs (zoals bijvoorbeeld bewakingsbeelden en het horen van getuigen) om na te gaan of het verstrekte alibi al dan niet waarachtig is.

Een alibi zou bij uitstek moeten differentiëren tussen een onschuldige verdachte en de dader. Vanuit die veronderstelling wordt in hoofdstuk 7 een laatste studie beschreven waarin rechercheurs en studenten worden vergeleken wat betreft de mate waarin zij in staat zijn om een onderscheid te maken tussen echte en valse alibi's verstrekt door verdachten die zich effectief in voorlopige hechtenis bevonden. Om meer inzicht te verwerven in hoe beide groepen een onderscheid maken tussen echte en valse alibi's werd eveneens nagegaan welke aspecten beide groepen belangrijk achten bij het differentiëren tussen echte en valse alibi's. De resultaten tonen aan dat, vergelijkbaar met de bevindingen van ander recent onderzoek, rechercheurs niet enkel belang hechten aan de aanwezigheid en de sterkte van het ondersteunende bewijs, maar ook aan het aantal getuigen dat het alibi kan verifiëren. Het is voorts opmerkelijk dat rechercheurs minder belang hechten aan de sterkte van het bewijs en zich meer richten op de mate waarin het genoemde bewijs kan worden geverifieerd. Waar studenten vooral uitgaan van de sterkte van het bewijs, vinden rechercheurs de controleerbaarheid van het bewijs en de lengte van de verklaring van de verdachte belangrijker. Bovendien worden meer alibi's als waarachtig beschouwd door rechercheurs in vergelijking met studenten. Tijdens de nabespreking van de studie stelden rechercheurs dan ook dat ze geneigd zijn om het alibi van de verdachte te geloven totdat het tegendeel is bewezen.

De resultaten van de beschreven studies en de implicaties ervan met betrekking tot de drie hoofdvragen worden besproken in hoofdstuk 8. Dit proefschrift toont aan dat zowel het verstrekken van een geloofwaardig alibi als het beoordelen van de geloofwaardigheid ervan in de praktijk geen sinecure is. Louter uitgaan van de sterkte van het ondersteunend bewijs lijkt onvoldoende om een alibi te beoordelen. Vanuit die optiek kan de validiteit van een dergelijke beoordeling mogelijk worden verhoogd door zowel de inhoud van het alibi, de haalbaarheid van (sterk) bewijs, als de feilbaarheid van het geheugen in beschouwing te nemen bij de beoordeling van de geloofwaardigheid van een 
alibi. Bovendien dient het alibi en het ondersteunende bewijs te worden beoordeeld rekening houdend met de ruimere context van de zaak en in het licht van welk bewijs er mag worden verwacht van een onschuldige verdachte op het tijdstip waarvoor naar een alibi wordt gevraagd. Toekomstig onderzoek, waarbij een samenwerking tussen academici en de praktijk wordt vooropgesteld, blijft evenwel noodzakelijk om alibi's beter naar waarde te schatten zodat onterechte veroordelingen en vrijlatingen kunnen worden voorkomen. 

DANKWOORD

\section{DANKWOORD}

Peter, allereerst wil ik jou bedanken. Dankzij jou leerde ik het PhD primacy and recency effect kennen, dus dat leek me een erg goede reden om met jou te beginnen in mijn dankwoord. Je bent een bijzondere promotor geweest van wie ik ontzettend veel heb kunnen leren. Door al je ervaring in zaaks- en rechtspsychologisch onderzoek heb je me geleerd om onderzoek te verrichten dat er toe doet. Het liefst kent dat onderzoek een eenvoudig opzet: één onderzoeksvraag en een design dat er enkel toe dient om die vraag te beantwoorden, zonder ingewikkelde vierwegsinteracties met factoren die ook wel leuk zijn om mee te nemen. Hoewel ik heb moeten wennen aan je directe manier van feedback geven, zeker wanneer je was gestopt met lezen, heb ik de eerlijkheid waarmee je steeds feedback geeft enorm leren waarderen. De complimenten over de hoofdstukken, wanneer je de manuscripten dan wel helemaal tot het einde hebt lezen, kregen zo nog meer waarde. Het is een mooi traject geweest, zeker als ik terugkijk naar waar het allemaal begon. Ik herinner me nog goed mijn sollicitatiegesprek voor het Project Gerede twijfel. Ik deed zo'n beetje alles fout wat je maar fout kon doen: betrouwbaarheid gebruiken waar validiteit wordt bedoeld, dader en verdachte door elkaar gooien, data bestempelen als enkelvoud en tot overmaat van ramp geloof hechten aan het onschuldige scenario in de Deventer moordzaak. Terugkijkend op dit hele proces en waar ik nu sta, heb ik ontzettend veel van jou mogen leren. Bedankt daarvoor!

Robert, ik ben ontzettend blij dat je op meerdere belangrijke momenten van mijn leven een belangrijke rol hebt gespeeld. Zo heb jij me samen met André - maar toch vooral jij - aan Lore gekoppeld op het zolderkamertje. Dat was toen een goede beslissing, maar achteraf gezien de beste beslissing in mijn leven. Om die reden wilden we ook niemand anders dan jou en Sas als ceremoniemeester bij ons huwelijk. Het is geweldig dat het is gelukt om een proefschrift te schrijven en dat jij ook bij deze mijlpaal in mijn leven nauw betrokken bent. Ik wil je verder graag bedanken voor alle memorabele avonden in de Tribunal in gezelschap van collega's, studenten, advocaten of enkel wij twee. Je hebt me geleerd om het leven niet altijd even serieus te nemen, bijvoorbeeld door bepaalde activiteiten te saboteren omdat je je geduld verloor (iets met schroeven en een wok). Je 
had ook een erg goede filterfunctie bij feedback op mijn stukken die een zeker eerste 'reddend' effect hadden voor de feedback die nog komen zou. Eveneens wil ik jouw warme gezin bedanken (Sas, Bente, Marit, Kris en Noor) voor alle leuke wandelingen, middagen en avonden met heerlijk eten, maar ook omdat zij het steeds begrepen dat we het af en toe ook even over het werk moesten hebben. Bedankt!

Ik wil ook graag alle studenten die mij hebben geholpen met de dataverzameling of die een interessante thesis hebben geschreven over het alibionderzoek hartelijk danken. Terugkijken naar deze samenwerkingen doe ik met een glimlach. Ik ben ook erg blij dat ik met een aantal van jullie nog steeds een goed contact heb en regelmatig nog afspreek om bij te praten. Het doet me dan ook veel deugd om te zien hoe jullie je dromen najagen en op interessante plekken werken. Bedankt om altijd op een leuke manier samen te werken!

Uiteraard wil ik ook graag de collega's van de capgroep hartelijk danken. Zij hebben mij verder wegwijs willen maken in de wondere wereld van het (straf)recht. In het bijzonder wil ik Jacques en Dorris hartelijk danken dat ik hun onderwijsgroepen mocht bijwonen om zo mijn kennis van het straf(proces)recht wat verder te kunnen uitbouwen. Ook wil ik graag de collega's van de andere zijde van de Maas hartelijk danken voor de fijne momenten tijdens de Heidagen, het begeleiden van scripties en de koffiemeetings op vrijdagochtend. Eveneens wil ik graag mijn nabije collega van iets verder weg - Claire - bedanken voor de fijne middagen waar wij het over het onderzoek, de feedback en de leuke dingen in het nietacademische leven hadden. Henk, bedankt voor je hulp bij sommige complexe analyses!

In het bijzonder wil ik mijn geweldige paranimfen hartelijk danken, niet alleen voor alles wat zij in de aanloop naar de verdediging voor mij hebben gedaan, maar zeker ook voor alle memorabele momenten. Ik begin met André - moateke - omdat, gevoelig als je bent, je je gepasseerd zou voelen als ik Tanja eerder dan jou zou bedanken. We kennen elkaar al zo lang, sinds de bachelor bij Lunatik. Je vertelde me pas later dat jij en Kim toen het gevoel hadden dat jullie goed voor mij moesten zorgen. Dat ben je blijven doen gedurende mijn promotietraject. Ik herinner me vooral onze gezellige tijden in het huisje van de faculteit en het stappenplan om jouw koffie te zetten: vier schepjes oploskoffie, drie schepjes Nesquik en nog wat suiker. Dat paste dan maar net in je grote Babarmok. Het feit dat ik deze stappen nog steeds weet, is te wijten aan die vervelende dobbelsteen die mij 
steeds aanduidde om koffie te gaan halen. Na een arbitrair aantal keer rollen, bleek de dobbelsteen jou gunstiger gestemd dan mij. Ook op congressen nam je me mee op sleeptouw om die wondere wereld en de personen van de belangrijke papers te leren kennen. Dat doet me denken aan mijn eerste congres in Cyprus waar ik, naïef als ik was, er niet bij had stilgestaan dat er meer is dan enkel het bijwonen van het congres en bijgevolg vergeten was om ook gemakkelijke schoenen mee te nemen. We zijn dan in de gedemilitariseerde zone tussen het noorden en het zuiden nog andere schoenen voor mij gaan kopen en maakten ook verschillende keren de gevaarlijke oversteek naar het separatistische noorden van het land, een plek waar jij je uiteraard prima in je sas voelt. Ik ben blij dat we tot op heden elkaars klankbord konden zijn voor de uitwerking van ons proefschrift en dat deze gesprekken na onze aanstellingen in Maastricht gepaard mochten gaan met een heerlijk door jou bereid diner, samen met Kim, Hanne, Dréke en Joris. Ik zet die trend graag verder om in de toekomst bij te praten over allerhande nieuwe anekdotes!

Tanja, je kwam iets later bij ons groepje, maar daar was eigenlijk weinig van te merken. Het klikte meteen en ik heb veel van je kunnen leren. Ik heb enorm genoten van onze fika's en fika-fika's om het over onderzoekdesigns en analyses te hebben, maar vooral over de dingen die ons bezighielden op persoonlijk vlak. Je bent een echte mensenmensenmens en ik kon altijd bij je terecht met alle vragen, hoe simpel het antwoord soms ook bleek te zijn. Hoewel je erg tegen je verblijf in Zweden opzag, was ik daar stiekem toch erg blij mee. Dat was een goede reden om jou en Nathalie te komen bezoeken in Gotenburg (we voelen ons nog steeds vereerd dat we jullie eerste logees mochten zijn) en daar een road trip aan te koppelen door Denemarken en Zweden en over de legendarische Bridge te kunnen rijden. Behalve een geweldige collega ben je ook een geweldige vriendin met wie ik erg kan genieten van de momenten waarop we, samen met Wouter en Lore, gezelschapsspelletjes kunnen spelen. Stiekem vind ik het trouwens erg prettig dat jij voor mij hebt verdedigd, want dat maakt het hele organisatorische proces van de verdediging een stuk makkelijker. Bovenal bewonder ik de manier waarop en de tijd waarin je jouw proefschrift hebt klaargespeeld. De lat is meteen hoog gelegd voor iedereen die na jou dit moment mag beleven. 
DANKWOORD

Verder wil ik mijn huidige collega's bij Vias institute bedanken om in mij te geloven en mij meteen te willen opnemen in een warme groep. Jullie werken allen ontzettend hard en toch is het nooit teveel gevraagd om elkaar te helpen als het nodig is. Ik denk dat dit een toonbeeld is voor andere onderzoekers van hoe je goed kan samenwerken in een competitieve omgeving zonder dat de individuele doelstellingen in het gedrang komen. Bedankt alvast voor alle leuke momenten samen en ik kijk alvast uit naar alle volgende "funny moments" die nog op ons staan te wachten!

Uiteraard wil ik ook alle vrienden hartelijk danken voor hun begrip dat ik de afgelopen jaren gezellige momenten aan me heb laten voorbijgaan omdat ik aan mijn boek moest werken. Bovenal bedankt voor alle ontspannende momenten die we wel samen hebben beleefd wanneer de riem er toch even af kon. Vanaf nu heb ik weer meer tijd voor jullie, dus ik kijk alvast uit naar deze momenten! In het bijzonder wil ik graag Astrid bedanken voor het meedenken over de lay-out en de kaft van het proefschrift. Het heeft ons een lange, maar erg gezellige avond gekost om een alibi te visualiseren. Dus Astrid, heel veel dank om dit idee zo mooi met ons uit te werken! Ik wil verder ook graag Milow bedanken om een blijvende inspiratiebron te zijn voor de titels of subtitels van hoofdstukken. De medefans zullen de (subtiele) hints naar zijn nummers in het proefschrift al hebben herkend en anders is het een goede reden om te beginnen luisteren naar zijn muziek.

Ik wil ook mijn (schoon)familie hartelijk danken voor hun begrip. Jullie begrepen het steeds als Lore alleen op bezoek of naar feestjes kwam omdat ik in het weekend weer aan mijn proefschrift wou werken. In het bijzonder wil ik graag nog even een woordje richten aan oma. Lieve oma, u was altijd erg trots op de kleinkinderen, al wist u niet altijd even goed wie wat nu precies deed. Het is erg jammer dat $u$ dit moment (net) niet meer heeft kunnen meemaken. Dan had u kunnen vertellen dat één van uw kleinkinderen doctor was, maar niet één in een witte jas die de bloeddruk kwam nemen hé. Ik ben trouwens stiekem heel blij dat u in mijn boek staat, als oudste deelnemer in hoofdstuk 3.

Stefano, jij verdient ook zeker een woordje van dank. Mede dankzij jou raakte ik gemakkelijk ingeburgerd bij mijn Vlaamse schoonfamilie en vrienden. Zonder jouw grote enthousiasme om samen met mij alle afleveringen van F.C. De Kampioenen (meermaals) te 
bekijken, was me dat wellicht nooit zo goed gelukt. Ik vond het ook heel fijn om mijn broer na verloop van tijd next door te hebben in Maastricht. Een broer als jij is ook geweldig als je van mooie en snelle auto's houdt. Ik ben dan ook blij dat je jouw passie voor auto's hebt nagestreefd in je baan en me zo van alle laatste nieuwe snufjes op de hoogte kan houden. Die "boten" van jou zullen alleen wellicht nooit echt mijn ding worden, maar ik ben trots om een broer te hebben als jij! Bedankt voor alle gekkigheid die we samen al hebben kunnen uithalen.

Uiteraard wil ik ook mijn ouders en schoonouders hartelijk danken voor hun steun tijdens dit hele traject. Lieve ouders, ik wil jullie in het bijzonder bedanken om mij de mogelijkheid te geven om iets te studeren dat mij echt interesseerde. Ik weet dat ik geen voorbeeldige student ben geweest, maar toch zijn jullie altijd in mij blijven geloven en mij blijven steunen, ook naar mijn masters en uiteindelijk deze promotieplek toe. Bedankt om steeds een warme thuis te bieden aan ons, gevuld met warmte, lekker eten en gezellige momenten die me altijd nieuwe energie geven om door te blijven gaan. Ik kan jullie niet genoeg bedanken.

Tot slot, lieve Lore kan ik nooit in woorden uitdrukken wat jij voor me betekent en vooral hoezeer je me hebt gesteund tijdens dit hele proces. Je mag gerust weten dat ik het meest tegenop heb gezien om aan dit dankwoord te beginnen met schrijven omdat ik nog steeds niet weet hoe ik jou kan bedanken. Niet omdat jij vindt dat ik je niet hoef te bedanken, daaruit blijkt nogmaals de noodzaak om dat juist wel te doen. Ik zie er vooral tegenop omdat ik het gevoel niet onder woorden kan brengen, het niet kan zingen of het in een vrije dans kan uitbeelden. Je staat altijd voor me klaar om een luisterend oor te bieden, teksten na te lezen, structuur te bieden (ik zorg voor de inhoud, jij voor de vorm) maar vooral om me op tijd en stond een schop onder m'n kont te geven om verder te werken en lijstjes en schema's op te stellen om de voortgang van het proefschrift in goede banen te leiden. Hoewel ik dat in het begin wat overdreven vond, ben ik daar eigenlijk erg blij mee geweest, want het is nu af! Nu is het mijn beurt om mijn uiterste best te doen om jou hopelijk even goed te kunnen ondersteunen bij de voortgang en afronding van jouw eigen proefschrift. Met de extra vrije tijd die nu vrijkomt, hoop ik zoveel mogelijk mooie herinneringen samen te creëren en kijk vol vertrouwen naar de toekomst. 
DANKWOORD

Besluiten schrijven zijn noodzakelijk heb ik van jou geleerd en dat doe ik niet liever dan met een passage uit the Scientist van één van je favoriete bands Coldplay die mijn gevoel perfect uitdrukt, zelfs na het afronden van mijn proefschrift:

"Questions of science, science and progress, do not speak as loud as my heart"

Dank je wel voor alles! 




\section{CURRICULUM VITAE}

Ricardo Nieuwkamp ( ${ }^{\circ} 1987$, Leuven) behaalde in 2005 zijn Europees Baccalaureaat aan de Europese School in Woluwe. Daarna studeerde hij Psychology and Neuroscience in Maastricht. In het derde jaar werd hij geselectereerd voor het Maastricht Research Based Learning (MaRBLe) programma. Over het onderzoek dat hij in dat kader verrichtte, schreef hij zijn bachelorthesis die eveneens werd gepubliceerd. Vervolgens behaalde hij in 2012 een master Psychology and Law (MSc) en een master Forensica, Criminologie en Rechtspleging (LL.M) aan de Maastricht University. Tijdens deze masteropleidingen werkte hij eveneens als interviewer voor het Nederlands Studiecentrum Criminaliteit en Rechtshandhaving (NSCR), liep hij stage bij The Maastricht Forensic Institute (TMFI) en werd hij geselecteerd om deel te nemen aan het Project Gerede Twijfel. Direct na het behalen van zijn masters begon hij als onderzoeker in opleiding (OIO) een promotieonderzoek naar de geloofwaardigheid van de alibi's van verdachten, gefinancierd door de Nederlandse Organisatie voor Wetenschappelijk Onderzoek (NWO). Voor de mondelinge presentatie van de studie naar kennis als ondersteunend bewijs voor alibi's won hij de derde prijs voor de beste mondelinge presentatie op het European Association of Psychology and Law (EAPL) congres 2014 in Sint-Petersburg, Rusland. Van augustus 2015 tot oktober 2016 werkte hij als onderzoeker aan de KU Leuven om de best practices van verdachtenverhoren in een internationale context te bepalen in het kader van een Horizon 2020-onderzoek. Sinds oktober 2016 is hij werkzaam als onderzoeker binnen het kenniscentrum van Vias institute (het voormalig Belgisch Instituut voor de Verkeersveiligheid (BIVV)) te Brussel. Zijn huidige onderzoeksbelangstelling gaat uit naar de maatregelen die op het vlak van verkeershandhaving kunnen worden genomen om de verkeersveiligheid te vergroten, waarbij in het bijzonder de samenwerking met de politiële en justitiële autoriteiten centraal staat. In dat kader is hij eveneens als vrijwillig wetenschappelijk medewerker verbonden aan het Nationaal Instituut voor Criminalistiek en Criminologie (NICC) in Brussel.

E-mail: ricardo.nieuwkamp@vias.be. 

PUBLICATIES EN PRESENTATIES

\title{
PUBLICATIES EN PRESENTATIES
}

\author{
PUBLICATIES
}

Aigner-Breuss, E., Kaiser, S., Usami, D. S., Reed, S., Weijermars, W., ... Nieuwkamp, R., et al. (2017). Inventory of road user related risk factors and safety measures, Deliverable 4.4 of the H2020 project SafetyCube.

Frères, J., Nieuwkamp, R., \& Silverans, P. (2018). Profil des "Driver Improvement". Analyse du profil des participants ayant effectué une formation "Driver Improvement". Bruxelles, Belgique: I'Institut Vias - Centre de Connaissance Sécurité Routière.

Nieuwkamp, R. (2015). De geloofwaardigheid van alibi's. Strafblad, 5, 428-434.

Nieuwkamp, R., Horselenberg, R., \& Van Koppen, P. J. (2016). A lie and a mistress: On increasing the believability of your alibi. Psychiatry, Psychology and Law, 23, 733745. doi:10.1080/13218719.2016.1142934

Nieuwkamp, R., Horselenberg, R., \& Van Koppen, P. J. (2017). The illusion of the perfect alibi: Establishing the base rate of non-offenders' alibis. Journal of Investigative Psychology and Offender Profiling, 14, 23-42. doi:10.1002/jip.1470

Nieuwkamp, R., Martensen, H., \& Meesmann, U. (2017). Synopsis on alcohol interlock. European Road Safety Decision Support System, developed by the H2O2O project SafetyCube.

Nieuwkamp, R., \& Meesmann, U. (2016). Meer controle nodig op rijden onder invloed van alcohol. Overzicht van de resultaten inzake handhaving uit de ESRA-bevraging 2015. Verkeersspecialist, 232, 8-12.

Nieuwkamp, R., \& Silverans, P. (2017). De kerfstok van verkeersrecidivisten. Een bestudering van 92.000 recidivedossiers uit het Centraal Strafregister tussen 1995 en 2013. Brussel, België: Vias institute - Kenniscentrum Verkeersveiligheid.

Nieuwkamp, R., Slootmans, F., \& Silverans, P. (2017). Verkeersrecidivisten nader bekeken. Verkenning op basis van een steekproef van gerechtelijke dossiers uit Mechelen en Leuven. Brussel, België: Vias institute - Kenniscentrum Verkeersveiligheid.

Silverans, P., Nieuwkamp, R., \& Van Den Berghe, W. (2017). Verwacht effect van puntensystemen en andere maatregelen tegen recidive. Brussel, België: Vias institute - Kenniscentrum Verkeersveiligheid.

Theofilatos, A., Aigner-Breuss, E., Kaiser, S., Alfonsi, R., Braun, E., Eichhorn, A., ... Nieuwkamp, R., et al. (2017). Identification and safety effects of road user related measures. Deliverable 4.2 of the $\mathrm{H} 2020$ project SafetyCube.

van 't Riet, J., Werrij, M. Q., Nieuwkamp, R., de Vries, H., \& Ruiter, R. A. C. (2013). Message frame and self-efficacy influence the persuasiveness of nutrition information in a 
PUBLICATIES EN PRESENTATIES

fast-food restaurant. Food Quality and Preference, 29, 1-5. doi:10.1016/j.foodqual.2013.01.007

Van Koppen, M. V., \& Nieuwkamp, R. (2017). Alibi's in P. J. van Koppen, J. W. de Keijser, R. Horselenberg \& M. Jelicic (Eds.), Routes van het Recht: Over de Rechtspsychologie (pp. 249-260). Den Haag: Boom Juridisch.

Nieuwkamp, R., Horselenberg, R., \& Van Koppen, P. J. Aligning expectations with reality: No alibi generation effect among police detectives. Manuscript in revision for publication.

Nieuwkamp, R., Horselenberg, R., \& Van Koppen, P. J. You don't know: Knowledge as supportive alibi evidence. Manuscript in revision for publication.

Nieuwkamp, R., Horselenberg, R., \& Van Koppen, P. J. True and false alibis among prisoners and its detection by police detectives. Manuscript submitted for publication.

\section{MONDELINGE PRESENTATIES}

Nieuwkamp, R., Horselenberg, R., \& Van Koppen, P. J. (2017). The "alibi generation effect" among police detectives. European Association of Psychology and Law (EAPL), Mechelen, Belgium.

Jaspaert, E., Nieuwkamp, R., Nahari, G., \& Vervaeke, G. (2017). Training trajectory for virtual training in transnational police collaboration and suspect interview. European Association of Psychology and Law (EAPL), Mechelen, Belgium.

Maegherman, E., Horselenberg, R., Van Koppen, P. J., \& Nieuwkamp R. (2017). Knowledge evidence for alibis. European Association of Psychology and Law (EAPL), Mechelen, Belgium.

Theofilatos, A., Nieuwkamp, R., Ziakopoulos, A., Papadimitriou, E., \& Yannis, G. (2017). Effectiveness of intelligent speed adaptation, collision warning and alcolock systems on driving behaviour and safety. Smart Cities \& Mobility as a Service, Patras, Greece.

Jaspaert, E., Nahari, G., Nieuwkamp, R., \& Vervaeke, G. (2016). Conducting investigative interviews in transnational investigations. European Association of Psychology and Law (EAPL), Toulouse, France.

Nieuwkamp, R., Horselenberg, R., \& Van Koppen, P. J. (2014). Knowledge as supporting alibi evidence. European Association of Psychology and Law (EAPL), Saint-Petersburg, Russia.

Nieuwkamp, R., Horselenberg, R., \& Van Koppen, P. J. (2013). Wat is jouw alibi? Forensic Psychology Update (FPU), Maastricht.

Nieuwkamp R., Horselenberg R., \& Van Koppen P. J. (2013). What is your alibi? European Association of Psychology and Law (EAPL), Coventry, UK. 

